\title{
Exploring high-quality student affairs learning outcomes assessment practices at three American research universities
}

Adam S. Green

West Virginia University

Follow this and additional works at: https://researchrepository.wvu.edu/etd

\section{Recommended Citation}

Green, Adam S., "Exploring high-quality student affairs learning outcomes assessment practices at three American research universities" (2006). Graduate Theses, Dissertations, and Problem Reports. 2746.

https://researchrepository.wvu.edu/etd/2746

This Dissertation is protected by copyright and/or related rights. It has been brought to you by the The Research Repository @ WVU with permission from the rights-holder(s). You are free to use this Dissertation in any way that is permitted by the copyright and related rights legislation that applies to your use. For other uses you must obtain permission from the rights-holder(s) directly, unless additional rights are indicated by a Creative Commons license in the record and/ or on the work itself. This Dissertation has been accepted for inclusion in WVU Graduate Theses, Dissertations, and Problem Reports collection by an authorized administrator of The Research Repository @ WVU.

For more information, please contact researchrepository@mail.wvu.edu. 


\title{
Exploring High Quality Student Affairs Learning Outcomes Assessment Practices at Three American Research Universities
}

\author{
Adam S. Green \\ Dissertation submitted to the \\ College of Human Resources \& Education at \\ West Virginia University in partial fulfillment of the \\ requirements for the degree of \\ Doctor of Education \\ in \\ Educational Leadership Studies \\ Elizabeth A. Jones, Ph.D., Chair \\ Ernest Goeres, Ph.D. \\ Patricia Obenauf, Ph.D. \\ Jon Reed, J.D. \\ Jacqueline Webb-Dempsey, Ph.D. \\ Department of Advanced Educational Studies
}

Morgantown, WV

Keywords: Assessment, Student Affairs, Learning Outcomes, Evaluation

Copyright 2006 Adam S. Green 


\begin{abstract}
Exploring High Quality Student Affairs Learning Outcomes

Assessment Practices at Three American Research Universities
\end{abstract}

Adam S. Green

This study was conducted because limited research has occurred in the area of cocurricular student learning outcomes assessment, which has resulted in confusion within the student affairs profession on how to develop and implement assessment plans. The purpose of this study was to examine high quality assessment practices of student affairs divisions at three different research institutions in order to advance the value, usefulness, and understanding of learning outcomes assessment within the student affairs profession, so more student affairs divisions may begin assessing the co-curricular. Those student affairs divisions selected for this study represented assessment models with significant experience in successfully implementing assessments of student learning and development. These mature student affairs divisions who have substantial experience in successfully implementing their assessment plans were important to examine closely so that others can learn from their experiences.

This study found that those student affairs divisions that participated in this study fostered a shared commitment to assessment. It became apparent that there are four levels of professional commitment to each student affairs division's assessment initiative. Those four levels of professional commitment included: vice presidents, directors/coordinators of assessment, assessment committees, and unit level professional staff.

This research clearly indicates that successful assessment of student affairs learning outcomes requires the understanding that units are experts in their particular field; therefore, a decentralized model of assessment, facilitated by a coordinator or director, is most appropriate in student affairs. This study also explores the most commonly used assessment methods in student affairs, as well as student affairs efforts to collaborate in the assessment process. Moreover, this study investigates how student learning outcomes assessment results are used to enhance the student co-curricular experience. Finally, this study highlights the assessment successes and challenges identified by each of the three institutions that participated in this study. 
Table of Contents

Chapter 1: Introduction and Statement of Problem .................................................... 1

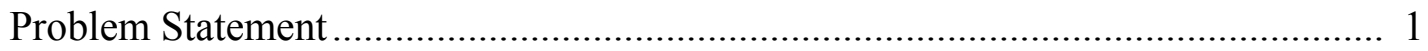

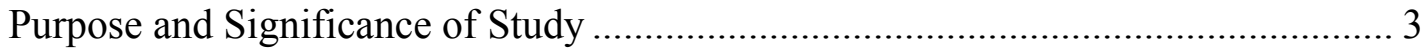

Research Questions ................................................................................... 4

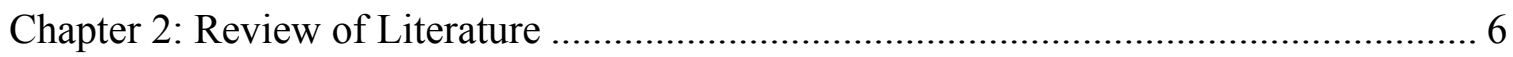

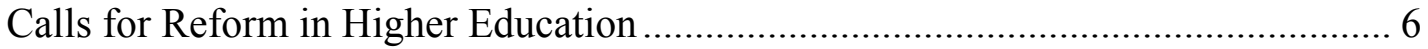

Responding to Calls for Reform: Understanding Student Affairs Educators'

Assessment Roles.......................................................................................... 8

Accountability Within Student Affairs ................................................................ 12

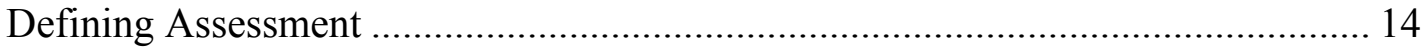

Articulating Student Learning Outcomes .......................................................... 18

Collecting Information About Current Learning Experiences and Current

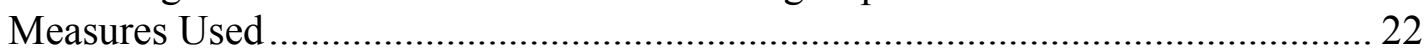

Selecting Appropriate Assessment Instruments................................................ 23

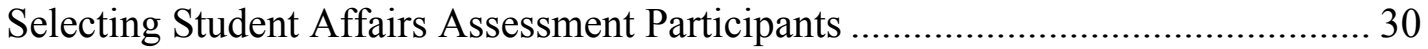

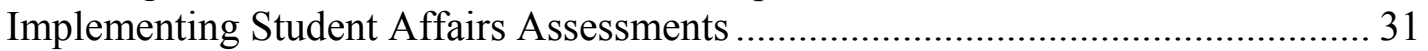

Analyzing Student Affairs Assessment Data ........................................................ 32

Reporting Student Affairs Assessment Results ..................................................... 34

Using Student Affairs Assessment Results to Enhance Student

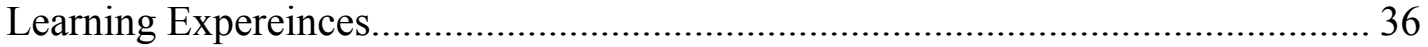

Evaluating the Assessment Process ................................................................... 39

Sustaining Student Affairs Assessment ............................................................. 40

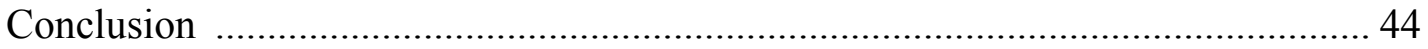

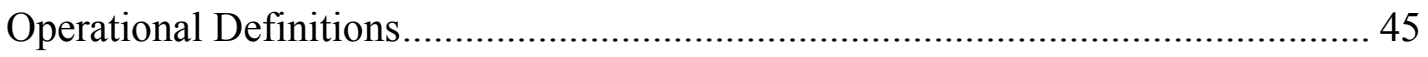

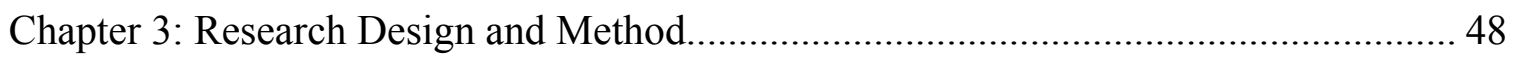

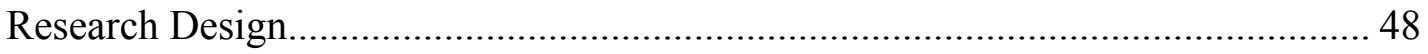

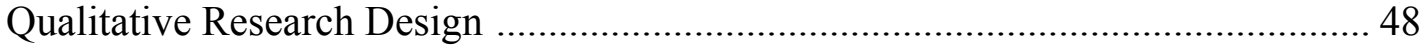

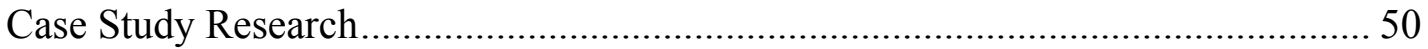

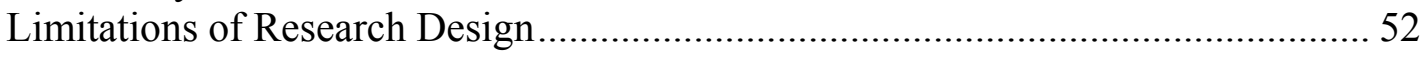

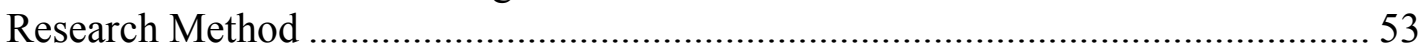

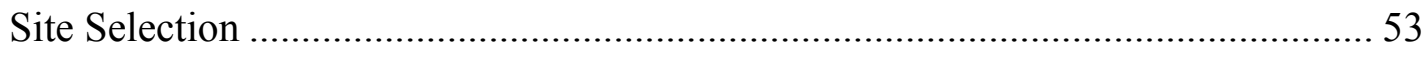

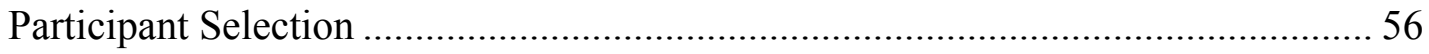

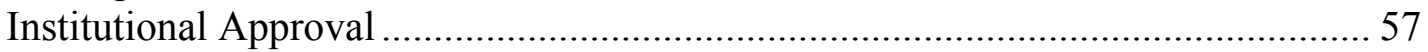

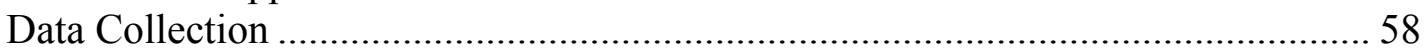

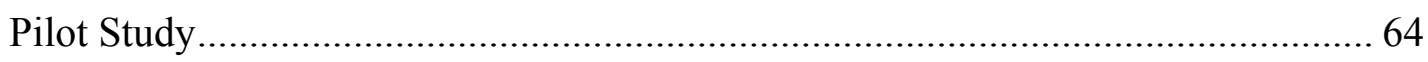

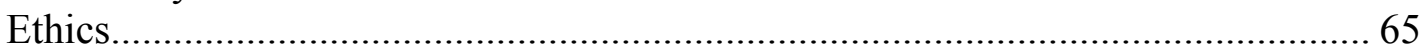

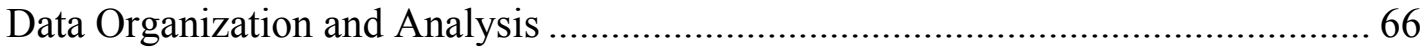




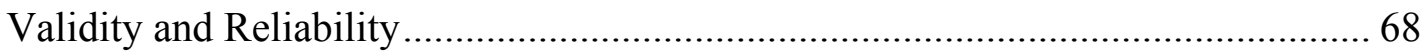

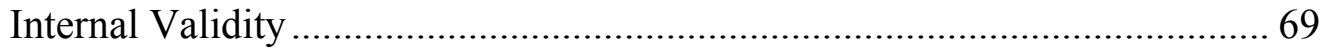

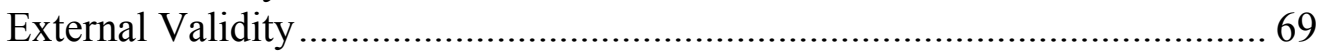

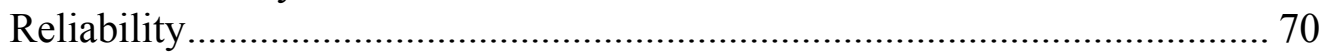

Relevant Past Experience of Researcher................................................................ 71

Statement of Personal Context.............................................................................. 72

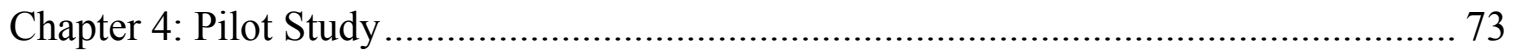

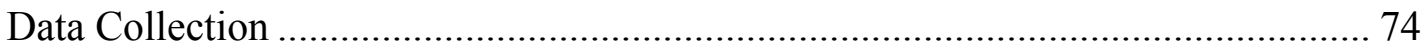

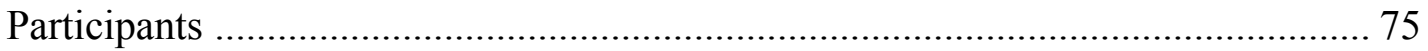

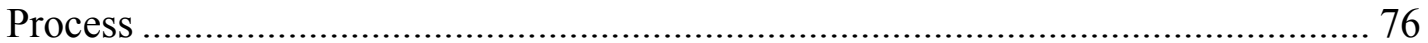

Data Analysis and Implications for the Formal Study …………............................. 77

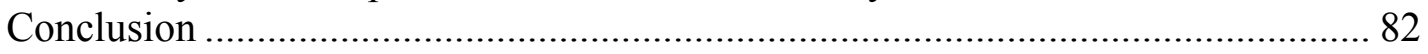

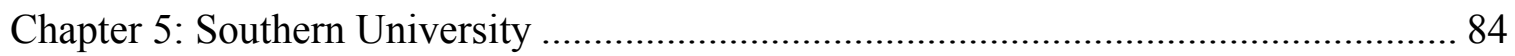

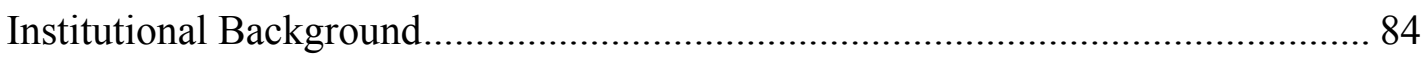

Mission Statement for Southern University Student Affairs .................................... 85

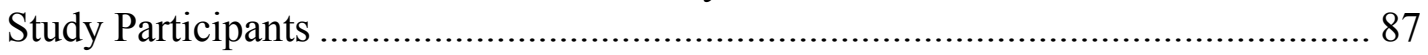

History of Southern University Student Affairs Assessment Efforts ....................... 89

Southern University Student Affairs Assessment Process and

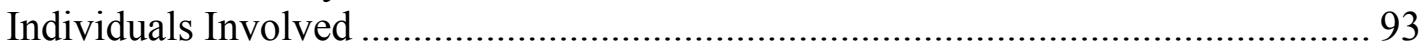

Southern University Student Affairs Learning Outcomes ........................................ 98

Southern University Student Affairs Assessment Methods..................................... 104

Southern University Student Affairs Assessment Collaboration............................. 111

Enhancing Student Learning Based Upon Southern's Student Affairs

Assessment Results ..................................................................................... 112

Southern University Student Affairs Assessment Successes and Challenges ........ 116

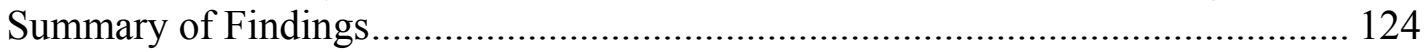

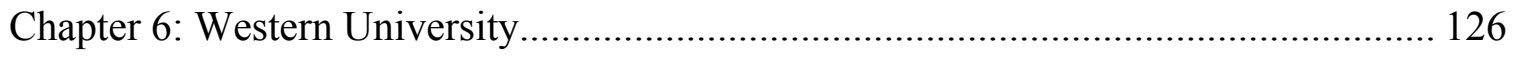

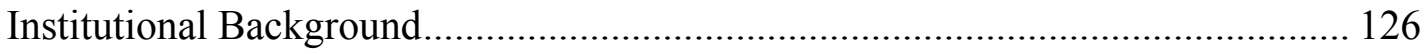

Mission Statement for Western University Student Affairs .................................. 127

Study Participants ........................................................................................ 129

History of Western University Student Affairs Assessment Efforts ....................... 131

Western University Student Affairs Assessment Process and

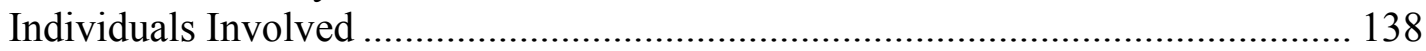

Western University Student Affairs Learning Outcomes ....................................... 144

Western University Student Affairs Assessment Methods ...................................... 152

Western University Student Affairs Assessment Collaboration.............................. 161

Enhancing Student Learning Based Upon Western's Student Affairs

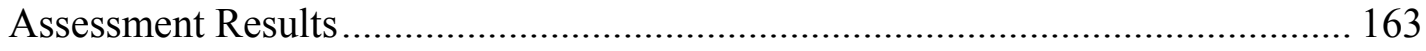

Western University Student Affairs Assessment Successes and Challenges ......... 168

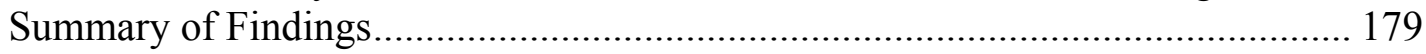




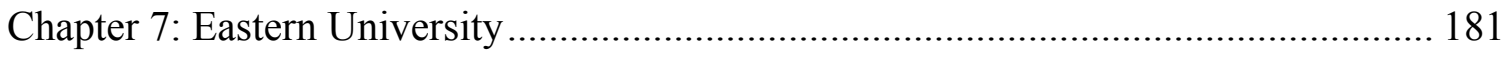

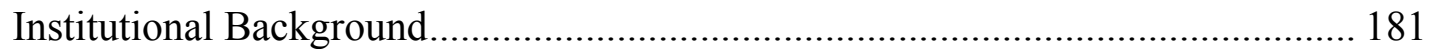

Mission Statement for Eastern University Student Affairs..................................... 183

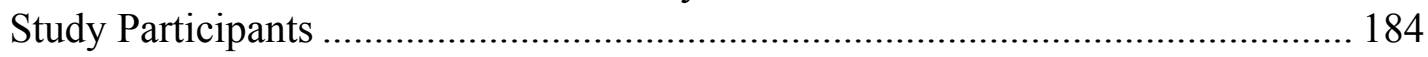

History of Eastern University Student Affairs Assessment Efforts........................ 186

Individuals Involved in Eastern University Student Affairs Assessment Process.. 190

Eastern University Student Affairs Centralized Assessment Method .................... 199

Eastern University Student Affairs Decentralized Assessment Process................. 203

Eastern University Student Affairs Educators' Perceptions of

High Quality Learning Outcomes ..................................................................... 212

Eastern University Student Affairs Assessment Collaboration .............................. 213

Eastern University Student Affairs Assessment Successes and Challenges........... 216

Summary of Findings................................................................................... 220

Chapter 8: High Quality Student Affairs Learning Outcomes Assessment Practices: Cross Site Analysis of Three American Research Institutions ....................................... 223

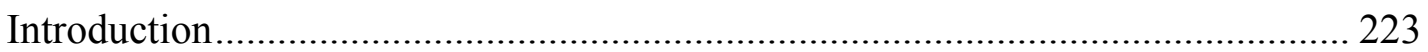

Assessment Processes ....................................................................................... 223

Individuals Involved in Student Affairs Assessment and

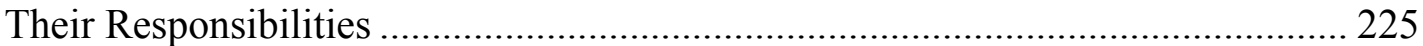

Articulated Student Affairs Learning Outcomes .................................................... 229

Methods Used When Assessing Student Affairs Learning Outcomes..................... 233

Student Affairs Assessment Collaboration ......................................................... 236

Enhancing Student Learning Based Upon Student Affairs Assessment Results.... 237

Student Affairs Assessment Successes and Challenges......................................... 240

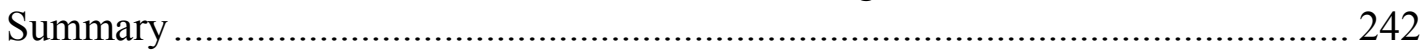

Chapter 9: Recommendations for Practice and Future Research.................................... 244

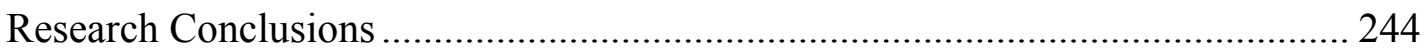

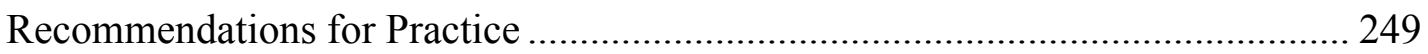

Recommendations for Future Research ............................................................. 251

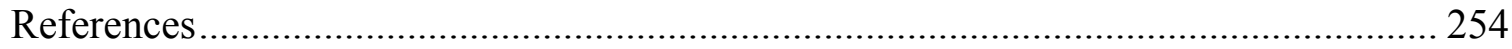

Appendix A: Case Study Selection Criteria................................................................ 263

Appendix B: Pilot Study Interview protocol ............................................................ 265

Appendix C: Follow-up Questions for Pilot Study........................................................ 268

Appendix D: Document Content Analysis Form.......................................................... 269

Appendix E: Letter to Request Institutional Site Approval for Pilot Study ................... 271

Appendix F: Letter From Pilot Study Granting Permission for Site Visit...................... 273

Appendix G: Cover Letter for Liaison at Participating Pilot Institution ......................... 274

Appendix H: Pilot Institution Participant Invitation Letter ........................................... 276

Appendix I: Letter to Request Institutional Site Approval ............................................. 278 
Appendix J: Letter From Case Study Institution Granting

Permission for Site Visit ..................................................................... 280

Appendix K: Cover Letter for Liaison at Participating Case Study Institution .............. 281

Appendix L: Case Study Participant Invitation Letter................................................ 283

Appendix M: Formal Study Interview Protocol ................................................... 285 


\section{List of Figures}

Figure

Page

List of Tables

Table

Page

1

2

3

4

5

6
Instistuions Identified as Possible Case Study Sites 55

Points of Data Collection Aligned With Research Questions

Interview Protocol Questions and Document Content Analysis

Protocol Questions Aligned With Research Questions

Southern University Interview Respondents 88

Southern University Interview Reponses: Reason Student Affairs Began Assessing Student Learning Outcomes 90

Southern University Interview Respondents: Purpose of Assessing Learning Outcomes. 91

Southern Univeristy Student Affairs Assessment History and Progress ... 93

Types of Learning Outcomes Identified in Southern University Student Affairs Assessment Plans (2004-05) 100

Southern University Student Affairs' 2004-05 Student Learning Outcomes Categorized Within Cognitive and Affective Taxonomies

Southern University Interview Responses: Characteristics of High Quality Learning Outcomes 104

Methods used to Assess Southern University Student Affairs'

Learning Outcomes in 2004-05

Types of Decisions Made by Southern University Student Affairs'

Educators Based on 2004-05 Assessment Results.

Southern University Student Affairs Interview Respondents'

Reported Assessment Successes 118 
14 Southern University Student Affairs Interview Respondents'

Reported Assessment Challenges

Western University Interview Respondents.

16 Western University Interview Responses: Reason Student Affairs

Began Assessing Learning Outcomes.

Western University Interview Responses: Purpose of Assessing Learning Outcomes

Western University Student Affairs Assessment History and Progress .. 137

Sample Portion of Rubric Used by Western's Student Affairs Assessment

Committee When Reviewing Unit-Level Assessment Plans

20 Types of Learning Outcomes Identified in Western University

Student Affaits Assessment Plans (2004-05)....

Western University Student Affairs' Student Learning 2004-05 Outcomes

Categorized Within Cognitive and Affective Taxonomies.

Western University Interview Responses: Characteristics of High

Quality Learning Outcomes.

Methods used to Assess Western University Student Affairs' Learning Outcomes in 2004-05.

Sample portion of Western University Admissions Office Rubric Used to Determine Tour Guide Competency Levels.

Sample Portion of Western University Career Services Rubric Used

During Student Mock Interviews.

Sample Portion of Western University Career Services Rubric Used When Reviewing Student Resumes

Types of Decisions Made by Western University Student Affairs' Educators Based on 2003-04 Assessment Results.

Western University Student Affairs Interview Respondents' Reported Assessment Challenges..... 
31 Eastern University Interview Responses: Reason Student Affairs Began Assessing Learning Outcomes................................................................. 187

32 Eastern University Interview Responses: Purpose of Assessing Learning Outcomes.

33 Eastern University Student Affairs Assessment History and Progress

34 Sample Portion of Eastern University Student Affairs' Participant Learning Evaluation

Number of Eastern University Student Affairs Programs, Estimated Student Attendance, and Number of Participant Learning Evaluations Completed During 2002 (Spring, Summer, and Fall) and 2003 (Spring, Summer, and Fall).

36 Eastern University Student Affairs Participant Learning Evaluation Aggregated Results During 2002 and 2003

Eastern University Orientation and Family Programs Office Student Employee Positions, Summary of Duties, and Competencies for Assessment.

38 Eastern University Interview Responses: Characteristics of High Quality Learning Outcomes

Eastern University Student Affairs Interview Respondents' Reported Assessment Successes.

Eastern University Student Affairs Interview Respondents' Reported Assessment Challenges

Types of Learning Outcomes in Student Affairs Assessment Plans.

43 Student Affairs Student Learning Outcomes Categorized Within Affective Taxonomy .... 
45 Types of Decisions Made by Southern and Western University Student Affairs' Educators Based Upon Assessment Results ................. 239 


\section{Chapter One \\ Introduction and Statement of Problem}

\section{Problem Statement}

Historically, student affairs professionals have been viewed as staff members who contribute to the extra-curricular development of college and university students through residence life, career services, and student activities. However, the late $20^{\text {th }}$ century and onset of the $21^{\text {st }}$ century resulted in calls for reform from the profession, which re-defined the role of student affairs professionals as educators who significantly contribute to not only student development, but also student learning (American Council on Education [ACE], 1983; National Association of Student Personnel Administrators [NAPSA], 1987; American College Personnel Association [ACPA], 1996; NASPA \& ACPA, 1997; ACE, ACPA, \& NASPA, 1998; Whitt, 1999; NASPA \& ACPA, 2004). Specifically, ACPA (1996) modified its 1994 hallmark document, The Student Learning Imperative: Implications for Student Affairs, affirming that learning and development are "inextricably intertwined and inseparable" (p. 2), thus calling upon student affairs educators to join other university and college educators in "...creating the conditions under which students are likely to expend time and energy in educational-purposeful activities" (p. 4). In order to achieve quality conditions of learning, ACPA called upon student affairs educators to articulate and assess learning outcomes associated with their co-curricular educational experiences in order to enhance student learning. They outlined five major outcomes all college graduates should achieve as listed below:

1. Complex cognitive skills such as reflection and critical thinking;

2. An ability to apply knowledge to practical problems encountered in one's vocation, family, or other areas of life; 
3. An understanding and appreciation of human differences;

4. Practical competence skills, [such as] decision making [and] conflict resolution; and

5. A coherent integrated sense of identify, self esteem, confidence, integrity, aesthetic sensibilities, and civic responsibility (ACPA, 1996, p. 2).

The calls for reform had a great impact upon the student affairs profession, resulting in vast discussions over the profession's purpose. However, limited research had been conducted in the area of co-curricular student learning outcomes assessment, resulting in confusion over how to develop and implement assessment plans. Up to this point in time, student affairs educators had based their assessments upon benchmarks and student satisfaction, attempting to determine how many students attended their programs and utilized their services and to what degree students reported satisfaction with those programs and services (Bresciani, Zelna, \& Anderson, 2004; NASPA \& ACPA, 2004). This information provided neither evidence regarding changes in a student's "understanding and appreciation of human differences," nor did it provide evidence of how to enhance this particular outcome (ACPA, 1996, p. 2). Hence, it became apparent to student affairs educators that they were not meeting the call from its professional organizations to assess student learning outcomes. For that reason, student affairs assessment literature began to emerge that provided insights about how to ideally assess student learning and development (Terenzini \& Pascarella, 1994; Upcraft and Schuh; 1996; Angelo, 1999; Pacarella \& Upcraft, 1999; Whitt, 1999; Bresciani et al., 2004; Maki, 2004).

Angelo (1999) noted that “...over the past two decades, we've made impressive progress in assessment. On the other hand, we still don't have much solid evidence of learning improvement" (p. 1). Much of the progress Angelo referred to was student affairs educators' realization that learning outcomes assessment was not simply a fad (Pascarella and Upcraft, 1999). Such a realization came, in part, from ACPA and NASPA's increased student learning 
outcomes assessment educational efforts, through professional development conferences and workshops, the creation of student affairs assessment knowledge communities, the publication of assessment guidebooks, and the development of online assessment web resources (NASPA Main Page, 2005; ACPA Main Page, 2005), all of which contribute to what Barr and Tagg (1995) refer to as a paradigm shift.

However, preliminary research indicates that only a few student affairs divisions have fully implemented their plans to assess student learning outcomes (Oregon State University Student Affairs Research \& Evaluation Main Page, 2005; North Carolina State Student Affairs Research and Assessment Main Page, 2005; Northern Arizona University Student Affairs Assessment Main Page, 2005; Penn State Student Affairs Research \& Assessment Main Page, 2005; \& Texas A\&M Student Life Studies Main Page, 2005). Other student affairs divisions are in the beginning stages of developing their assessment plans. The mature student affairs divisions who have substantial experience in successfully implementing their assessment plans are important to examine closely so that others can learn from their experiences. No research has been conducted on how these student affairs divisions have successfully and fully implemented their assessment plans. Since no in-depth case studies of student affairs divisions' assessment practices have been conducted, the majority of student affairs educators have no practical guidance on how to facilitate their own division's assessment plans and focus on student learning and development.

\section{Purpose and Significance of Study}

Because " $\ldots$ assessing student learning and development is the responsibility of both academic and student affairs" (Maki, 2002a, p. 1), the purpose of this study was to examine assessment practices of student affairs divisions at three different institutions. These student 
affairs divisions represented models with significant experience in successfully implementing assessments of student learning and development. Valuable information for the entire student affairs profession was collected through interviews with various student affairs staff including senior officers, assessment directors and coordinators and committee members, and selected educators within the student affairs division. Additionally, evidence was gathered through document analysis of assessment plans, annual reports, divisional newsletters and web-pages, and assessment committee meeting minutes. After a thorough analysis, synthesis, and evaluation of the collected data, the best student affairs assessment practices and limitations are shared.

It is clear that pressures to show evidence of co-curricular learning are not going to disappear, "and as a consequence, programs, services, and activities that fail to implement assessment processes and/or fail to demonstrate specific contributions to the educational mission of the institutions place themselves in jeopardy" (Terenzini \& Upcraft, 1999, pp. 64 -65). Therefore, this study advances the value, usefulness, and understanding of learning outcomes assessment within the student affairs profession, so more student affairs divisions may begin assessing learning within the co-curricular. Moreover, this study produces beneficial information that will help student affairs educators develop strategies to address problems that academic affairs are currently facing, sixteen years after the North Central Association of College and Schools issued its first Statement on Assessment and Student Academic Achievement (Lopez, 2004).

\section{Research Questions}

The following research questions were addressed:

1. What are the student learning outcomes articulated in the student affairs assessment plans?

2. How are these learning outcomes assessed? 
3. Who is involved in the assessment planning process, and what are the major responsibilities of these individuals?

4. Are student affairs educators collaborating with others, such as academic affairs, in the creation and administration of assessments? How?

5. How are student affairs assessment data used to enhance student learning experiences?

6. What successes and challenges do student affairs educators face as they implement their assessment plans?

In order to effectively address the above six research questions, the researcher first conducted a thorough literature review of student affairs learning outcomes assessment practices in Chapter Two. He also examined calls for reform in higher education and how student affairs educators are responding to those calls. Moreover, the literature review includes a detailed description of the each step involved in the assessment process and strategies for sustaining student affairs learning outcomes assessment. Thereafter, the researcher presents his research design and methodology in Chapter Three. In order to address the proposed research questions, a qualitative case study methodology was used; thus, Chapter Three clearly explains and justifies the study's research design. Evidence was gathered by interviewing student affairs educators involved with their division's assessment process, as well as through reviewing relevant documents, such as assessment plans, annual reports, divisional newsletters and web-pages, and assessment committee meeting minutes. After a systematic analysis, synthesis, and evaluation of collected data, the researcher produced a rich and descriptive explanation of high quality model assessment practices of student learning outcomes within three American research universities' student affairs divisions. 


\section{Chapter Two}

\section{Review of Literature}

The purpose of this literature review is to create a conceptual framework of student affairs learning outcomes assessment practices. The review focuses on the calls for higher education as a whole to reexamine its contributions to student learning, followed by an explanation of how student affairs educators responded to those calls for reform, specifically addressing their student learning outcomes assessment efforts. Thereafter, the review concentrates on models of learning outcomes assessment, addressing eight key steps in the process, ranging from the articulation of learning outcomes to implementation of assessments and how to use the results to enhance student learning. The review concludes with essential strategies and practices student affairs educators must address in order to sustain their learning outcomes assessment practices.

\section{Calls for Reform in Higher Education}

The landscape of American higher education has greatly changed during the past 20 years. Pressures for institutions to compete among one another for declining state funds has created an environment where higher education costs continue to rise. As result, prospective students, parents, and potential donors are critically examining where they choose to spend their money, insisting that institutions provide a return on their investment. At the same time, cooperate leaders claim that college graduates no longer possess the knowledge and skills needed to meet the demands of the workplace, ultimately resulting in the general public's decreased confidence of the efficiency and effectiveness of higher education (Wingspread Group, 1993; Kellogg Commission, 1997). 
The increase in the public's skepticism about the effectiveness and efficiency of higher education resulted in multiple calls for reform (National Institute of Higher Education, 1984; Wingspread Group; 1997; Kellogg Commission; 1997). The premise of each report focused upon the need for institutions to create a community of learners, where faculty, staff, and students are engaged in lifelong learning, rather than a place where learning culminates upon the receipt of a student's degree. Specifically, the Kellogg Commission's report (1997) stated,

To create such a community and satisfy public expectations about our performance, our institutions must strive to continue to be centers of excellence, committed to firm standards and expectations... [Educators] must help students develop essential life skills and values: critical thinking; knowing how to learn; effective oral and written communication; a multicultural perspective; respect for individuals and the sources of individuality; civic and individual responsibility; self-esteem and self-confidence; and a sense of one's own competences; and the leadership and the ability to work well with others, either as a leader or member of a team (p. 2-3).

In order to achieve high standards and expectations, changes in university and college classrooms began to occur. Barr and Tagg (1995) refer to this as a shift from an Instruction Paradigm to a Learning Paradigm. They note that faculty began moving away from environments that fostered traditional methods of teaching, such as three, 50-minute academic lectures per week. In the place of traditional pedagogy, faculty began exploring new methods of learning, such as active learning, problem-based learning, and cooperative learning. By adopting these new methods of learning, faculty created conditions where students took responsibility for their own learning. Moreover, faculty created multiple opportunities for students to display what they had learned; consequently, resulting in multiple and ongoing assessment opportunities that 
provided useful information on "how to produce more learning with each graduating class, each entering student” (Barr \& Tagg, 1995, p. 14).

Producing more learning is possible within the learning paradigm, because the educational environment is cooperative, collaborative, and supportive. "Faculty, and everybody else in the institution, are unambiguously committed to each student's success" (Barr \& Tagg, p. 23). Yet, Barr and Tagg (1995) emphasize that adoption of the learning paradigm "changes everything" (p. 13). For that reason, it was only a matter of time, before everybody else, including student affairs educators, began exploring their role in enhancing student learning. Responding to Calls for Reform: Understanding Student Affairs Educators' Assessment Roles

Calls for higher education reform and the shift to a learning paradigm had a considerable impact upon the student affairs profession. Most notably, a call to measure co-curricular learning outcomes first emerged in 1996 when the American College Personnel Association [ACPA] issued, The Student Learning Imperative: Implications for Student Affairs. The document's intent was to create dialogues on how to improve the overall student experience "by affirming student learning and personal development as the primary goals of undergraduate education" (p. 8), thus requiring student affairs to redefine its role as a not only a service-provider, but also as an educator. Moreover, the document called for student affairs educators to critically examine how they could better contribute to institutional missions of learning.

In order for student affairs educators to measure how effectively they contribute to student learning, ACPA created a list of learner-oriented characteristics for divisions to weigh their own effectiveness against. Those characteristics, as summarized by Andreas \& Schuh (1999) include: 
1. The student affairs mission complements and reinforces the institution's mission of learning. In addition, achieving student learning - in the form of desired educational outcomes - is the primary goal for student affairs policies, services, and programs;

2. Resources are allocated to foster student learning;

3. Student affairs staff collaborate with colleagues in other areas of the institution to plan for, and foster, student learning;

4. Student affairs staff are experts on students, their environments, and teaching and learning processes; and

5. Policies and practices are grounded in research and institutional assessment on student learning outcomes. (p. 8)

ACPA (1996) clearly acknowledged that student affairs educators possess the expertise to contribute to the leaner-centered missions of higher education. Yet, the document lacked guidance on how student affairs educators who are not achieving the aforementioned benchmarks should change their practices in order to become more learner-centered.

In response, the National Association of Student Personnel Administrators [NASPA] and ACPA (1997) produced Principles of Good Practice for Student Affairs. The report provided student affairs educators with approaches to provide quality co-curricular educational experiences, thus leading to enhanced student learning. According to the report, in order for student affairs divisions to achieve the characteristics as outlined by the Student Learning Imperative, specific actions are required. The following list includes those actions with a brief explanation and example of each:

1. Engage students in active learning. Active learning experiences include, for example, leadership involvement, service learning opportunities, and on-campus resident advising. Such opportunities not only allow students to carry their life experiences into the learning process, but allow students to apply what they have learned to their personal lives. For instance, a carefully designed volunteer opportunity may result in a student's greater awareness of American poverty issues. As a direct result, the student may lead (with proper facilitation) a food-drive within his or her residence hall to assist those less fortunate in the community, thus producing evidence that the 
student has not only received information, but he or she has also responded to that information and perhaps, begun to internalize the value of empathy.

2. Help students develop coherent values and ethical standards. Student affairs educators must create learning experiences that build character. Specifically, student affairs educators must provide learning experiences focusing upon academic integrity and conduct standards, ethical responsibilities of community living and decision making, and civic responsibility. For instance, student affairs educators may create opportunities for students to openly discuss what makes them different from others within their residence halls, thus creating conditions for students to explore and accept racial, gender, and sexuality differences.

3. Set and communicate high expectations for learning. Student affairs educators must clearly create and articulate challenging learning expectations of students based upon student backgrounds and abilities. For instance, if student affairs educators expect students to attend three cultural events on the campus during the academic year, then the division must clearly relay those expectations to students as well as faculty and staff. Moreover, student affairs educators must provide multiple cultural events throughout the academic year to assure opportunities for students to meet the desired expectations.

4. Use systematic inquiry to improve student and institutional performance. Systematic inquiry is a process for collecting evidence of student learning, requiring student affairs divisions to develop and implement assessment plan(s). The purpose is to discover if student learning outcomes are being reached and how to enhance student learning experiences. Further discussion of this Principle follows later in the chapter.

5. Use resources effectively to achieve institutional mission and goals. Student affairs educators must prioritize their work based upon meeting the student learning mission of its institution. For instance, if a student affairs division commits itself to student learning outcomes assessment, the leadership of that division must appropriately allocate resources to provide staff with professional development opportunities, resources for staff to share assessment results at appropriate conferences and seminars, and resources for data management, instrument purchase, and support staff.

6. Forge educational partnerships that advance student learning. Student affairs educators must encourage connections between students, faculty, and staff. For instance, new student orientation should provide opportunities for diverse student interaction and invitations for students to become involved on- and-off campus. Additionally, first-year student seminar courses provide student affairs educators, faculty, and upperclassmen students the opportunity to partner, allowing first-year students a greater chance to connect with a mentor.

7. Build supportive and inclusive communities. The primary goal of a supportive and inclusive community must support the institution's mission of student learning. Only then will such communities be created. Student affairs educators have the 
responsibility to create and provide learning experiences for multiple students, faculty, and staff to participate. For instance, student affairs educators must take an active role in the internal governance of its institution. This means that the senior student affairs office should have a good working relationship with the chair of the faculty senate and president of the student government, allowing for the student affairs division to better understand how they may contribute and work with others in achieving the institution's mission of student learning (NASPA \& ACPA, 1997; Blimling \& Whitt, 1999; AAHE, ACPA, \& NASPA, 1998; NASPA \& ACPA, 2004).

It is important to note that the aforementioned actions and use of language are consistent with Barr and Tagg's (1995) description of a learning paradigm. For instance, Principle One, engage students in active learning, is written with student learning as the objective. As Barr and Tagg (1995) explain, the shift from an Instruction Paradigm to a Learning Paradigm requires educators not to focus their objectives upon providing or delivering instruction or services, but rather focus their efforts on producing student learning. Likewise, Principles Three and Four echo Barr and Tagg's criteria for measuring student success, noting the need to not only articulate learning outcomes, but to also systematically measure those outcomes.

While it became clear to student affairs educators that they too were adopting the learning paradigm, questions of how to assess what students were learning from their experiences remained unclear, because up to this point, student affairs educators had based their assessments upon student satisfaction. However, student affairs assessment scholars, Bresciani, Zelna, \& Anderson, (2004) argue that student affairs educators must move beyond the traditional assessment of student satisfaction and begin assessing student learning outcomes. Bresciani, et al. (2004) maintain that student affairs satisfaction assessments do not inevitably offer information that demonstrates how student affairs is contributing to the entire student educational experiences. Likewise, NASPA and ACPA (2004) assert that student affairs educators have the “...opportunity and responsibility to lead and participate in the comprehensive systematic, and consistent assessment... of student learning in all domains" (p. 26). The authors continue, 
“...assessment methods focus primarily on student learning rather than on student satisfaction... Although satisfaction assessments provide data on a student's fulfillment, the evidence they produce does not inform others about how students learn and what they know" (p. 27).

To help guide student affairs educators in their learning outcomes assessment efforts, Upcraft and Schuh (1996) adapted the American Association for Higher Education's (AAHE) (1992) Principles of Good Practice for Assessment to fit the context of student affairs education. In summary, effective student affairs outcomes assessments:

1. begin with educational values and are guided by the institution's mission and goals;

2. understand that learning is multidimensional; therefore, assessments must be diverse;

3. have clear and explicit goals and outcomes;

4. are concerned with both outcomes and processes;

5. are ongoing;

6. are the result of collaboration within student affairs and with other educators; and

7. consider what issues and questions must be answered.

\section{Accountability in Student Affairs}

The call for accountability from institutional administrators, government leaders, accrediting bodies, stakeholders, and the general market continues to rise (Woodard, Love, \& Komives, 2000). Specifically, Blimling (1999) insists that student affairs educators of the 21st century are being held accountable for student behavior, the effectiveness of programs, and cost efficiency. Most importantly, Blimling states:

The demand for increased accountability for student learning is an invitation for student affairs to demonstrate its contributions. Although many performance-based assessments 
are devoid of measures of student affairs' efforts to advance student learning, the opportunity exists to expand these measures of assessment (p. 6).

One must also note advantages to the profession itself with the employment of assessment. Maki (2004) believes that assessments provide evidence in response to questions of curiosity about the work of educators. Posner (2003) insists that while assessment enhances student learning, it also is beneficial to the entire student affairs profession. Posner states, “...we can:

- Quantify our professionalism;

- Provide a feedback mechanism for students and the entire academic community;

- Help establish areas of strength and areas of concern that need to be addressed;

- Enhance how student affairs contributes to the overall educational experience; [and]

- Help design future learning outcomes (p. 2).

The Council of Regional Accrediting Commissions (2003), outlines its assessment expectations of accrediting-seeking institutions. Those expectations include:

1. Having student learning at the center of its mission;

2. Documenting of student learning, which requires:

A. Setting clear goals

B. Collecting evidence from multiple sources, including the co-curricular

C. Providing judgments based upon evidence

D. Using evidence to make changes and improve student learning.

3. Involving stakeholders; [and]

4. Exhibiting commitment to educational improvement (pp. 3-4).

As illustrated by point $2 \mathrm{~B}$, outside-of-class learning opportunities should provide evidence of student learning. Hence, student affairs educators must plan, implement, and conduct student learning outcomes assessments to address accreditation standards. 
While accountability may be one driving force behind student affairs learning outcomes assessment, Maki (2004) cautions that "though legislators, policy makers, and accreditors become external drivers of an institutional commitment to assessment, it is important to shift from an externally driven process to an internally driven one" (p. 13). Maki explains that accrediting agencies are not interested in episodic assessments. On the contrary, they are interested in an institution's ability to develop and maintain an “....internally driven core process of inquiry to improve student learning..." (p. 13). In order to create a core process of inquiry within student affairs, educators must consider the following questions:

1. What knowledge, talents, and skills do college graduates need in order to live and work fully?

2. What must they do to master such knowledge, talents, and skills? Are they doing these things?

3. Do students find in our colleges a coherent body of experiences that help them to become competent, capable, and interesting people?

4. Do they understand what they have memorized? Can they act on it?

5. Has the experience of college made our students flexible and adaptable learners, able to thrive in a knowledge society (Barr \& Tagg, 1995, p. 25).

The following sections clearly define assessment and explain how the creation and implementation of student learning outcomes assessments produce information which allows student affairs educators to respond to the aforementioned questions.

\section{Defining Assessment}

Vast discussions over the meaning of assessment, as referenced by multiple, yet similar definitions, appear in the literature. For instance, Angelo (1995) defines assessment as "an ongoing process aimed at understanding and improving student learning," contending that assessment requires: 
- Making our expectations explicit;

- Setting appropriate criteria and high standards for learning;

- Systematically gathering, analyzing, and interpreting evidence to determine how well performance matches those expectations and standards; and

- Using the resulting information to document explain, and improve performance (p. 7).

In addition to Angelo's definition of assessment, various other assessment scholars collectively agree that assessment is an ongoing process aimed at enhancing student learning (AAHE, 1992; Angelo, 1999; Palomba \& Banta, 1999; Bresciani, 2002; Huba \& Freed, 2000; Maki, 2002a; Marchese, 1987, Anderson, 2001a; Suskie, 2004). Additionally, student affairs assessment literature is emerging. For example, Bresciani (2003a) addresses the need for student affairs educators to assess learning and development of the whole student, thus calling for cocurricular outcomes to be measured. Moreover, Maki (2002b) explains, "assessment is a means of discovering — both inside and outside of the classroom — what, how, when, and which students learn and develop an institution's expected learning outcomes" (p. 1). It is important to note, that for the purpose of this study, assessment is defined as:

The process of gathering and discovering information from multiple and diverse sources in order to develop a deep understanding of what students know, understand and can do with their knowledge as a result of their educational experiences; the process culminates when assessment results are used to improve subsequent learning" (Huba \& Freed, 2000, p. 8).

Once student affairs educators commit themselves to measuring student learning outcomes, they must begin the process of developing comprehensive assessment plans and/or individual department plans. However, Terenzini (1989) cautions that the creation of student learning outcomes assessment “...is not something that can be done quickly or casually. Several 
conceptual, administrative, political, and methodological issues may prove troublesome in developing a successful and beneficial assessment program” (p. 662). In order to avoid such pitfalls, it is important for student affairs educators to clearly identify a researched assessment planning process.

Multiple assessment scholars (AAHE, 1992; Huba \& Freed 2000; Palomba \& Banta, 1999; Council for Higher Education Accreditation, 2003, Bresciani et al., 2004; \& Maki, 2004) widely agree on the assessment process. The assessment progression should involve:

1. the creation and articulation of student learning outcomes which flow directly from the institution's mission, goals, and objectives.

2. the development or selection of assessment measures.

3. the selection of assessment participants.

4. the implementation of assessments.

5. the analysis of assessment results.

6. the reporting of assessment results.

7. the use of assessment results to enhance student learning experiences.

8. the evaluation of the assessment process.

Figure 1, on the next page, clearly illustrates the ongoing learning outcomes assessment process. A discussion of the eight steps involved in the assessment process follows the illustration. 
Figure 1:

The Assessment Process

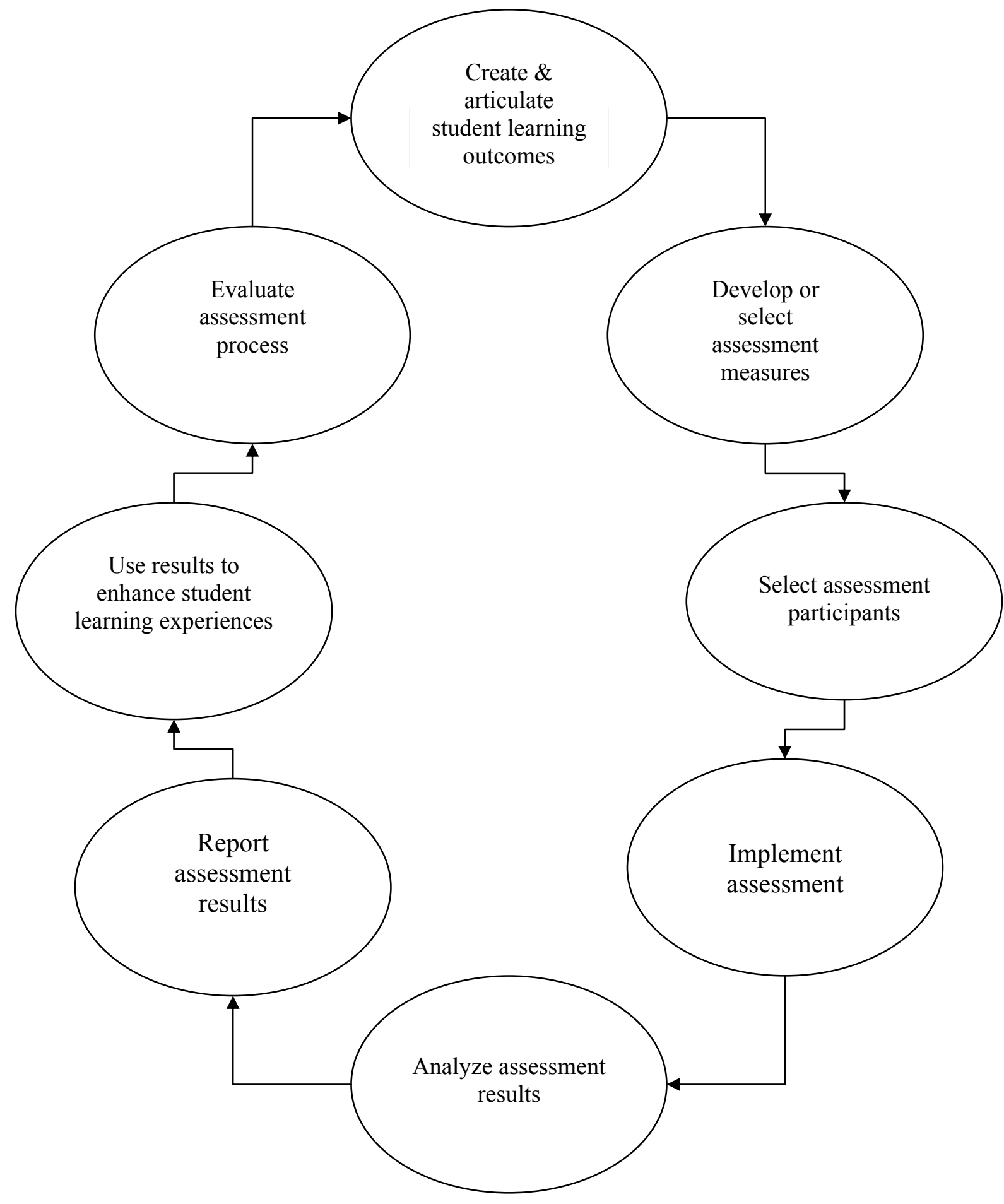




\section{Articulating Student Learning Outcomes}

Huba and Freed (2000) explain that student learning outcomes indicate what educators want students to know or do rather than what educational experience will be offered, maintaining that clearly stated learning outcomes offer guidance for all activities, services, and programs and inform undergraduates about student affairs educators' intentions. Moreover, literature synthesized by Bresciani et al., (2004), reveals that student learning outcomes are “...cognitive abilities, as well as affective dimensions that [student affairs] desire [their] program[s] to instill or enhance" (p. 11).

The articulation and assessment of student learning outcomes begins with an understanding of the institution's educational values (AAHE, 1992). Therefore, student affairs educators must create and articulate student learning outcomes that directly flow from existing institutional mission statements, as well as student affairs division and unit mission statements (Maki, 2004). Multiple scholars assert that student affairs educators must reach a consensual comprehension of the institution's mission prior to the creation of student learning outcomes, thus requiring critical examination of the meaning and intent of the actual statement (AAHE, 1992; Palomba \& Banta, 1999; Huba \& Freed 2000; Bresciani et al., 2004; \& Maki, 2004).

For example, Massachusetts's Babson College's (1998) mission focuses upon "educat[ing] innovative leaders capable of anticipating, initiating and managing change" (as cited in Huba \& Freed 2000, p. 103). Moreover, Babson's mission includes a competency area, involving leadership, teamwork, and social responsibility. Before creating student learning outcomes, Babson student affairs educators must consider how their division contributes to achieving its institutional mission. Since there is evidence that “...students benefit in many ways from out-of-class experiences, ranging from gains in critical thinking to relational and 
organizational skills..." as well as reported gains in abilities to communicate and cooperate (Kuh, 1995, p. 149-150), Babson College's student affairs educators may choose to develop learning outcomes that emerge from co-curricular experiences, such as student involvement in campus clubs, organizations, cultural awareness programs, and learning communities, all of which contribute to students' cognitive gains (Whitt \& Miller, 1999). Moreover, Babson student affairs educators may look to study abroad experiences and student leadership programs when articulating their learning outcomes, since both contribute to intrapersonal competencies or, in the case of this study, affective gains (Whitt \& Miller, 1999).

In addition to aligning outcomes with institutional missions, assessment scholars agree that student learning outcomes should be measurable, meaningful, realistic, and ongoing (Huba \& Freed, 2000; Bresciani et al., 2004; Maki, 2004). To guide the creation of good learning outcomes, Bresciani (2001) suggests that student affairs educators ask themselves the following questions:

- What are we trying to do and why?

- How well are we doing it?

- How do we know?

- How do we use the information to improve or celebrate successes?

- Do the improvements we make work? (p.1).

The development of learning outcomes should occur early in the assessment process before decisions are made about specific assessment methods. According to Huba and Freed (2000), clear outcomes begin with, "Students will be able to..." (p. 10). For that reason, student affairs educators may choose to align their outcomes with cognitive and affective taxonomies of 
educational objectives (Bloom, 1956; Krathwohl, Bloom, \& Masia, 1964; Anderson, Krathwohl, Airasian, Cruikshank, Mayer, Pintrich, Raths, \& Wittrock, 2001).

According to Anderson et al., (2001) cognitive learning may be categorized using six levels of thinking ranging from basic recall of information to advanced levels of evaluation and creation. The description of each level of thinking and examples of active verbs consistent with each level are presented below:

1. Remember: involves students' abilities to remember and recall information, but students may not understand what they remember. Example verbs include: define, describe, identify, know, label, list, match, name, outline, recognize, reproduce, and state.

2. Understand: involves students' abilities to understand the meaning of learned information. Example verbs include: classify, comprehend, explain, express, infer, interpret, paraphrase, and summarize.

3. Apply: involves students' abilities to apply a concept in a new situation, ideally integrating application into their solving problems strategies. Example verbs include: to apply, choose, construct, employ, illustrate, modify, and solve.

4. Analyze: involves students' abilities to distinguish between facts and inferences through the breakdown of information into separate components. Example verbs include: to analyze, calculate, categorize, contrasts, differentiate, distinguishes, and estimate. 5. Evaluate: involves students' abilities to make judgments about the validity of presented evidence. Example verbs include: to appraise, assess, criticize, defend, evaluate, and judge. 
6. Create: involves students' abilities to put parts together to create something whole and original, with an emphasis on the creation of meaning. Example verbs include: to arrange, assemble, collect, compose, design, formulate, synthesize, and revise.

In addition to this cognitive process, Krathwohl et al. have (1964) have identified a taxonomy for the affective domain, which demonstrates student awareness and growth in feelings, emotions and attitudes. The affective domain represents a hierarchy of five different categories. The description of each category and examples of active verbs are presented below: 1. Receiving: involves students' abilities to hear and demonstrate awareness. Example verbs include: Interest, open, attentive, describe, reply, willing to change (behavior), and willing to engage (in learning process).

2. Responding: involves students' abilities to participate as a learner. Example verbs include: comply, interact, participate, present, reflect upon, and question.

3. Valuing: involves students' abilities to internalize a set of specified values and often express those values in identifiable behaviors. Example verbs include: believe, demonstrate, differentiate, facilitate, invite, justify, respect, share, and value. 4. Organizing: involves students' abilities to organize values and contrast between differing values. Example verbs include: contrast/compare different values, combine, defend, formulate, integrate, synthesize, and resolve conflicts between values. 5. Internalizing Values: involves students' abilities to demonstrate characterization of a value system. Students have developed an internal value system that controls their behaviors. Example verbs include: judge, act, solve, modify, practice, serve, qualify, and verify. 
Student affairs educators can use the cognitive and affective taxonomies to categorize student learning. For example, a director of student recreation may choose to align his or her learning outcomes with Anderson's et al. (2001) cognitive domain. One outcome may read: Students will assess their health and wellness goals and utilize such information to identify appropriate exercise activities and healthy eating habits. This particular outcome aligns with fifth level of evaluation. Additionally, a director of the campus newspaper may align his or her outcomes with Krathwohl's et al. (1964) affective domain. One outcome may read: Students who work for the campus newspaper will prioritize their time effectively to meet the needs of their self, family, academics, and the campus newspaper. This particular outcome aligns with the fourth level, organization, within the affective domain.

According to AAHE (1992), assessments are effective when they acknowledge that learning is multidimensional. Therefore, student affairs educators must make every effort to provide learning experiences where students have opportunities to demonstrate gains in all levels of cognitive thinking. Additionally, this suggests that student affairs educators must provide learning experiences which enable students to develop their emotions, feelings, and attitudes at all levels within the affective domain. Clear and measurable student learning outcomes ultimately drive major decisions about which assessment methods are most appropriate to utilize. Collecting Information about Current Learning Experiences and Current Measures Used

As Palomba and Banta (2000) explain, it is essential for student affairs educators to complete an inventory of existing programs, services, activities, and existing data collection methods prior to the selection of new assessment measures. Maki (2004) encourages the use of maps and inventories, explaining that maps record where and how all educators contribute to the student learning experience. More importantly, the creation of maps provides assessment 
planners "information about what and even how students learn over time..." (p. 37).

Furthermore, maps inspire dialogues on the entire learning experience, illustrating the extent to which shared expectations align with educational practices. Maps also reveal a depiction of the circumstances under which students learn. While maps attempt to present educators with an outline of the student learning experience, Maki (2004) asserts that "inventories drill down into actual educational practices to develop shared understanding of and discussion about how students learn over time and how educators value that learning through assessment” (p. 38).

The creation of maps and inventories are ideal beginnings for the selection of assessment measures within student affairs. For instance, assume that a student affairs division has the expectation that its students will effectively organize and document their credentials on a resume. The creation of a map identifies the entire picture of effective resume writing learning opportunities; whereas, inventories critically examine each learning opportunity to determine if offered educational experiences are appropriate for meeting the desired outcome. Inventories also reveal what methods of assessment are currently being utilized to measure the desired outcome, in this case, appropriate resume writing. Most importantly, if inventories reveal that current learning opportunities do not provide experiences for students to reach desired outcomes, Bresciani (2003a) explains that student affairs educators may need to re-package their student services and learning experiences in order for the outcome to be successfully achieved.

\section{Selecting Appropriate Assessment Instruments}

It is important, as Palomba and Banta (1999) explain, for student affairs educators to create criteria for choosing their assessment methods. As Astin notes (1996), "Our choice of both student outcomes and of instruments for measuring these outcomes are ultimately based on value judgments" (as cited in Bresciani et al., 2004, p. 25). A synthesis of the literature reviewed 
(AAHE, 1992; Upcraft \& Schuh, 1996; Palomba \& Banta, 1999; Bresciani, et al., 2004; Maki, 2004) provides the following ten questions for student affairs educators to consider when selecting their assessment methods:

1. Are the assessment methods consistent with what student affairs educators are attempting to measure?

2. Do the assessment methods provide appropriate student learning evidence?

3. Can student affairs educators justify choices of assessment methods?

4. Will the assessment methods provide appropriate information to be shared with audiences?

5. Are financial resources and technology available to develop, purchase, and administer assessments?

6. Are the assessment methods appropriate in the context of the student affairs assessment plan timeline?

7. Are the assessment methods valid?

8. Are the assessment methods reliable?

9. Do the student affairs educators have the appropriate knowledge and resources to analyze the assessment data produced from the selected assessment measures?

10. When will students complete the assessments? Who will participate? Will samples of students be drawn or will the entire population of students participate?

When addressing questions one and three, student affairs educators must first recognize the importance of using multiple methods when assessing learning outcomes. Maki (2004) says that "relying on one method to assess the learning described in the outcome statements restricts interpretations of student achievement within the parameters of that method" (p. 86). By choosing multiple assessment measures, student affairs educators provide students several opportunities to exhibit their learning. Additionally, multiple methods allow data to be validated 
through triangulation, resulting in concrete evidence that may be used to make appropriate changes to student learning experiences.

It is essential for student affairs educators to select measures which accurately provide evidence of student learning, as stated in question two. Assessment scholars (Palomba \& Banta, 1999; Bresciani, et al., 2004; \& Maki, 2004) stress the importance of addressing both direct and indirect methods of assessment. As described by Palomba and Banta (1999), "Direct measures of learning require students to display their knowledge and skills as they respond to the instrument itself' (p. 11). Examples of direct assessment methods include objective tests, essays, portfolios, pre- and post-tests, and presentations. "Indirect methods such as surveys and interviews ask students to reflect on their learning rather than to demonstrate it" (p. 11-12). Maki (2004) points to the value of both direct and indirect methods of assessment data collection, explaining that while the use of indirect methods alone "cannot substitute for the evidence of learning that direct methods provide... they can, however, contribute to interpreting the results of direct methods..." (p. 89).

In addition to the consideration of both direct and indirect methods of assessment, student affairs educators must also determine what type of decisions they are seeking to make based upon desired assessment data, thus requiring an understanding of assessment methodologies. Whitt and Miller's (1999) synthesis of literature indicates that most research and assessments on student learning have been performed using quantitative methods, "that is, the data are numbers and most have been collected by means of questionnaires or surveys administered as single point in time" (p. 52). However, the authors also explain that student affairs educators should consider the use of qualitative methods, including interviews, observations, and document analyses (Patton, 2002). Maki (2004) explains that "qualitative methods enable [student affairs educators] 
to assess broader dimensions of learning, such as how individuals translate understanding into behaviors, dispositions, reactions, and interactions" (p. 87).

Assessments may be categorized as either formative or summative (Palomba and Banta, 1999). Formative assessments are ongoing and administered throughout the educational experience. Data produced from formative assessments are used to enhance the experience while it is occurring. On the contrary, summative assessments are not ongoing and are administered at the conclusion of an entire learning experience. Data produced from summative assessments are used to make decisions regarding the quality of an entire program, service, and/or activity. (Palomba \& Banta, 1999).

Questions four, five and six, which address audience, financial resources, and assessment timeline, require student affairs educators to examine the use of commercially- or locallydeveloped assessment measures. Commercially-developed measures for student affairs are available for purchase and include, for example, the National Survey of Student Engagement and the College Student Experiences Questionnaire (Buros Institute of Mental Measurements, 2005). Jones (2002) describes validity and reliability as the typical advantages of commerciallydeveloped instruments (as cited in Aloi, 2004). The Metal Measurements Yearbook and Tests in Print produced by the Buros Institute of Mental Measurements (2005) offer a formal analysis of commercially-developed assessment measurement instruments, including the purpose, limitations, validity, and reliability of each.

An example of data produced from commercially-developed instruments comes from assessments conducted by Zhoe and Kuh (2004). Zhoe and Kuh administered the National Survey of Student Engagement (NSSE) across 365 four-year institutions to first-year and senioryear students and discovered that: 
participating in learning communities is uniformly and positively linked with student academic performance, engagement in educationally fruitful activities (such as academic integration, active and collaborative learning, and interaction with faculty), gains associated with college attendance, and overall satisfaction with the college experience (p. 14).

As a result of Zhoe and Kuh's findings, participating institutions are equipped with data to make positive changes which enhance student learning. For instance, student affairs educators may use data which identifies at-risk students coupled with data produced from Zhoe and Kuh's assessments and decide that it is appropriate for all at-risk students to reside in learning communities. Additionally, student affairs educators may use Zhoe and Kuh's findings to support the creation of more learning communities across the campus, giving all students the opportunity to participate and grow as learners. Some student affairs educators may be interested in comparing their results with similar institutions. This type of assessment allows college and universities to determine if their students score at similar levels as their peer institutions.

While commercially-developed instruments are useful at times, there may be instances when student affairs educators discover that available commercially-developed instruments do not accurately measure their articulated learning outcomes. Moreover, the administration of the commercially-developed instruments and data feedback may not coincide with the established assessment timelines. Therefore, student affairs educators may choose to develop their own assessment measures (Upcraft \& Schuh, 1996). If student affairs educators cannot identify appropriate commercially-developed instruments, or they do not have the financial resources to purchase such instruments, they should explore the option of locally-developed assessment 
measures. Upcraft and Schuh (1996) maintain that "local assessment studies will have the desired impact of demonstrating the worth of student services and programs and ensuring their survival" (p. 10). Yet, Palomba and Banta (1999) caution that "locally developed instruments can take a great deal of time to construct and may provide results that are difficult to interpret" (p. 100). However, they continue to say that locally-developed instruments also create opportunities for collaboration in the assessment process, are the most likely to match desired outcomes, and address circumstances unique to the assessment environment. Maki (2004) explains that while results from locally-developed instruments "provide us with the richest information about the efficacy of our own educational practices" (p. 94), they must also be validated, thus leading this literature review into an exploration of questions seven and eight. Validity, according to Maki (2004) "refers to the extent to which a method prompts students to represent the dimensions learning desired" (p. 93). More simply explained, "Does an instrument measure what we want it to measure?" (Palomba \& Banta, 1999, p. 90). Gay and Airasian (2003), explain that:

...validity requires both item validity and sampling validity. Item validity is concerned with whether the [assessment] items are relevant to measurement of the intended content area. Sampling validity is concerned with how well the [assessment] samples the total content area being [assessed] (p. 136).

Reliability of measures, according to Palomba and Banta (1999) refers to "ones that can be counted on to produce consistent responses over time" (p. 88). Similarly, Gay and Airasian (2003) explain, "the more reliable a[n] [assessment] is, the more confidence we can have that the scores obtained from the [assessments] are essentially the same scores that would be obtained if the [assessments] were re-administered to the same test takers" (p. 141). Assuring reliability at 
the local-level requires the use of pilot assessments and dialogues based upon the following questions developed by Maki (2004):

- How well do trial tests yield the same results after multiple administrations?

- ... how well do representative populations respond to levels or types of questions or stimuli?

- Does the language of questions or instructions or the sequence or format of questions or tasks disadvantage certain populations?

- How consistent are scores across observer, graders, or an automated grading system? (p. 93).

Student affairs educators must address their data analysis capabilities prior to the selection of assessment measures. Bresciani et al. (2004) explain that assessment planners must "make sure, prior to committing any resources to a tool or method, that [they] know how [they] will have the data analyzed" (p. 26). A thorough discussion of how to analyze and interpret data follows later in this literature review.

It also important for student affairs educators to acknowledge the student learner when choosing assessment methods. Anderson (2001b) explains that the selection or development of assessment instruments must account for diverse learning styles and cultural differences in learning styles. Anderson continues to explain that while learning can be modified, students have preferred styles based upon how they receive, perceive, organize, process, and understand information. For that reason, student affairs educators may choose to administer "a learning styles-preference survey simply to give self-assessment feedback to students, so they can see themselves, maybe for the first time ever, as a learner" (p. 4). Data from such an assessment may also yield beneficial information to student affairs educators and assist them in their selection or development of measures. 


\section{Selecting Student Affairs Assessment Participants}

Before implementing student affairs assessment measures on a large scale, student affairs educators must specifically determine what population or samples they need to assess in order to collect evidence based upon their desired learning outcomes. Gay and Airasian (2003) explain that quantitative assessments are seldom administered to an entire population, hence the need for sampling. "Sampling is the process of selecting a number of participants for a study in such a way that they represent the larger group from which they were selected" (p. 101). They continue by explaining that there are four basic sampling techniques as outlined below:

- Random sampling is the process of selecting a sample in such a way that all individuals in the selected population have an equal and independent chance to be selected for the sample.

- Stratified sampling is the process of selecting a sample in such a way that identified subgroups in the population are represented in the same proportion that they exist in the population.

- Cluster sampling randomly selects groups, not individuals. All the members of selected groups have similar characteristics.

- Systematic sampling is sampling in which individuals are selected from a list taking every Kth name ( $\mathrm{K}$ is representative of a randomly selected number) (p. 109-10).

Because quantitative approaches attempt to generalize findings to a larger population, a larger and representative sample is required. However, qualitative assessments attempt to describe a particular phenomenon (Patton, 2002). Therefore, students will typically be purposefully selected when completing qualitative assessments. "This leads to selecting information-rich cases for study in depth. Information-rich cases are those from which one can learn a great deal about issues of central importance to the purpose of the [assessment]..." (p. 46). 


\section{Implementing Student Affairs Assessments}

Once student affairs educators have developed an assessment plan, selected appropriate measures, and preliminarily identified student participants, they must progressively implement assessments into their practices, by first administering funded pilot assessments (Terenzini, 1991; Huba \& Freed, 2000). Pilot assessments gradually introduce assessment into the student affairs culture and foster a learning environment for first-time assessors. As explained earlier in this review, the administration of pilot assessments allows student affairs educators to request student feedback on the assessment instrument itself, thus addressing concerns of clarity, comprehension, and administration format and ultimately allowing for modifications to the quality of instruments prior to assessing a larger population (Palomba \& Banta 1999; Maki, 2004).

Once the pilot assessments are completed and appropriate modifications are made, student affairs educators begin to administer the formal assessments. The actual administration of the assessments hinge upon the assessment measure selected. Bresciani et al. (2004) explain that "the implementation of assessment is all about the details of who is doing what when... thus you may first need a plan for the actual delivery of the information to students before you can [assess] whether the students have learned" (p. 14).

Implementation requires student affairs educators to consider how to best embed their strategies into their everyday practices so that they can gain the highest response rate from undergraduates. Different methods result in different response rates. Therefore, student affairs educators must consider how students are asked to complete assessments, which ultimately affect assessment response rate (Gay \& Airasian, 2003). For instance, survey assessments that are mailed result in lower student response rates when compared with surveys that are administered 
during the actual student learning experience, because students are gathered in one group. Posner (2003) explains that students typically do not mind completing assessments "as long as they could do it at their conveniences and not spend a great deal of time completing the [assessment]" (p. 1). Moreover, if faculty and student affairs educators reinforce the importance of the assessment and use of multiple methods of assessment, such as interviews, portfolios, and surveys, then undergraduates may be more likely to participate.

\section{Analyzing Student Affairs Assessment Data}

The literature reviewed reveals a variety analyses techniques, dependent upon the type of assessment measure used. For instance, Maki (2004) explains the importance of reaching $a$ consensus about criteria and statements of judgment, and explains that a consensus is reached only through a group discussion acknowledging the following questions:

- Will criteria and standards of judgment be externally or internally established?

- What kind of results do externally and internally developed criteria and standards of judgment provide?

- How useful are results in promoting collective and targeted interpretations of student achievement within the context of educational practices? (p. 120).

In addition to conversing and agreeing upon judgment criteria, Huba and Freed (2000) stress the importance of sharing those criteria with students in order to promote ongoing learning. One method of creating and sharing criteria is through the use of rubrics. "[A rubric] explains to students the criteria against which their work will be judged. More importantly... it makes public key criteria that students can use in developing, revising, and judging their own work" (p. 155). Rubrics can be used in conjunction with a variety of assessment instruments, including, but not limited to portfolios, presentations, observations, and event response papers. 
For example, student affairs educators could develop rubrics to assess the quality of resumes that undergraduates prepare. In addition, another set of rubrics could be used by the staff to assess the quality of students' simulated interviews.

As shown below, Bresciani et al., (2004) offer concise steps for student affairs educators to follow when creating a rubric.

1. Articulate the outcome you wish to assess with the rubric.

2. Decide what meaning the outcome looks like- "How do you know the outcome has been met? What does it look like?

3. Identify the activity in which you will be gathering the evidence of student learning.

4. Articulate exactly what you are looking for and how you will know when it has been met.

5. List the aforementioned as criteria or a detailed description.

6. Choose a model for rubric (checklists or full descriptive models) that best fits your project. Articulate the levels you would expect that criteria to be demonstrated.

7. [When appropriate] define those levels in great detail.

8. Norm the group using the rubric.

9. Pilot the rubric.

10. Revise the rubric (p. 35).

Assessors using rubrics should summarize assessment data collected, specifically citing examples of which rubric categories or cells students most often demonstrated. Typically reports are written in a narrative format and include assessors' conclusions regarding student learning. Some reports include summaries of which rubric cells students most often occupied using percentages. Moreover, reports should include recommendations for enhancing the student learning experience (Bresciani et al., 2004). 
In addition to the use of rubrics, statistical programs (i.e. SAS and SPSS) can be useful for the analysis of data, particularly when a large group of students are surveyed (Gay \& Airasian, 2003). In assessment, descriptive and inferential statistics are often used to analyze data. "Descriptive statistics permit the researcher to meaningfully describe many pieces of data with a few indices" (p. 413). Student affairs educators may use descriptive statistics to reduce a large amount of data into frequency or average indices. On the other hand, "inferential statistics allow the researcher to generalize to a population of individuals based on information obtained from a limited number of research participants" (p. 445).

Reporting Student Affairs Assessment Results

Before reporting assessment results, Suskie $(1996,2004)$ encourages student affairs educators to critically think about who will be reading the report. Specifically, Palomba and Banta (1999), explain that internal audiences include those within the institution, such as administrators, faculty, staff, and students. Conversely, external audiences include accreditors, state and federal governments, prospective students, and parents.

In order to determine what the needs of student affairs assessment audiences are, Suskie (1996) stresses the importance of discussions based upon the following summarized questions:

- Who are your audiences? Reports will differ for internal and external audiences.

- What are the audiences' understandings of your student affairs division and learning opportunities? Some readers will have extensive knowledge of daily student affairs' practices, while other readers will have no frame of reference.

- What are the needs of your audience?

- Will your audience only be interested in your assessment findings, recommendations, and plans for changes to learning experiences?

- How much time does your audience have to read your report? 
Once student affairs educators have determined who their target audiences are, they must determine appropriate means of conveying their results and recommendations. While report formats will vary in some degree based upon the type of inquiry, assessment scholars agree there are typically five types of assessment reports, and often, more than one type of report is utilized to reach audiences (Suskie, 1996, 2004; Schuh \& Upcraft, 2004). The first type of report most commonly used is the executive summary, which provides a brief synopsis of the study rational and methodology. However, an executive summary tends to be far-reaching; hence, student affairs educators must accurately condense assessment findings (Suskie, 1996, 2004; Schuh \& Upcraft, 2004).

A more lengthy and detailed assessment description is illustrated by a technical report, which includes:

- A meaningful title

- Author(s), student affairs office, and date

- Appropriate acknowledgements

- Executive summary

- Purpose of assessment

- Description of how the assessment was conducted. This section should include the assessment start and end dates; methods used to select participants; methods used to assess participants; and methods used to administer assessments.

- Assessment results. This section should include the participant response rate (if appropriate); analyses techniques used; tables and graphs that condense numeric findings; and direct quotes that represent qualitative findings.

- Conclusions and recommendations for enhancing student learning experience. This section includes an explanation of what factors may have influenced assessment results; an educated explanation of why assessment results turned out the way they $d i d$; and recommendations for program, service, or activity improvement (Suskie, 1996, 2004). 
In addition to using executive reports and full technical reports, student affairs educators may determine it is appropriate to use short reports, supplemental reports and/or report their assessment findings orally (Suskie, 1996, 2004; Schuh \& Upcraft, 2004). Oral presentations should focus on major assessment findings, and those findings should be aided by the use of charts and graphs. Moreover, oral presentations must allow time for the audience to ask questions.

Regardless of the techniques chosen to report student affairs assessment findings, Suskie (1996) identifies hallmarks of readable, useful, and interesting assessment reports, insisting that assessment reports always focus on what really matters to the audience. For instance, most audiences will not be interested in findings that indicate students utilizing the campus recreation center have an average of 1.8 siblings. Suskie also encourages the use of story telling when reporting, thus creating contexts for readers or listeners. Lastly, reports should be reviewed before publication or oral delivery, include proper citations, and make generous use of straightforward tables and graphs (Suskie, 1996).

Using Student Affairs Assessment Results to Enhance Student Learning Experiences

As Palomba and Banta (1999) explain, "Assessment should foster conditions in which meaningful questions are raised and addressed and in which assessment evidence is valued and used" (p. 14). A specific student affairs assessment example which demonstrates Palomba and Banta's statement comes from J. Jones and D. Jones (2004) as described in the following paragraph.

By using indirect measures, Jones and Jones (2004) assessed 1,400 students living in traditional residence halls and 600 students residing in learning communities. Their meaningful question: Do students who reside in learning communities report a more positive college 
experience as compared to those who live in traditional residence halls? Their evidence indicated, "with certainty... that students' experiences are more positive residing in residential learning communities than traditional residence halls" (p. 2). As a result of the assessment evidence, they called for ongoing assessment and the "re-examination of goals based on the assessment [evidence]... [perhaps leading] to more focused programmatic efforts to meet intended outcomes" (p. 4). Additionally, Jones and Jones explained that the “... continuous assessment of students' residential learning experiences will provide sound information on which... to justify financial resources to constituents while continuing to meet the learning needs of our college students" (pp. 4-5).

When considering how to appropriately use assessment results to enhance student learning, student affairs officials should acknowledge Principle Eight of AAHE's (1992) Principles of Good Practice for Assessing Student Learning. The Principle reads, "Assessment is most likely to lead to improvement when it is part of a larger set of conditions that promote change. On such campuses, information about learning outcomes is seen as an integral part of decision making, and avidly sought" (p. 3). The literature reviewed revealed an example of one such institution, North Carolina State University.

Allen, Zelna, \& Bresciani (2002) share the story of their collaborative assessment efforts at North Carolina State. Student affairs and academic affairs educators worked together to design and conduct an online survey, attempting to capture what students reported as their understanding, attitudes and behaviors in regard to academic integrity. Results indicated a “... 'disconnect' between what students claim to value (integrity) and how they behave; (2) students want the definition and consequences of cheating to be clear; and (3) students want extenuating circumstances to be considered in decisions about sanctions" (as cited in Maki, 2004, p. 110). 
A host of changes and modifications were made by the collaborative group as a result of the survey, with "most strategies involv[ing] further partnering between Undergraduate Affairs and Student Affairs" (p. 111). The following list includes a brief summary of how North Carolina State educators used assessment results in an attempt to enhance student learning experiences.

- Student government created an honor statement reflecting the students' view of the value and seriousness of academic integrity. Through student voting, the statement is now placed in the student government constitution.

- The creation of academic integrity resources for new faculty, including orientation packets with information on "pursuing academic integrity violations and resources for helping students avoid violations" (p. 111).

- Increased the amount of available information on The Office of Student Conduct's website "to include judicial statistics, academic integrity case studies to help faculty handle cases of academic dishonesty, and presentations on academic integrity" ( $p$. 111).

- Appropriate changes were made to presentations delivered by the Office of Student Conduct such as, "...case studies were altered to include those that involved the violations that students incorrectly identified as "not cheating"' (p. 112).

- Survey results were presented to the student judicial board, prompting student educational initiatives, such as the "creation of banners placed in various locations on campus during exam week to remind students of the importance of integrity and academic work" (p. 112)

- Future plans to enhance the student learning experience include: the implementation of "Honor and Integrity Week," a mailing from the chancellor to new students promoting academic integrity, and the development of posters encourage academic integrity to be placed throughout the campus.

- No modifications were made to an often mandatory eight-hour computer activity for those students who violated academic integrity policies (Maki, 2004).

As illustrated in the previous two examples, assessment data provide substantial benefits in the accountability and budget areas; however, a greater incentive lies in the opportunities for student affairs educators to learn more about their educational experiences and the effects those 
expereinces have upon student learning. (Upcraft \& Schuh, 1996; Bresciani et al., 2004; Maki, 2004).

Evaluating the Assessment Process

The evaluation of the assessment process should focus upon characteristics of good assessment practices. Palomba and Banta (1999) explain that assessment is about student learning and learning about the assessment process. "Attention to the way assessment is carried out invariably points to opportunities for improvement... introspection about assessment should occur throughout the process, not just intermittently" (p. 15). Therefore it is essential for student affairs educators to design standards which will enable them to evaluate their assessment process and models.

A synthesis of literature from Bresciani (2003b), Pet-Armacost \& Armacost (2002), Huba \& Freed (2000), and Palomba \& Banta (1999) has resulted in the following 12 questions for student affairs educators to ask themselves when evaluating their assessment process:

1. Did the assessment provide valid information on student learning?

2. Was the assessment process coherent? Was the process structured to measure learning?

3. Was the assessment authentic? Did it address appropriate areas of student learning concern?

4. Was the assessment rigorous enough to allow students to show gains over time?

5. Were students interested in participating in the assessment and learning?

6. Was the assessment criteria used to judge student learning properly designed?

7. Did the assessment use multiple methods of data collection and allow for students to demonstrate how they best learn?

8. Was assessment data appropriately reported? 
9. Were students provided with ongoing feedback on how they could enhance their learning?

10. Does the entire educational community recognize that the reason for assessment is to enhance student learning, not for punishment?

11. Is assessment cost-effective and based on data gathered from multiple measures?

12. Does assessment support diversity efforts rather than restrict them?

By addressing the aforementioned questions, student affairs educators demonstrate their commitment to long-term and ongoing assessment. Moreover, the evaluation of the assessment process provides student affairs educators with a greater sense of ownership. These educators are involved from the very beginning including the initial development and administration of the assessment and they also make crucial decisions and modifications to the entire assessment process. A strong assessment plan will help student affairs educators to ultimately demonstrate growth in student learning and values over time (Huba \& Freed, 2000).

\section{Sustaining Student Affairs Assessment}

In order to sustain ongoing learning outcomes assessment, scholars agree that student affairs educators must collaborate with other educators, particularly academic affairs, during the entire assessment process. (Pascarella, 1991; AAHE, 1992; AAHE et al., 1998; Banta \& Kuh, 1998; Pascarella \& Upcraft, 1999; Schroeder, 1999; Kuh \& Banta, 2000; Green, Kirkland, \& Kulick, 2002; Maki, 2002b; Kezar, 2003; NASPA \& ACPA, 2004). Schroeder (1999) insists that collaborative assessment partnerships allow student affairs educators "to create performance support systems that link, align and integrate a variety of resources, both on and off-campus, to promote the attainment of various learning outcomes (p. 3-4). Other assessment scholars, Banta and Kuh (1998), assert that collaborative assessment work yields evidence that illustrates a connection between students' cognitive and affective development, thus proving that "curricular 
and out-of-class activities are not discrete, independent events; they affect one another (sometimes profoundly) in ways that often are not immediately obvious" (p. 42).

When student affairs commit themselves to a learning outcomes assessment culture, they should acknowledge the aforementioned benefits and possibilities of collaborative assessment. Thereafter, if indeed a collaborative assessment culture is sought, Banta and Kuh (1998), explain that there are characteristics that will foster and advance the collaborative philosophy. In summary, the authors indicate that assessment partners must gain support and display dedication from the institution's administrators, thus cultivating a culture of curriculum, co-curriculum, and assessment mutual planning. Additionally, collaborations allow student affairs educators the opportunity to advance the awareness of student learning goals; to organize complimentary curricular and co-curricular learning activities; to plan, organize, and conduct assessments which measure stated outcomes; and to utilize findings to enhance student learning experiences.

Another advantage of collaboration is that student affairs educators are more likely to avoid the problems that academic affairs are currently facing in their assessment efforts, as explained in Chapter One (Lopez, 2004). For instance, some faculty have struggled on how to effectively and appropriately communicate their assessment results. The inclusion of such faculty in the student affairs assessment planning process will enable student affairs educators to learn from faculty members' trials-and-errors. Moreover, student affairs educators may ask faculty at the onset of their assessment planning process to provide on-campus professional development workshops for the entire student affairs division, thus demonstrating that the division is committed to working with academic affairs in order to sustain their assessment efforts.

Collaboration with faculty also provides student affairs educators with the opportunity to efficiently allocate funds for their assessment efforts. Maki (2004) notes that sustaining 
assessment requires that “...resources come from multiple institutional contributors, reflecting the depth and pervasiveness of a campus commitment..." (p. 180). In order to sustain learning outcomes assessment, student affairs educators must recognize costs arise from:

- Professional development, including on- and off-campus opportunities for student affairs educators to develop a deep sense of learning outcomes assessment understanding.

- The hiring of additional staff to assist with assessment implementation, analysis, and communication.

- The creation of an assessment resources center, including a webpage and current assessment literature and other educational materials.

- The use of technology to administer assessment instruments and analyze assessment data.

- Time student affairs educators spend away from their daily responsibilities developing assessment plans.

- Rewards provided to student affairs educators who exemplify high quality assessment practices.

Student affairs educators and faculty may choose to pull their resources together to create one on-campus assessment resources center; hence, they are demonstrating that they are not only committed to sustaining assessment through collaboration, but also through creative and efficient spending measures. However, simply sharing the costs of a resource center, does not demonstrate that student affairs educators and faculty are committed to enhancing student learning experiences.

In order for student affairs and faculty to demonstrate that they are collaborating to enhance student learning, they must look to specific educational opportunities where they may partner. Often such educational experiences come from efforts to improve first- and senior-year student experiences (Upcraft, Gardner, \& Associates 1989; Gardner \& Van der Veer, 1998). For instance, Gardner and Van der Veer (1998) point to campus leadership programs as an example 
where collaborative assessment is appropriate. They note that "comprehensive leadership education should begin in the first year and continue through the senior;" moreover, "programs and courses should involve partnerships with faculty, student affairs professionals, alumni, and community leaders" (p.130). Thus, it is only appropriate that all entities involved with designing educational experiences are also involved with the assessment design and implementation. However, Edwards (2003) notes that student affairs educators must recognize that collaboration with faculty often requires them to make the initial effort, with student affairs educators “... serv[ing] as change agents during this learning revolution" (p. 4).

In order to successfully serve as change agents, thus sustaining assessment, student affairs educators must look to other student affairs divisions across the country and learn from their assessment efforts. For example, Sanderson (2003) shares the experience of one sizable research institution's quest for formal assessment within student affairs, explaining that in order for the institution's student affairs educators to answer what students were learning from their services, a series of beneficial changes had to occur within the division. The division acknowledged its previous, yet limited assessment efforts, resulting in the decision by the Senior Student Affairs Officer to appoint a Director of Student Affairs Research and Evaluation. Simultaneously, the Senior Student Affairs Officer called for the creation of a division-wide assessment council charged with the task of leading the assessment initiative. It must be noted that Sanderson did not reference other assessment committees within the university. However, Maki (2004) revealed that multiple assessment councils or committees often co-exist within institutions that are devoted to assessment—a campus wide assessment committee and program level assessment committees (also established in schools, divisions, departments or services) ( $\mathrm{p}$. 33). Therefore, student affairs educators must recognize that the creation of their own assessment 
committee is not enough to sustain assessment. Members of the student affairs assessment committee must be aware that similar groups exist on their campus, and should communicate on a regular basis with such groups to sustain collaborations and assessment.

\section{Conclusion}

Student affairs educators greatly contribute to student learning. Furthermore, it is evident that the field is beginning to assess student learning outcomes. However, the literature reviewed reveals no evidence of actual case studies of model student affairs learning outcomes assessment practices, thus leaving a gap within the literature. It is anticipated that the findings from this research study will enlighten student affairs educators about best practices in assessment. Three different institutions' efforts in assessment will be closely analyzed so that other student affairs educators may learn to effectively utilize assessment results to enhance student learning. Moreover, as explained in Chapter One, this study will produce beneficial information that will help student affairs educators develop strategies to address problems that academic affairs are currently facing.

Based upon the literature presented in this chapter, the researcher identifies appropriate methods (see Chapter Three) to address the six proposed research questions that were listed in Chapter One. Moreover, the conceptual framework presented in this chapter served as a guide for the selection of three Research I institutions. These indicators of excellence, or criteria, were used to select three institutions for the study. The researcher then determined how analyzed results supported and/or disputed the literature presented in this chapter, ultimately presenting best practices of learning outcomes assessment with three student affairs divisions. 


\section{Operational Definitions}

Affective Gains: The development of values, attitudes, commitments, and ways of responding, such as valuing others' perspectives, responding to situations that disadvantage a group of people, exercising tenacity in practicing an ability to improve it over time, or demonstrating a passion for learning (Maki, 2004, p. 32; Krathwohl et al., 1964).

Assessment: The process of gathering and discussing information from multiple and diverse sources in order to develop a deep understanding of what students know, understand, and can do with their knowledge as a result of their educational experiences; the process (Huba \& Freed, 2000, p. 8).

Formative Assessment: Those undertaken while student learning is taking place (Suskie, 2004, p. 95).

Summative Assessment: Those obtained at the end of a course or program (Suskie, 2004, p. 95).

Direct Assessment Method: Prompts students to represent or demonstrate their learning or produce work so that observers can assess how well students' texts or responses fit institution- or program-level expectations (Maki, 2004, p. 88)

Indirect Assessment Method: Captures students' perceptions of their learning and the educational environment that supports that learning (Maki, 2004, p. 88).

Audiences: Groups that receive assessment findings. Audience may be both internal and external and include: faculty and staff involved in the program; other faculty and staff; assessment steering committee members; institutional leaders; governing board members; current students and their parents; prospective students and their parents; alumni, prospective employers; and accreditation organizations; state and federal agencies; and legislators (Suskie, 2004, p. 53-54).

Internal Audiences: Groups within an institution, such as administrators, faculty, staff, and students (Palomba \& Banta, 1999)

External Audiences: Groups outside of an institution, such as accreditors, state and federal government bodies, parents, and prospective students (Palomba \& Banta, 1999).

Cognitive Gains: The development of intellectual abilities including: remembering, understanding, applying, analyzing, evaluating, and synthesizing, such as an undergraduate student's evaluation of multiple solutions to an on-campus student organization problem (Anderson et al., 2001).

Co-Curriculum: Encompasses learning experiences that are held outside and, in some cases, in conjunction with, the normal academic timetable of scheduled classes. 
Commercially-developed measure: Used to measure student competencies under controlled conditions. Instruments are developed and measured nationally to determine the level of learning that students have acquired and include an explanation of the instrument's limitations, validity, and reliability (Buros Institute, 2005).

Curriculum: An academic plan... that incorporates a total blueprint for action, including purposes, activities, and ways of measuring success (Stark \& Lattuca, 1997, p. 9).

Evaluation: Using assessment information to make an informed judgment (Suskie, 2004, p. 5).

Goals: Desired ends that guide organizational behavior (Hoy \& Miskel, 2001, p. 8).

Implementation: Where you plan for the actual [execution] of programs, workshops, and training sessions designed to deliver as well as measure the intended outcomes (Bresciani et al;., 2004, p. 14).

Institutional Assessment Committee/Council: Group that reaches a consensus about collective expectations for student learning at both the institution and program levels (Maki, 2004, p. 33).

Learning Outcome: The knowledge, skills, attitudes, and habits of mind that students take with them from a learning experience (Suskie, 2004, p. 75).

Locally-developed measure: measurement instrument designed within an institution to measure student achievement of specific learning outcomes with the purpose of identifying where improvement is needed within the academic or administrative program.

Student Affairs Program/Activity/Service: Delivers the end results of what you are assessing (Bresciani, et al., 2004, p. 10).

Program Outcome: Illustrate what you want your program to accomplish (Bresciani, et al., 2004, p. 11).

Reliability: Refers to measurement instruments that can be counted on to produce consistent responses over time" (Palomba \& Banta, 1999, p. 88).

Sampling: The process of selecting a number of participants for a study in such a way that they represent the larger group from which they were selected (Gay and Airasian, 2003, p. 101).

Random sampling: The process of selecting a sample in such a way that all individuals in the selected population have an equal and independent chance to be selected for the sample.

Stratified sampling: The process of selecting a sample in such a way that identified subgroups in the population are represented in the same proportion that they exist in the population. 
Cluster sampling: Randomly selects groups, not individuals. All the members of selected groups have similar characteristics.

Systematic sampling: Sampling in which individuals are selected from a list taking every Kth name, ( $\mathrm{K}$ is representative of a randomly selected number) (p. 109-10)

Student Affairs Assessment Committee/Council: Classified as a program-level assessment committee that works much in the same way as the [institutional] assessment committee. Program level-committees consist of broad representation from their educational constituencies and contributors. Committee members initiate assessment development, implementation, reporting, and decision making (Maki, 2004, p. 34).

Validity: Refers to the extent to which a method prompts students to represent the dimensions learning desired (Maki, 2004, p. 93). 


\section{Chapter Three}

Research Design and Method

\section{Research Design}

The intent of this research study was to critically examine model student learning outcomes assessment practices within student affairs divisions and to advance the understanding, value, and usefulness of learning outcomes assessment within the student affairs profession. Since no research had been conducted on this topic and there was a great need to gain in-depth information about what assessments were being conducted and how they were implemented, a qualitative research design was necessary. In particular, three case studies were examined to produce collective and comparative evidence, because "the more cases included in the study, and the greater variation across the cases, the more compelling an interpretation is likely to be" (Merriam, 1998, p. 40). Data produced from multiple case studies allowed the researcher to address the research questions presented in Chapter One. Moreover, information gathered from these case studies allowed the researcher to triangulate the collected data, thus producing a comprehensive review that identified high quality student affairs learning outcomes assessment practices.

\section{Qualitative Research Design}

Patton (2002) emphasizes that "qualitative methods are first and foremost research methods. They are ways of finding out what people do, know, think, and feel by observing, interviewing, and analyzing documents" (p. 145). Furthermore, Merriam (1998) explains, "qualitative research is an umbrella concept covering several forms of inquiry that help us understand and explain the meaning of social phenomena with as little disruption of the natural setting as possible" (p. 5). More simply put, qualitative inquiry allows a researcher to grasp the 
"meaning people have constructed; that is, how they make sense of their world and the experiences they have in the world" (p. 6).

A summary of characteristics of qualitative research as synthesized by (Merriam, 1998) include:

1. Qualitative research requires the researcher to understand how research participants perceive their own experiences, not how the researcher perceives participants' experiences.

2. Qualitative research requires the researcher to serve as "the primary instrument for data collection and analysis" (p. 7). The researcher uses multiple data collection methods, including interviews, observation, and document analysis in order to triangulate his or her findings.

3. Qualitative research requires fieldwork; hence, the researcher must be willing to "go to the people, setting, site, institution (the field) in order to observe behavior in its natural setting" (p. 7).

4. Qualitative research is inductive, thus requiring the researcher to use data to construct "abstractions, concepts, hypotheses, or theories rather than test existing theory" (p. 7).

5. Qualitative research requires the researcher to produce a richly descriptive explanation of the phenomenon, focusing upon the comprehensive and holistic explanation of the process and participant meaning.

6. Qualitative research requires a researcher to be flexible and able to evolve during fieldwork in order to avoid disruption of the natural setting.

There are multiple reasons for choosing a qualitative research design. Corbin (1990)

provides five motives for selecting a qualitative design. Reasons include:

1. The conviction of the researcher based on research experience;

2. The nature of the research problem;

3. To uncover and understand what lies behind any phenomenon about which little is yet known;

4. To gain novel and fresh slants on things about which quite a bit is already known; [and]

5. To give intricate details of phenomena that are difficult to convey with quantitative 
methods (as cited in Roberts, 2004, p. 111).

The choice of a qualitative design for this study was based upon the aforementioned reasons $\# 1, \# 2, \# 3$, and \#5. The research problem and questions posed in Chapter One could only be answered through qualitative inquiry. The researcher examined and reported the findings of three institutions to document high quality student affairs learning outcomes practices. This study was exploratory and descriptive and focused on how and why student affairs educators were planning, implementing, and reporting learning outcomes assessment(s) and how those individuals were using assessment results to enhance student learning experiences. Furthermore, the qualitative method and design yielded in-depth information and appropriate data which allowed the researcher to analyze and describe the actual practices of high quality student affairs learning outcomes assessment initiatives.

\section{Case Study Research}

As Yin (2003) explains, "how and why questions are more explanatory and likely lead to the use of case studies... this is because such questions deal with operational links needing to be traced over time, rather than mere frequencies or incidence" (p. 6). Additionally, Merriam (1998) notes that "... a researcher selects a case study design because of the nature of the research problem and the questions being asked. Case study is the best plan for answering the research questions; its strengths outweigh its weaknesses" (p. 41). Patton (2002) agrees, stating that "well-crafted cases studies can tell the sorties behind the numbers, capture unintended impacts and ripple effects, and illuminate dimensions of desired outcomes that are difficult to quantify" (p. 152). Therefore, the researcher relied upon data collected from three qualitative case studies in order to address the research questions. 
An in-depth explanation of case studies comes from Yin (2003) who explains that "a case study is empirical inquiry that investigates a contemporary phenomenon within its real-life context, especially when the boundaries between phenomenon and context are not clearly evident" (p. 13). Specifically, the case investigation "copes with the technically distinctive situation in which there will be many more variables of interest than data points, and as one result relies on multiple sources of evidence, with data needing to converge in a triangulating fashion..." (pp. 13-14).

Merriam (1998) declares that "qualitative case studies can be characterized as being particularistic, descriptive, and heuristic" (p. 29). Since the purpose of this study was to explore high quality student affairs learning outcomes assessment practices, it may be classified as descriptive, meaning that the final results of each case study will produce thick, rich, and explanatory descriptions. In addition, this study may be characterized, in part, as heuristic, resulting in an 'illuminat[ion] of the reader's understanding of [high quality student affairs learning outcomes assessment practices]" (p. 30). A final research report based upon case studies yields new evidence to readers, allowing each to uncover new understandings of the phenomenon, enlarge their knowledge base, and a verify of what they already know.

Designing qualitative case studies require "a logical plan for getting from here to there, where here may be defined the initial set of questions to be answered, and there is some set of conclusions (answers) about these questions" (Yin, 2003, p. 20). Yin asserts, that five components must be included in the design: a study's questions; its propositions, if any; its unit(s) of analysis; the logic linking the data to propositions; and the criteria for interpreting findings (p. 21). The remainder of this chapter is structured to address such components as outlined by Yin. 


\section{Limitations of Research Design}

There were three particular criticisms of qualitative research that were addressed for this study. First of all, both Merriam (1998) and Patton (2002) report that qualitative analysis is linked with subjectivity, while quantitative analysis relies upon objective statistical methods of analysis, thus leading to concerns of qualitative analysis processes and the validity and reliability of results.

In order to address such concerns, the researcher formally structured how data was collected and managed. For instance, the interview protocol, which was used at each case study institution, was carefully designed based upon the literature review presented in Chapter Two. By using the same interview protocol with different participants at each case study institution, the reliability of data collected was enhanced. Moreover, a pilot study (see Chapter Four) was conducted to improve the clarity and structure of the interview protocol and process.

An additional technique used to reduce the researcher's subjectivity was the triangulation of multiple data sources. Besides the collection and analysis of interview data, the researcher collected and analyzed multiple documents, including assessment plans and reports, in order to verify and supplement interview responses.

A second criticism of qualitative research, as explained by Merriam (1998) and Patton (2003) is that a researcher brings some level of sensitivity and bias to the study. Since the researcher is the primary instrument for data collection, it is vital for he or she to not only recognize his or her bias, but the researcher should also share that bias or biases with the audience of his or her research report. To address this concern, the researcher included, later in this chapter, his personal experiences relating to student affairs learning outcomes assessment that may have biased his research. 
A third, and final criticism of qualitative research, as described by Merriam (1998) and Patton (2002) focuses upon generalizing research results. For that reason, the researcher carefully designed criteria for purposefully selecting case study institutions and case participants. A detailed explanation of the criteria follows later in this chapter. However, it should be noted that criteria was based upon choosing student affairs divisions that had implemented high quality learning outcomes assessment plans and practices. Additionally, the use of pre-determined selection criteria of case study institutions provided the researcher with similar institutions for site visits, resulting in the selection of three research institutions that provided rich information related to the study's research questions.

The researcher recognized that results from the study may not be generalized, and the study itself may not be identically duplicated; however, the purpose of this study was not necessarily to generalize results but rather to critically examine the employment of student affairs learning outcomes assessment practices. The analysis of results provides the profession with lessons from the field and possibly new student affairs assessment learning outcomes applications.

\section{Research Method}

This portion of Chapter Three outlines and presents the reasons the researcher selected specific case study institutions and case participants, data collection methods, and approaches for the organization and analysis of data. An appendix section contains site selection criteria, interview and document protocols, and required cover letters.

\section{Site Selection}

In order to select three American research universities (intensive or extensive), as classified by The Carnegie Classification of Institutions of Higher Education (2005), where high 
quality student learning outcomes assessment practices were occurring within each institution's student affairs division, the researcher meticulously followed a series of steps as explained in the succeeding paragraphs.

In order to initially identify possible case study institutions that were conducting student affairs outcomes assessment practices, the researcher sought expert advice from:

1. Student affairs learning outcomes assessment experts the researcher met while attending ACPA's assessment seminar in June 2004, NASPA's national conference in March, 2005, and NASPA's conference on assessment and retention in June 2005;

\section{NASPA’s Assessment Knowledge Community;}

3. Institutional web pages and documents; and

4. Dr. Elizabeth A. Jones, the researcher's doctoral committee chair who is considered an assessment expert within higher education. Dr. Jones's primary research interests include the examination of internal and external policies that impact curriculum plans and assessment programs in colleges and universities.

By using the expert advice from aforementioned individuals, the researcher narrowed the potential number of case study institutions to fifteen (see Table 1). The researcher closely examined those institutions in order to determine which universities most clearly mirrored models of high quality student affairs learning outcomes assessment practices. The researcher acknowledged that there may have been Research I institutions that were conducting learning outcomes assessment within their student affairs divisions that were not included in Table 1. 
Table 1

Institutions Identified as Possible Case Study Sites

\begin{tabular}{ccccc}
\hline \multicolumn{3}{c}{ Name of University } \\
University & $\begin{array}{c}\text { Indiana } \\
\text { University- } \\
\text { Purdue } \\
\text { University }\end{array}$ & Ohio State & Syracuse & University \\
& Undianapolis & & & Georgity of \\
& India & & \\
George Mason & Indiana State & Oregon State & Southern & University of \\
University & University & University & Methodist & Maryland \\
& & & University & \\
Georgia State & North Carolina & Penn State & Texas A\&M & University of \\
University & State University & University & University & Utah \\
\hline
\end{tabular}

To guide the selection of three institutions from Table 1, the researcher used site selection criteria, included in Appendix A, to determine to what degree each of the fifteen possible sites exhibited practices of high quality assessment. These criteria, based upon the conceptual framework outlined in Chapter Two, were indicators of high quality student affairs assessment practices; they were indicators of excellence. In order to determine if the potential institution was meeting the stated criteria, the researcher reviewed web pages and public documents, spoke with identified student affairs assessment directors, coordinators, and/or facilitators, and consulted with his doctoral committee chair.

Those criteria, or indicators of excellence, were divided into three sections. Sections, with example questions, included:

1. Student affairs assessment structure:

- Is there a student affairs assessment unit?

- Is there a student affairs assessment committee within the division?

2. Comprehensive and/or unit level student affairs assessment plans and reports:

- Does the division and/or units have fully developed assessment plans?

- Does the division and/or units have fully implemented assessment plans?

- Are learning outcomes clearly articulated? 


\section{Institutional criteria:}

- Is the university classified by the Carnegie Foundation as Research I (extensive or intensive)?

- Is the institution willing to participate in this study?

The use of such criteria helped insure that the researcher chose the best case study sites with the highest level of quality assessment practices (Merriam, 1998). After an extensive review of possible case study institutions, using the pre-determined criteria, the researcher ranked each institution. Those institutions ranked one through three were asked to participate in this study and the two Directors of Assessment and the one Associate Dean of Students Affairs who coordinated assessment efforts for her division at those top three ranked institutions agreed that they, along with their colleagues would participate.

\section{Participant Selection}

Purposeful sampling was used to select each interview participant within each case study. Merriam (1998) asserts that "purposeful sampling is based on the assumption that the investigator wants to discover, understand, and gain insight and therefore must select a sample from which the most can be learned" (p. 61). Purposeful sampling of interview participants, or informants, provide the researcher with a sample that "understand the culture but is also able to reflect on it and articulate for the researcher what is going on.... thus becoming a guide in unfamiliar territory" (p. 85).

During the selection process of each case institution, the researcher pinpointed an individual who coordinated or highly participated in the student affairs learning outcomes assessment efforts. That individual was asked to serve as the case study liaison, and he or she offered expert judgment and provided the researcher with important information based upon 
defined criteria to select the appropriate interview participants. Participant selection criteria included:

- One Senior Student Affairs Officer (if not available then the Assistant Senior Student Affairs Officer)

- One Director/Coordinator of Student Affairs Assessment

- Three Student Affairs Assessment Committee/Council Members

- Three Other Student Affairs Professional Staff Members (with at least one serving in the capacity of unit director and one non-unit director)

The researcher also worked with the case study liaison to secure interview locations and times that were convenient for the participants. Moreover, the case liaison was asked to work with the researcher to secure and authenticate appropriate documents for analysis, including:

- Student affairs assessment plan(s);

- Student affairs assessment reports;

- Student affairs assessment committee/council meeting agendas and minutes;

- Institutional and divisional organizational charts;

- Relevant student affairs assessment correspondence; and

- Other appropriate student affairs assessment documents.

\section{Institutional Approval}

Initially, the researcher sought approval from the administration at the case study institutions and asked each for a letter of approval that was included in the West Virginia University's Institutional Review Board for the Protection of Human Subjects packet prepared by the researcher. After approval was received, the researcher worked with the institutional liaison to identify case study participants and arranged a convenient time to conduct his site visit.

The researcher followed the following steps in securing institutional approval: 
1. Sent letter to Senior Student Affairs Officer of selected case study institutions seeking approval (see Appendix I). Included template letter for administrator to grant site visit approval (see Appendix J).

2. Applied for West Virginia University Human Subjects Exemption Review Approval.

3. Upon Institutional Review Board approval, sent invitation letters to case study institutions' liaison and participants (see Appendices K and L)

4. Conducted on site interviews and collected documents using appropriate protocols (see Appendices M and D).

\section{Data Collection}

As noted in Chapter One, this study proposed to explore six research questions:

1. What are the student learning outcomes articulated in the student affairs assessment plans?

2. How are these learning outcomes assessed?

3. Who is involved in the assessment planning process, and what are the major responsibilities of these individuals?

4. Are student affairs educators collaborating with others, such as academic affairs, in the creation and administration of assessments? How?

5. How are student affairs assessment data used to enhance student learning experiences?

6. What successes and challenges do student affairs educators face as they implement their assessment plans?

In order to address each of the six research questions, multiple data collection techniques were required. Data gathered from a qualitative study may come from three collection formats: in-depth, open ended interviews; direct observations; and written documents (Merriam, 1998; Patton, 2002; \& Yin, 2003). This study relied upon data gathered through interviews and documents. Table 2 details the contribution each data collection point provided and its alignment with this study's proposed six research questions. There were multiple data collection points, consisting of interview data and document analysis data. 
Table 2

Points of Data Collection Aligned with Research Questions

\begin{tabular}{c|cccc}
\hline $\begin{array}{c}\text { Research } \\
\text { Question }\end{array}$ & Interview(s) & $\begin{array}{c}\text { Assessment } \\
\text { Plan(s) }\end{array}$ & $\begin{array}{c}\text { Assessment } \\
\text { Report(s) }\end{array}$ & $\begin{array}{c}\text { Other } \\
\text { Document(s) }\end{array}$ \\
\hline 1 & $\mathrm{X}$ & $\mathrm{X}$ & $\mathrm{X}$ & $\mathrm{X}$ \\
2 & $\mathrm{X}$ & $\mathrm{X}$ & $\mathrm{X}$ & $\mathrm{X}$ \\
3 & $\mathrm{X}$ & $\mathrm{X}$ & $\mathrm{X}$ & $\mathrm{X}$ \\
4 & $\mathrm{X}$ & $\mathrm{X}$ & $\mathrm{X}$ & $\mathrm{X}$ \\
5 & $\mathrm{X}$ & $\mathrm{X}$ & $\mathrm{X}$ & $\mathrm{X}$ \\
6 & $\mathrm{X}$ & & $\mathrm{X}$ & $\mathrm{X}$ \\
\hline
\end{tabular}

In order to conduct semi-structured focused interviews, which Yin (2003) describes as situations where "a respondent is interviewed for a short period of time - an hour, for example" (p. 90), the researcher developed an open-ended, interview protocol based upon the literature review presented in Chapter Two. That formal protocol (see Appendix M) contained important elements of good student affairs learning outcomes, as identified in Chapter Two, thus ultimately addressing the study's research questions. For instance, research question \#1 asked: What are the student learning outcomes articulated in the student affairs assessment plans? In Chapter Two, the literature review indicated that good student learning outcomes flow from an institution's mission and goals and begin with, "Students will be able to..." (Huba and Freed, 2000, p. 10). Therefore, the researcher included questions within the interview protocol that asked participants to explain characteristics of good learning outcomes and to share examples of their student affairs division's student learning outcomes. Information gathered from those particular questions provided data with "direct quotations from people about their experiences, opinions, feelings, and knowledge" (Patton, 2002, p. 4) that allowed the researcher to address research question \#1.

It was important for the researcher to acknowledge that limitations existed when using interviewing as a data collection method. For instance, Creswell (1994) suggests that interview 
participants filter their responses based upon a variety of factors, thus providing the researcher with indirect evidence. Furthermore, participants' responses may be influenced by the interview location and the company of a researcher. Lastly, the researcher must account for variances between participants' abilities to comprehend interview questions and express their responses (as cited in Aloi, 2004). The researcher clearly addressed how he dealt with the aforementioned limitations in the Data Organization and Analysis section of this chapter.

In addition to conducting interviews, the researcher analyzed relevant student affairs assessment documents. According to Patton (2002), “document analysis includes studying excerpts, quotations, or entire passages from organizational, clinical, or program records; memoranda and correspondence; official publications and reports; personal diaries; and openended written responses to questionnaires and surveys" (p. 4). As explained earlier in this chapter, the researcher worked with the case study liaison to secure and authenticate appropriate documents for analysis, including, but not limited to the institution's student affairs assessment plans and reports and student affairs assessment committee/council meeting agendas and minutes.

Merriam (1998) explains that "in qualitative case studies, a form of content analysis is used to analyze documents... content analysis is a systematic procedure for describing the content of communications" (p. 123). Therefore, the researcher created a document content analysis form (see Appendix D), based upon the literature review and Merriam's suggested questions to consider when authenticating documents. .

Much like interviewing methods, there are limitations to relying upon document analysis as a data collection method. For example, Riley (1963) explains that the researcher must "reconstruct the process by which the data were originally assembled by somebody else... [and 
establish] the conditions under which these data were produced, what specific methodological and technical decisions may have been made... and the consequent impact on the nature of the data now to be taken over" (as cited in Merriam, 1998, p. 121). Therefore, it was essential for the researcher to adhere to the established document content analysis form when analyzing and triangulating data results.

To conclude the data collection section of this chapter, it is important to illustrate how each interview protocol question and each document content analysis protocol question aligned with the study's proposed research questions. Table 3 identifies specific questions that produced data for the researcher. For instance, research question \#1 relied upon data produced from interview questions \#1 through \#3 and \#13 and \#14 as well as multiple data produced from the document analysis protocol. It must be noted, that some protocol questions may produce data for more than one research question. For example, interview protocol question \#14: Is there anything else that you would like to share with me today regarding your assessment efforts? may produce responses relevant to each research question. 
Table 3

Interview Protocol and Document Content Analysis Protocol Aligned with Research Questions

\begin{tabular}{|c|c|c|}
\hline $\begin{array}{l}\text { Research } \\
\text { Question }\end{array}$ & $\begin{array}{c}\text { Interview Protocol } \\
\text { Question } \\
\end{array}$ & $\begin{array}{l}\text { Document Content Analysis } \\
\text { Protocol Question }\end{array}$ \\
\hline $\begin{array}{l}\text { 1. What are the } \\
\text { student } \\
\text { learning } \\
\text { outcomes } \\
\text { articulated in } \\
\text { the student } \\
\text { affairs } \\
\text { assessment } \\
\text { plans? }\end{array}$ & $\begin{array}{l}\text { 1. What are some of the student } \\
\text { learning outcomes articulated in the } \\
\text { [insert institution's name] student } \\
\text { affairs assessment plans? } \\
\text { 2. What are some of the learning } \\
\text { outcomes articulated within [insert } \\
\text { interview participant's unit name] }\end{array}$ & $\begin{array}{l}\text { 1. What are the articulated learning } \\
\text { outcomes? } \\
\text { 2. What is the rationale for } \\
\text { articulating these specific learning } \\
\text { outcomes? How were they } \\
\text { developed? }\end{array}$ \\
\hline & $\begin{array}{l}\text { 3. What do you believe to be the } \\
\text { characteristics of high quality } \\
\text { learning outcomes? } \\
\text { 13. How would you improve your } \\
\text { institution's student affairs } \\
\text { assessment process? } \\
\text { 14. Is there anything else that you } \\
\text { would like to share with me today } \\
\text { regarding your assessment efforts? }\end{array}$ & $\begin{array}{l}\text { 12. What recommendations are made } \\
\text { to improve learning, services, } \\
\text { activities, programs, and future } \\
\text { assessment efforts? } \\
\text { 13. What information presented in } \\
\text { this document is unaccounted for in } \\
\text { the aforementioned questions? }\end{array}$ \\
\hline $\begin{array}{l}\text { 2. How are } \\
\text { these learning } \\
\text { outcomes } \\
\text { assessed? }\end{array}$ & $\begin{array}{l}\text { 4. How are those student affairs } \\
\text { learning outcomes assessed? } \\
\text { Questions } 13 \& 14\end{array}$ & $\begin{array}{l}\text { 3. How are these learning outcomes } \\
\text { assessed? What methods are used to } \\
\text { determine if learning outcomes are } \\
\text { being achieved? } \\
\text { 4. What are the major purposes of } \\
\text { assessing these student learning } \\
\text { outcomes? } \\
\text { 5. How are validity and reliability of } \\
\text { assessment methods assured? } \\
\text { Questions } 12 \& 13\end{array}$ \\
\hline
\end{tabular}


Table 3

Interview Protocol and Document Content Analysis Protocol Aligned with Research Questions (continued)

\begin{tabular}{|c|c|c|}
\hline $\begin{array}{l}\text { Research } \\
\text { Question }\end{array}$ & $\begin{array}{c}\text { Interview Protocol } \\
\text { Question }\end{array}$ & $\begin{array}{l}\text { Document Content Analysis } \\
\text { Protocol Question }\end{array}$ \\
\hline $\begin{array}{l}\text { 3. Who is } \\
\text { involved in the } \\
\text { assessment } \\
\text { planning } \\
\text { process, and } \\
\text { what are the } \\
\text { major } \\
\text { responsibilities } \\
\text { of these } \\
\text { individuals? }\end{array}$ & $\begin{array}{l}\text { 5. Who is involved in the assessment } \\
\text { planning process, and what are the } \\
\text { major responsibilities of these } \\
\text { individuals? } \\
6 \text {. Who is involved in the assessment } \\
\text { implementation? } \\
\text { 7. What, if any, incentives and } \\
\text { rewards are provided for those } \\
\text { student affairs educators who } \\
\text { participate in the assessment process? } \\
\text { Questions } 13 \& 14\end{array}$ & $\begin{array}{l}\text { 6. Who is involved in the assessment } \\
\text { process, and what are the major } \\
\text { responsibilities of these individuals? } \\
\text { 7. How are student participants } \\
\text { chosen? } \\
\text { Questions } 12 \& 13\end{array}$ \\
\hline $\begin{array}{l}\text { 4. Are student } \\
\text { affairs } \\
\text { educators } \\
\text { collaborating } \\
\text { with others, } \\
\text { such as } \\
\text { academic } \\
\text { affairs, in the } \\
\text { creation and } \\
\text { administration } \\
\text { of assessments? } \\
\text { How? }\end{array}$ & $\begin{array}{l}\text { 8. Are student affairs educators } \\
\text { collaborating with others, such as } \\
\text { academic affairs, in the creation and } \\
\text { administration of assessments? How? } \\
\text { Questions } 13 \& 14\end{array}$ & $\begin{array}{l}\text { 8. Are student affairs educators } \\
\text { collaborating with others, such as } \\
\text { academic affairs, in the creation and } \\
\text { administration of assessments? How? } \\
\text { Questions } 12 \& 13\end{array}$ \\
\hline
\end{tabular}


Table 3

Interview Protocol and Document Content Analysis Protocol Aligned with Research Questions (continued)

\begin{tabular}{|c|c|c|}
\hline $\begin{array}{l}\text { Research } \\
\text { Question }\end{array}$ & $\begin{array}{c}\text { Interview Protocol } \\
\text { Question }\end{array}$ & $\begin{array}{c}\text { Document Content Analysis } \\
\text { Protocol Question }\end{array}$ \\
\hline $\begin{array}{l}\text { 5. How are } \\
\text { student affairs } \\
\text { assessment data } \\
\text { used to enhance } \\
\text { student } \\
\text { learning } \\
\text { experiences? }\end{array}$ & $\begin{array}{l}\text { 9. How are student affairs assessment } \\
\text { data and results used to } \\
\text { change/modify programs, activities, } \\
\text { and services and ultimately student } \\
\text { learning? } \\
\text { 10. How is your assessment program } \\
\text { evaluated? } \\
\text { Questions } 13 \& 14\end{array}$ & $\begin{array}{l}\text { 9. How are student affairs assessment } \\
\text { data used to enhance student learning } \\
\text { experiences? Specific examples? } \\
\text { Questions } 12 \& 13\end{array}$ \\
\hline $\begin{array}{l}\text { 6. What } \\
\text { successes and } \\
\text { challenges do } \\
\text { student affairs } \\
\text { educators face } \\
\text { as they } \\
\text { implement their } \\
\text { assessment } \\
\text { nlans? }\end{array}$ & $\begin{array}{l}\text { 11. What are the challenges of your } \\
\text { student affairs assessment process? } \\
\text { 12. How would you improve your } \\
\text { institution's student affairs } \\
\text { assessment process? } \\
\text { Questions } 13 \& 14\end{array}$ & $\begin{array}{l}\text { 10. How is the assessment program } \\
\text { evaluated? } \\
11 . \text { What are the successes and } \\
\text { challenges of the assessment process? } \\
\text { Questions } 12 \& 13\end{array}$ \\
\hline
\end{tabular}

\section{Pilot Study}

The researcher conducted a pilot study in order to assure validity and reliability of the site-selection and participant-selection criteria, interview and document content analysis protocols, and the study's data collection administration process. A pilot institution was chosen, in part on the pre-determined case institution selection criteria, and based upon convenience, access, and geographic proximity. Yin (2003) believes, "this will allow for a less structured and more prolonged relationship to develop between the interviewees and the case study 
investigator... “ (p. 78). The original interview protocol, included in Appendix B, was used during the pilot study and was followed with a pilot-study specific interview protocol, included in Appendix C. The follow-up pilot study protocol provided the researcher with evidence to determine the clarity and appropriateness of questions asked. The researcher also noted questions that were very difficult for participants to answer. The selection of interview participants at the pilot study institution was based upon the study's interview participant criteria. Specifically, one participant from each of the case participant criteria was interviewed, which consisted of:

- One Senior Student Affairs Officer (if not available then the Assistant Senior Student Affairs Officer)

- One Director/Coordinator of Student Affairs Assessment

- One Student Affairs Assessment Committee/Council Member

- One Other Student Affairs Professional Staff Member

By conducting a pilot study, the researcher could refine his data collection plans, thus allowing the researcher to make formative decisions before conducting his formal study (Yin, 2003). Results from the pilot study provided information "explicit about the lessons learned from both research design and filed procedures" (Yin, 2004 p. 80), consequently allowing the researcher, alongside his doctoral committee chair, to identify necessary modifications to the study's protocols and processes. Chapter Four provides a full description of the pilot study and specific changes made, including modifications to the interview protocol.

\section{Ethics}

The researcher explained the ethical standards of this study to each of the interview participants, as required from West Virginia University's Institutional Review Board. Participants were informed that their names or any other information that may identify them 
would not be released in the reported results and all responses would remain confidential.

Moreover, interview participants were informed that their participation was be entirely

voluntary, and they did not have to respond to every question asked, and that their employment status would not be affected by refusing to participate.

After the researcher gained permission to interview participants, each was asked if the researcher could tape record and later transcribe verbatim responses in order to assure accuracy of collected data. Transcribed data resulted in a code assigned to each participant, so that he or she could not be identified. Furthermore, the researcher recorded notes throughout the interview processes. Collected notes, along with the researcher's personal, yet relevant, observations were documented following each interview.

\section{Data Organization and Analysis}

Merriam asserts that a researcher may undermine his or her entire study "by waiting until after all the data are collected before beginning the analysis" (p. 160). Moreover, Merriam states that "the right way to analyze data in a qualitative study is to do it simultaneously with data collection" (p. 162). Likewise, Patton (2002) explains that "ideas for making sense of the data that emerge while still in the field constitute the beginning of analysis; they are part of the record of field notes" (p. 436). Therefore, the researcher adopted a concurrent process of analysis during the data collection stage.

More specifically, the researcher analyzed participant responses to the interview protocol and findings from the document content analysis protocol by first analyzing responses within a case institution, thus producing a within-case analysis. By initially focusing the analysis of data within a particular university, the researcher was able to identify similarities and differences within each case. The researcher then wrote a case study chapter for each university that he 
studied (see Chapters Five, Six, and Seven). Thereafter, the researcher conducted a cross-case synthesis (Yin, 2003). The researcher compared similarities and differences across universities as well as identified high quality characteristics and practices of three student affairs learning outcomes assessment models. That triangulation technique allowed the researcher to construct meaning from large amounts of data and "involve[ed] reducing the volume of raw information, sifting trivia from significant patterns, and constructing a framework for communicating the essence of what the data reveal" (Patton, 2002, p. 432).

The researcher used coding procedures in order to effectively categorize data. Since interviews were transcribed verbatim upon the conclusion of interviews, and documents were analyzed simultaneously, it was important for coding to first occur during that process. Merriam (1998) believes "coding occurs at two levels - identifying information about the data and interpretive constructs related to the analysis" (p. 164).

The researcher clearly identified information about the data retrieved from both interviews and documents. To do such, the researcher of this study listed basic demographic questions at the beginning of both the interview protocol and document content analysis protocol. By collecting such information, the researcher coded each point of data collection. For example, each case study participant was identified using an alias. Original data that included identifiers was stored separately from data that had been coded.

In order to manage the large amount of data collected from this study and clearly provide interpretive constructs related to the analysis, the researcher created a data analysis map, adopting six levels of analysis as outlined by the work of Harry, Sturges, and Klingner's (2005, p. 6). Those levels were modified to meet the needs of this research study and included:

Level 1. The researcher constructed open codes, labeling all key points derived from interviews and documents analyses. 
Level 2. The researcher created conceptual category codes, derived from a comparison of all open codes to one another. Conceptual category codes included clustered open codes.

Level 3. The researcher identified and developed themes focusing upon the most predominant perspectives of interview participants.

Level 4. The researcher tested the themes by triangulating the interview data with the document content analysis data. Additionally, the researcher sought expert advice from his doctoral committee chair and other committee members when developing themes.

Level 5. The researcher conducted a cross case synthesis that interrelated the explanations of high quality learning outcomes assessment practices. He did so by comparing identified themes across cases.

Level 6. The researcher determined how analyzed results addressed his stated six research questions and supported and/or was not consistent with the learning outcomes literature in Chapter Two.

Levels one through four allowed the researcher to analyze data within each of the three case studies, thus the researcher wrote a chapter in this dissertation about each university. Levels five and six allowed the researcher to produce the final chapters of this dissertation, focusing upon a cross-case institutional comparison. The researcher used an analysis map to produce a rich and descriptive analysis and results section of this study.

\section{Validity and Reliability}

It was important to note how validity and reliability were assured during the data collection process and analysis of this study. Merriam (1998) synthesized the literature and suggests several approaches for researchers to employ to address internal validity, reliability and external validity. The following section explains how the researcher enhanced both validity and reliability. 


\section{Internal Validity}

"Internal validity deals with the question of how research findings match reality" (Merriam, 1998, p. 201). Merriam explains that because the researcher is the primary data collection instrument, he or she is "closer to reality than if a data collection instrument had been interjected between [the researcher] and the participants" (p. 202). Therefore it is essential for a qualitative case study researcher to use multiple methods of triangulation. Triangulation involves the use of "multiple investigators, multiple sources of data, or methods to confirm the emerging findings" (p. 204)

To assure internal validity for this study, the researcher used multiple methods of data collection, primarily relying upon data produced from interviews and document analysis. The triangulation of multiple data sources allowed the researcher to produce a "holistic [and] multidimensional" analysis of data (Merriam, 1998, p. 202).

In addition to the use of triangulation, the researcher utilized the process of peer examination, by asking colleagues and experts to offer remarks and insights into his evolving results (Merriam, 1998). Merriam (1998) also suggests that a researcher make clear his or her "assumptions, worldview, and theoretical orientation at the outset of the study" (p. 205). Therefore, the researcher has included such at the conclusion of this chapter.

\section{External Validity}

"External validity is concerned with the extent to which the findings of one study can be applied to other situations" (Merriam, 1998, p. 207). As explained earlier in this chapter, the intent of this study was not to generalize findings, but rather to develop an understanding of high quality student affairs learning outcomes assessment practices. However, steps were taken by the researcher of this study to enhance external validity. For instance, the researcher examined 
multiple cases for this study, thus providing the opportunity for cross-case synthesis. Moreover, he conducted a pilot study that, in part, helped validate predetermined site selection criteria, participant selection criteria, procedures for coding data, procedures for analyzing data, and procedures for conducting on-site administration of protocols.

\section{Reliability}

Reliability is concerned with the degree to which a study's findings can be reproduced. (Merriam, 1998, \& Patton, 2002). However, Merriam (1998) is quick to explain that "there is no benchmark by which to take repeated measures and establish reliability in the traditional sense [when conducting qualitative case study research]" (p. 205).

The objective of this study was to assure reliability within the context of this study - that meant to assure that results were reliable based upon data collected. For that reason, the researcher constructed an audit trail throughout the data collection process. An audit trail required the researcher to account for and provide authentication of the data collection process. As Merriam (1998) explains, "in order for an audit to take place, the investigator must describe in detail how data were collected, how categories were derived, and how decisions were made throughout the inquiry" (p. 207). As presented earlier, the researcher used pre-designed matrices in order to reach an appropriate synthesis of data. The use of those matrices allowed the researcher to account for the steps taken to reach his results. Moreover, the researcher addressed reliability through the use of pre-determined interview and document analysis content protocols, which were be pilot tested and modified based upon those pilot study results.

The researcher also assured reliability through the authentication of documents collected for analysis. Questions included at the beginning of the document content analysis form, included in the Appendix section, were based upon Merriam's (1998) questions the researcher 
should ask in order to authenticate the record. For instance, the researcher determined the history of the document, its author, its completeness, its purpose, and the document's source of information.

\section{Relevant Past Experiences of the Researcher}

At the time of this study, I was serving as a full-time doctoral student and graduate assistant at West Virginia University, majoring in higher education leadership studies. Previously, I earned a bachelor of science degree in public relations, a post-graduate degree in secondary English education, and a Master's degree in higher education leadership studies. I worked within a student affairs division for two-years at a private liberal arts institution as an admissions counselor. Additionally, I recently completed an assessment internship with West Virginia University's Student Affairs Division. My primary role was to coordinate and deliver, alongside my doctoral committee chair and the Coordinator of Assessment and Planning for West Virginia University's College of Human Resources and Education, a series of six professional development workshops for West Virginia University's Student Affairs. These workshops focused upon building student-centered assessment plans. Furthermore, I recently co-presented with my doctoral committee chair on Building comprehensive student affairs learning outcomes assessment plans at the Graduate Student Faculty Forum held at Florida State University as well as a day-long presentation on creating student affairs learning outcomes at the Association of Institutional Researchers' Annual Forum. Moreover, I co-presented at the National Association of Student Personnel Administrators [NASPA] Annual Assessment and Retention Conference during the summer of 2006. 


\section{Statement of Personal Context}

In this section, the researcher discusses his philosophical assumptions and attitudes that may impact his data analysis capabilities. In particular, the researcher acknowledged that his professional involvement in a series of outcomes assessment workshops for West Virginia University's Student Affairs Division may have greatly influenced his perceptions and understandings of how a student affairs division may initiate a paradigm shift. However, the researcher clearly recognized that all higher education institutions are unique and do not approach such challenges homogeneously.

In addition to his professional involvement with learning outcomes assessment, the researcher believed that a genuine paradigm shift would not occur within student affairs' divisions whose purpose of assessment was solely based upon accreditation and accountability. On the contrary, he believed that an assessment culture would only be created and enhanced when divisions recognized that they are truly contributing to co-curricular learning and that they should be working to improve such learning. This belief was consistent with calls for reform by the National Association of Student Personnel Administrators.

Lastly, the researcher acknowledged that he was actively involved in the co-curricular during his undergraduate education, including a year-long term as president of the student body. For that reason, the researcher experienced cognitive and affective gains as a result of cocurricular experiences. He has a personal interest in advancing the value and importance of learning outcomes assessment. 


\section{Chapter Four}

\section{Pilot Study}

Patton (2002) explains that "the credibility of qualitative methods... hinges to a great extent on the skill, competence and rigor of the person doing the fieldwork" (p. 14). Therefore, to enhance the researcher's fieldwork capabilities and to validate and resolve any problems with this study's research design and methodology, a pilot study was conducted in late July 2005 . The main objective of the pilot study was to gather feedback from participants about the interview protocol and cover letter that could be used to improve future data collection at the three case institutions selected for the formal study. The researcher also had the opportunity to practice his interviewing techniques and data analysis capabilities. The pilot study was conducted at a statesupported university located in the Eastern portion of the United States. According the institution's undergraduate catalog, it was founded in 1871, currently enrolled 3,700 students, offered more than 75 academic programs, and officially gained university status in 2004 . The pilot institution received regional and national accreditation and was classified by the Carnegie Foundation (2005) as a Baccalaureate Colleges-General.

Because the researcher examined three student affairs divisions with high quality student learning outcomes models for his formal study, the selection of the pilot institution was based, in part on the criteria, or indicators of excellence, used to select those institutions. The student affairs division at the pilot institution had been assessing learning outcomes since 2000, the same time when the entire university began assessing learning outcomes due to calls from their accrediting body to better demonstrate student learning over time.

The student affairs division at the pilot institution consisted of fourteen departments including the Career Development Center, the Student Center, Counseling, Dining Service, 
Health Services, Greek Life, Judicial Affairs, Multicultural Student Affairs and Disability Services, Orientation, Residence Life, Student Activities, Student Leadership Programs and Organizations, Student Community Services and Service Learning, and Veteran's Affairs. Each of these departments produced annual assessment plans, implemented their assessments, and reported their results since 2000. Units within the division used assessment data for programmatic change, and according the Vice President, results were also used to restructure some of the division's offices in an attempt to enrich undergraduate students' co-curricular experiences.

\section{Data Collection}

The researcher focused on two data collection methods for this pilot study. The first method, included "open-ended questions and probes [designed to] yield in-depth responses about people's experiences, perceptions, feelings, and knowledge" (Patton, 2002, p. 4). Four participants within the student affairs division who had been actively involved in the organization's student learning outcomes assessment practices were asked to respond to a series of protocol questions based upon elements of high quality assessment. Each interview lasted approximately fifty minutes. Furthermore, the researcher asked eight open-ended questions requesting participants to consider how he could improve the interview process which followed the assessment-specific questions. These follow-up questions focused on the clarity of the protocol and the flow of the interview, as well as questions that sought feedback on the cover letter used to invite student affairs participants. Copies of the original pilot study interview protocol and follow-up questions are included in the Appendicies B and C of this study.

The second method of data collection came from appropriate assessment documents provided by the pilot study university. Those documents included assessment plans and reports 
of each student affairs department from June 2003 through June 2004, university-wide assessment task force meeting agendas and minutes, sample assessment educational handouts, assessment checklists and templates, and an assessment schedule for the entire university and student affairs division from 2001 through 2004. The document content analysis protocol form used to analyze these documents may be found in Appendix D.

\section{Participants}

Four separate, face-to-face interviews were conducted and tape-recorded with participant permission. The interview with the Vice President was conducted in her private office, and the other three interviews were conducted in a private office adjacent to the Vice President's office. Participants included: the Vice President of Student Affairs; an Assistant Vice President of Student Affairs and Dean of Students, who has led the facilitation of the assessment initiative within the division since its conception; an Assistant Vice President of Student Affairs and Director of Residence Life; and the Director of Multicultural Student Affairs and Disability Support Services. Participants were purposefully chosen with the guidance of the designated institutional liaison.

The Vice President and Assistant Vice Presidents all reported having earned doctorates in a higher education field, and the Director of Multicultural Services and Disability Support Services reported having a Master's Degree in Student Personnel Services. Pilot study participants represented the individuals who would be formally interviewed during the actual case study site visits. However it must be noted that the pilot study institution's student affairs division did not have an assessment committee that functioned separately from the universitywide assessment task force. Whereas, selected case study institutions had student affairs 
assessment committees. The formal site visits included interviews with selected members from those student affairs assessment committees.

\section{Process}

The pilot institution was chosen, in part, on the pre-determined case institution selection criteria, and based upon convenience, access, and geographic proximity (Yin, 2003, p. 78). The pilot student affairs division closely reflected the criteria that were used to select the actual case institutions. Specifically, the pilot institution's student affairs division has a five year history of assessing leaning outcomes, thus demonstrating the division's ability to plan, implement, and use assessment results to enhance learning — all of which are critical elements in the criteria that were used to select three high quality case institutions.

In order to determine if the pilot institution was appropriate for this study, the researcher first spoke its Vice President of Student Affairs during the 2005 NASPA Annual Conference. She indicated that her division was assessing learning outcomes and was interested in serving as the pilot institution. That conversation prompted a follow-up email, where the researcher requested additional information, including assessment plans and reports. She responded quickly by forwarding the researcher's request to the Assistant Vice President of Student Affairs and Dean of Students, who facilitates the division's assessment efforts. That individual then provided the researcher with the appropriate documents needed to determine if the proposed site was indeed a match for this study. After reviewing those documents, the researcher spoke with Vice President of Student Affairs to seek additional information including how long her division had actually been assessing learning outcomes and how they were using those results to improve student learning. 
Once the researcher determined that the university met the site selection criteria for this pilot study, he sought access to conduct on-site interviews. Because the researcher had developed a good rapport with the Vice President, she agreed to serve as the liaison and identify those individuals who could best inform the researcher about the division's assessment model. Once the researcher received written permission from the institution to conduct the pilot study and Institutional Review Board approval was granted from West Virginia University, the researcher mailed a letter detailing an explanation of the pilot study to the liaison, as well as participant invitation letters that were to be distributed to the four individuals who were to be interviewed over a one-day period in July 2005.

\section{Data Analysis and Implications for the Formal Study}

The researcher used a constant comparative analysis of data collected from the pilot study, including transcribed audiotape recordings of the interviews, field notes, participant feedback, and assessment documents. As previously stated, the primary purpose of the pilot study was to determine the appropriateness and clarity of the cover letter and interview and document content protocols.

After analyzing the feedback obtained from the pilot study interview participants, the researcher made appropriate changes to the process and interview protocol. The following paragraphs detail the rationale for such changes that will enhance the researcher's data collection strategies.

When asked about the clarity of the cover letter used to invite individuals to participate in the study, each of the participants indicated that the cover letter was clear and explained the researcher's intent. Moreover, all participants indicated that they were motivated to participate in the pilot study, primarily because each felt a "responsibility" and "obligation" to assist 
aspiring doctoral candidates. Such motivation may be in part to the advanced level of student affairs experience and higher education each participant possessed.

When asked what suggestions participants had for the researcher to improve the cover letter, one respondent indicated that he "liked color" and stated that he may have been more motivated to participate if the cover letter been placed on an original West Virginia University College of Human Resources and Education letter head. However, he recognized that the researcher was required to invite participants using the cover letter that included the Institutional Review Board (IRB) stamp of approval.

The researcher acknowledged the need to motivate participation in his formal study; therefore, he made sure that the IRB stamped cover letter was copied in color and used those color copies to invite participants.

Based upon only positive participant feedback regarding the cover letter's explanation of the study's purpose, no modifications were made for the formal study to the content within the cover letter. However, changes were made to the distribution process of the cover letter. One participant suggested that the cover letter not only be distributed to participants via the identified liaison. He stated, "Make sure that the participants that you are interviewing are getting the same information. Don't assume that they are. This will also help them understand how you narrowed down the institutions for your research." For that reason, the researcher asked the liaison at each case study institution to provide him with the email addresses of those individuals the liaison had identified as interview participants. The researcher then sent each participant a separate, informal email to assure their receipt of the cover letter and again allowed each participant the opportunity to ask the researcher any questions they may have about the study. By doing such, the researcher believed that participants had a better understanding of why they were being asked 
to reflect upon their division's learning outcomes assessment model. This also assured that each participant was properly invited to participate in the study.

When participants were asked how the researcher could make the purpose of the interview clearer, all indicated that the purpose was clear in the cover letter. Additionally, two participants indicated that the researcher's intent became even clearer when the interview script was read. Again, the researcher felt that by informally emailing each participant prior to the actual interview to confirm receipt of the cover letter, each had another opportunity to ask questions should the researcher's interview purpose be unclear.

Participants also provided feedback regarding the clarity, appropriateness, and flow of the interview protocol. All participants described the flow of the interview as "good," with one individual stating

I think you did well. You didn't stop me, which was good. I think if you don't read your introduction [word-for-word], your flow will start off easier. You made it very comfortable for me. You made good eye contact. You paid attention. You were encouraging. I don't feel like you led me in any way. You looked at me and nodded and asked me for information and gave some very helpful prompts, and don't be afraid to do that.

Although this participant mentioned that the researcher may not want to read his script word-for-word, the researcher recognizes that he is required by West Virginia University's IRB to adhere to the approved script, so that it is identical each time he meets with a participant, thus assuring reliability. Therefore, the researcher read the script as required during the formal site visits. No other participants suggested changes on how the researcher could improve the flow of the interview process. 
Participants made a few suggestions regarding how the interview protocol could be strengthened. The first suggestion focused on question one of the interview protocol: What do you believe are the characteristics of good learning outcomes? The first respondent interviewed stated that, "Your first question was very difficult. I wasn't sure how to answer it." The researcher agreed, having documented in his observation notes the participant's anxiety and discomfort when he asked this question. Furthermore, Patton (2002) argues that "knowledge and skill questions... need context. Such questions can be quite threatening if asked too abruptly" (p. $352)$.

When the researcher asked how he could better phrase that question, the participant suggested, “... a little conversation about learning outcomes and then move to that one. You may want to point out one of the things that [you] really want to find out is... What do you think are the components of good learning outcomes?" The participant suggested that the researcher should explain to the interview participant his interest in their articulation of learning outcomes. For that reason, the researcher wrote additional script that was added to the interview protocol to clarify that the pilot institution was selected partially because of their ability to articulate learning outcomes, followed by the actual question. None of the remaining three participants suggested that question one was difficult or inappropriate for the formal study.

Because the additional script, read before beginning Part B of the interview, strengthened the protocol, the researcher included it, along with a greater explanation of learning outcomes in the interview protocol used during the formal study, which is included in Appendix M. Moreover, after a discussion with his doctoral committee chair, the researcher modified and moved that question to be asked after participants had been asked to describe the learning outcomes articulated in their division and within their respective units. The researcher agreed 
with his doctoral chair and Patton (2002) that by asking this question later in the interview, participants were provided with a context of learning outcomes; therefore, they are more likely to be comfortable when responding, thus providing the researcher with richer data.

The question was changed to: Since you have explained to me the learning outcomes within the division and the learning outcomes within your unit, what do you believe are the characteristics of good learning outcomes? The researcher included appropriate probes for that question within the formal study protocol.

Another suggestion on how the researcher could improve the interview protocol came from the individual who coordinates the division's assessment efforts. He felt that the researcher should ask interview participants how their student affairs division began assessing learning outcomes, specifically suggesting the question, "Was assessment campus generated or did this just come from student affairs?" He felt that it was important for the researcher to clearly understand the factors that may influence the articulation of learning outcomes. The researcher agreed with this feedback and inserted question number fifteen in Part A, the demographic section of the interview protocol, which reads: How and why did [insert institution's name] student affairs division begin assessing learning outcomes? In order to distinguish the difference between this question and question number sixteen, which reads: What is the purpose of assessing learning outcomes? the researcher included appropriate probes after each question.

Another participant suggested that the researcher include a final question seeking permission to contact the respondent should the researcher have additional questions or need to clarify responses stating, "You may want to ask if you have permission to follow up with participants." Again, the researcher agreed with that feedback and amended Part B of the interview protocol by inserting a final question that reads: Should I need clarification of any of 
your responses or additional information, may I contact you in the future? Could you provide me with your contact information? The revised interview protocol that was used during the formal study is included in Appendix M.

All participants suggested the month of October to conduct the formal study in order to obtain the highest rates of participation. One respondent initially suggested the summer months, but then changed his mind because he believed vacation schedules would interfere. Based upon this feedback and the timeline of this study, the researcher conducted his formal case study site visits during late September 2005 and October 2005.

The researcher tested the appropriateness of the document content protocol, which was designed to be comprehensive. Therefore, the researcher recognized that each document content analysis question was not relevant for all documents that he analyzed. Nevertheless, a collective analysis of those retrieved documents provided an in-depth insight into the pilot student affairs division's assessment practices and procedures. Therefore, no modifications were made to the document content analysis form.

\section{Conclusion}

The researcher strongly believed that this pilot study experience was extremely valuable and provided beneficial feedback that was used to make modifications to the interview protocol and the process used to invite individuals to participate in the formal study. Moreover, this pilot study had a positive impact on the researcher's interviewing techniques, helping him recognize that he must be flexible when interviewing participants. Some pilot study respondents required more probing than others. These participants appeared to be less familiar with the day-to-day assessment practices within the division. However, other respondents answered questions before even being asked, most likely because of most likely because of their involvement with the 
institution's assessment committee and knowledge and experience in actually writing assessment plans and reports.

The process of conducting a pilot study also increased the researcher's confidence in the quality of the interview protocol (with modifications) and the document content analysis form. The researcher believed that those protocols, coupled with a comparative analysis, produced reliable information, thus validating their appropriateness for the formal study. Moreover, the researcher reaffirmed his selection of a qualitative methodology in order to address his six research questions. 


\section{Chapter Five}

Southern University

\section{Institutional Background}

Classified by the Carnegie Foundation (2005) as a Research I-Extensive institution, Southern University is located in a metropolitan city in the southeastern region of the United States. According to Southern University's online undergraduate catalog, the university founded under the Land-Grant Act in 1887, considers itself "a national center for research, teaching, and extension in the sciences and technologies, in the humanities and social sciences, and in a wide range of professional programs" (Southern University Catalog, 2005).

The university has approximately 7,500 employees, including nearly 2,000 faculty members. Fall 2004 undergraduate enrollment totaled 20,302 and 5,977 graduate students, with approximately fifty-eight percent male and forty-two percent female. Minorities account for nearly twenty percent of the total student body. More than 1,000 international students are enrolled and about 600 students are pursuing degrees off campus via distance education. The university, which is fully accredited by the Southern Association of Colleges and Schools, is organized into ten colleges, the Graduate School, and the Division of Undergraduate Programs, all of which offer baccalaureate degrees in 102 fields, master's degrees in 108 fields, and doctoral degrees in 61 fields (Southern University website, 2005).

According to Southern University's mission, its purpose is to ...serve its students and the people of [the home state of Southern University] as a doctoral, research extensive, land-grant university. Through the active integration of teaching, research, extension and engagement, [Southern] University creates an innovative learning environment that stresses mastery of fundamentals, intellectual 
discipline, creativity, problem solving, and responsibility. Enhancing its historic strengths in agriculture, science, and engineering with a commitment to excellence in a comprehensive range of academic disciplines, [Southern] University provides leadership for intellectual, cultural, social, economic and technological development within the state, the nation, and the world (Southern University website, 2005).

\section{Mission Statement for Southern University Student Affairs}

According to Southern University's Student Affairs mission statement on its website, the division is committed to provid[ing] programs and services for students and the larger community to enhance quality of life, facilitate intellectual, ethical and personal growth, and create a culture which engenders respect for human diversity. It is through these activities that we promote student learning with our principle of "Students First." (Southern University Student Affairs website, 2005).

In addition to its mission, the division has listed eight core values that serve as "the foundation of [its] work with students" (Southern University Student Affairs website, 2005). Those core values, along with a brief description provided by an Assistant Vice President of Student Affairs, include:

1. Students first-Southern University Student Affairs exists to provide support to students, with student education as the division's first priority.

2. Commitment to student learning - When working with students, the division is committed to not only providing students with the services, but is also committed to educating students and supporting students' academic efforts.

3. Diverse and inclusive campus community-Through various co-curricular educational opportunities, Southern University Student Affairs strives to create an allembracing environment of learning. 
4. Integrity - The division defines the foundation of integrity as the development and demonstration of trust, honesty, respect, personal responsibility, and fairness.

5. Compassion for individuals and communities - Through its daily operations, Southern University Student Affairs demonstrates compassion for students and the community, with the intent of educating students the importance of compassion in their own work.

6. Collaboration within the Division, University, profession, and with other constituents - When appropriate and possible, the division works with other entities to provide the best possible programs, experiences, and learning opportunities.

7. Culture of innovation-Student Affairs professionals value and support originality in their work and encourage students to be innovative in their work.

8. Effective and efficient use of resources-Southern University Student Affairs uses resources effectively and efficiently in order to provide the experiences students need to learn and to develop habits of learning. (Southern University Student Affairs website, 2005).

According to Southern University’s Student Affairs' webpage (2005), the division also articulates general goals focused on facilitating "the total educational growth and development of [Southern University] students to include personal, social, physical, cultural, leadership, and intellectual development." A seasoned Vice President that reports directly to the President of the university leads the Student Affairs division. He has led the division for 12 years, with two of those years serving as the Interim Vice President.

The division's structure is arranged in a top-to-bottom flow chart. The Vice President directly oversees eight direct reports: five Associate Vice Presidents, one Assistant Vice President, one academic department head, and one Scholarship and Leadership Program Director. These eight individuals supervise unit directors who manage 30 units, some of which include sub-units.

Southern University's Student Affairs Division consists of a variety of units, including those traditionally placed in student affairs, such as Career Services, Campus Activities, 
Housing, Greek Life, Campus Recreation, and Multicultural Services. However, Southern University's Student Affairs Division is unique because it also includes academic departments, such as physical education and music, as well as ROTC programs (Southern University Student Affairs website, 2005).

Study Participants

Eight student affairs educators were individually interviewed for approximately one hour during late September, 2005 for this study. Participants were purposefully selected with the guidance of the division's director of assessment, who served as the liaison for this study. The researcher interviewed the following individuals:

- an Assistant Vice President of Student Affairs (who was the highest ranking administrator in Student Affairs available for an interview);

- the Director of Student Affairs Assessment, who served as the liaison for this study and sits on the division's assessment committee;

- three other members of the assessment committee, including an Associate Director of the Scholars Office, the Director of Distance Education and Technology Services, and the Director of Campus Activities; and

- three non-assessment committee members that included the Director of Multicultural Services, the Director of Residence Life, and a Unit Program Coordinator of University Theatre.

Of the eight respondents, seven were female and one was male. Moreover, seven described themselves as Caucasian and one described herself as African American. At the time of the site visit, five respondents held doctoral degrees, two held Master's degrees and one held a Bachelor's degree. The average length of reported employment within their current position at Southern was nearly five years (see Table 4). 
Table 4

Southern University Interview Respondents

\begin{tabular}{|c|c|c|c|c|c|c|}
\hline Participant & Position & Education & Gender & Race & $\begin{array}{c}\text { SA } \\
\text { Assessment } \\
\text { Committee } \\
\text { Member }\end{array}$ & $\begin{array}{l}\text { Length of } \\
\text { Employ- } \\
\text { ment in } \\
\text { Current } \\
\text { Position }\end{array}$ \\
\hline 1 & $\begin{array}{l}\text { Asst. Vice } \\
\text { President }\end{array}$ & $\mathrm{PhD}$ & Female & Caucasian & & $7 \mathrm{yrs}$ \\
\hline 2 & $\begin{array}{c}\text { Unit Director, } \\
\text { Assessment } \\
\text { Office }\end{array}$ & $\mathrm{PhD}$ & Female & Caucasian & $X$ & $1.5 \mathrm{yrs}$ \\
\hline 3 & $\begin{array}{c}\text { Unit } \\
\text { Associate } \\
\text { Director, } \\
\text { Scholars } \\
\text { Office }\end{array}$ & MA & Male & Caucasian & $X$ & 8 yrs \\
\hline 4 & $\begin{array}{l}\text { Unit Director, } \\
\text { Distance Ed. } \\
\text { \& Tech. } \\
\text { Services }\end{array}$ & $\mathrm{PhD}$ & Female & Caucasian & $X$ & 4 yrs \\
\hline 5 & $\begin{array}{c}\text { Unit Director, } \\
\text { Campus } \\
\text { Activities }\end{array}$ & EdD & Female & Caucasian & $\mathrm{X}$ & 8 yrs \\
\hline 6 & $\begin{array}{c}\text { Unit Director, } \\
\text { Multi-cultural } \\
\text { Services }\end{array}$ & $\mathrm{PhD}$ & Female & $\begin{array}{c}\text { African } \\
\text { American }\end{array}$ & & 4 yrs \\
\hline 7 & $\begin{array}{c}\text { Unit Director, } \\
\text { Residence } \\
\text { Life }\end{array}$ & MA & Female & Caucasian & & $1 \mathrm{yr}$ \\
\hline 8 & $\begin{array}{c}\text { Unit Program } \\
\text { Coordinator, } \\
\text { University } \\
\text { Theatre }\end{array}$ & BA & Female & Caucasian & & $5 \mathrm{yrs}$ \\
\hline
\end{tabular}


History of Southern University Student Affairs Assessment Efforts

The Southern University Student Affairs Division has been formally engaged in learning outcomes assessment since 2002 according to all participants interviewed. The Director of Assessment explained, “[We] started learning about learning outcomes three years ago." When asked why the division began articulating and assessing learning outcomes, one-half (50\%) of the respondents explained that the division began the process to adhere to accreditation requirements. Specifically, an Assistant Vice President stated, "We knew that it was the right thing to do, [but] in reality we were going through the accreditation process." In addition to accreditation, two respondents explained that Southern University's Academic Affairs Division had engaged in learning outcomes assessment many years before Student Affairs began the process. For that reason, Student Affairs began to see the benefits of decision making based upon assessment data. Hence, the division "wanted to participate in the broader campus [assessment] discussion," as explained by the Associate Director of the Scholars Office. Moreover, twenty-five percent of respondents described the reason for assessing learning outcomes as a response to a direct order from the student affairs leadership, with one respondent stating, "[I assess] because somebody told me to" (see Table 5). 
Table 5

Southern University Interview Responses: Reasons Student Affairs Began Assessing Learning Outcomes

\begin{tabular}{lcc}
\hline $\begin{array}{c}\text { Interview response: Reasons division began } \\
\text { assessing learning outcomes }\end{array}$ & $\begin{array}{c}\text { Number of } \\
\text { responses } \\
\mathrm{N}=9\end{array}$ & $\begin{array}{c}\text { \% based upon number } \\
\text { of respondents } \\
\text { (N=8) }\end{array}$ \\
\hline Accreditation requirements & 4 & 50.0 \\
$\begin{array}{l}\text { To participate in a broader campus assessment } \\
\text { discussion }\end{array}$ & 2 & 25.0 \\
Request from Student Affairs Administration & 2 & 25.0 \\
The right thing to do & 1 & 15.5 \\
\hline
\end{tabular}

Respondents were also asked to reflect upon what they viewed as the purpose of assessing learning outcomes. Table 6 illustrates that the majority of respondents believed that the main purpose of assessing learning outcomes within their division and respective units was to provide evidence that they were actually accomplishing their goals. The Assistant Vice President clarified by stating, “[We] can make plans, implement programs, [and] do workshops all day long, but unless [we] are actually doing the assessment and measuring the effectiveness of those programs, [we] can be going in the wrong direction."

Two respondents indicated that purpose of assessment was to allow units to demonstrate how they contributed to the institution's mission and division's mission. The Director of Distance Education and Technology explained that assessment of learning outcomes "ties into the greater mission of the university." The Associate Director of the Scholars Office stated the division "contributes to the intellectual mission of the university... [and] to demonstrate [that contribution], it was necessary to sit down and ask everyone to think about what [we] were doing and write assessment plans.” 
The Director of Multicultural Services felt the purpose of assessment was to provide evidence to justify the need for greater resources and explicitly stated, "For me, it helps to provide justification and reinforcement of our programs and services and largely to be able to advocate for greater funding, additional staff, etc. So, it gives me the ammunition I need to be able to advocate for our departmental needs."

Other respondents $(12.5 \%)$ explained that the purpose of assessment was to meet a direct order from a supervisor; to show that the division was committed to producing quality citizens; and to justify to students why their resources were used in certain areas.

Table 6

Southern University Interview Responses: Purpose of Assessing Learning Outcomes

\begin{tabular}{lcc}
\hline \multicolumn{1}{c}{$\begin{array}{c}\text { Interview responses: } \\
\text { Purpose for assessing learning outcomes }\end{array}$} & $\begin{array}{c}\text { Number of } \\
\text { responses } \\
\text { N=11 }\end{array}$ & $\begin{array}{c}\text { \% based upon } \\
\text { number of } \\
\text { respondents (N=8) }\end{array}$ \\
\hline $\begin{array}{l}\text { To show evidence that the units within the division are } \\
\text { doing what they say they are doing }\end{array}$ & 62.5 \\
$\begin{array}{l}\text { To demonstrate that units are contributing to the } \\
\text { institution's and division's mission }\end{array}$ & 25.0 \\
$\begin{array}{l}\text { To provide evidence used to justify and advocate for } \\
\text { greater resources }\end{array}$ & 1 & 12.5 \\
To meet a direct order from supervisor & 1 & 12.5 \\
$\begin{array}{l}\text { To show that the division is committed to producing } \\
\text { quality citizens }\end{array}$ & 1 & 12.5 \\
To justify to students where their resources are being used & 1 & 12.5 \\
\hline
\end{tabular}

To initially facilitate a discussion about learning outcomes assessment, the Student Affairs division partnered with the university's Academic Affairs division in 2002. The Director of Assessment elaborated on this partnership. "When Student Affairs first started doing assessment of learning outcomes... they paid [Academic] Affairs a fair amount of money to 
work part-time with Student Affairs to help them with that process." As part of the agreement, Academic Affairs first provided voluntary, professional development workshops for employees within the Student Affairs division, “...trying to get people to just articulate what it is that they [were] all about," she explained.

That same year, the division created an assessment committee, modeled after the Academic Affairs assessment committee, consisting of volunteers from across the division to provide direction for the initiative. The committee members met regularly with a part-time consultant, who was an Academic Affairs Administrator, for one year in order to determine the needs of the division to sustain the assessment effort. According to the Assistant Vice President, it became clear after that first year that the division needed to hire a full-time Director of Student Affairs Assessment in order to provide the division with the support it needed to sustain the effort saying that "it wasn't enough just having a consultant and committee... we had to have somebody who was dedicated to this." Therefore, in 2003 the division used the money it had been paying Academic Affairs for a part-time consultant, along with reallocated funds within the division, to hire a full-time director of assessment to oversee the division's assessment efforts and provide support to units. The Assistant Vice President continued by explaining,

We now have someone who comes from an assessment background [and] who comes from a Student Affairs background, which makes all the difference in the world, because [the assessment director] understands Student Affairs units. I think [the Assessment Director's] particular skills are very well suited for this and help provide the leadership we need.

Since the appointment of the Director of Assessment, the Student Affairs division had progressed in its efforts to further build a culture of learning outcomes assessment and sustain 
that culture. The assessment committee continued to meet monthly and units have completed two full cycles of planning, implementing, and reporting assessment results (see Table 7).

Table 7

Southern University Student Affairs Assessment History and Progress

\begin{tabular}{|c|c|}
\hline Academic Year & Activity \\
\hline $2002-03$ & $\begin{array}{l}\text { - Student affairs partnered with academic affairs to provide division } \\
\text { with assessment professional development workshops and guidance. } \\
\text { - Student affairs created a division-wide voluntary assessment } \\
\text { committee. }\end{array}$ \\
\hline 2003-04 & $\begin{array}{l}\text { - Student affairs hired a full-time director of assessment to provide } \\
\text { support to student affairs units and the assessment committee. } \\
\text { - Many Student Affairs units began to articulate learning outcomes and } \\
\text { most submitted plans and results. }\end{array}$ \\
\hline 2004-05 & $\begin{array}{l}\text { - The majority of student affairs units submitted assessment plans. } \\
\text { - The majority of student affairs units measured articulated outcomes } \\
\text { in assessment plans. }\end{array}$ \\
\hline 2005-06 & $\begin{array}{l}\text { - The majority of student affairs units submitted results from } 2004 \\
\text { assessment plans along with assessment plans for } 2005 \text {. } \\
\text { - The student affairs division adopted broad learning objectives for the } \\
\text { entire division. }\end{array}$ \\
\hline
\end{tabular}

Southern University Student Affairs Assessment Process and Individuals Involved

Many individuals were involved in Southern University's Student Affairs assessment efforts, depending upon the level within the organization, because it was a decentralized process. Because there was not a division-wide assessment plan, the individual(s) involved in the planning and implementation of assessment, according to all respondents, depended on each unit. For instance, one respondent explained that she was the only full-time employee in the office, "so [I] am solely responsible for assessment activities.” Although, she continued by explaining that she sits down with her direct supervisor, an Assistant Vice President to review plans and 
results. Another respondent who oversees residence life explained that her unit was so large that assessment was a decentralized process within the residence life unit itself, explaining:

The associates probably help write the plan, the assistants give input on the different elements of learning and other types of assessment topics, and the graduates students and resident directors may be asked for their opinion as well. With a unit the size of ours, if all of those people got together in one room to do things, it would be over 35 people... and the efforts would be stymied.

To gauge the level of professional staff involvement, the Director of Assessment conducted an evaluation of the assessment processes within the division in 2004. The assessment director interviewed 25 individuals across the division to determine who was involved in the process, and found that

- At least 16 units list the director as the primary assessment contact. In some cases, there were others who were equally responsible, but the director was one of the leaders in the assessment process.

- Nine units indicated that someone other than the director was ultimately responsible of the assessment process for the unit.

- At least four units had assessment committees within [their unit].

- Most units reported that multiple staff members had some role in the assessment process, and a small number indicated that one person handled all aspects of the process Nine units indicated that someone other than the director was ultimately responsible for the assessment process for the unit (Southern University Student Affairs Assessment Department Evaluation Report, 2005).

In that same evaluation, the Director of Assessment asked these individuals what incentives and/or rewards should be offered to those staff members who highly participate in Southern's Student Affairs assessment efforts. The director found that "almost no one wanted a reward." She continued by explaining, "That was actually one of the most rewarding parts... 
because I taught them [assessment] is about improving learning and making sure we do the best we can do."

The assessment initiative was strongly endorsed by the Vice President of the Student Affairs division. The Assistant Vice President stated, "The Vice President has been an extremely strong advocate and makes it known that this is important to him and to the division."

The Vice President's leadership team of eight direct reports provided support for those units they oversaw. However, as admitted by the Director of Assessment, not all of the Vice President's direct reports were initially committed to the assessment of student learning outcomes. "Some fought really hard for [the creation of the Student Affairs Assessment Director] position, and some really thought it was just a passing phase... they are slowly getting there." However, the Assistant Vice President explained, "Since we made the commitment [to assessing learning outcomes], and as we move forward, the people that were most concerned about it, are our strongest advocates. Not everyone is going to be $100 \%$ supportive, but we have come a long way."

The only full-time professional staff person within the assessment unit is the director. She does not have any support staff such as an administrative assistant or secretary. The director says her role is to "coordinate, educate, and support all the units' [assessment efforts]." Specifically, the director's responsibilities, according to the position's job description, are to:

- Increase Division of Student Affairs effectiveness by systematically gathering, analyzing, interpreting, reporting and using assessment information.

- Provide assistance to units in the Division of Student Affairs in conducting systematic assessment of their programs and services.

- Coordinate the Student Affairs Assessment Committee.

- Develop and deliver assessment training sessions, workshops, and seminars for faculty, staff, administrators, and students. 
- Partner with units both within Student Affairs and in other divisions/departments.

- Facilitate discussions within appropriate groups in order to advance Division of Student Affairs' research and assessment initiatives.

- Develop and maintain comprehensive research and assessment website for the Division.

- Write grants for the Division and individual units in the Division to secure funding for assessment efforts.

- Represent the Division on University assessment committees.

- Coordinate responses to data requests made of the Division of Student Affairs.

- Ensure the Division's compliance with the accreditation requirements for assessment (Southern University Student Affairs Assessment website, 2005).

As briefly mentioned earlier in this chapter, Southern University's Student Affairs assessment efforts were also supported by a voluntary, nine-person assessment committee, with one member chairing the group. According to Southern's Student Affairs assessment website, the committee is a group of individuals "interested in learning more about assessment and providing guidance to the division on assessment issues. The group is comprised of one to two representatives for each Assistant/Associate Vice president.” This committee, modeled after Southern University's Academic Affairs assessment committee, meets on a monthly basis as a whole and is responsible for:

- $\quad$ setting broad assessment expectations for the units;

- $\quad$ setting a yearly assessment schedule for the units;

- reviewing assessment reports and providing constructive feedback to the units;

- initiating Student Affairs Division-wide objectives conversations as appropriate;

- training and empowering unit representatives as appropriate; 
- discussing overlapping outcomes and appropriate means to combine assessment initiatives; [and]

- discussing rewards structure for participating in assessment (Southern University Student Affairs Assessment website, 2005).

One member of the assessment committee chairs the group on an annual rotating basis. According to the division's assessment webpage, the chair of the committee at the time of this study was an Associate Director of Residence Life. However, she was unavailable to be interviewed during the researcher's site visit. Although, according to the Director of Assessment, she serves as the committee's "advisor" or "facilitator," and she explained that "everyone will say I might as well [be the chair]."

In order to review assessment plans and provide feedback to units, committee members divided into sub-groups of two or three and met periodically, along with the Director of Assessment, to review assessment plans and reports. According to one respondent, feedback was initially provided in an individualized letter to each unit; however, the committee now feels that it is more efficient and useful for units to receive committee feedback that is directly embedded into their assessment plans - typing questions and suggestions into the electronic versions of the assessment plans themselves. According to the Director of Assessment, units were not required to adhere to the feedback, because the assessment committee is not an enforcing body within the unit. However, she continued,

As you might expect some units appear to value the input and implement it in their work and others do not. They are not required to use all the feedback and much of it is in the form of questions or ideas to consider. We do not assume that someone's choice not to follow a suggestion indicates that they do not value the [feedback]. 
In order to maintain consistency across reviews, the committee used a standardized checklist, which was made available through the Internet to all units within the division. The checklist was organized into a "yes" or "no" format, with 24 questions that address mission, objectives, outcomes, methodologies, results, decisions being made based upon data, and evidence of ongoing assessment. Examples of these questions included:

- Learning outcomes clearly distinguish between the things the program wants students to know (cognitive), ways students think (affective/attitudinal), or things students should be able to do (behavioral, performance, psychomotor).

- The assessment methods or tools are appropriate to the outcome being measured.

- Data is used appropriately throughout to explain well-organized decisions. (Southern University Student Affairs Checklist for the Assessment Process, 2005).

While the assessment committee relied upon a standardized checklist to evaluate assessment plans, units were not required to adhere to a standardized assessment planning template. However, the majority of those assessment plans reviewed included mission statements, learning outcomes, assessment measures. Final assessment reports included the aforementioned and incorporated assessment results and decisions made by the unit based upon those results.

\section{Southern University Student Affairs Learning Outcomes}

At the time of the researcher's site visit, Southern University Student Affairs had completed two full cycles of the assessment planning process, which included the articulation of learning outcomes, the measurement of those outcomes, and making decisions on the data retrieved from measuring outcomes. For this study, the researcher thoroughly examined the division's most recent 32 authenticated assessment plans and reports from the 2004-05 academic year provided to him by the Director of Assessment. 
According to the Director of Assessment, units were asked to articulate at least one student learning outcome for the 2004-05 academic year in their individual assessment plans. These plans also, at times, included programmatic or service outcomes, where units focused on the services they provided to students as opposed to the gains students make because of those programs or services. For instance, the Women's Center not only articulated the learning outcome that "student advocates will demonstrate skills and knowledge to assist individuals who contact the hotline," but the unit also articulated a program outcome in its plan that read, “Specific student groups will be targeted to raise awareness about Women's Center programs and services."

The Director of Assessment, as well as the Director of Distance Education and Technology explained that some units were not required to articulate learning outcomes, because they provided support to the division as a whole, such as the Student Affairs assessment unit itself, which did not have a direct influence on student learning.

Of the 32 reviewed assessment plans, a total of 22 plans included the articulation of at least one learning outcome, with some units articulating as many as three learning outcomes. Ten of these 32 reviewed unit assessment plans did not have clearly articulated learning outcomes. Eight of those ten plans only articulated program and/or service outcomes and two unit assessment plans articulated one learning outcome in their plans; however, the outcome was too broad and would be defined as a goal according to the operational definitions of the study. Therefore the researcher did not further analyze these ten assessment plans.

Of the 22 plans that were further analyzed, the researcher discovered that each were organized differently; however, every assessment plan included the unit's mission statement, the unit's objectives (or broad goals), the unit's outcomes (at least one learning outcome when 
appropriate), basic assessment methods, and a general timeframe for measuring the articulated outcomes.

The researcher, along with his doctoral committee chair's guidance, categorized Southern's learning outcomes into cognitive and affective taxonomies as illustrated in Table 8. The researcher found that the majority $(68.8 \%)$ of the articulated learning outcomes were classified within the cognitive domain while about one-third (31.3\%) were classified within the affective domain.

Table 8

Types of Learning Outcomes Identified in Southern University Student Affairs Assessment Plans (2004-05)

\begin{tabular}{lcc}
\hline Taxonomy & $\mathrm{N}=32$ & \% of outcomes \\
\hline Cognitive & 22 & 68.8 \\
Affective & 10 & 31.3 \\
\hline
\end{tabular}

Of the 22 student learning outcomes found within the cognitive domain, all were classified within the four lowest levels of thinking, with five $(22.7 \%)$ categorized within the remember level, six (27.3\%) categorized within the understand level, nine (40.9\%) categorized within the application level, and two (9.1\%) categorized within the analysis level (see Table 9). Examples of Southern University Student Affairs cognitive learning outcomes that were articulated in plans included:

- Remember: Students will report after participating in a leadership program a greater awareness of the social issue(s) addressed by the agency they served.

- Understand: Students will demonstrate the ability to communicate effectively in both oral and in written form as measured by their ability to appropriately develop and present information for a given target audience.

- Apply: Student will apply the fundamentals of health-related fitness toward developing, maintaining, and sustaining an active and healthy lifestyle by being in 
agreement at $75 \%$ or higher on each item of an alumni survey concerning personal fitness habits.

- Analyze: The Office of Student Conduct student board members, assistants, and the student chief justice will demonstrate increased critical thinking skills.

Of the ten categorized affective outcomes, three (30\%) were categorized within the receiving level, five $(50 \%)$ within the responding level, and two $(20 \%)$ within the valuing level (see Table 9). 
Table 9

Southern University Student Affairs’2004- 05 Student Learning Outcomes Categorized Within Cognitive and Affective Taxonomies

\begin{tabular}{|c|c|c|}
\hline Taxonomy & $\mathrm{N}$ & $\%$ of Outcomes \\
\hline \multicolumn{3}{|l|}{ Cognitive } \\
\hline Remember & 5 & 22.7 \\
\hline Understand & 6 & 27.3 \\
\hline Apply & 9 & 40.9 \\
\hline Analyze & 2 & 9.1 \\
\hline Evaluate & 0 & 0.0 \\
\hline Create & 0 & 0.0 \\
\hline Total cognitive outcomes & 22 & 100.0 \\
\hline Taxonomy & $\mathrm{N}$ & $\%$ of Outcomes \\
\hline \multicolumn{3}{|l|}{ Affective } \\
\hline Receive & 3 & 30.0 \\
\hline Respond & 5 & 50.0 \\
\hline Value & 2 & 20.0 \\
\hline Organize & 0 & 0.0 \\
\hline Internalize values & 0 & 0.0 \\
\hline Total affective outcomes & 10 & 100.0 \\
\hline
\end{tabular}

Specific examples of Southern University Student Affairs affective learning outcomes articulated in their assessment plans included:

- Receiving: Students will report after participating in a leadership program an increased interest in their community. 
- Responding: As a function of judicial board training, student board members will demonstrate impartial treatment of students and staff that come before the board regardless of race, color, religion, creed, sex, national origin, age, disability, sexual orientation or veteran status, consistent with Southern University's administrative regulations.

- Valuing: Students will experience an improvement in the areas of crisis management, personal growth, and the reduction of psychological stressors that interfere with their academic and personal objectives.

Respondents were asked to reflect upon what they believed to be characteristics of high quality learning outcomes (see Table 10). All eight respondents indicated that it was essential for learning outcomes to be measurable. The Assistant Vice President stated, "The outcome shouldn't be so broad and have so many components that it is too hard to measure." Although respondents indicated that learning outcomes must be measurable, an analysis of assessment plans found that two units' articulated learning outcomes were actually broad goals, as previously stated.

Three respondents noted that outcomes must reflect what the unit is actually doing and must be attainable or realistic, with the Director of Distance Education and Technology stating, "If all I had was a piece of paper that listed all the learning outcomes [in a unit], that should really give me a good sense of what that unit is all about." Others $(25 \%)$ indicated that high quality learning outcomes must be specific and meaningful. A Theatre Programming Coordinator clarified by stating, "If you are going to measure something, measure something meaningful.... something that actually might make a difference in somebody's life... at least something they can take away with them." In addition, learning outcomes should flow from the division's mission and be sophisticated according to $12.5 \%$ of the respondents. 
Table 10

Southern University Interview Responses: Characteristics of High Quality Learning Outcomes

\begin{tabular}{lcc}
\hline $\begin{array}{c}\text { Interview response: } \\
\text { Characteristics of high quality learning } \\
\text { outcomes }\end{array}$ & $\begin{array}{c}\text { Number of } \\
\text { responses } \\
\mathrm{N}=20\end{array}$ & $\begin{array}{c}\text { \% based upon number of } \\
\text { respondents } \\
(\mathrm{N}=8)\end{array}$ \\
\hline Measurable & 8 & 100.0 \\
Reflect what unit is actually doing & 3 & 37.5 \\
Attainable & 3 & 37.5 \\
Specific & 2 & 25.0 \\
Meaningful & 2 & 25.0 \\
$\begin{array}{l}\text { Flow from division's mission and } \\
\text { objectives }\end{array}$ & 1 & 12.5 \\
Sophisticated & & 12.5 \\
\hline
\end{tabular}

Southern University Student Affairs Assessment Methods

According to all respondents, choosing or developing assessment methods was a unitlevel decision. Moreover, the Director of Assessment explained that the assessment committee did not require units to submit their measurement instruments when submitting their assessment plans for review. She stated, "We are not experts on instruments. Often times [instruments] are provided to us, and when [they] are provided to us, either the group or I will provide feedback."

A thorough review of assessment plans by the researcher revealed that Southern's Student Affairs units identified 11 different methods of assessment data collection during the 2004-05 academic year (see Table 11). Of the 32 articulated learning outcomes, only 28 had clearly defined methods of assessment, with 10 (31.3\%) indicating the use of multiple methods, $18(56.3 \%)$ indicating the use of only one method of assessment, and four (12.5\%) not indicating 
the use of any assessment method. All but two outcomes were measured using locallydeveloped instruments.

Table 11

Methods used to Assess Southern University Student Affairs' Learning Outcomes in 2004-05

\begin{tabular}{lcc}
\hline $\begin{array}{l}\text { Methods used to assess learning } \\
\text { outcomes }\end{array}$ & $\begin{array}{c}\text { Number of reported } \\
\text { methods } \\
\text { N }\end{array}$ & $\begin{array}{c}\text { \% based upon total number of } \\
\text { articulated learning outcomes } \\
(\mathrm{N}=32)\end{array}$ \\
\hline Survey & 17 & 53.1 \\
Observation & 6 & 18.8 \\
Pre- and post-reflection & 3 & 9.38 \\
Interview & 3 & 9.4 \\
Document analysis & 3 & 9.4 \\
Post-reflective journal & 2 & 6.3 \\
Pre- and post-test & 2 & 6.3 \\
Portfolio review & 1 & 3.1 \\
Post-test & 1 & 3.1 \\
Focus group & 1 & 3.1 \\
GPA comparison & 4 & 3.1 \\
No method indicated & 1 & 12.5 \\
\hline
\end{tabular}

The majority $(53.1 \%)$ of the learning outcomes were measured, at least in part, using surveys. The Director of Distance Education and Technology explained, "Online surveys have become popular because people think they are easy and our office said we would help provide that service and that is all everybody wanted to do." Additionally, the Assistant Vice President explained, "It has been a challenge for folks to understand there are other ways [than surveys] to measure outcomes that are often more appropriate." However, most of respondents indicated 
that surveys were often the most appropriate method of measurement. The succeeding paragraphs provide three detailed examples of Southern University Student Affairs units using surveys as assessment methods.

Firstly, the Physical Education (PE) unit's assessment plan and report indicated a reliance on a survey to measure whether or not "students applied the fundamentals of health-related fitness toward developing, maintaining, and sustaining active and healthy lifestyles [upon graduation]." In order to assess whether or not that articulated outcome was achieved, the PE unit surveyed a random sample of 1,500 alumni who graduated between 1997 and 2004. Alumni were asked to indicate their level of agreement on a Likert scale concerning their personal fitness habits. The response rate was $17.8 \%$ and a total of 267 surveys were completed and returned. Results indicated that most alumni were not exercising at least once a week. They cited "time" as the main reason for their lack of exercise. As a result, PE determined that it may need to focus more on "time management and exercise adherence," noting, "perhaps students learn how to develop but need more assistance in maintaining and sustaining an active lifestyle."

A second example of a unit using a survey to measure student learning was revealed by the Scholars Office assessment report. The Associate Director of this office explained that his unit measured students' reported knowledge gains after attending a series of lectures and presentations designed and implemented by student scholar assistants that featured Southern University faculty members. Presentations included:

- Ancient remedies and contemporary medical breakthroughs;

- Contemporary court cases and freedom of religion; and

- What if the requirements of love are not the requirements of the relationship? 
Students who attended the programs responded to a series of eight questions, reporting their perceptions on a scale of one (least positive) to five (most positive). The assessment report did not indicate the number of students who attended the events or the number of students who completed the surveys, thus the researcher was unable to determine a response rate.

A sample of the eight questions asked along with an average rating included:

- I gained a deeper understanding of the topic covered (4.6)

- I felt that I was able to express my ideas about the topic (4.3)

- The event increased my interest in the topic covered (4.3)

The purpose of that assessment was to measure whether or not student scholar assistants were "designing and implementing activities that inform scholars members about selected contemporary issues." As a result of the survey, the Scholars Office made the decision to continue with its first-time initiative where student assistants designed and implemented learning activities for the unit. Moreover, the unit planned to reassess this student learning outcome in the 2005-06 academic year.

A final example of using surveys to assess student learning came from Career Services, where that unit sought to assess students abilities to "create high quality resumes and other formats of job related communications" as a result of a resume or interviewing counseling workshop session. Students were given the opportunity to complete a Likert-scale survey at the conclusion of each workshop. Students were asked to rate their responses to three questions on a five point scale: $5=$ agree, $4=$ tend to agree, $3=$ neutral, $2=$ tend to disagree, and $1=$ disagree.

During the Fall 2004, 109 students responded to the career services survey. The reviewed assessment report did not indicate the number of students who participated in a counseling workshop; thus the researcher was unable to determine a student response rate. 
Results of the survey indicated that the average score of question number one: "I increased my understanding of how to write a resume with effective content" was 4.7. An average score of 4.7 was reported when students were asked if they "increased their understanding of how to present their skills, experiences, and education to employers on a resume." Lastly, an average score of 4.6 was reported when students were asked if they "increased their level of confidence to create or amend their resume." As a result of this survey, Career Services indicated that it would continue its indirect assessment method of student surveys, indicating no changes to the method or educational opportunities provided.

The second most reported method of assessment at Southern was observation $(18.8 \%)$. The Director of Assessment commented that "ROTC does a lot of observation, [using] very formalized rubrics to make decisions about quality." An examination of the Army Reserve Officer Training Corps assessment plan verified the Assessment Director's comments. In order to determine a student's ability to "effectively communicate in both oral and in written format as measured by their ability to appropriately develop and present information for a given target audience," Army ROTC developed appropriate matrices to measure sixteen student performances at their summer camp. Students were assessed while participating in "eight defined leadership opportunities as well as while they were followers during the 33 day camp." Results indicated that only one student was above average in achieving the desired outcomes, 12 students were average, and three students needed additional development. Army ROTC expected at least three more students would have achieved above average ratings on their matrix scales, thus their observation results prompted them to place "additional emphasis to the teaching of the individual elements contained within the matrices in the 100 and 200 level course." 
Furthermore, a specific example of a unit using observation as its data collection method was referenced in an assessment plan and report produced by the division's Centralized Box Office for the Visual and Performing Arts. That unit measured student employees' abilities to "become comfortable and confident handling a lot of problems on their own (following policy) without involving management." According to their assessment report, that articulated outcome was measured through observing student employees' abilities to process mail orders, indicating that "often orders are received with incomplete or incorrect information." Therefore, the unit wanted to assess whether or not student employees "were able to identify the problem, notify the client, and find a solution." The assessors informally observed five student employees during the Fall 2004 academic term to determine whether or not the outcome was achieved. Additionally, the assessors scheduled meetings with each of the student employees, providing them with the opportunity to reflect upon their job performance and ability to solve problems.

Of the 32 articulated learning outcomes within the assessment plans, only $9.4 \%$ of Southern's Student Affairs learning outcomes were measured using pre- and post-reflections, interviews, and document analysis. An example of using pre- and post-reflection as a method of assessment was revealed in the Center for Student Leadership, Ethics, and Public Service's assessment plan. In the plan, the center indicated that they would ask students to create pre- and post reflections regarding an alternative spring break trip, seeking to measure, for instance, students" "awareness of privilege in their personal life as a community member." However, no results or decisions were reported within the center's assessment report.

An example of using interviews coupled with document analysis as assessment methods was described in a plan and report produced by the division's Student Union Activities Board. In an attempt to measure students abilities to "articulate three personal goals that they will focus 
on developing over the course of the academic year accompanied by an action plan to accomplish these goals," after participating in a fall training session, students were asked to submit written evidence of their personal goals and achievements as well as sit down with their advisor for an informal reflective interview. The number of students who participated in the fall training and the number of students who completed the assessments were not indicated in the assessment report, thus the researcher was unable to determine a response rate.

According to reported Union Activities Board assessment results, "Advisors often spent time connecting dots for the students with the goal process and illustrating how to accomplish goals." Moreover, results indicated that students were more engaged and likely to discuss their goal setting strategies when advisors assisted them in "breaking the goals into manageable tasks that related to school, work, relationships, and events..."

As a result of the aforementioned assessments, the Union Activities Board recognized that advisors should spend more time assisting students in their goal development and their development of strategies to achieve those goals, and establish a formal process to "obtain, discuss and track goals." Moreover, it should be noted that the researcher was unable to find evidence that indicated specific changes to the formal fall training for students in an attempt to enhance goal setting strategies.

A review of these documents illustrated that the other methods of assessment reported in Southern University Student Affairs unit plans included post reflective journals, and pre- and post-tests. The least utilized methods of assessment included portfolio review, post-tests, focus groups, and grade point average comparisons (3.1\%). The Assistant Vice President of Student Affairs explained that some units are just beginning to explore the use of portfolios as an assessment method. She stated, "Some people don't understand what portfolios can do. I think 
that [they] will become more exciting once people understand [their uses], but we're not there yet." The researcher discovered that the one unit indicated the use of a portfolio as an assessment method to measure student leader's growth; although, that method of assessment was not implemented.

Southern University Student Affairs Assessment Collaboration

Most respondents cited evidence of collaboration of programming efforts, but were unable to do so when it came to actually developing or implementing assessment plans. However, two respondents referenced the same specific example of departmental collaboration between Multicultural Services and Greek Life. The Director of Multicultural Services described that collaboration.

We partner[ed] with Greek Life to do an assessment. We were assessing what out first year students knew about Greek letter organizations - what they believed to be true about hazing and rights of passage. The whole point of that was to educate our current Greek students on what first year students believe to be true, so that if we needed to dispel myths [we could do so based upon assessment data].

The director continued by explaining that the results of that collaborative assessment found that a third of surveyed students felt that hazing was acceptable, a third reported they were unsure if hazing was acceptable, and a third reported that hazing was unacceptable. She continued, "If two-thirds of your population either accepts [hazing] or is unsure or not if it is acceptable, that is a problem, especially when you talk about trying to prevent [hazing].” In response to these findings, Multicultural Services and Greek Life were working to dispel the myths of hazing through educational programs for active Greek members and first-year students 
at the time of this study. "We now have data that helps us educate our students... one thing we absolutely want to be sure of is that students know and understand that hazing is not acceptable." Other than the above example, the researcher did not find other examples of collaborative assessment planning and implementation. Although, one respondent commented that

I think that will change as people recognize what they are doing, and I think the [division-wide] objectives (which are explained in depth later in this chapter) are going to help us. That is going to help more with planning because people are going to be able to see what their peers are doing.

Additionally, the Director of Distance Education and Technology explained that the Director of Assessment was in the process of identifying commonalities across units' assessment plans in order to develop an "omnibus survey, so we can collaborate and reduce the amount of assessment measures that are floating around out there."

\section{Enhancing Student Learning Based Upon Southern's Student Affairs Assessment Results}

The researcher asked all respondents to share examples of how data and results were used to enhance student learning and development. Additionally, the researcher thoroughly examined authenticated assessment reports from the 2004-05 academic year.

According to all respondents, units were asked to submit assessment results to the assessment committee annually. Units were expected to include decisions they made based upon those results and next they identified the learning outcomes they plan to assess the following year. The Assistant Vice President explained, “They have to actually close the loop...they have to write out how they used that data and what they plan to assess in the following year." She continued, 
...some folks recognize that the data shows that they are actually accomplishing what they wanted to. Other times they recognize [they are not accomplishing what they wanted to]. For example, Campus Recreation found that $80 \%$ of the [students assessed] missed question number two on a rock wall climbing class quiz... they recognized that they were not conveying what they wanted and they modified their workshop based upon that [data].

Through document analysis, the researcher determined that a total of twenty decisions were included in the assessment reports. The majority (45\%) of those decisions involved units' plans to modify the program or service where student learning was assessed in order to enhance that learning; $35 \%$ indicated that the outcome was achieved and they would continue their current practices; and 20\% indicated that they could not determine whether or not their outcome had been achieved, because the method of assessment needed to be modified (see Table 12). It should also be noted that researcher discovered that $60 \%$ of the reported results included the unit's decision to reassess the articulated outcome.

Table 12

Types of Decisions Made by Southern University Student Affairs' Educators Based on 2004-05 Assessment Results

\begin{tabular}{lcc}
\hline Type of decision made based on assessment results & $\mathrm{N}=20$ & \% of decisions made \\
\hline Modify educational program or service & 9 & 45.0 \\
Continue same practices & 7 & 35.0 \\
Modify assessment instrument & 4 & 20.0 \\
\hline
\end{tabular}

Two explicit examples of how assessment data was used to enhance student learning were revealed during interviews. The first example, as described by the Director of Residence Life, involved an assessment of residence hall student desk workers' knowledge of quality 
customer service. To determine students' "knowledge of quality customer service," student employees completed a multiple choice test after being formally trained and after a few weeks of actually working at a residence hall front desk. The test included fourteen multiple choice procedural questions "concerning topics such as signing out temporary keys, submitting work requests, [and] assisting upset customers." After analyzing the assessment results, Residence Life identified nine questions where students were only correctly responding at a $63 \%$ to $84 \%$ rate, thus "indicating a need for improvement." As a result of this particular assessment, the Director of Residence Life explained, "We have really good data to base training for our desk workers and we are wanting to take the results of the assessment... and turn that into some computer training modules... we [have] a wealth of information that we can [use] to improve our training, which will hopefully improve the service of desk workers."

The second detailed example of how assessment data was used to enhance student learning that was described to the researcher came from the Director of Multicultural Services. She explained how she had assessed student learning in her unit before it was formally introduced to the division and described how her unit used data to completely change a preorientation program for African American Students where “...we tell them everything that is not told to them during [regular] student orientation in terms of how to navigate [their] way through the university — how to be successful at the university." According to the respondent, the unit compared first-semester grade point averages of those students who attended the summer preorientation session to those who students who attended a shorter pre-orientation session just before the beginning of the fall semester. Results indicated that those students who attended the summer pre-orientation session were earning higher grade-point averages as compared to those who attended the later session indicating a possible correlation. Moreover, results indicated that 
those African American students who did not attend a pre-orientation session at all were actually earning higher grade point averages as compared to those who attended the late pre-orientation session.

As a result of the data, the Director of Multicultural Services explained “...that told us that our late session was not being effective at all, so either we needed to get rid of it or revise it." The unit decided to revise the late pre-orientation session to "include the best of the best" of the summer pre-orientation session in the late session. After reassessing, the respondent explained that her unit discovered

Those who attended [the summer] session performed slightly lower than those who attended [the late session], but if you look that those two groups that attended a session, they outperformed, in a very statistically significant way, the student who did not attend [a session].

According to the Director of Multicultural Services, results of the reassessment indicated that they had made informed decisions based upon data that resulted in enhanced student learning. Moreover, she explained, "We are also using our [results] in marketing to say: 'this is a worthwhile program and this is why — this is why your son or daughter need to attend or this is why you need to attend."' As a result of using the results for marketing purposes, the respondent explained that their pre-orientation attendance has increased to now include nearly $77 \%$ of the African American new student population.

Evidence of enhancing student learning based upon assessment data was not limited to interview responses. A review of assessment reports revealed other examples of how units were using their assessment data to make informed decisions. For instance, when using a rubric and observing students' abilities to effectively communicate, Army ROTC reported that they "need 
to adjust [their] training and that students need to be better prepared to present information orally." Thus they made the decision to modify their training for the upcoming class of cadets.

Another example of where a decision was made to modify student training workshops was revealed in the Women's Center assessment report. The Women's Center measured students' abilities to demonstrate skills and knowledge to assist individuals who contacted their hotline. The assessed students had attended a two day training workshop to learn how to properly assist hotline callers. Attendees were assessed by completing a survey and through observation of role playing activities. Results indicated that students were not achieving the desired learning outcome; "therefore, the entire training has been restructured to allow the [student] advocates to learn from several different speakers from the counseling center, campus police, office of student conduct, etc..."

In addition to modifying training workshops, some units report using their results to modify programs. For instance, Talent Search was enhancing their services by providing after school tutoring for "identified at risk-students." Naval ROTC was encouraging student advisors "to be more aggressive in identifying struggling students and targeting them for study hall and more frequent progress reports." Student Health Services was enhancing its educational outreach efforts in order to help students make informed decisions to get flu and meningococcal disease vaccinations.

Southern University Student Affairs Assessment Successes and Challenges

Respondents were asked to reflect upon what they viewed as the successes and challenges of Southern University's Student Affairs assessment efforts. An overwhelming majority (75\%) discussed a positive shift in attitude towards assessment among the division's educators as a success (see Table 13). The Director of Assessment stated, "I believe that most 
people actually understand why it is we're doing it and believe it to a certain level. They will continue to struggle with how to make it happen in terms of resources... but it is definitely a success." The Assistant Vice President explained, "People recognize the value of assessment. It is exciting as people are building new programs, building workshops and services and new activities and they are starting to think automatically, 'How am I going to assess that?'” Moreover, the Director of Distance Education and Technology explained that her personal view of her own unit has changed because of assessment specifically. She sated, "Having to engage in the assessment planning and reporting process has allowed me to reframe what my unit is all about." 
Table 13

Southern University Student Affairs Interview Respondents' Reported Assessment Successes

\begin{tabular}{lcc}
\hline \multicolumn{1}{c}{$\begin{array}{l}\text { Interview Responses: } \\
\text { Success of assessing student learning outcomes }\end{array}$} & $\begin{array}{c}\text { Number of } \\
\text { Responses } \\
\mathrm{N}=17\end{array}$ & $\begin{array}{c}\text { \% based upon } \\
\text { number of } \\
\text { respondents } \\
\text { (N=8) }\end{array}$ \\
\hline $\begin{array}{l}\text { Student Affairs educators are embracing assessment and } \\
\text { seeing the value in assessing student learning }\end{array}$ & 6 & 75.0 \\
$\begin{array}{l}\text { Creation of systematic data collection strategies within } \\
\text { division }\end{array}$ & 2 & 25.0 \\
$\begin{array}{l}\text { Student affairs educators are now making decisions based } \\
\text { upon data }\end{array}$ & 2 & 25.0 \\
$\begin{array}{l}\text { The student affairs division has created division-level } \\
\text { objectives }\end{array}$ & 2 & 12.5 \\
$\begin{array}{l}\text { Student affairs educators are finding assessment to be an } \\
\text { enjoyable process }\end{array}$ & 1 & 12.0 \\
$\begin{array}{l}\text { Student affairs educators are providing students with an } \\
\text { opportunity to express their learning }\end{array}$ & 1 & 12.5 \\
$\begin{array}{l}\text { Student affairs educators are naturally, without a mandate, } \\
\text { beginning to link planning and assessment together }\end{array}$ & 1 & 1 \\
$\begin{array}{l}\text { Student affairs educators are finding assessment to be an } \\
\text { engaging process } \\
\text { Potential new student affairs employees are being asked about } \\
\text { being hired }\end{array}$ & & 12.5 \\
\hline
\end{tabular}

In addition to an attitude change occurring within the division, two respondents cited the creation of systematic data collection strategies within the division as a success. The Associate Director of the Scholars Office explained that “.... asking people to be a little bit systematic in thinking about what they do has been pretty successful." The Director of Multicultural Services agreed stating, "The more we know, the better we can do our job in an objective way. To me, 
any time you learn something, whether it be positive or negative, it is a success, because [the data] tells you something you didn't know before."

Two respondents described decision making based upon assessment data as a success. For instance, the Director of Residence Life explained that her unit was "really proud of getting a handle on customer service levels of student desk workers" allowing the unit to reframe its training to enhance the knowledge of student desk workers. Furthermore, two respondents described the creation of division level learning objectives as a success. Both the Directors of Assessment and of Distance Education and Technology described the creation of division-wide learning objectives as the "biggest success."

Those ten division level learning objectives were the first broad statements of learning across the division. The objectives were in draft format at the time of this study and were born out of the institution's goals, student affairs unit objectives, a brainstorming activity that involved the division's Vice President, the university's general education objectives, and the missions and visions of the institution and division. Moreover, the Student Affairs assessment committee had the opportunity to provide feedback. According to the drafted document, the Student Affairs broad learning objectives were:

1. Contribute to the intellectual development, academic success, and persistence to degree of our students.

2. Nurture the social, emotional, and cognitive dimensions of student learning and development.

3. Promote an inclusive environment by supporting a diversity of people, cultures, and perspectives.

4. Challenge and support students as they engage in self-exploration in pursuit of selfknowledge.

5. Facilitate the development of leadership skills. 
6. Help students maximize their potential as responsible and ethical citizens, leaders and professionals.

7. Provide support to students and the community during times of crisis.

8. Encourage a physically active and healthy lifestyle.

9. Cultivate creativity and self-expression.

10. Foster communities rich in the arts.

While those broad objectives were new to the division, the Assessment Director explained that units will be expected to align their learning outcomes with these objectives, if appropriate. Specifically, one respondent explained that the creation of these objectives gave the educators within the division "...something to put our hands on that we can use to frame what it is that we are trying to do, how the different outcomes that people are articulating roll up to make the division a success and to create the student experience we want them to have."

In addition to the newly articulated division-wide leaning objectives, $12.5 \%$ of respondents cited other successes including: the belief that Southern University Student Affairs educators were finding assessment to be an enjoyable and engaging process; Student Affairs educators were providing students with an opportunity to express their learning; and potential new employees were being asked about their knowledge of assessment. A Program Coordinator in the Theatre Program explained, "We have finally given students an opportunity to speak up about what they weren't getting out of our program... we actually have been forced in this to move back and consider student services."

A final success that was mentioned by the Director of Assessment was that Student Affairs educators were naturally, without a mandate, beginning to link planning and assessment together. The Director of Assessment explained that “...the last set of [assessment] plans got wildly out of control... some of them got enormous... they were starting to use it as a strategic 
planning document. It is a sign to me that they were thinking about this stuff and they were linking planning and assessment." As a result of units beginning to link strategic planning and assessment together, the Director of Assessment was recently asked to coordinate the division's planning process in addition to her assessment duties. Because guiding the division's planning was a new responsibility to the director of assessment, she admitted that she was just figuring out "how we can reorganize... based on how we can use information." However, she did explain that requesting funding for new initiatives always required a plan. She believed that units would, in the future, be required to demonstrate how they would assess student learning, programs, and services within future budget request plans.

Respondents were asked to describe the challenges of Southern University's Student Affairs assessment initiative. The majority of respondents (75\%) said that finding the time to develop assessment plans, implementing those plans, and reporting the results was a challenge, and $62.5 \%$ indicated that limited financial resources created a challenge (see Table 14). The Assistant Vice President explained that for"... assessment, to be done correctly and to document everything, takes a fair amount of time, and if you have a one or two person [unit], that can be very very difficult... very very hard.” The Associate Director of the Scholars Office concurred with the Assistant Vice President explaining that scarce resources limit the number of staff members in his office, thus they were unable to spend as much time on the assessment planning process as they would prefer. He continued by explaining that they still assessed student learning, "captur[ing] what we can based on our structure." 
Table 14

Southern University Student Affairs Interview Respondents' Reported Assessment Challenges

\begin{tabular}{lcc}
\hline \multicolumn{1}{c}{$\begin{array}{l}\text { Interview Responses: } \\
\text { Challenges of assessing student learning outcomes }\end{array}$} & $\begin{array}{c}\text { Number of } \\
\text { Responses } \\
\mathrm{N}=20\end{array}$ & $\begin{array}{c}\text { \% based upon } \\
\text { number of } \\
\text { respondents } \\
(\mathrm{N}=8)\end{array}$ \\
\hline Time constraints & 6 & 75.0 \\
Limited financial resources & 5 & 62.5 \\
Limited assessment expertise within units & 25.0 \\
$\begin{array}{l}\text { Assessment is not a priority to everyone within the student } \\
\text { affairs division }\end{array}$ & 25.0 \\
$\begin{array}{l}\text { Difficult to get students to complete assessments } \\
\text { Lack of collaboration }\end{array}$ & 1 & 12.5 \\
$\begin{array}{l}\text { Do not celebrate successes } \\
\text { New employees are not provided with assessment } \\
\text { professional development }\end{array}$ & 1 & 12.5 \\
Difficult to share results with external audiences & 1 & 12.5 \\
\hline
\end{tabular}

One quarter of respondents indicated that the narrow amount of assessment expertise within the units was a challenge. The Associate Director of the Scholars Office commented, "None of us, with the exception of [the director of assessment] is in the [assessment] business...so writing learning outcomes [and] coming up with instruments that measure these things is challenging." Moreover, the Director of Multicultural Services stated that it "is really hard for a lot of folks, so I would say [assessment] expertise within their office is a challenge.” Additionally, $25 \%$ of respondents believed that assessment was not a priority to everyone within the division, with the Director of Assessment stating, "There are people who don't want to do it. This just isn't a priority to them. There is always going to be that." Additionally the Director of 
Distance Education and Technology explained that "there are going to be those individual pockets of people or units... who have been resistant to this, and they resist this because they may be apathetic [and/or] they don't necessarily believe this is useful..." Although the Director of Assessment continued by explaining that the assessment committee "...tries to focus on the positives; work with people who give them what they need; and help them... to move forward." The least mentioned challenges (12.5\%) included the difficulty in getting students to complete assessments; the lack of assessment collaboration within the division; the lack of celebrating assessment successes; the lack of assessment professional development for new Student Affairs employees; and the difficulties of sharing assessment results with external audiences." A Program Coordinator in the Theatre Program who was not a member of the assessment committee stated, "I think [we should have] more sharing of information, processes, successes, failures, what works and what doesn't, how to do things...." The Director of Campus Activities stated, "I think it is time after three years for us to celebrate what we have accomplished."

Respondents also reflected upon what they believed would enhance their assessment efforts. Three respondents reported that efforts would be enhanced by sharing of information. For instance, the Director of Multicultural Services commented that most units only share results and decisions with the committee, she continued, "I would like the ability to share information; share our best practices; share what is working here with other institutions." Another respondent who was not a member of the assessment committee explained that she would like to see more sharing within the division, describing a fear of over-assessing students. She stated that it was difficult "not knowing what other units want to assess and if [their assessments] have an impact on our [students]." 
Three respondents also reported the need to enhance assessment resources within the division, suggesting the division should hire additional staff to support the effort or provide units with additional funding to enhance their efforts. The Assistant Vice President stated that the Director of Assessment needed additional support, especially since the director would be leading the initiative to combine planning and assessment. The respondent continued, "If I had my way, we would hire an assistant director for [the Director of Assessment]. If I could hire a staff for her, I would do that in a heartbeat, but resources are limited." Likewise, the Director of Assessment explained that Southern University's Student Affairs assessment efforts could be enhanced by hiring additional staff in her office. She continued, "I would hire a couple of more people, including a statistician, because I'm not a statistician." The director felt that additional staff would allow her time to sit down with units once assessment results were gathered and assist each with decision making based upon those results. She stated, "I think people miss things, or don't get to the [analysis] part... data gets put on a shelf until at least the next report comes due." In addition, the Associate Director of the Scholars Office believed that the division was "at the point [where] there are opportunities for more collaboration." However, he acknowledged that the Director of Assessment was "only a single person" providing support to the entire division.

\section{Summary of Findings}

The assessment of student learning outcomes within Southern University's Student Affairs Division began with the need to adhere to accreditation requirements and the division's desire to demonstrate its contribution to student learning. As a result, Student Affairs committed resources to an assessment initiative partnering and then modeling its work after the institution's Academic Affairs Division. 
Assessment of learning outcomes at Southern was a decentralized process. Each unit was expected to develop assessment plans, implement those plans, and make informed decisions based upon assessment data. Unit's efforts were supported by a full-time Director of Assessment and a voluntary assessment committee that met monthly.

Student Affairs units articulated learning outcomes in annual plans that were submitted to the assessment committee for review. The majority of these outcomes were categorized within the cognitive taxonomy with fewer categorized within the affective taxonomy. The majority of outcomes were assessed indirectly with students completing surveys. However, evidence of other methods, including observation, document analysis, pre- and post-tests, just to name a few, were also being used by Southern University Student Affairs educators to measure learning.

The study revealed very little evidence of collaboration when planning and implementing assessments. Only one example of departmental assessment collaboration was revealed. However that one collaborative experience provided useful data, allowing Multicultural Services and Greek Life to develop programs to dispel myths about hazing rituals. Non-collaborative assessment efforts were also producing results that units were using to enhance student learning. The majority of results were used to make programmatic changes and to reassess whether or not those programmatic changes enhanced future student learning.

The most reported success of Southern's assessment efforts was a more positive attitude towards assessment. However, limited resources and time constraints continued to provide challenges for Southern University Student Affairs educators. 


\section{Chapter Six}

\section{Western University}

\section{Institutional Background}

Western University, located in the Pacific Northwestern portion of the United States, is classified by the Carnegie Foundation (2005) as a Research I—Extensive institution. According to Western's website, the institution is situated in a town of 50,000 and is within 90 miles of a major metropolitan city. Initially, Western was founded as a private academy in 1858 and was later designated as the state-assisted agricultural college in 1868 , thus becoming the state's land grant institution. Sea grant and space grant designation came later, making Western University one of only six institutions to have all three titles (Western University website, 2005).

According to the most recent report available on Western University's Institutional Research website, Fall 2004 undergraduate enrollment totaled 19,159, with 15,412 undergraduate students and 3,006 graduate students and 741 students taking classes but not fully admitted to the university. Roughly eighty percent of those students are considered in-state residents and nearly fifty-three percent of those students are male and forty-seven percent female. Minorities account for approximately fourteen percent of the total student body, and 944 international students are enrolled at Western University. Students come from all 50 states and more than 90 countries. The institution, which is fully accredited by the Commission on Colleges of the Northwest Association of Schools and Colleges, employs almost 4,000 individuals including 635 faculty members. Western offers 73 undergraduate degree programs, 22 master's degree programs, 42 doctoral degree programs, as well as 10 certificate programs. Academic departments are organized into 10 colleges, along with the graduate college and the honors college (Western University Institutional Research website, 2005). 
According to its mission statement, Western University "aspires to stimulate a lasting attitude of inquiry, openness, and social responsibility... [by] excellent academic programs, educational experiences and creative scholarship." In order to guide its effort, the institution fosters five core values "fundamental to success" that include:

1. Accountability: Demonstrated by committed stewards of the loyalty and good will of alumni and friends and the human, fiscal, and physical resources entrusted to the institution.

2. Diversity: Demonstrated by the recognition that diversity and excellence go hand-inhand, enhancing teaching, scholarship, and service as well as the institution's ability to welcome, respect, and interact with other people.

3. Integrity: Demonstrated by the practice of honesty, freedom, truth and, integrity in all that the institution does.

4. Respect: Demonstrated by treating others with civility, dignity, and respect.

5. Social responsibility: Demonstrated by a contribution to society's intellectual, cultural, spiritual and economic progress and well-being to the maximum possible extent (Western University website, 2005).

\section{Mission Statement for Western University Student Affairs}

Western University Student Affairs' mission statement flows directly from the institution's mission statement. Specifically, the Student Affairs' mission statement focuses on a context statement of how it contributes to "simulate[ing] a lasting attitude of inquiry, openness and social responsibility." An excerpt from that statement reads:

As a division, we will position ourselves to be learners and leaders in a dynamic educational and social environment. We choose to empower students to pursue their best possible futures and we contribute to our institution in a way that supports achievement of its desired outcomes (Western University website, 2005). 
Western University Student Affairs has also integrated five core values into its mission to direct its work that are "reflective of and complementary to the values and mission" of the institution. Those core values, along with a brief description include:

1. Knowledge: To foster an academic environment founded on intellectual freedom, creativity, and the pursuit, elaboration, and application of knowledge, the division collaborates with teaching and learning partners.

2. Humanity: Student affairs is inclusive and compassionate; honoring and upholding diversity, civility, and dignity.

3. Responsibility: Student affairs professionals are stewards of Western University's community and its human, intellectual, fiscal, and physical resources.

4. Integrity: Student affairs is dedicated to wholeness, honesty, and maintaining congruence with its stated values.

5. Community: The student affairs division is a caring and responsible community whose members are engaged, nurtured, stimulated, and sustained.

To guide Student Affairs in its efforts to achieve its mission, the division is led by a Vice President. Unlike, Southern University's top-to-bottom flow chart, Western University's Student Affairs organizational chart is structured in a semi-circle. The Vice President of ten years supervises 14 units that would traditionally be found in an institution's student affairs division, such as Residential Education, Recreational Sports, Student Union, Student Support Services, Student Health Services, and Services for Students with Disabilities. Western University's Student Affairs structure does not include any Associate or Assistant Vice Presidents. However, two of the fourteen unit leaders within the division are responsible for supervising sub-units. For instance, the Dean of Student Life is responsible for overseeing such sub-units as Diversity Development, Greek Life, and Student Conduct, while the Director of Enrollment Management oversees such sub-units as Admissions, Financial Aid, and the Registrar's Office (Western University Student Affairs website, 2005). 


\section{Study Participants}

The researcher interviewed eight Western University student affairs educators for approximately one hour during late October, 2005 for this study. Like Southern University, participants at Western University were purposefully selected with the guidance of the division's director of assessment, who served as the liaison for this study.

At Western university, the researcher interviewed the Vice President of Student Affairs; the Director of Student Affairs Assessment, who served as the liaison for this study and leads the division's assessment committee; and three members of the assessment committee, including an Assistant Director of Residence Life, a Career Services Program Coordinator, and an Assistant Director of Student Health Services. Moreover, the researcher interviewed three non-assessment committee members that included the Director of Students with Disabilities, the Dean of Student Life, and a Recreational Sports Program Coordinator.

Six of the eight interview respondents were female and two were male. All but one of the respondents described his or her race as Caucasian, with the Vice President describing his race as African American. At the time of the site visit, four of the respondents held doctoral degrees, three respondents held Master's degree, and one respondent's highest level of education was a Bachelor's degree. The average length of respondents' employment in their current positions at Western University was almost seven years (see Table 15). 
Table 15

Western University Interview Respondents

\begin{tabular}{|c|c|c|c|c|c|c|}
\hline Participant & Position & Education & Gender & Race & $\begin{array}{c}\text { SA } \\
\text { Assessment } \\
\text { Committee } \\
\text { Member }\end{array}$ & $\begin{array}{l}\text { Length of } \\
\text { Employ- } \\
\text { ment in } \\
\text { Current } \\
\text { Position }\end{array}$ \\
\hline 1 & $\begin{array}{c}\text { Vice } \\
\text { President }\end{array}$ & $\mathrm{PhD}$ & Male & $\begin{array}{c}\text { African } \\
\text { American }\end{array}$ & & $10 \mathrm{yrs}$ \\
\hline 2 & $\begin{array}{c}\text { Unit } \\
\text { Director, } \\
\text { Assessment } \\
\text { Office }\end{array}$ & $\mathrm{PhD}$ & Female & Caucasian & $X$ & $3 \mathrm{yrs}$ \\
\hline 3 & $\begin{array}{l}\text { Unit Asst. } \\
\text { Director, } \\
\text { Res. Life }\end{array}$ & MA & Male & Caucasian & $X$ & $6 \mathrm{yrs}$ \\
\hline 4 & $\begin{array}{c}\text { Unit } \\
\text { Program } \\
\text { Coordinator, } \\
\text { Career } \\
\text { Services }\end{array}$ & $\mathrm{BA}$ & Female & Caucasian & $X$ & 8 yrs \\
\hline 5 & $\begin{array}{l}\text { Unit Asst. } \\
\text { Director, } \\
\text { Student } \\
\text { Health }\end{array}$ & $\mathrm{PhD}$ & Female & Caucasian & $X$ & $5 \mathrm{yrs}$ \\
\hline 6 & $\begin{array}{c}\text { Unit } \\
\text { Director, } \\
\text { Students } \\
\text { with } \\
\text { Disabilities }\end{array}$ & $\mathrm{PhD}$ & Female & Caucasian & & $15 \mathrm{yrs}$ \\
\hline 7 & $\begin{array}{c}\text { Dean, } \\
\text { Student Life }\end{array}$ & MA & Female & Caucasian & & $\begin{array}{l}2.25 \text { yrs } \\
\text { (2 yrs as } \\
\text { interim) }\end{array}$ \\
\hline 8 & $\begin{array}{c}\text { Unit } \\
\text { Program } \\
\text { Coordinator, } \\
\text { Rec. Sports }\end{array}$ & MA & Female & Caucasian & & $5 \mathrm{yrs}$ \\
\hline
\end{tabular}




\section{History of Western University Student Affairs Assessment Efforts}

Western University's initial assessment efforts were born out of what the Vice President described as “ ... conversations about student success... trying to figure out the added value our leadership [has] on the university" in 1995. These conversations, which formally began among Student Affairs professionals led to what the division refers to as the "Campus Compact" (Western University Student Affairs website, 2005).

The Campus Compact was essentially a strategic planning document produced by a committee within the division in 1996. The document originally included five significant areas the division collectively agreed it needed to focus upon in order to enhance students' successes, as previously referenced by the Vice President of the division. These five areas of focus included commitments to: (1) strengthen the co-curriculum, (2) support students' transition needs, (3) enhance the learning environment, (4) provide comprehensive professional development for the division, and (5) develop on-going assessment plans (Western University Student Affairs Assessment website, 2005).

Thus, in 1996 the Vice President created a voluntary Student Affairs assessment committee that worked "...to implement a comprehensive, on-going assessment program to measure student and staff perception, assess needs, and establish baselines for staff performance and Student Affairs services." However, as the Director of Assessment explained, during the 2001-02 academic year, Western University Student Affairs “....began moving into learning outcomes, I think, because that's the way in which the assessment field [had] moved." She continued to explain that in the mid-1990s, the assessment committee brought consultants to Western's campus to discuss assessment. She explained, 
...they weren't really talking a whole lot about learning outcomes. They were talking about services and improving services... When we first started talking about [assessment], it was really looking at sort of service or business outcomes. How many hamburgers did we sell? How many coffee drinks and how much money was collected? Who were our participants in activities?

As assessment literature evolved, so did the efforts of Western University Student Affairs. When respondents were asked to reflect upon the reasons why their division began assessing learning outcomes, one-half (50\%) of the respondents explained that the division wanted to learn how to do a better job educating students. For instance, the Assistant Director of Residence Life, who chaired the assessment committee from 1995 until 2001—the time when a full-time Director of Student Affairs Assessment was hired, explained, "I think what drove [us to examine learning outcomes] was the idea that we are very busy people, and we want[ed] to get to a point where we under[stood] for ourselves... that what we do makes a difference." Moreover, the Director of Services for Students with Disabilities explained, “...we should be able to find out what students know, think, and what they are getting out of our services" (see Table 16).

As previously described by the Director of Assessment, the division also began assessing learning outcomes because assessment literature began calling for student affairs units to examine their contributions to student learning. In addition to the Director of Assessment, two other respondents specifically cited this as a reason their division began assessing learning outcomes. The Director of Services for Students with Disabilities explained, "I think it is just a movement of the field...." The Dean of Student Life further elaborated, "I would say our division tends to be very aware of current practices." She continued, "Our style tends to be if we have some work we need to do... first we need to learn." She went on to explain, for instance, 
that more than ten members of the assessment committee were sent to a conference in North Carolina to learn about assessment. Thereafter, the division, under the guidance of the Director of Assessment and the assessment committee, hosted a two-day, on-campus assessment symposium for the entire university and brought assessment scholars, such as Drs. Marilee Bresciani and Peggy Maki to campus to assist in enhancing the institution's assessment knowledge and Student Affairs efforts in creating learning outcomes assessment plans. The information provided by the Dean of Students and confirmed by the Vice President of Student Affairs and the Director of Assessment indicated to the researcher a high level of financial resource commitment from the Vice President of Student Affairs in regard to learning outcomes assessment.

Two respondents also indicated that the division began assessing learning outcomes to better align itself with the intuition's mission. A Program Coordinator for Career Services explained that articulating and assessing learning outcomes “...weds us better to the academy, because it is an academy of learning." Likewise, two respondents indicated the purpose of assessing learning outcomes was to justify the division's efforts to external stakeholders. The Director of Services for Students with Disabilities stated that assessing learning outcomes allows the division to provide "... more justification about what we do and why we do it." Additionally, the Vice President stated, "I think there was always in the back of [our] subconscious that learning outcomes [were] an important issue to accreditors... but it wasn't explicitly stated." He went on to explain that accreditation was not used as a means of motivating division-wide assessment efforts. He cited one of the reasons that the division began assessing learning outcomes was to enhance the division's planning efforts. 
Table 16

Western University Interview Responses: Reason Student Affairs Began Assessing Learning Outcomes

\begin{tabular}{lcc}
\hline Reason division began assessing learning outcomes & $\begin{array}{c}\text { Interview response: } \\
\text { responses } \\
\text { N=11 }\end{array}$ & $\begin{array}{c}\text { \% based upon number of } \\
\text { respondents (N=8) }\end{array}$ \\
\hline To learn how to do a better job educating students & 4 & 50.0 \\
$\begin{array}{l}\text { Assessment literature moved in the direction of } \\
\text { assessing learning outcomes, not just student } \\
\text { satisfaction }\end{array}$ & 3 & 37.5 \\
$\begin{array}{l}\text { To better align division with the institutional mission } \\
\text { To justify purpose to external stakeholders }\end{array}$ & 2 & 25.0 \\
To enhance the division's planning efforts & 2 & 25.0 \\
\hline
\end{tabular}

In addition to being asked why the division began assessing learning outcomes, respondents were asked to reflect upon what they viewed as the purpose of assessing learning outcomes. Table 17 illustrates that the majority (75\%) of respondents believed that the main purpose was to show evidence that the units in the division were contributing to the institution's mission of student learning. The Director of Assessment explained

One of the things that we know and we have known for a long time in Student Affairs is that what happens outside of the class is very important to students and often times it can be life changing for students. We know students don't just learn math in the classroom, but they learn over time and as they make meaning of things. [Making meaning] can come as they begin to tutor other students... or as they work in somebody's office and use Excel and have to put formulas into that program... or while they are serving as a club treasurer. 
Five $(62.5 \%)$ of respondents indicated that the purpose of assessing learning outcomes was to validate the division's existence within the institution. The Assistant Director of Student Health elaborated, "If we are [going] to be considered a viable part of the function of the university, I think we definitely [have] to show that what we do makes a difference in students time at the university, and to do that we have to show data." However, the Vice President commented, "I am not interested in learning outcomes that only serve to preserve the unit or to justify that unit's existence. I want outcomes that reinforce our presence at the university and the value that we bring to the overall university mission.” The Director of Assessment agreed. She stated,

We have always framed this in terms of learning for improvement, not to justify [a unit's existence], not to prove [a unit] is the best or the worst. [This is for] units to use for improvements and document how they are making decisions for improvements. In addition to validation, the Dean of Student Life indicated that the purpose of assessment was to give intention or to provide direction to the work of units within the division. She stated, "You have to know where you are trying to go. It's not just about students just feeling good from our programs. We need to think about the curriculum. What do we want students to be able to do out there as a result of their experiences with us in here?" 
Table 17

Western University Interview Responses: Purpose of Assessing Learning Outcomes

\begin{tabular}{lcc}
\hline \multicolumn{1}{c}{$\begin{array}{c}\text { Interview response: } \\
\text { Purpose for assessing learning outcomes }\end{array}$} & $\begin{array}{c}\text { Number of } \\
\text { responses } \\
\text { N=12 }\end{array}$ & $\begin{array}{c}\text { \% based upon } \\
\text { number of } \\
\text { respondents (N=8) }\end{array}$ \\
\hline $\begin{array}{l}\text { To show evidence that the units in the division are } \\
\text { contributing to the institution's mission of student } \\
\text { learning. }\end{array}$ & 6 & 75.0 \\
To validate the division's existence within the institution. & 5 & 62.5 \\
$\begin{array}{l}\text { To give intention/provide direction to the work of units } \\
\text { within the division }\end{array}$ & 1 & 12.5 \\
\hline
\end{tabular}

As previously explained, the division formally began discussing learning outcomes assessment efforts in the 2001-02 academic year (see Table 18). It should be noted that the researcher combined the accomplishments from 1995-2001 because those initial assessment efforts were focused on satisfaction and benchmarking. However, as a result of those initial activities, the assessment committee recognized a shift in the field of assessment from measuring satisfaction to measuring student learning. Therefore, that assessment committee twice recommended to the Vice President that the division hire a full time Director of Student Affairs Assessment to guide the division in its efforts measure student learning outcomes. During the 2001-02 academic year, a full time director of assessment was hired to assist units and the assessment committee as described by the Vice President of Student Affairs. 
Table 18

Western University Student Affairs Assessment History and Progress

\begin{tabular}{|c|c|}
\hline Academic Year(s) & Activity \\
\hline $1995-2001$ & $\begin{array}{l}\text { - Student Affairs identified assessment as one of } 5 \text { key initiatives for the } \\
\text { division. Efforts initially focused on satisfaction and benchmarking. } \\
\text { - Student affairs created a voluntary assessment committee. } \\
\text { - Assessment committee produced a brochure that outlined the } \\
\text { assessment process for units and best assessment practices for the } \\
\text { division. } \\
\text { - Assessment committee proposed the establishment of a Director of } \\
\text { - Student Affairs Assessment position. } \\
\text { Assessment committee members attended assessment training } \\
\text { provided by NASPA }\end{array}$ \\
\hline $2001-02$ & $\begin{array}{l}\text { - Student Affairs hired a full-time Director of Assessment to support to } \\
\text { student affairs units and the assessment committee in efforts to move } \\
\text { from solely measuring satisfaction to measuring learning outcomes. }\end{array}$ \\
\hline $2002-03$ & $\begin{array}{l}\text { - Student Affairs assessment website created. } \\
\text { - Student Affairs Assessment Director produced first quarterly } \\
\text { newsletter for entire institution. } \\
\text { - A new charge focused on learning outcomes was issued to the } \\
\text { assessment committee. }\end{array}$ \\
\hline 2003-04 & $\begin{array}{l}\text { - Few student affairs articulated learning outcomes in assessment plans. } \\
\text { - Student affairs assessment committee hosted a two-day assessment } \\
\text { symposium with a nationally known assessment experts. } \\
\text { - Assessment committee created template for units to use when planning } \\
\text { and reporting assessments. } \\
\text { - Student Affairs conducted a series of five assessment workshops for } \\
\text { units to assist each in the assessment process. }\end{array}$ \\
\hline 2004-05 & $\begin{array}{l}\text { - Those units who articulated learning outcomes in 2003-04 reported } \\
\text { results. } \\
\text { - The majority of units submitted assessment plans, with nearly one-half } \\
\text { articulating learning outcomes in those plans. }\end{array}$ \\
\hline $2005-06$ & $\begin{array}{l}\text { - Student Affairs units submitted results from 2004-05 assessments. } \\
\text { (These documents were unavailable for review at the time of this } \\
\text { study.) } \\
\text { - Assessment committee produced an assessment handbook for the } \\
\text { division. } \\
\text { - Student Affairs division adopted six broad learning goals. }\end{array}$ \\
\hline
\end{tabular}




\section{Western University Student Affairs Assessment Process and Individuals Involved}

Like Southern University, many individuals were engaged in Western University's Student Affairs assessment efforts, because the division's assessment efforts were primarily decentralized. The majority of respondents indicated that the Vice President provided the overall leadership for the assessment initiative. However, the Vice President explained that his leadership style, as indicated by the organizational structure, was team oriented. He continued to explain that the assessment committee was primarily in charge of leading the initiative. $\mathrm{He}$ described that committee as an "incredible [and] intensive [group] that learns to work together, play together, and willing to vision together." The Director of Assessment explained that the "Vice President is very supportive and has been very clear that assessment is something we are going to do as a division... it is valued and he has supported the assessment council." The Director of Assessment continued, "[the assessment committee] is leading the effort, so there has been clear support at the [Vice President's] level including that we have opportunities to travel to conferences for our training, purchasing of books, and things that we might need to learn."

The only full-time professional staff within the assessment unit is the director. Like Southern University, the director does not have any support staff such as an administrative assistant or secretary. The Vice President explained that the Director of Assessment reports directly to him and described her role as the "convener and facilitator of the [assessment committee]." The director's responsibilities, according to her official job description were to "provide leadership for the coordination and dissemination of data gathered by Student Affairs units and offices. Dissemination will take the form of reports, a web site, and newsletters." Specific responsibilities of the director included in her job description were:

- Maintain on-going communication with assessment coordinators within Student Affairs units; 
- Monitor and catalog unit level assessment plans and activities;

- Act as a central coordinating agent for data gathered by Student Affairs units;

- Aggregate data gathered by Student Affairs units into a report to illustrate the division's performance in the areas of research and assessment;

- Coordinate Student Affairs' university-wide research activities;

- Prepare various reports an newsletters as a way of sharing important findings with faculty, staff, students, and parents;

- Facilitate discussions within appropriate groups in order to advance Division of Student Affairs assessment initiatives;

- Attend Student Affairs department heads meetings; and

- Coordinate response to data requests made of the Division of Student Affairs (Western University Student Affairs Assessment Director's official job description, 2005).

At the time of this study, the assessment committee, chaired by the Director of Assessment, included at least one volunteer from each of the 14 units within the division; however, each meeting was open to anyone who wanted to attend. The Director of Assessment explained, "The [committee] is made up of anyone in the division who wants to be on it, including graduate students in the college student services administrative program.” According to the Student Affairs assessment website (2005) the group consisted of 20 members during the 2002-03; however, that group has grown to include 37 members for the 2005-06 academic year. The Director of Assessment explained that not all members attended every meeting. She stated, "We meet twice a month for an hour-and-a-half... we meet through the summer once a month depending on the project and we are working on... maybe twice a month. Everyone is responsible for what the group puts out to the division in terms of expectations." She explained that the committee's work was ongoing and didn't halt if a member was not present at a meeting. 
She stated, "The agreement is... we don't stop and wait for [them] to come and make decisions. We work with who is there. We send out minutes so [they] know what happened..."

The assessment committee provided leadership and direction for the entire division, and their primary charge "is to establish and monitor the assessment agenda for Student Affairs and other collaborating units” (Western University Student Affairs Assessment website, 2005).

According to the Student Affairs assessment website (2005) specific responsibilities of the committee included:

- Guiding division-wide assessment projects;

- Implementing a cohesive and coordinated assessment program across Student Affairs units;

- Implementing specific assessment projects;

- Establishing approaches to share and maximize the use of resources across Student Affairs units;

- Implementing assessment planning, reporting, and evaluation of assessment efforts, including providing feedback to departments on their assessment plans and activities;

- Developing mechanisms to monitor the degree to which and the manner in which assessment results are being used to improve programs and services;

- Monitoring the level of assessment activity;

- Providing reinforcement and support for assessment efforts - design a reward structure;

- Establishing a standard format for unit level assessment annual reports, which will be integrated into a Division of Student Affairs assessment report;

- Identifying a set of common set learning outcomes and areas of impact that are common to and will be assessed by all units;

- Functioning as a learning community -one that consistently advances its own learning and uses its acquired knowledge to consult with individuals and groups; and 
- Ensuring that a structure is in place that will produce a common data reporting structure, that all departments have assessment plans, that plans are implemented, that results are reported, and that results are applied to continuous improvement efforts.

Some of the major accomplishments of the assessment committee, revealed through interviews included the creation of a standard assessment planning template for units and the creation of a 42-page assessment handbook for the division that included best assessment practices, useful assessment planning and reporting templates, and suggested assessment resources for gaining a greater understanding of learning outcomes assessment. The committee hosted an on-campus, two day assessment symposium to enhance the level of assessment knowledge on Western's campus.

As briefly stated earlier in this chapter, the two-day symposium was open to anyone on Western's campus and included sessions and workshops with assessment scholars Drs. Marilee Bresciani and Peggy Maki. According to Western's Student Affairs Assessment Director, units within the division also had the opportunity to email their assessment plans to Dr. Bresciani prior to the symposium. By doing such, Dr. Bresciani had time to review the plans prior to the event. She then provided her expertise on how individual units could enhance their assessment plans during the symposium.

According to all respondents, one of their major tasks of the assessment committee was to review assessment plans from each unit annually. The researcher thoroughly reviewed the 17 unit level assessment plans made available to him by the study's liaison and discovered that all of the reviewed assessment plans adhered to the assessment planning template designed by the assessment committee. The template included seven sections that asked units to identify the unit's mission, goals, outcomes, methods, implementation strategies, results, and decisions/recommendations made based upon analyzed data. In order to assure accuracy of 
reviewed assessment plans produced at the unit level, assessment committee members broke into groups of two or three and used a standardized rubric for their review. The rubric, which was included on the assessment committee's website and division's assessment handbook, was designed to address the clarity of goals, the quality of outcomes, and the appropriateness of assessment methods. Moreover, the rubric included dimensions to determine levels of assessment analysis, interpretation of results, and decisions made based upon those results. The rubric included a rating scale divided into four levels (4=Exemplary, 3=Accomplished, 2= Developing; 1=Beginning). For example, a detailed outcome was considered exemplarily if it was "consistently detailed and meaningful enough to guide decisions in program planning and improvement," while it was considered at the beginning level if it "lacked detail to be useful in decision making or is merely a list of things to do." An additional example may be found in Table 19. (Western University Student Affairs Assessment Handbook, 2005).

Table 19

Sample Portion of Rubric Used by Western's Student Affairs Assessment Committee When Reviewing Unit-Level Assessment Plans

\begin{tabular}{lllll}
\hline Category & Exemplary: 4 & Accomplished: 3 & Developing: 2 & Beginning: 1 \\
\hline $\begin{array}{l}\text { Appropriateness } \\
\text { of Assessment }\end{array}$ & Consistently & Generally able & Able to produce & Often used \\
Methods & used appropriate & to identify, & assessment & methods that did \\
& assessment & use and defend & methods to fit & not measure the \\
& methods to & appropriate & most outcomes, & outcome \\
& measure all & assessment & though & \\
& outcomes in & methods to & sometimes the & \\
& support of & measure & method did not & \\
& goals. & outcomes & measure the & \\
& & & & \\
\end{tabular}

According to the Vice President of Student Affairs, small groups of individuals from the assessment committee were not the only individuals reviewing assessment plans and reports. He stated that the Director of Assessment reviewed each and kept him informed as to the progress of 
each unit. He elaborated, "[The Director of Assessment] looks at all of them and I look at all of them, and then she and I sit down and discuss. Also, the assessment committee reviews the reports and provides feedback to [units]." The Vice President's statement reinforced to the researcher his high level of commitment to the assessment process at Western University.

The assessment process at Western University was a decentralized process, with assessment planning, implementing, and reporting assessment results primarily occurring at the unit level according to all respondents. The Assistant Director of Student Health explained, "[The process] has been left up to units... so they can do the best possible work." She continued, "Each unit, I believe, has a variance of structure. Some have committees that meet quite consistently; others just have a couple people meeting periodically. I would imagine in some units there is only one person sitting at the table."

Examples of such variances of assessment participation at the unit level were revealed during interviews. For instance, a Program Coordinator for Career Services explained that her director was ultimately responsible for her unit's assessment activities; however, she indicated that because she represented her unit on the assessment council, she was primarily responsible for assuring progress within Career Services. Likewise, the Director of Services for Students with Disabilities explained that her assistant director, who was a member of the assessment committee, was primarily responsible for the assessments efforts within her unit. Although the Director of Services for Students with Disabilities continued to explain that when implementing assessments, "We take care of our own assessments, so there are a number of people involved [at the unit level]."

Some of the larger units, such as Recreational Sports, had unit level assessment committees. According to a Program Coordinator for Recreational Sports, her unit had its own 
assessment committee made up of various individuals across the unit. She indicated that "one or two folks who are on our department committee attend the Student Affairs assessment group" so that the unit level assessment committee may stay informed. That internal committee worked to assure that learning outcomes within various programs, which were led by program coordinators, were aligned with their focus of "healthy living." As a result, the Recreational Sports assessment committee had recently produced a drafted comprehensive assessment plan for the overall unit. Likewise, an Assistant Director of Student Health explained that they too had a unit level assessment committee. She stated, “...in Student Health Services, this has really come back to more of a conversation at the managerial level, so managers throughout the clinic [focus on assessment] rather than all seventy employees.”

To determine levels of how the Student Affairs Assessment Office was contributing to units level assessment efforts and to determine how to improve those efforts, the Director of Assessment conducted a survey across the division in 2005. The online survey was administered to 46 professional staff members in the division and garnered a $41 \%$ response rate. Examples of the survey's findings included:

- Results suggest that units have increased some of their assessment planning discussions as well as using data to plan and make decisions.

- The rating of the office's website had improved compared to the 2004 results credited to a commitment to improve that site based on previous results.

- The ratings of the office's quarterly newsletter had fallen some, thus the director indicated a need to focus future articles more on the needs of unit level assessment practices (Western University Student Affairs Assessment Department 2005 Survey Results, 2005).

\section{Western University Student Affairs Learning Outcomes}

The researcher thoroughly examined 17 unit-level assessment plans from the 2004-05 academic year that were provided to him by Western's Student Affairs Director of Assessment. 
It should be noted that those plans did not include assessment results at the time of the site visit. However, the researcher was able to secure three units' assessment plans that included results from the 2003-04 academic year. Therefore, the researcher examined those three plans and results as discussed later in the Enhancing Student Learning section of this chapter.

Much like Southern University, many of the 17 assessment plans from 2004-05 reviewed did not solely articulate learning outcomes. Some of the units, such as the Women's Center, included programmatic or service outcomes in their plans, in addition to their articulated learning outcomes. Specifically, the Women's Center assessment plan included nine learning outcomes as classified by the operational definition for this study, as well as some programmatic outcomes. Programmatic outcomes focused upon what the unit would provide, as opposed to what students would gain from their experiences with the Women's Center. Examples of those programmatic outcomes included, "Programs at the Women's Center reflect our diverse student body," and the Women's Center has a "strong, positive, collaborative relationships with the community."

Of the 17 assessment plans reviewed from 2004-05, only seven plans included clearly articulated learning outcomes. Some assessment plans, such as the plan from the Office of Assessment, did not include any student learning outcomes, because according to many respondents, that office provides support to the division as a whole, not to students. Moreover, other units that did not articulate learning outcomes were not ready to do so, according to the Director of Assessment. She explained, "How fast [the assessment process] moves in departments isn't dictated, other than [units] need to be working toward this...." She continued, [Units] are going to progress at this at different rates, partly because of resources or personnel or training or whatever. [The division] does not want to say this department is doing a crummy job at assessment, because they don't have the expertise yet, or they are 
in the process of learning and just moving slowly versus a [unit] that has more resources, more money, more people... and are moving faster.

The Director of Services for Students with Disabilities agreed. She stated, "I very much look at this as a developmental or evolutionary process. As we get smarter and better and are asking better questions and are asking more of ourselves and more of the departments... this will continue to evolve." Moreover, the Dean of Student Life, who supervised multiple sub units such as Greek Life and Student Conduct stated, 'I have programs who [haven't] managed to get their assessments done, and I will keep working with them and working with them until they are ready. They are not going to get fired over it or punished for it." She continued to explain that she asked program coordinators, "What do you need to get there? Do you need to go to a conference? It is unacceptable that you are never going to get there, but I know you are not doing it on purpose."

After analyzing the seven Western University Student Affairs Assessment plans that included learning outcomes, the researcher found that units articulated what they believed to be 47 learning outcomes. Every unit plan included the articulation of at least three learning outcomes, with the Orientation Office articulating the most outcomes. The Orientation unit's assessment plan included 11 student learning outcomes; although further analysis by the researcher determined that 3 of those 11 were actually broad goals. Moreover, further examination of the 47 articulated learning outcomes in the seven plans revealed that only 39 were actually student learning outcomes; the other 8 were too broad and were classified as goals in accordance to the operational definition of this study. Thus, only 39 student learning outcomes were further examined by the researcher. 
Of the 39 further analyzed learning outcomes, the researcher, along with his doctoral committee chair's guidance, categorized those learning outcomes into cognitive and affective taxonomies as illustrated in Table 20. The researcher identified that the majority (61.5\%) of the outcomes were within the cognitive domain, and $38.5 \%$ within the affective domain.

Table 20

Types of Learning Outcomes Identified in Western University Student Affairs Assessment Plans (2004-05)

\begin{tabular}{lcc}
\hline Taxonomy & $\mathrm{N}=39$ & \% of outcomes \\
\hline Cognitive & 24 & 61.5 \\
Affective & 15 & 38.5 \\
\hline
\end{tabular}

Of the 24 learning outcomes that were categorized within the cognitive domain, all were classified within the three lowest levels of thinking. Seven (29.2\%) were categorized within the remember level, eight (33.3\%) were categorized within the understand level, and nine (37.5\%) were categorized within the analysis level (see Table 20). Examples of Western University's Student Affairs cognitive learning outcomes that were articulated in plans included:

- Remember: [Student tour guides for admissions] will increase their content knowledge about Western University and the admission process.

- Understand: Student employees understand the Women's Center mission, budget, goals, strategic plan, and can articulate these to others.

- Analyze: [The Office of Services for Students with Disabilities (SSD)] student workers will be able to navigate and demonstrate use of the online database, in the areas defined by the skills rubric, in order to assist students SSD students who require additional assistance in requesting, monitoring, and updating their accommodations.

An examination of the 15 articulated affective outcomes revealed that the majority (46.7\%) may be categorized within the receiving level. Additionally, five (33.3\%) may be categorized within the responding level, and three (20\%) may be categorized within the valuing 
level (see Table 21). Examples of affective learning outcomes that were articulated in Western's Student Affairs assessment plans included:

- Receiving: As a result of attending the IMPACT program (mandatory alcohol abuse class for those who violate law) $80 \%$ of students will indicate the class made them think about their choices.

- Responding: [Student tour guides for Admissions] will enhance their ability to collaborate and work as a team.

- Valuing: Students living in the residence halls will demonstrate social responsibility and good citizenship skills. 
Table 21

Western University Student Affairs' Student Learning 2004-05 Outcomes Categorized Within Cognitive and Affective Taxonomies

\begin{tabular}{|c|c|c|}
\hline Taxonomy & $\mathrm{N}$ & $\%$ of Outcomes \\
\hline \multicolumn{3}{|l|}{ Cognitive } \\
\hline Remember & 7 & 29.2 \\
\hline Understand & 8 & 33.3 \\
\hline Apply & 9 & 37.5 \\
\hline Analyze & 0 & 0.0 \\
\hline Evaluate & 0 & 0.0 \\
\hline Create & 0 & 0.0 \\
\hline Total cognitive outcomes & 24 & 100.0 \\
\hline Taxonomy & $\mathrm{N}$ & $\%$ of Outcomes \\
\hline \multicolumn{3}{|l|}{ Affective } \\
\hline Receive & 7 & 46.7 \\
\hline Respond & 5 & 33.3 \\
\hline Value & 3 & 20.0 \\
\hline Organize & 0 & 0.0 \\
\hline Internalize values & 0 & 0.0 \\
\hline Total affective outcomes & 15 & 100.0 \\
\hline
\end{tabular}

All respondents were provided the opportunity to discuss what they believed to be the characteristics of high quality learning outcomes (see Table 22). Six (75\%) of the respondents indicated that high quality learning outcomes must be measurable. The Director of Assessment explained, "It is easy to generate a ton of outcomes, [yet] it becomes more difficult to say what 
that will look like. How will I know when we get there?" Moreover, The Dean of Student Life also expected learning outcomes to be measurable. She stated, "For me, it goes around language. Is it measurable? Does it support action language, not fake words? Is it truly some you can measure?" However, as previously explained in this chapter, an analysis of the articulated learning outcomes revealed that eight were actually broad goals, thus they were not considered measurable outcomes by the researcher.

Table 22

Western University Interview Responses: Characteristics of High Quality Learning Outcomes

\begin{tabular}{lcc}
\hline \begin{tabular}{c} 
Interview response: \\
\multicolumn{1}{c}{$\begin{array}{c}\text { Characteristics of high quality learning } \\
\text { outcomes }\end{array}$}
\end{tabular} & $\begin{array}{c}\text { Number of } \\
\text { responses } \\
\mathrm{N}=21\end{array}$ & $\begin{array}{c}\text { \% based upon number of } \\
\text { respondents } \\
(\mathrm{N}=8)\end{array}$ \\
\hline Measurable & 6 & 75.0 \\
$\begin{array}{l}\text { Flow from division's mission and } \\
\text { institution's mission }\end{array}$ & 5 & 62.5 \\
$\begin{array}{l}\text { Generated by a group } \\
\text { Attainable }\end{array}$ & 4 & 50.0 \\
Rooted in research & 4 & 50.0 \\
Can be measured by more than one & 1 & 12.5 \\
assessment method & 1 & 12.5 \\
Meaningful & & 12.5 \\
\hline
\end{tabular}

In addition, the majority of respondents indicated that high quality learning outcomes flowed from the division's and institution's mission (62.5\%). The Vice President indicated that high quality learning outcomes " “...have broad value to our institution... and show whether or not their work has anything to do with the overall mission of [Western] University.” Furthermore, the Dean of Student Life stated that high quality learning outcomes "support our student affairs mission, vision, and our student life vision." 
One-half of the respondents indicated that high quality learning outcomes were generated by a group of individuals through a collaborative process. For instance, according to the Assistant Director of Residence Life, his unit "tried to create learning outcomes from a grass roots conversation" among professional staff members. Likewise, a Program Coordinator for Recreational Sports explained that a group generated assessment plan allowed for the professional staff in her office to "learn from each other... that really help[ed] us to get [our drafted assessment plan] done.” Furthermore, the Director of Services for Students with Disabilities agreed. She stated, that she believed high quality learning outcomes were created by a "dialogue around the table, because as a staff, [they] spent quite a lot of time trying to identify what [they] thought [they] meant by self advocacy" when articulating outcomes based upon the goal of promoting self-determination for individuals with disabilities.

Respondents also identified other characteristics of high quality learning outcomes. For instance, four (50\%) felt that learning outcomes must be attainable or realistic. The Dean of Student Life expects her sub-units to ask themselves, "is this something we have any control over?" Additionally, the Director of Assessment wants units to ask themselves, "is this doable?" when developing learning outcomes. Other respondents (12.5\%) stated that high quality learning outcomes must be attainable, rooted in research, measurable by more than one method, and meaningful. For example, the Vice President explained that high quality learning outcomes should be derived, in part, from academic literature. In particular, he stated, "We certainly looked at the knowledge realm; we looked at the behavioral components; we look at the attitudinal components... all of which are important to assess." Moreover, the Director of Assessment stated that the first thing in her mind was that learning outcomes "are meaningful to 
the department... that the department has identified this as an area they need to know more about."

In regard to multiple methods of assessment, a Program Coordinator for Career Services explained that her unit's articulated outcomes were measured by more than one method of assessment. She stated, “...our outcomes are measurable by not just one method, we have a variety of methodology." A review of the Career Services assessment plan verified that statement. Each of the three articulated outcomes in their plan identified two methods of assessment. For instance, when measuring whether or not students learned effective interview skills after participating in on-campus interviews, Career Services identified an indirect student survey as one method of assessment, and direct staff observation of video recorded interviews as another method. Further analysis of assessment methods is discussed in the next section of this chapter.

\section{Western University Student Affairs Assessment Methods}

Like Southern University, all respondents indicated that choosing or developing assessment methods was a unit level decision. However, unlike Southern University, the Assistant Director of Student Health, who is a member of the assessment committee, indicated that units at Western University did submit their assessment instruments. She stated, I don't think they were initially in the assessment plans, but once [units] started attaching them to their plans, it became very helpful to us. We don't necessarily go through every item on the instrument.... it is used to help [the committee reviewers] understand what was actually written in the assessment plans. 
It should be noted that the researcher was not provided with each unit's assessment instrument(s) at the time of the site visit. Few units attached their assessment plans as explained in the succeeding paragraphs.

A thorough review of the seven assessment plans, that clearly included articulated learning outcomes, revealed that Western University Student Affairs identified seven different assessment data collection strategies in their 2004-05 (see Table 23). Of the 39 learning outcomes, 38 had clearly defined methods of assessment to determine if the outcome was being achieved. Moreover, 29 (74.4\%) were measured using only one method of assessment, and nine (23.1\%) were measured using multiple methods of assessment, and one (2.6\%) did not have a clear method of measurement identified in the plan. All but two units indicated the use of locally developed instruments, while Student Health Services and Services for Students with Disabilities identified the use of a commercially- developed instruments to measure at least one of their articulated outcomes. 
Table 23

Methods used to Assess Western University Student Affairs' Learning Outcomes in 2004-05

\begin{tabular}{lcc}
\hline $\begin{array}{l}\text { Methods used to assess learning } \\
\text { outcomes }\end{array}$ & $\begin{array}{c}\text { Number of reported } \\
\text { methods } \\
\text { N }\end{array}$ & $\begin{array}{c}\text { \% based upon total number of } \\
\text { articulated learning outcomes } \\
(\mathrm{N}=39)\end{array}$ \\
\hline Survey & 24 & 61.5 \\
Interview & 10 & 25.6 \\
Observation & 5 & 12.8 \\
Pre- and post-test & 5 & 12.8 \\
Document analysis & 4 & 10.3 \\
Focus group & 2 & 5.1 \\
Post-test & 1 & 2.6 \\
No method indicated & 1 & 2.6 \\
\hline
\end{tabular}

Unlike Southern University, assessment results from Western's 2004-05 assessment plans were not available at the time of this study; therefore the researcher was unable to confirm their implementation. However, the researcher discovered that units identified surveys as the primary method of assessment when measuring learning outcomes (61.5\%). The Director of Assessment commented, "We are over-surveying, and we know that." The Assistant Director of Residence Life expressed challenges his unit faced since surveys were the most popular method of assessment. He stated, "The problem with [surveys] is that a lot of folks are doing it, so response rates are dwindling and the other challenge is that you can not get the deeper meaning and understanding with a survey as you can with interviews or portfolios or other things." The Director of Assessment explained that actions were to be taken to provide "...further training and further education...to help [units] think of other methodologies." 
A thorough review of Western's assessment plans highlighted examples of survey assessment methods. For instance, the Student Orientation and Retention Unit identified in their plan that students who attended a summer day-and-a-half orientation program would, for example:

- Know how to get to and log into Student Online Services;

- Know how to use [Western's] web registration system to register for classes;

- Have a basic understanding of the baccalaureate core requirements;

- Understand how to use [Western's] online catalog and schedule of classes;

- Know how to contact the academic advising office; and

- Know where to find information about, for example, academic success, financial aid, and personal safety [These were just a few examples, 11 areas were identified on the survey].

All students who attended the orientation session activated their university email account. Therefore, in order to determine if the aforementioned outcomes were being achieved, the orientation unit indicated that it would email one indirect survey to each of those students allowing students to respond electronically. The survey, which was attached to the unit's assessment plan, included a variety of demographic questions as well as satisfaction questions. However, the unit included a section entitled "Things I've Learned." Questions contained in the survey addressed each of their articulated learning outcomes (one question per outcome), allowing students to rate their perceptions of knowledge gained on a one to five scale (5=strongly agree, $4=$ agree, $3=$ neutral, $2=$ disagree, $1=$ strongly disagree) as well as the student option to mark "not applicable." Moreover, the survey included a qualitative component that 
permitted students to indicate what resources they would like to learn more about before the beginning of the fall academic term.

Another example of survey use at Western University was revealed in the Student Health Services assessment plan. The unit identified the use of an online survey to determine if students that were mandated to complete an alcohol education class indicated the program

- Caused them to consider moderating their drinking;

- Resulted them learning at lest three tips for harm reduction when using alcohol; and

- Caused them to realize that their alcohol use could create more problems for them than they originally thought.

All students who completed the alcohol class were emailed the survey; however, the Assistant Director of Health Services stated, "They can choose not to participate in the follow-up [survey] and that is totally their decision, so we don't coerce them in any way." The survey instrument was not included in the Health Services assessment plan and was not made available to the researcher during his site visit. Although, the Health Services' assessment plan did indicate that they believed their cognitive and affective outcomes would be achieved if $60 \%$ of students

- reported learning something new;

- indicated the class made them think about their choices; and

- indicated the class made them think about changing their behaviors.

Other units, including Counseling and Psychological Services and Career Services, used survey methods. Counseling and Psychological Services' assessment plan indicated that it would survey students who utilized their services to determine if they learned how to improve their stress and mood management skills; to improve and effectively manage interpersonal relationships; and to effectively manage academic challenges. The unit's survey was not 
included in the assessment plan; thus, the researcher was unable to determine if the survey questions aligned with the desired outcomes. However, Career Services did include their survey instrument in their assessment plan, which sought to measure students' perceived knowledge gains after attending a resume and cover letter presentation.

The survey showed that students who attended the workshop were asked to complete demographic questions focused on such areas as race, gender, major, and class rank as well as seven learning-related questions. The first of the five questions were quantitative in nature, allowing students to identify their knowledge gains on a one to five scale (1=strongly agree, 4=agree, $3=$ =neutral, $2=$ disagree, $1=$ strongly disagree). Those questions included:

1. I have learned the components of an effective resume.

2. I have learned about the format of an effective resume.

3. I have learned about resume content.

4. I feel I can apply the knowledge I gained today.

5. As a result of this presentation, I feel more confident.

As well as the inclusion of the aforementioned five questions, the survey included two open-ended questions asking students: What was effective and what needed improvement? And, did the student feel he or she needed an individual follow-up meeting with the presenter of the workshop?

Career Services also identified the use of a survey to measure whether or not students learned professional etiquette after attending a networking and etiquette dinner program. The survey included 10 questions, seven of which were directly related to the articulated outcome. The survey allowed students to rate their responses on a one to five scale (1=strongly agree, 4=agree, $3=$ neutral, $2=$ disagree, $1=$ strongly disagree) to such questions as: "Did they feel more 
confident in their abilities to meet people? Did they feel better informed about table etiquette and manners? Did they feel better prepared for an interview conducted during a meal?"

In addition to surveys, $25.6 \%$ of the total articulated outcomes reviewed in Western's Student Affairs assessment plans were measured, at least in part, by conducting interviews with students. For example, the Office of Admissions wrote in their assessment plan that they would interview student tour guides at the onset of the academic year to determine their "baseline knowledge and skills" related to their job. The plan also indicated that the student tour guides would be interviewed mid-way through the academic year and then again at the end of the academic year. A rubric to assess student gains was attached to the plan (see Table 24 for sample portion). The interview protocol was not attached to the assessment plan; thus the researcher was unable to confirm whether or not the interview protocol aligned with the rubric. However, the rubric layout specifically addressed each of the articulated outcomes which included: students' sensitivity and ability to work with diverse populations; students' knowledge about Western University; students' knowledge about the admissions process; students' communication skills; and students' abilities to collaborate. 
Table 24

Sample portion of Western University Admissions Office Rubric Used to Determine Tour Guide Competency Levels

\begin{tabular}{|c|c|c|c|c|}
\hline Outcome & Exemplary & Accomplished & Developing & Beginning \\
\hline $\begin{array}{l}\text { Knowledge } \\
\text { about Western } \\
\text { University }\end{array}$ & $\begin{array}{l}\text { Wide range of } \\
\text { knowledge } \\
\text { regarding } \\
\text { programs and } \\
\text { facilities. Keeps up } \\
\text { to date on current } \\
\text { events on campus. }\end{array}$ & $\begin{array}{l}\text { Depth } \\
\text { knowledge in a } \\
\text { few specific } \\
\text { areas }\end{array}$ & $\begin{array}{l}\text { Knowledge } \\
\text { limited to one or } \\
\text { two areas. }\end{array}$ & $\begin{array}{l}\text { Very limited } \\
\text { knowledge of } \\
\text { any specific area. }\end{array}$ \\
\hline $\begin{array}{l}\text { Communication } \\
\text { Skills: Written } \\
\text { Component }\end{array}$ & $\begin{array}{l}\text { Grammar, spelling } \\
\text { always correct; } \\
\text { details in } \\
\text { confirmation } \\
\text { letters correct; } \\
\text { personal style or } \\
\text { comments added } \\
\text { effectively. }\end{array}$ & $\begin{array}{l}\text { Grammar, } \\
\text { spelling correct; } \\
\text { confirmation } \\
\text { details correct; } \\
\text { does not add } \\
\text { additional } \\
\text { comments. }\end{array}$ & $\begin{array}{l}\text { Few grammatical } \\
\text { spelling errors; } \\
\text { details correct. }\end{array}$ & $\begin{array}{l}\text { Grammatical and } \\
\text { spelling errors }\end{array}$ \\
\hline
\end{tabular}

In addition to using rubrics for interviews, $12.8 \%$ reported the use of direct observations coupled with rubrics to measure articulated outcomes. For example, Career Services indicated the use of direct observation to measure students' ability to demonstrate effective interview skills during video-recorded mock interviews. Career Services created a rubric to determine what effective interview skills looked like (see Table 25 for sample portion). The plan indicated that each student who completed a mock interview would be assessed. However, the plan did not indicate how many mock interviews were conducted each year. 
Table 25

Sample Portion of Western University Career Services Rubric Used During Student Mock Interviews

\begin{tabular}{l|l|l|l|l|l}
\hline \multicolumn{1}{c|}{ Characteristics } & Excellent & Good & Fair & $\begin{array}{c}\text { Needs } \\
\text { Improvement }\end{array}$ & Comments \\
\hline $\begin{array}{l}\text { Appearance: Dressed appropriately } \\
\text { for position they are interviewing }\end{array}$ & & & & & \\
$\begin{array}{l}\text { Greeting/Introduction: Firm } \\
\text { handshake, used interviewers name, } \\
\text { maintained eye contact while } \\
\text { speaking }\end{array}$ & & & & & \\
$\begin{array}{l}\text { Direction: Well-defined career goals; } \\
\text { confidence in abilities }\end{array}$ & & & & & \\
$\begin{array}{l}\text { Oral Communication: Clear } \\
\text { articulation; proper grammar, and } \\
\text { vocabulary; well thought out and } \\
\text { organized responses }\end{array}$ & & & & & \\
\hline
\end{tabular}

Document analysis accounted for $10.3 \%$ of the methods used to assess articulated outcomes in Western's Student Affairs' assessment plans. Career Services indicated the use of a rubric when analyzing resumes of students (see Table 26 for a sample portion). According to their assessment plan, this method was coupled with a survey at the conclusion of a resume writing workshop explained earlier in this chapter; thus multiple methods "will hopefully allow us to examine student perceptions of their resume writing versus an direct document analysis of their resumes," according to a Program Coordinator in Career Services. She continued to explain that they assessed students who "dropped-in during the Spring Career Week." 
Table 26

Sample Portion of Western University Career Services Rubric Used When Reviewing Student Resumes

\begin{tabular}{llll}
\hline Content & Needs Improvement & Good & Excellent \\
\hline Action voice & None or mixed & Used consistently & $\begin{array}{l}\text { Consistent, and } \\
\text { appropriate variety }\end{array}$ \\
$\begin{array}{l}\text { Statements vs. } \\
\text { sentences }\end{array}$ & $\begin{array}{l}\text { Paragraphs and } \\
\text { sentences }\end{array}$ & Statements & Bullet points, concise \\
$\begin{array}{l}\text { Thoughtfully reflects } \\
\text { transferable skills }\end{array}$ & No focus on skills & $\begin{array}{l}\text { Good use of skills- } \\
\text { not tailored }\end{array}$ & $\begin{array}{l}\text { Tailored resume with } \\
\text { skills appropriate for } \\
\text { job applying to }\end{array}$ \\
\hline
\end{tabular}

Pre- and post-tests $(12.8 \%)$, focus groups $(5.1 \%)$ and post-tests $(2.6 \%)$ were the other identified methods of assessment. The Women's Center indicated that it would use focus groups to determine if "students report receiving consistent information from the Women's Center and complementary campus constituents." and if "students receiving information in classroom settings are aware of the programs, opportunities, and services provided by the Women's Center." The Women's Center also wrote in their assessment plans that they would administer a pre- and post-test to measure student employees' abilities to "apply training material to the implementation of tasks and the development of initiatives." It should be noted that the assessment plan did not include the focus group protocol, pre- and post-tests, or the number of students that would be assessed.

\section{Western University Student Affairs Assessment Collaboration}

Planning and implementing assessments at Western University was primarily a singleunit task at the time of the study, according to all respondents. When asked if units were collaborating within the division or outside the division on the creation and implementation of their assessments, the Vice President stated, "generally not." Another respondent explained, "I 
would give us a ' $\mathrm{D}$ ' if I were to grade us [on assessment collaboration], but I think a lot of it is that we are still kind of new to what assessment is, so were are trying to figure out what assessment means to our work areas first." When asked if Student Affairs was collaborating with Academic Affairs, a Program Coordinator for Career Services stated, "No, we are light years ahead of the academic side of the house, I think we are supporting them in their learning."

While there was no evidence of collaborative work when planning and implementing assessments, the Director of Assessment explained that the assessment committee operated in a very collaborative function. For instance, she explained that Western University Student Affairs assessment committee had recently identified six broad learning goals for the entire division, with future learning outcomes expected to align with the goals.

Those six learning goals included:

1. Effective communication: This goal embodies the ability to receive information, exchange ideas, present information, and convey messages in ways that are effective and appropriate to the situation and audience.

2. Healthy living: This goal focuses on students' abilities to make informed decisions and act on those decisions to enhance both personal and community health.

3. Active citizenship and responsibility: This goal embodies effectively contributing in a variety of social contexts at the macro and micro levels including, seizing opportunities to use knowledge, skill, and education to improve the well-being of self and others.

4. Interpersonal and intrapersonal competence: This goal involves both the effective management of personal/professional affairs and future development as well as the ability to collaborate, to develop and sustain meaningful relationships, to engage effectively in multicultural teams, and to live a satisfying life.

5. Critical thinking and analytical skills: This goal refers to the ability to use resources and prior learning to independently and accurately evaluate information and data from multiple perspectives. It also includes applying appropriate methods of inquiry, assessment of the quality of evidence, integrity, and effective use of knowledge to solve problems and/or create plans that promote success. 
6. Attitude of inquiry: This goal promotes a life-long interest in learning, embracing possibilities, and being open to new ideas (Western University Student Affairs Assessment Handbook, 2005).

According to the Director of Assessment, future unit assessment plan templates will include a grid which will allow units identify how their learning outcomes align with the division's learning goals. Moreover, the Director of Assessment and assessment committee will use that complied information to "tell the division's learning story... as well as to examine those areas in which were are successful and those areas in which we could better focus our learning efforts" (Western University Student Affairs Assessment Handbook, 2005). One assessment committee member commented, "Once we see the bigger picture of how units align with one another on learning, I think we will get better at collaboration."

\section{Enhancing Student Learning Based Upon Western's Student Affairs Assessment Results}

To determine how Western University Student Affairs educators were using assessment results to enhance student learning, the researcher asked each respondent to share examples. Furthermore, the researcher thoroughly examined authenticated assessment reports from the 2003-04 academic year. As previously stated, assessment results for the 2004-05 academic year were not made available to the researcher at the time of this study.

The majority of respondents explained that each unit was asked to submit their assessment results annually. Units were expected to include decisions and recommendations made based upon their results. The Vice President explained, "One of our expectations is that... [units] do a report of their assessment of the previous year's assessment and part of the expectation is that demonstrate how the previous year's data [was] used and what, if any, changes in programs and services came about... from that data." 
Through document analysis of 2003-04 assessment reports, the researcher determined that nine learning outcomes were measured, resulting in nine data-driven decisions. Those nine learning outcomes were articulated in a total of three assessment reports. Units that reported assessment results included, Career Services, Student Media, Services for Students with Disabilities, and Student Health Services. Table 27 shows that $45 \%$ of decisions focused on modifying the program or service where student learning was assessed in order to enhance that learning. Likewise, $45 \%$ indicated that they could not determine whether or not the outcome was achieved due to flawed assessment instruments; therefore, they planned to modify their instrument and reassess the articulated outcome during the next assessment cycle. In addition to identifying flaws with their rubric assessment instrument used to determine if students demonstrated effective resume writing skills, Career Service reported in their results, that "it became clear that we had not done an appropriate amount of training for raters [and then reassess]."

Table 27

Types of Decisions Made by Western University Student Affairs' Educators Based on 2003-04 Assessment Results

\begin{tabular}{lcc}
\hline Type of decision made based on assessment results & $\mathrm{N}=9$ & $\%$ of decisions made \\
\hline Modify educational program or service & 4 & 44.5 \\
Modify assessment instrument & 4 & 44.5 \\
Enhance assessment administration training & 1 & 11.1 \\
\hline
\end{tabular}

Specific examples of assessment data-driven decisions were revealed during interviews. For example, an Assistant Director of Student Health Services explained that her unit administered the National College Health Assessment (NCHA) to garner a "snapshot of student 
behaviors and attitudes." Student Health was interested in determining who students perceived as believable sources of health information

After randomly selecting 46 Western University classes, Student Health educators administered 1,129 NCHA surveys to students, resulting in a 92\% response rate. Results, according to Student Health's assessment report, indicated that $92 \%$ of students reported health center medical staff as credible sources, and $90 \%$ of students reported health educators as credible sources.

The Assistant Director of Student Health Services also explained that results indicated that students did not view their peers as credible conveyors of health information, but they did believe their parents and professors. She continued, “....it [made] us think about how we spend our resources...." Specifically, she described an ongoing discussion regarding the purpose of the institution's Peer Health Advocate program. The Peer Health Advocate program, according the Health Services' website (2005) is “a peer-to-peer volunteer organization/program, which provides educational, non-judgmental health information and resources to the [Western University] community." The Assistant Director stated, "What we really started to question [since peer believability was low according to the NCHA]: Was that a really good way for us to spend our resources and training students [as peer educators]?... so we restructured the program." She indicated that peer educators "used to go into classroom and talk to their peers... but who really wants to send students into a situation where they really are not being believed and really not professionals?" As a result, professional health educators have enhanced their roles as information providers to students at Western. Moreover, the Assistant Director explained that since their results indicated that parents were perceived as very believable sources of health information, Student Health began speaking with parents during new student 
orientation and encouraged them "...to communicate with their students [about health-related issues] and keep an open dialogue, because [students] do believe their parents..."

The Peer Health Advocate program continues at Western University; although, less emphasis is placed on student volunteers as those who disseminate health information to fellow students in classrooms and residence halls. However, the Peer Health Advocate program has enhanced student volunteers' roles as service providers, allowing them to benefit from civic engagement activities such as Habitat for Humanity and local soup kitchen events. Furthermore, advocates assist health services with social advocacy programs on campus and in the community, such as the annual Great American Smokeout. Peer advocates may also participate in peer theatre, which "combines health and social issues with theatre to create interactive workshops that educate, entertain and generate conversations about a variety of health issues... focusing on issues, real stories, [with] all of the scripts are based on interviews with [Western University] students” (Western University Student Health Services webpage, 2005).

Another example of a Student Affairs unit using assessment data to enhance student learning was revealed during an interview with the Director of Services for Students with Disabilities. She explained, "The first real assessment that we did [involved] our student workers..." Specifically, the unit's assessment results indicated the articulated outcome measured was, "Services for Students with Disabilities student workers will demonstrate skills required of entry-level office workers."

In order to determine whether or not students demonstrated such skills, the office used two methods of assessment - direct observation and a self-report survey. A rubric was locally created and used when observing all front-desk student employees' working habits during a twoweek period. However, results "highlighted some flaws in the methodology used." For that 
reason, the primary decision made by Services for Students with Disabilities was to revise the instrument for a future assessment to provide detailed sub-categories within the eleven major skills they had identified. For instance, 'demonstrated' would be further defined to include competency levels on a scale of one to five, with a rating of one indicating the need for improvement and five indicating a mastery of the skill being observed. Moreover, the report indicated that they would not limit their observation period to two-weeks, but rather observe periodically throughout the academic term.

The second method of assessment used to determine student workers' skill levels was a self-report survey that allowed the unit to determine areas where students needed additional training. Results indicated that "student front desk employees desired further training in psychiatric disabilities and methods for responding appropriately to a student in crisis." As a result, the Director of Services for Students with Disabilities explained that her office enhanced student employee educational opportunities. Such opportunities included release time from work to complete online training modules and a round-table lunch that included a video focused on "factors that influence student transition to college" in an attempt to help student workers understand what may be prompting a student crisis and how to respond to that crisis.

Another example of enhancing student learning based upon assessment data from the 2003-04 academic year was revealed in the Services for Students with Disabilities assessment results. The unit measured whether or not "Real time transcribers demonstrate effective transcribing skills as defined by law and current best practices.” A skills checklist rubric and document analysis were used to assess four transcribers. The skills checklist was developed by TypeWell, a national company that produces transcription software. Western University Services for Students with Disabilities used TypeWell's software, allowing a hearing student (Real time 
transcriber) to use abbreviations to type what a college lecturer is saying into a one laptop computer, which then instantaneously converts into full text on another laptop computer read by the hearing-impaired student. In addition to the checklist, “...a sample transcript of each transcriber was reviewed by the Coordinator [of Deaf and Hard of Hearing Access Services] for clarity, completeness, accuracy, and formatting" (Services for Students with Disabilities Assessment Plan, 2004).

Results, according to the plan indicated that "three transcribers met the minimum criteria for in-class work; one did not." Therefore, the unit decided to remove the transcriber who did not meet the minimum criteria from his/her in-class transcription responsibilities. Moreover, Services for Students with Disabilities provided that individual with "skill-development strategies (which were not defined in the assessment results).... and told the transcriber to contact the Coordinator if/when [he or she] was ready for a re-[assessment]."

\section{Western University Student Affairs Assessment Successes and Challenges}

All of the interviewed participants at Western University were asked to describe what they perceived to be the successes and challenges of their assessment efforts. Responses were notably mixed, with no more than four individuals referencing the same success. One-half of the respondents indicated Student Affairs educators enjoy assessment related learning and professional development opportunities (see Table 28). The Director of Assessment explained, "A lot of people work on campuses because they like learning, and sometimes we can just get our job done and it doesn't hold the intellectual challenge for us." She perceived that working on the assessment committee, for many, provided that intellectual challenge and "had sparked their interest." She continued 
We have always framed this in terms of learning for improvement — not to justify your existence, not to prove you are the best or the worst-but for departments to use [assessments] for improvement and documenting how they are making decisions for improvements and whether those decisions mattered or made a difference.

A Career Services Program Coordinator, who was a member of the assessment committee, echoed the Assessment Director's comment. She stated, “A success has been, I have learned a ton. I think the success has been more of a personal success for [me] within my unit, because I come away with the skill, unfortunately most of them will not have [come away with that skill]." Moreover, a non-assessment committee member cited learning as a success. The Director of Services for Students with Disabilities stated, "I think it was fascinating [to learn how our student workers] came to appreciate the diversity in humanity, different skills... and [how these students] have a better appreciation of what people may experience with a disability." 
Table 28

Western University Student Affairs Interview Respondents’ Reported Assessment Successes

\begin{tabular}{lcc}
\hline \multicolumn{1}{c}{$\begin{array}{c}\text { Interview Responses: } \\
\text { Success of assessing student learning outcomes }\end{array}$} & $\begin{array}{c}\text { Number of } \\
\text { Responses } \\
\mathrm{N}=14\end{array}$ & $\begin{array}{c}\text { \% based upon } \\
\text { number of } \\
\text { respondents } \\
(\mathrm{N}=8)\end{array}$ \\
\hline $\begin{array}{l}\text { Student affairs educators enjoy assessment related learning } \\
\text { and professional development opportunities }\end{array}$ & 4 & 50.0 \\
$\begin{array}{l}\text { Student affairs educators demonstrate a high level of } \\
\text { dedication the assessment initiative }\end{array}$ & 4 & 50.0 \\
$\begin{array}{l}\text { Creation and appointment of a division-level director of } \\
\text { assessment }\end{array}$ & 25.0 \\
$\begin{array}{l}\text { Student affairs educators are viewed as leaders of the } \\
\text { assessment initiative at the institution }\end{array}$ & 2 & 25.0 \\
$\begin{array}{l}\text { Student affairs educators are now making decisions based } \\
\text { upon data }\end{array}$ & 1 & 12.5 \\
$\begin{array}{l}\text { The student affairs assessment committee is established and } \\
\text { welcoming to anyone who chooses to participate }\end{array}$ & 1 & 12.5 \\
\hline
\end{tabular}

In addition to learning, $50 \%$ of respondents indicated that a success was that student affairs educators demonstrated a high level of dedication to the assessment process. The Assistant Director of Student Health stated that “...the energy level still continues to be high around this issue, and people aren't frightened by it anymore." The Vice President explained that dedication level across the division was a success because

... we have been able to create a functioning culture around assessment, and it's functioning in a way that will allow it to sustain and evolve. It is a model that is based upon reasonable expectations and attainable expectations, and so we acknowledge that there will be unevenness in the types of plans submitted by folks. We weren't looking for perfection, and I think the assessment [committee] has been very clear bout that. [The 
assessment model] has created a space for people no matter where they were on the learning curve, they could still participate in the process and be able to take part in this journey.

A Program Coordinator for Recreational Sports commented that she felt the assessment model established by the division allowed her unit to create an assessment plan that was meaningful to their respective unit. She indicated that Recreational Sports was not as far along in the assessment process as many other units within division; however, "We are a little bit closer than we were last year. This is a critical year for us [in the assessment process].” She continued to explain that her unit did not have a formal assessment plan until this year (a plan that was in draft format at the time of this study). Recreational Sports had also demonstrated dedication to the assessment initiative through the creation of its own unit level assessment committee, as explained previously in this chapter.

The appointment of a full-time Director of Assessment for the division was mentioned as a success (25\%) according to the Dean of Student Life and an Assistant Director of Residence Life. Specifically, the Dean of Student Life asserted that it was essential for the division to "put some resources into finding [an Assessment Director] who could help us learn, as a community." She continued to explain that it was essential to appoint a division-wide assessment director because “... somebody has to make sure the [assessment committee] keeps going... and someone like [the Assessment Director] has to take the idea of an on-campus assessment symposium and work with the [assessment committee] to really make it happen."

In addition to the appointment of a full-time director of assessment, two respondents indicated that a success was that student affairs educators were viewed as leaders of the assessment initiative at their institution, because academic affairs had yet to formally engage in 
systematic assessment efforts. The Assistant Director of Residence Life explained, "We are not only engaged in this [assessment] conversation, but to a large degree, we are leading [the institution-wide conversation]." The Director of Assessment clarified, "I get calls from faculty. We have academic people sit on our assessment [committee], because they want to be associated with the community of people who are talking about assessment issues. There is no other place in the university where that is happening." She continued to explain the division's assessment efforts have "...gotten Student Affairs at the table..." in discussions regarding the articulation university-wide learning goals in conjunction with the faculty senate as well as discussions centered around the institution's teaching and learning center as well as the academic success center. She concluded, "I think we are providing a model on how you can get assessment going with very little resources."

Other assessment successes revealed through interviews (12.5\%) included that Student Affairs professionals were making decisions based upon assessment data and that the assessment committee structure is clearly established, functioning, and welcoming to anyone who chooses to take part. The Director of Services for Students with Disabilities specifically cited the use of assessment data to make decisions regarding learning as a success for her unit. She stated, "We identified what we wanted student learners to know... so we were able to actually have more intentional [assessment] questions and then see if we are hitting what we actually need to be hitting." Moreover, the Director of Assessment explained that the organization of the assessment committee was a success that attracted new members because it was "a structure open to anybody [in the institution]... we have never turned anybody away who asked to be a part of the [committee]." She continued, "It is not like we have gone out and invited extra people, but people hear about the work we are doing and they contact us [about joining]." 
Respondents at Western University were asked to reflect upon what they believed to be assessment challenges. Responses varied, with $37.5 \%$ indicating time constraints as major challenge (see Table 29). The Assistant Director of Student Health stated, "Finding the time [is a challenge] because it does kind of creep into your workload... So much of the work one does in student affairs is reactionary, so finding the balance and time for [assessment]." A Program Coordinator in Career Services agreed and explained that it had been a challenge for her unit to produce assessment plans, conduct assessments, and analyze assessment results because “... as a student services unit... we have an open door policy where there are people in and out of my office all of the time... so time is a challenge. 
Table 29

Western University Student Affairs Interview Respondents' Reported Assessment Challenges

\begin{tabular}{lcc}
\hline \multicolumn{1}{c}{$\begin{array}{l}\text { Interview Responses: } \\
\text { Challenges of assessing student learning outcomes }\end{array}$} & $\begin{array}{c}\text { Number of } \\
\text { Responses } \\
\mathrm{N}=15\end{array}$ & $\begin{array}{c}\text { \% based upon } \\
\text { number of } \\
\text { respondents } \\
\text { (N=8) }\end{array}$ \\
\hline Time constraints & 3 & 37.5 \\
$\begin{array}{l}\text { Additional education is needed to help student affairs } \\
\text { educators understand the value of assessment within the } \\
\text { profession }\end{array}$ & 37.5 \\
$\begin{array}{l}\text { There is an absence of an institution-wide assessment culture } \\
\text { Some student affairs units struggle to articulate manageable } \\
\text { outcomes }\end{array}$ & 2 & 25.0 \\
Limited financial resources & 1 & 25.0 \\
$\begin{array}{l}\text { Difficult to share results with students } \\
\text { Units need computer software to help manage assessments } \\
\text { and make the assessment process transparent }\end{array}$ & 1 & 12.5 \\
$\begin{array}{l}\text { Questions are arising on how to creatively sustain assessment } \\
\text { initiative }\end{array}$ & 1 & 12.5 \\
Lacking reward structure for assessment efforts & & 12.5 \\
\hline
\end{tabular}

Another challenge highlighted by three respondents (37.5\%) during interviews was the need for additional professional staff development opportunities in order to help some student affairs educators understand the value of assessment within the professions. The Vice President explained, “...there are some units that still haven’t gotten clarity or internalized the significance of doing assessments..." He believed his division's internal efforts to educate student affairs staff on value of assessment had been successful; however, he thought that some units continued to struggle because their professional associations had not adopted assessment as a "core value." He continued to explain that professional associations often lead the mindset of student affairs 
educators. For instance, he stated, "You wouldn't have to tell people in student health to keep sound medical records, they know that. They understand that because that is a core value in their profession." Thus, the Vice President believed in order for some units to internalize the value of learning outcomes assessment, Student Affairs professional associations must embrace it as a "core value."

The Director of Services for Students with Disabilities also expressed the need for further educational opportunities to help “...get folks to understand that [assessment] is not a performance evaluation, it is a tool to help us be better and provide better services..." Moreover, the Dean of Student Life explained that some individuals struggled to understand the purpose of assessing student learning. She stated, that some Student Affairs educators asked questions such as: "Will it be used for merit raises? Will it be used to evaluate me as a student affairs professional?" She continued to explain the challenge has been "getting over that" and assuring Student Affairs educators that assessment is about “...connecting to student learning [and] that is what [student affairs assessment] is all about.”

Two respondents indicated that a lack in institution-wide culture was a challenge for Western University's Student Affairs Division. For instance, the Assistant Director of Residence Life explained, "...my only disappointment is that we had to pull the academic folks to the table, because they were not committed to assessment.” The Vice President elaborated, “...there is an absence of an overall institutional [assessment] culture that validates the importance of this." However, he continued to explain that the division was purposefully “...mov[ing] our leadership out to influence the thinking of others" in order to help create an institution-wide assessment culture. Specifically, the Vice President cited the Student Affairs sponsored institution-wide assessment symposium as one effort to help build that culture. 
In addition the lack of an institution-wide assessment culture, one-quarter of the respondents stated that some student affairs units struggled to articulate manageable outcomes. For instance, a Program Coordinator for Recreational Sports stated, "I think our biggest challenge is that we still struggle to focus on something that is manageable. I think we as a unit try to take on too much right away, and I think that is one of the reasons we haven't had a lot of success in assessment." The Director of Assessment commented that it had been a challenge to get some units to narrow down the scope of what they wanted to assess annually. She continued to explain that some units struggle to understand “...if you want to look at only one area of learning a year that is ok, and that is enough."

Other challenges (12.5\%) revealed during interviews included limited financial resources; difficulty sharing results with students; the need for computer software to help manage assessments and make the assessment process transparent; concerns about sustaining the assessment initiative; and a lack of a reward structure for assessment efforts. In reference to limited financial resources, the Vice President stated, "I think a constant challenge is resources. I think we do a lot with smoke and mirrors." However, he clearly demonstrated his commitment to the assessment initiative and stated, “...one of the things I commit to do when we have something that we know is important for all of us to do, all I say is "We will find the money."” He continued, "I don't want this effort to get derailed and the energy to diffuse because people say there is not support for them... so I have to find a way to say yes even in the absence of resources.”

The Director of Assessment discussed two challenges she felt the division faced in their efforts to create an ongoing assessment culture. First of all, she stated that sharing results with 
students who had completed the assessments had been a challenge for many units and she also explained that

It has become very clear to us that we need some software to help us mange our plans and to make them visible to everybody in the [division]. We are working with our internal [technology] folks to get that working, and we are collaborating with Academic Affairs to make that happen so that the university has a structure for having plans up on the web both for Student Affairs and Academic Affairs... and academic affairs is paying for it. Another challenge, identified by the Assistant Director of Residential Education, was figuring out how to "make [assessment] a sustainable effort. You can put your heart and soul into something with a small group of folks and get some very rich data, but will that sustain the whole organization's efforts?" However, he continued to explain that he felt that the recently developed student affairs broad learning goals described earlier in this chapter would help the division move forward and better align unit level outcomes with one another.

The final challenge cited by one respondent who asked not be identified regarding his/her comments was the lack of reward structure within his/her respective unit. He/she explained I am acknowledged as the one who does [assessment for my unit], but it is not acknowledged as part of my work. Those in my unit certainly appreciate that I am the one doing it, [but] it is not in my job description. I do not formally get evaluated on it as part of my job and nothing was dropped off my plate in order to add this to it, and quite frankly there are some times when it is very time consuming. I think [my efforts] should be acknowledged and rewarded, definitely.

After being asked about the challenges of Western's Student Affairs assessment efforts, respondents were asked to reflect upon what they believed would enhance the assessment 
initiative. Fifty-percent indicated the need to collaborate within the division and outside of the division in their assessment efforts. The Director of Assessment stated, "I think there needs to be better coordination at the university [level] for assessment." Likewise, the Assistant Director of Health Services expressed her desire for enhanced collaborative assessment efforts. She stated, “....as I reflect more, and I am sure what everyone wants more, is an academic integrated blend with student affairs—looking for ways what we can work together in the assessment process." She continued to explain that collaboration with Academic Affairs had not occurred, in her opinion because of “...time and I think it is resources, but I think we could certainly look at other institutions that are further along down the road with student affairs assessment [to learn how to better collaborate with Academic Affairs]." A Program Coordinator for Career Services explained that she felt a central data base that tracked the division's assessment efforts would enhance their collaborative efforts. "If we could go to a data base and see that [a particular unit] is measuring these outcomes, maybe we can attach one question to whatever they are doing. If we partnered with them, I think it would streamline [the process], and it would be more effective."

Besides improving collaborative efforts, three respondents (27.5\%) indicated the need to enhance resources devoted to the initiative, specifically in man-power. The Vice President said, "I would employ another full time [assessment] person." The Assistant Director of Residence Life stated that more resources were need as well. He explained, "[The Director of Assessment] needs more support than she has.” The Assistant Director of Assessment agreed, “...increase the staffing, because I can see us getting bigger and bigger, and we are at a point where we doing what we can. I think everyone is satisfied, but we could do more, which really comes down to resources.” 
A final area of improvement identified by respondents included was the need for more professional development opportunities (37.5\%). A Program Coordinator for Recreational Sports explained that her unit needed more professional development to help the staff understand "that it is ok not to do all of things we have done in the past...let go of the baggage. It just seems [assessment] is one more thing we have to do. It would be helpful to have more direction as far as what Student Affairs as a division is looking for." The Dean of Student Life explained, "I think there are just a number of folks that would be much more excited about [assessment] if we could take them all and have an additional symposium just about learning." She continued, "Not everyone has a student development background." She felt additional educational opportunities would help her colleagues, "start to identify [themselves] as faculty in a different form."

\section{Summary of Findings}

Western University's Student Affairs Division first began discussing satisfaction-based assessment in 1996 and began exploring learning outcomes assessment 2001, when a full-time Student Affairs Assessment Director was appointed. Beginning in 2003-04, units within Western's Student Affairs Division were expected to produce annual learning outcomes assessment plans, implement those plans, and make decisions to enhance student learning based upon their assessment results. Since the assessment model is decentralized, the division's Director of Assessment and a voluntary division-wide assessment committee provided support to each unit.

The majority of the outcomes that were articulated in 2004-05 were categorized within the cognitive taxonomy with fewer categorized within the affective taxonomy. The majority of outcomes were assessed indirectly with students completing surveys. However, evidence of other methods, including interviews, observation, and pre- and post-tests, as well as others, were 
also being used by Western University Student Affairs educators to measure student learning. This case study yielded no evidence of collaboration when creating and implementing assessment plans.

Professionals in the division valued the educational opportunities related to assessment and reported a high level of commitment to the assessment imitative across the division. Yet, more than one-third of the respondents still indicated the need for additional assessment-related professional development opportunities. Furthermore, many respondents cited time constraints as a challenge when conducting high quality assessments. 


\section{Chapter Seven}

\section{Eastern University}

\section{Institutional Background}

Eastern University, classified by the Carnegie Foundation (2005) as a Research IIntensive institution, is located in the Eastern portion of the United States and is only minutes from a major metropolitan city. Eastern was originally founded as a branch campus to the state's Flagship University in 1956. However, in 1972 Eastern became its own state-assisted university when the Governor approved legislation (Eastern University website, 2006).

According to the most recent report available on Eastern University's Institutional Research website, Fall 2005 undergraduate enrollment totaled 29,728, with 17,529 undergraduate students and 9,248 graduate and professional students, as well as 2,951 nondegree seeking students. Nearly eighty-three percent of students who attended Eastern University were classified as in-state residents. Females comprised nearly 55 percent of the total student body, males comprised of 43 percent, and three percent of the students did not identify their gender. The student body was very diverse; twenty-seven percent identified themselves as a minority and another six percent identified themselves as an international student.

Eastern University, which is fully accredited by the Southern Association of Colleges and Schools, has three campuses that are located in three adjoining counties. Each campus has a distinctive academic focus; however, the main campus offers the majority of courses, is the home of the central administration, and is the only location that offers on-campus housing. Only thirteen percent of the students who attend Eastern University live on campus. 
Students who attend Eastern University may choose from 62 undergraduate academic programs, 69 masters' level programs, 24 doctoral programs, and one professional law school, all of which are housed within 11 academic divisions. Eastern employs roughly 4,600 employees and 1,200 of those serve as full-time faculty (Eastern University Institutional Research website, 2006).

According to its mission statement, Eastern University strives "to be an institution of international academic reputation providing superior education for students to develop critical, analytical, and imaginative thinking and to make well-founded ethical decisions." Specifically, the President of the institution articulated his vision on achieving that mission through six statements included on the institutions website. According to the President, Eastern University strives to:

1. Be a magnet for outstanding faculty who will devise new ways to approach problems, invent new ways to teach, and develop new knowledge for the benefit of the region and nation.

2. Attract inventive, industrious students of all ages and cultures and produce citizens who are intellectually and technologically literate people who will lead by the force of their ideas.

3. Transform into knowledge and wisdom the vast amounts of information now accessible through new technologies.

4. Build strong alliances that bring the know-how of business and the community into the university and take the knowledge of the university into the workplace and the larger society.

5. Be a center of inquiry, knowledge, and professional expertise in fields with vital implications for human needs and opportunities in the future.

6. Remain innovative, resourceful, and responsive, while drawing on the intellectual and cultural heritage of the classical university. 


\section{Mission Statement for Eastern University Student Affairs}

According to the assessment liaison for this study, Eastern University's Student Affairs Division is “....in the midst of an 'identity' project... using a consultant to help us envision and better communicate our mission, purpose, [and] identity to all our various constituents. So you will not find a formal mission statement on the web site at this time." She continued to explain that the official interim statement being used by the division reads:

[Eastern University Student Affairs] cultivates and develops partnerships and cocurricular programs across the university that focus on multicultural/diversity education, international education, academic and career success, student leadership, health and wellness, and civic responsibility/engagement.

Like the other institutions explored in this study, Eastern University was led by a Vice President who directly reported to the President of the institution. Unlike the Vice President at Southern and Western, the Vice President of Student Affairs at Eastern was female and had only been the Vice President for roughly one year at the time of this study.

The Student Affairs organizational chart indicated a top-to-bottom reporting structure. The Vice President directly oversees one Dean of Students, six Associate Deans, a Director of Community Relations, and one Assistant Dean for a branch campus. The Dean and Associate Deans are responsible for directly overseeing more than twenty units that are traditionally found within a Student Affairs division, such as a Counseling Center, Disability Services, Multicultural Services, Student Health Services, Career Services, New Student Orientation Office, and Student Activities (Eastern University Student Affairs website, 2006). 


\section{Study Participants}

The researcher interviewed nine Eastern University Student Affairs educators for approximately one hour in September, 2005 for this study. Like Southern and Western Universities, participants at Eastern University were purposefully selected with the guidance of the division's Coordinator of Assessment, who served as the liaison for this study.

At Eastern University, the researcher interviewed the Vice President of Student Affairs; an Associate Dean of Students, who also served as the Coordinator of Assessment for the division; and three members of the division's assessment committee, including an Assistant Director of Leaning Services, a Coordinator of Faculty and Curriculum Development, and Director of the Student Union and Student Affairs Programs. Additionally the researcher interviewed four non-assessment committee members including an Associate Dean who had previously coordinated the division's assessment efforts, an Assistant Dean of a branch campus, a Director of Orientation and Family Programs, and the Acting Director of the Office of Diversity Programs and Services.

All nine of the interview respondents were female. Two described their race as African American, and the others described their race as Caucasian. At the time of the site visit, two of the respondents held doctoral degrees and seven respondents held master's degrees. The average length of the respondents' employment in their current positions at Eastern University was nearly 4.5 years (see Table 30$)$. 
Table 30

Eastern University Interview Respondents

\begin{tabular}{|c|c|c|c|c|c|c|}
\hline Participant & Position & Education & Gender & Race & $\begin{array}{c}\text { SA } \\
\text { Assessment } \\
\text { Committee } \\
\text { Member }\end{array}$ & $\begin{array}{l}\text { Length of } \\
\text { Employ- } \\
\text { ment in } \\
\text { Current } \\
\text { Position } \\
\end{array}$ \\
\hline 1 & Vice President & Ed.D. & Female & Caucasian & & $1 \mathrm{yr}$ \\
\hline 2 & $\begin{array}{l}\text { Assoc. Dean/ } \\
\text { Coordinator of } \\
\text { Assessment }\end{array}$ & MA & Female & Caucasian & $\mathrm{X}$ & $6 \mathrm{yrs}$ \\
\hline 3 & $\begin{array}{l}\text { Unit Asst. } \\
\text { Director, } \\
\text { Learning } \\
\text { Services }\end{array}$ & Ph.D. & Female & Caucasian & $\mathrm{X}$ & $18 \mathrm{yrs}$ \\
\hline 4 & $\begin{array}{l}\text { Unit Program } \\
\text { Coordinator, } \\
\text { Faculty \& } \\
\text { Curriculum } \\
\text { Development }\end{array}$ & MA & Female & Caucasian & $\mathrm{X}$ & $5 \mathrm{mths}$ \\
\hline 5 & $\begin{array}{l}\text { Unit Director, } \\
\text { Student Union } \\
\text { and Programs }\end{array}$ & MA & Female & Caucasian & $\mathrm{X}$ & $7 \mathrm{yrs}$ \\
\hline 6 & Assoc. Dean & MA & Female & Caucasian & & $6 \mathrm{yrs}$ \\
\hline 7 & $\begin{array}{l}\text { Unit Director, } \\
\text { Orientation \& } \\
\text { Family } \\
\text { Programs }\end{array}$ & MA & Female & $\begin{array}{l}\text { African } \\
\text { American }\end{array}$ & & $3 \mathrm{mths}$ \\
\hline 8 & $\begin{array}{l}\text { Acting Unit } \\
\text { Director, } \\
\text { Diversity } \\
\text { Services and } \\
\text { Programs }\end{array}$ & MA & Female & $\begin{array}{c}\text { African } \\
\text { American }\end{array}$ & & $4 \mathrm{mths}$ \\
\hline 9 & $\begin{array}{c}\text { Asst. Dean, } \\
\text { Branch Campus }\end{array}$ & MA & Female & Caucasian & & $1 \mathrm{yr}$ \\
\hline
\end{tabular}


History of Eastern University Student Affairs Assessment Efforts

Eastern University Student Affairs began its assessment efforts in 2000. According to the Director of the Student Union and Student Affairs Programs, assessment efforts initially began when the President of the University appointed an Eastern University Sociology professor to lead the Student Affairs division. An Associate Dean, who coordinated the assessment efforts from 2000 through the summer of 2005 for division concurred that the division began its assessment efforts as a result of the appointment of the new Vice President. She stated that the initiative was internally driven. Specifically she stated,

It did not come from an external mandate. It did not begin because the Vice President wanted to reorganize people, jobs, or resources. It really came out of introspect... let's really take a systematic look at what we were doing; how we might do it better; how we might do it differently.

All interview respondents were given the opportunity to describe their perception of why the division initiated its assessment efforts (see Table 31). Four respondents (44.4\%) indicated that the division began assessing to improve the work that was occurring in student affairs. An Associate Dean explained, "Certainly we stated with the really basic questions: Why are we doing what we are doing? And, how do we know what we are doing makes sense?" Another Associate Dean and newly appointed Coordinator of Assessment (who for the remainder of this chapter will simply be referred to as the Coordinator of Assessment) stated that, "We knew we were doing great things but we had to ask ourselves: How do we go about improving what we are doing? How will this information help us think about what is working and what is not working?" 
Table 31

Eastern University Interview Responses: Reason Student Affairs Began Assessing Learning Outcomes

\begin{tabular}{lcc}
\hline Reason division began assessing learning outcomes & $\begin{array}{c}\text { Interview response: } \\
\text { responses } \\
\text { N=9 }\end{array}$ & $\begin{array}{c}\text { \% based upon number of } \\
\text { respondents (N=9) }\end{array}$ \\
\hline $\begin{array}{l}\text { To improve the programs/services/learning } \\
\text { opportunities provided by Student Affairs }\end{array}$ & 2 & 44.4 \\
$\begin{array}{l}\text { To validate role of Student Affairs in higher } \\
\text { education }\end{array}$ & 1 & 22.2 \\
To better align division with the institutional mission & 1 & 11.1 \\
To enhance the division's planning efforts & 1 & 11.1 \\
\hline
\end{tabular}

Another reason Eastern Student Affairs began assessing revealed by $22.2 \%$ of the respondents was to validate the role of Student Affairs in higher education. An Associate Dean explained, very few units had any kind of data to actually validate their decision making. She explained that systematic data collection allowed the division to ...raise our visibility and elevate the kinds of good work that we do, not with just each other, but with the rest of the university and the rest of the profession. [Assessment data] would provide people with the... information they needed in order to share their expertise, their programs, and their services with others in the field. In fact, it did increase the number of publications and number of presentations that happened." Other reasons identified by respondents for initiating a commitment to assessment were to better align the division with the institutional mission $(11.1 \%)$, to enhance the division's planning efforts (11.1\%) and to demonstrate accountability $(11.1 \%)$. 
Respondents were also asked to reflect upon what they viewed as the purpose of assessing learning outcomes. Table 32 illustrates that the majority of respondents $(68.7 \%)$ perceived that the purpose of assessing student learning outcomes was to show evidence that units were contributing to the institution's mission of student learning. A Curriculum and Faculty Development Program Coordinator stated, "To me this [contributed] to the mission of education, the mission of our university." Likewise, the Vice President explained, ...we want to find out what students are learning; how our programs are impacting that; and most importantly, is that the bigger picture of connecting the co-curricular and the [curricular]. We really have to be on top of that to really show our importance in the university.

The Director of the Student Union and Student Affairs Programs also indicated the purpose of assessing student learning helped the division to better align itself with the Eastern's mission. She stated, "I think when [the former Vice President] came on board, she had a faculty perspective and saw very early on the importance of assessment and using that information to determine how [we were] affecting student learning," thus contributing to the Eastern's mission. Table 32

Eastern University Interview Responses: Purpose of Assessing Learning Outcomes

\begin{tabular}{lcc}
\hline \multicolumn{1}{c}{ Purpose for assessing learning outcomes } & $\begin{array}{c}\text { Interview response: } \\
\text { responses } \\
\mathrm{N}=9\end{array}$ & $\begin{array}{c}\text { \% based upon } \\
\text { number of } \\
\text { respondents (N=9) }\end{array}$ \\
\hline $\begin{array}{l}\text { To show evidence that the units in the division are } \\
\text { contributing to the institution's mission of student learning }\end{array}$ & 1 & 66.7 \\
Raise the visibility of the institution & 1 & 11.1 \\
To justify budget requests & 1 & 11.1 \\
To better meet the needs of students & & 11 \\
\hline
\end{tabular}


An Associate Dean indicated that one of the purposes of assessing student learning was to elevate the visibility of the institution. While, the Assistant Director of Learning Services, a subunit of the counseling center, believed the purpose of assessment was to "provide excellent data for budget requests... for justifying services for supporting the improvement [of student learning], and at times the expansion of services..." She also stated that the purpose of assessment was to "...get feedback from [students] that help us to see what we might need to do to better meet the needs of students."

As previously explained, the division formally began their assessment efforts in 2000 under the direction of a new Vice President appointed from Eastern's faculty ranks. Table 33 provides a synopsis of the history of Eastern University's Student Affairs assessment efforts. 
Table 33

Eastern University Student Affairs Assessment History and Progress

\begin{tabular}{|c|c|}
\hline Academic Year(s) & Activity \\
\hline $2000-2001$ & $\begin{array}{l}\text { - Appointment of new Vice President of Student Affairs. } \\
\text { - Associate Dean begins to coordinate division-wide assessment efforts. } \\
\text { - Assessment committee created. } \\
\text { - Series of assessment-related professional development activities occur. }\end{array}$ \\
\hline 2001-2002 & $\begin{array}{l}\text { - Creation of a standardized assessment survey, known as the Participant } \\
\text { Learning Evaluation. } \\
\text { - Participant Learning Evaluations are distributed to students at every } \\
\text { program offered by units. } \\
\text { - Some units begin developing unit level assessment plans. }\end{array}$ \\
\hline $2002-03$ & $\begin{array}{l}\text { - Internal grant program established for high quality assessment } \\
\text { activities. } \\
\text { - Assessment website created. }\end{array}$ \\
\hline 2003-04 & $\begin{array}{l}\text { - Search begins for new Student Affairs Vice President. } \\
\text { - New Vice President appointed (2004). } \\
\text { - Comprehensive assessment report written (2004 document provided to } \\
\text { the researcher of this study). }\end{array}$ \\
\hline 2004-05 & $\begin{array}{l}\text { - Participant Learning Evaluations no longer administered. } \\
\text { - New Coordinator of Assessment identified. } \\
\text { - Division partners with StudentVoice. }\end{array}$ \\
\hline
\end{tabular}

Individuals Involved in Eastern University Student Affairs Assessment Process

Like Southern and Western Universities, many individuals were involved in Eastern's Student Affairs assessment activities. All respondents, including the Vice President, indicated that the former Coordinator of Assessment and the current Coordinator of Assessment provided the overall leadership for the initiative. The Vice President indicated that the current Coordinator of Assessment was expected to serve as a liaison between her office and unit level offices in regard to assessment activities. The Vice President also indicated a high level of faith in the Coordinator of Assessment. She stated, 
She is regularly communicating with the staff and she has done a good job getting people prepared. I think one of things that she is doing is that she is focusing on things that get people into the [leaning outcomes assessment] mindset, and that is difficult. She is making it exciting for units. I really like her approach.

The Coordinator of Assessment, who also held the title Associate Dean stated, "I would say that only about $50 \%$ of my job is assessment related." When asked to elaborate on her role as the Coordinator of Assessment, she explained that she had been creating a new division-level assessment committee, to replace the committee that had dissolved due to administrative changes and reorganization. She stated that each unit would identify an assessment liaison that will serve on the committee, and "I will be meeting with every [unit] to assure that people feel empowered and are making progress." Moreover, she indicated that she was the primary liaison between the division and StudentVoice, a consulting firm that ...helps guide the assessment curriculum of North America's most innovative institutions, not by replacing existing efforts or simply supplying technology, but by providing a complementary set of tools and a set of programs that makes assessment practice actionable, effective and non-intrusive. StudentVoice's expert consultants offer in-depth assistance on all aspects of program development including creation of departmental goals and objectives, scheduling and alignment of assessment opportunities, technology applications, and questionnaire design (Student Voice webpage, 2006). The Coordinator of Assessment provided the researcher with a copy of her official job description. The document included sixteen items, with the majority of those items related to her role as an Associate Dean who oversaw Career Services, Counseling Center, and the Early 
Identification Program. Only two items were clearly linked to her role as the Coordinator of

Assessment. According to the document, the Coordinator of Assessment was expected to:

1. Lead [Student Affairs] division-wide assessment, evaluation and benchmarking initiatives.

2. Develop mutually beneficial connections and partnerships with academic areas to enhance [Student Affairs] co-curricular agenda (Student Affairs Assessment Coordinator's official job-description, 2005).

Soon after assuming her role as the new Coordinator of Assessment, she wrote and distributed a memo to each of the division's directors and coordinators on August 31, 2005 that outlined her agenda. The memo provided the researcher with a better understand of her role as the Coordinator of Assessment. The memo, which was provided to researcher, outlined the following goals:

1. Introduce new easy-to-use, flexible data collection methods using StudentVoice and other tools and resources. Phase out the Participant Learning Evaluation currently used.

2. Ensure common data collection and reporting strategies across departments and programs so that data can be easily aggregated into departmental annual reports as well as division-wide reports

3. Develop front-end strategic assessment plans that drive data collection to ensure that the targeted data is collected, analyzed and used effectively. Focus will be on better understanding student needs, the alignment between programs and student needs, and the impact of the service provided, especially on student learning and development.

4. Develop a system and framework for monitoring/managing assessment plans, tasks, outcomes and reporting.

5. Maintain an environment/culture of learning from one another, sharing useful practices with our colleagues at [Eastern] and through professional association conference presentations and publications, supporting one another, and recognizing/rewarding successful initiatives.

She concluded in her memo, "To help us achieve these goals, I will be forming an assessment committee with representation from each [Student Affairs] department/program." 
Each unit director was expected to email her before September 7, 2005 with the name of the individual from that unit who would serve on the assessment committee. She explained to the researcher that since the division was now "stabilized," a new assessment committee was being created "...primarily continue to look at student learning and use the tools that we have through StudentVoice." Only weeks before this study, each of those unit representatives met with a consultant from StudentVoice who provided a professional development workshop focused upon how to use StudentVoice as an assessment resource. A specific charge to this newly created assessment committee was not available at the time of this study, however the researcher followed-up with the Coordinator of Assessment, inquiring about the purpose of the committee. In an email response, she wrote

Each [Student Affairs] unit has identified an individual to serve as its assessment liaison. I work directly with these individuals and with this group. These individuals are responsible for working within their units on the development of the unit's assessment plans and final reports. They monitor within their units the progress each unit is making with assessment initiatives. They bring issues and concerns to me and the larger group for assistance in finding solutions. They share strategies and practices that have worked well within their units with the other assessment council members. They provide me feedback on questions I raise and guidance on development and implementation of assessment policies and procedures, for example, changes to how/what we request in terms of demographic data. They have and will continue to assist in offering workshops within the division on assessment related topics. In addition to meeting with the entire group, I meet individually with the assessment liaisons. 
The focus of the new assessment committee differed from the committee that had been in place under the former Coordinator of Assessment and former Vice President. The former Coordinator of Assessment and Associate Dean explained that the original assessment committee was formed in 2000 to support the help support and guide the assessment efforts within the division. The group was chaired by the former Coordinator of Assessment and consisted of seven people who, according to the former Coordinator, "had expressed an interest." She explained, "Their units, initially, received some additional money to cover for the time they would spend on the assessment committee. It also involved a person from Institutional Research, but it was primarily an internal group." However, the current Coordinator of Assessment explained that, the division would not be ...buying out anyone's time [who served on the new committee], because we believe assessment should be embedded in the work of each unit. We contracted with StudentVoice in $2005-06 \ldots$ in order to make it easier for each unit to fully integrate assessment into their planning and operations; in order to empower them to collect meaningful data about programs, services or activities they deem important; and to in order to use the data to make quality improvements.

When asked what the former committee's role in the assessment initiative was, the former Coordinator stated, "That group developed the Performance Learning Evaluation" (a standardized survey for the division to be discussed later in this chapter) with each unit having the opportunity to provide feedback before it was finalized." She also explained that group spent a great deal of time providing optional, on-campus assessment related professional development workshops. She then referred to the researcher to the assessment website for further information 
on the committee's formal charge. According to that website, during the 2000-01 academic year, the Vice President's issued a charge to the former assessment committee that read:

The [Student Affairs Assessment Committee] is charged to develop a unit-level assessment model and advise the Vice-President and support [Student Affairs] units [with] related to assessment issues, needs, policies, procedures, resources, timelines, and quality control mechanisms.

The charge also included "Assessment Guidelines" that read:

1. [Student Affairs] assessment activities will be integrated into the division's ongoing operations, such as planning, staff development, and other efforts to better understand student needs and improve services.

2. The [Student Affairs] assessment model emphasizes student outcomes. That is the model responds to the question - What should students learn and be able to do as a result of their participation in [Student Affairs] activities/programs and use of services?

3. The [Student Affairs] assessment model intends to be sufficiently flexible to respond to the unique assessment needs and character of various [Student Affairs] units.

4. [Student Affairs] assessment processes will be appropriately rigorous in terms of research conceptualization, design, analysis and use and reporting of data. Particular attention will be paid to providing support and ensuring quality related to technical issues (developing instruments, analysis, interpretation and use of data, etc.)

5. Assessment in [Student Affairs] will be continuous, and ongoing (processes will be iterative and findings will be used to increase understanding of issues and guide the development of new questions and corresponding assessment processes).

6. The [Student Affairs] Assessment [committee] will oversee the development, implementation, and coordination of unit and division assessment plans, processes, and procedures (Eastern University Student Affairs Assessment website, 2005).

The former Coordinator of Assessment as well as many respondents described to the researcher the major accomplishments of the former assessment committee. One of those accomplishments included the creation of a centralized assessment method for data collection. The former Coordinator of Assessment explained, “...because it was important for everyone to 
be on the same page, [the assessment committee] formulated a set of questions to get at both knowledge and attitudinal things, and that emerged as the Participant Learning Evaluation.” The Participant Learning Evaluation included ten standardized questions, five of which asked students to reflect upon their learning. Student were asked to rate their responses on a one to five scale $(1=$ strongly disagree and $5=$ strongly agree). The survey also included basic demographic questions for students complete.

Table 34 displays a sample portion of the survey. The researcher included the questions that were directly related to student learning, not the questions related to student satisfaction. The document classified its learning related questions into the cognitive and affective domains. It should also be noted that the Participant Learning Evaluation was organized with the use of Scantron software and Scantron scanners were used to aggregate the data at the end of each academic semester with the assistance of a graduate assistant. Later in this chapter, the researcher discusses the implementation of the Participant Learning Evaluation across the division as well as the results and decisions made based upon the centralized method of data collection. 
Table 34

Sample Portion of Eastern University Student Affairs' Participant Learning Evaluation

\begin{tabular}{|c|c|c|c|c|c|c|}
\hline $\begin{array}{c}\text { Student Learning } \\
\text { Outcome }\end{array}$ & $\begin{array}{l}\text { Strongly } \\
\text { Disagree } \\
\end{array}$ & Disagree & Neutral & Agree & $\begin{array}{c}\text { Strongly } \\
\text { Agree }\end{array}$ & $\begin{array}{c}\text { Not } \\
\text { Applicable }\end{array}$ \\
\hline $\begin{array}{l}\text { Cognitive Domain } \\
\text { I learned new } \\
\text { information. }\end{array}$ & 0 & 0 & 0 & 0 & 0 & 0 \\
\hline $\begin{array}{l}\text { - I can apply what } \\
\text { I have learned. }\end{array}$ & 0 & 0 & 0 & 0 & 0 & 0 \\
\hline $\begin{array}{l}\text { Affective Domain } \\
\qquad \quad \text { I learned new }\end{array}$ & 0 & 0 & 0 & 0 & 0 & 0 \\
\hline $\begin{array}{l}\text { - I expect to do } \\
\text { things } \\
\text { differently. } \\
\text { - } \text { My attitudes } \\
\text { have changed. }\end{array}$ & 0 & 0 & 0 & 0 & 0 & 0 \\
\hline
\end{tabular}

In addition to the creation of the Participant Learning Evaluation, the assessment committee, with the support of the Vice President, created an internal assessment "mini-grant" program that began in the Spring of 2002. According to the division's assessment website, "The program [provided] grants of up to $\$ 700$ to individuals or teams [that proposed] projects that [assessed] student learning at the program or unit level. Each individual or team [that received] a mini-grant [shared] information about the project both in writing and in a presentation on campus." In order to receive a mini-grant, applicants were required to submit a two to three page proposal that focused upon assessing and improving student learning and identified methods to measure that learning along with a budget with expense justifications. The former Coordinator of Assessment explained that the mini-grant program only was in effect for one year in an attempt to "not do anything punitive to units that did not participate... instead reward those who did." The current Coordinator of Assessment explained that she had received a mini-grant when she was 
leading the Career Service's division as part of her Associate Dean responsibilities. She said that she used the funds to purchase data analysis software for the Career Services unit.

In addition to the assessment committees' creation of a one-year mini-grant program, another grant program had been established in the division prior to the assessment initiative that focused upon programming. The "Student Affair Programming Grant," was awarded and selected by the Director of the Student Union and Student Affairs Programs' office, allowed units across the entire university to receive "thousands" of dollars for innovative programs that enhanced the mission of the Student Affairs Division, according to the Director of the Student Union and Student Affairs Programs. She explained, as did the Coordinator of Assessment and an Associate Dean, that the grant application was modified as a result of a recommendation from the assessment committee. The application was changed to include a section asking grant writers to include a "100-word assessment plan" (Eastern University Student Affairs Assessment website, 2005).

All respondents explained that professionals within each unit were encouraged to engage in the assessment process as well. Most often, the director of the unit was in charge of coordinating unit level assessment efforts, which primarily focused upon administering the Participant Learning Evaluation and completing Program Improvement Goals based upon the data. Further explanation of this process is included in the next section of this chapter, Eastern University Student Affairs Centralized Assessment Method. Moreover, it should be noted that some units had created and implemented their own unit level assessment plans as explained later in the portion of this chapter entitled Eastern University Student Affairs Decentralized Assessment Method. 
Unlike Southern University and Western University, Eastern University Student Affairs did not formally evaluate how the assessment model or how the Coordinator of Assessment was contributing to unit level assessment efforts. However, the Coordinator of Assessment explained, "that is one of the questions that the assessment committee and I will sit down and look at. I will be looking at things such as participation, unit goal and outcomes, and reflection. I will be looking at whether or not there are shifts in people's attitudes [in regard to assessment]." Eastern University Student Affairs Centralized Assessment Method

The assessment model at Eastern University was two-fold. There was a centralized assessment method used for data collection and a decentralized process, which meant that some individual units were producing unit level assessment plans. This portion of the chapter is designed to focus upon the division's centralized efforts, while the following section will focus upon the decentralized assessment efforts.

The centralized method of assessment involved the use of the Participant Learning Evaluation as explained earlier in the chapter. The use of the Participant Learning Evaluation appeared to be the primary method of assessment for Eastern Student Affairs from 2002 through 2005, as revealed by the majority of respondents. The Coordinator of Assessment stated, Up until now, it has been predominately the Participant Learning Evaluations-with StudentVoice [customized surveys] being our primary investment for the upcoming year. We are really excited about using and empowering individual units to try some webbased surveying and through palm held devices. It is going to give them data instantaneously, instead of having to wait a whole semester to get results. The Coordinator of Assessment provided the researcher with a comprehensive assessment report based upon Participant Learning Evaluation data that was prepared in July, 
2004. The report highlighted results and provided a comparison between the number of programs offered during the 2002 (Spring, Summer, and Fall) and 2003 (Spring, Summer, and Fall). Table 35 indicates that 273 programs were offered to students in 2002 with an estimated student attendance of 19,099 . Nearly $50 \%$ of the student who attended a program in 2002 completed a Participant Learning Evaluation. The number of programs offered in 2003 was much greater, with a total of 573 programs offered. It was estimated the 26,590 students attended the programs and $42 \%$ of those students completed a Participant Learning Evaluation. However, it should be noted that the report included the statement, "Because 2002 was a the pilot year for developing and using the Participant Learning Evaluation, the data for that year provides a conservative estimate of the number of programs provided. The 2003 data provide a more accurate representation.”

Table 35

Number of Eastern University Student Affairs Programs, Estimated Student Attendance, and Number of Participant Learning Evaluations Completed During 2002 (Spring, Summer, and Fall) and 2003 (Spring, Summer, and Fall)

\begin{tabular}{cccc}
\hline Year & $\begin{array}{c}\text { Number of Student } \\
\text { Affairs Programs }\end{array}$ & $\begin{array}{c}\text { Estimated } \\
\text { Attendance }\end{array}$ & $\begin{array}{c}\text { Number of Participant Learning } \\
\text { Evaluations Completed }\end{array}$ \\
\hline 2002 & 273 & 19,099 & $9,465(49.6 \%)$ \\
2003 & 575 & 26,590 & $11,161(42.0 \%)$ \\
\hline
\end{tabular}

In addition to identifying the number of programs offered, the estimated attendance, and the number of Participant Learning Evaluations completed, the comprehensive assessment report provided an aggregated results section that compared the mean scores reported by the students who completed Participant Learning Evaluations in 2002 and in 2003 (see Table 36).

The data indicated that student mean responses increased from 2002 to 2003 in each of the learning related questions. The highest mean difference $(+0.27)$ between 2002 and 2003 
occurred within the affective domain, where students were asked if they learned new skills; whereas, the least mean difference $(+0.09)$ between 2002 and 2003 occurred within the cognitive domain, where students were asked if they learned new information. The report stated, "This is likely because the mean for this area was the highest (ceiling effect) and thus it may be difficult to continue to show gains."

Table 36

Eastern University Student Affairs Participant Learning Evaluation Aggregated Results During 2002 and 2003

\begin{tabular}{lccc}
\hline Student Learning Outcome & 2002 Mean & 2003 Mean & $\begin{array}{c}\text { Mean } \\
\text { Difference }\end{array}$ \\
\hline $\begin{array}{l}\text { Cognitive Domain } \\
\text { • I learned new information }\end{array}$ & 4.23 & 4.32 & +0.09 \\
• I can apply what I have learned & 4.10 & 4.25 & +0.15 \\
Affective Domain & & & \\
• I learned new skills & 3.76 & 4.03 & +0.27 \\
- I expect to do things differently & 3.85 & 3.97 & +0.12 \\
- My attitudes have changed & 3.62 & 3.80 & +0.18 \\
\hline Mean Average & 3.91 & 4.07 & +0.16 \\
\hline
\end{tabular}

The July 2004 Performance Learning Evaluation report also identified five recommendations for enhancing the division's assessment efforts. Those recommendations included:

1. Using data that already existed on campus and develop a process for analyzing and using that existing data.

2. Ensuring that the assessment process moves from sporadic to on-going. Having a half or full-time assessment person who has the skills to coordinate the efforts would be helpful.

3. Developing a process for ensuing the flow and use of information at the unit level.

4. Highlighting and supporting the exemplary work being done at the unit level (e.g. Orientation's study of Orientation Leaders). 
5. Expanding and documenting the division's academic partnership to focus on diversity and its impact on student needs, issues, values and learning styles.

In addition to a master report that was prepared by the division, units were also provided customized Participant Learning Evaluation results at the end of each semester. According to the an Associate Dean and former Coordinator of Assessment, each unit was then expected identify their "Program Improvement Goals" for each program where the Participant Learning Evaluation was administered. According to the Program Improvement Goals template, units were required to address the "program description, learning outcomes, and identify areas for improvement."

The researcher was provided with one example of a unit's program improvement goals based upon their Participant Learning Evaluation results. The document was produced by Career Services in 2004. Career Services administered the Participant Learning Evaluation during an internship fair, described as a "a two-day event featuring 140+ organizations recruiting for internships, co-ops, and summer jobs." According to the document, the estimated number of students that attended the fair was 1,200 and 160 (13.3\%) of attendees completed a Participant Learning Evaluation. Results indicated that students reported an average score of 3.7 when asked if they learned new information, which was an increase of 0.14 from the score reported in 2003. However, Career Services indicated in its report that it desired to increase student learning for the following year when it would reassess using the Participant Learning Evaluation during the internship fair. Specifically, the unit outlined the following program improvement goals:

- Set up a table/display in a prominent location in the entrance area to the Internship Fair. The table will offer last minute help before entering the job fair - what to say to employers and help identifying the right employers. Table will be staffed by Career Services counselors and other volunteers

- Inside the Internship Fair, Career Services will maintain a display table offering help and other resources on how to find other internships if you didn't find it today at the fair. 
According to the Coordinator of Assessment, the use of the Participant Learning Evaluations continued through the spring of 2005; however, she explained that they were being "phased-out" because "they only gave us basic baseline information." One respondent commented that the use of the use of the Participant Learning Evaluations had limitations and she was pleased that they were being "phased-out." She stated, "I don't think everybody has bought into assessment. They were using the Participant Learning Evaluations... and people are always complaining about it."

The Vice President indicated that she believed the appointment of the new Coordinator of Assessment and the contract with StudentVoice would assist units with "buy-in" and in the articulation of their learning outcomes. She continued, "I think they [units] have all kept attendance data and things like that... but my senses tell me that people haven't really gotten into learning outcomes, but that should be the base for assessment." She, along with many other respondents indicated a strong belief in StudentVoice's abilities to help them advance their assessment efforts and decentralize much of the process.

Eastern University Student Affairs Decentralized Assessment Process

In addition to the use of Participant Learning Evaluation, the researcher discovered that some units had created and implemented unit level learning outcomes assessment plans. The former Coordinator of Assessment concluded,

What remained centralized was the collection of the Participant Learning Evaluation data and the analysis of [that data]. What kind of got decentralized... were individual units that did their own assessment activities, for instance, Orientation and the Women's Center. 
The researcher was unable to secure and authenticate every single unit's assessment plan, because every unit did not have an assessment plan. Thus the researcher was unable to aggregate the data to include the number of outcomes classified in the cognitive and affective taxonomies, the number of assessment methods, and the types of decisions made based upon results, as done in the previous two case studies. When asked about the lack of articulated learning outcomes at the unit level, the former Coordinator of Assessment explained,

It was difficult for some units to develop learning outcomes, and they would say partly because there wasn't an articulated, overall more comprehensive vision. So, there were several units who felt like if they had more guidance overall... For instance, what are the learning outcomes of the divisions? We had not articulated those. There were general directives from the Vice President like... increasing co-curricular programming, community building, general themes, but it would have been helpful if units had more overall direction. I think... if we would have had that it would have been a more useful way for units to develop their own.

While it may have been difficult for some units to develop learning outcomes, evidence of learning outcomes assessment activities did exist within the division. This portion of the chapter focuses on two unit level assessment plans that were prepared by the Women's Center and Orientation and Family Programs, which were provided to the researcher.

The researcher first reviewed a 2001 pilot assessment plan by the Women's Center. According to the plan, the Women's Center sought to measure a variety of learning outcomes associated with Take Back the Night, an annual rally, “...to protest the ways in which violence permeates the lives of women worldwide."

Cognitive outcomes that were articulated in the assessment plan included: 
- Students who attend the Take Back the Night Event will know campus and national statistics for rape and assault.

- Students who attend the Take Back the Night Event will know definitions of sexual assault and domestic violent.

- Students who attend the Take Back the Night Event will know the institution acknowledges and takes seriously rape and domestic violence.

- Students who attend the Take Back the Night Event will know that protecting those who assault it condoning their behavior

- Students who attend the Take Back the Night Event will know about existing resources for victims and prevention

The aforementioned cognitive outcomes were categorized, by the researcher, within the lowest levels of cognitive thinking — understand and respond. Additionally the plan included affective learning outcomes such as, "Students will develop a sense of sympathy for victims," as well as, "Students will gain a sense of activism to protect self and others."

The Women's Center applied two methods of assessment in order to determine if their articulated outcomes were being achieved. Firstly, they developed a survey which was administered at the completion of the Take Back the Night rally. The plan indicated that nearly 3,000 participants attended the event and $11 \%$ of those attending completed the survey. The survey included basic demographic and satisfaction questions and nine questions that required students to demonstrate direct gains, and seven questions that asked students to reflect upon their knowledge gains as a result of attending the event. For example, one knowledge question was designed to measure whether or not "Students who attend the Take Back the Night Event will know campus and national statistics for rape and assault." In order to determine if, in part, that outcome was being achieved, students were asked on the survey, "According to national research, what percent of college students have been victims of rape or attempted rape?" Students had four choices- $10 \%, 25 \%, 50 \%$, or $75 \%$. An example of a question created to 
measure students' perceptions of their knowledge included on the survey was, "Do you know what actions to take if you are sexually assaulted?" Students had three choices-Yes, No, or Not Sure.

In addition to surveying students, a select group were asked to participate in a focus group three months after the event to determine if students were achieving the desired outcomes. According to the plan, approximately nine Take Back the Night attendees were asked to participate in a one-hour and fifteen-minute focus group. Students were asked six open-ended questions. Example questions included:

1. Tell us about your initial reaction to Take Back the Night?

2. During the rally, we heard that one in four college-age women are victims of rape or attempted rate, and that every nine seconds in the USA a woman is raped. Why do you think this is the case? What might be going on?

3. Will you do anything or have you already done something differently as a result of attending Take Back the Night?

Assessment results were not included in the Women's Center assessment plan. The researcher made multiple attempts through phone calls and emails after the his site visit to secure those results; however, the individual who coordinated the assessment activities for the Women's Center explained in an email that she was "...no longer [in] that position and [did] not have access to files with all of [that]information." However, she did direct the researcher to an article that she co-authored in early 2002 for the National Association of Student Personnel Administrators NetResults webpage, which described their assessment plan, thus indicating to the researcher a high quality assessment project worthy of publication. The researcher was unable to cite the article, because if he did so, he risked revealing the identity of human participants in this study. However, the article included decisions made by the Women's Center based upon their collected data. Those decisions included: 
- The Women's Center will reassess student learning the following year; however in order to enhance response rates, they will provide Take Back the Night T-Shirts in exchange for a completed survey. Moreover, surveys will be administered in a well lit area inside at a reception rather than outside as done in 2001.

- The Women's Center will create focus groups for both men and women "to assess long-term impact of the [event] and to better understand student issues and perceptions related to sexual assault and domestic violence" (NASPA NetResults webpage, 2001).

An interview with the Director of Orientation and Family Programs revealed to the researcher another unit level driven assessment plan. The Director of Orientation and Family Programs explained, "We have a tiered leadership model" that was has involved ongoing assessment. This complex model, created by the Director, involved measuring levels of student workers' gains in a variety of student learning areas. In order to understand the assessment plan, one must first understand what the Director called a "very intricate model."

The model was based upon measuring what the Director of Orientation and Family Programs referred to as "competencies" that student workers should have demonstrated over time. Table 37 provides a summary of the student employee positions, a summary of their duties, and the competency areas for assessment. Information contained from in Table 37 was described to the researcher during the interview by the Director of Orientation and Family Programs and was also included on the Orientation and Family Programs' website. 
Table 37

Eastern University Orientation and Family Programs Office Student Employee Positions,

Summary of Duties, and Competencies for Assessment

\begin{tabular}{|c|c|c|}
\hline Job Title & Summary of duties & Competency Areas to Assess \\
\hline $\begin{array}{l}\text { Office } \\
\text { Specialist }\end{array}$ & $\begin{array}{l}\text { Office specialists are highly } \\
\text { motivated individuals... who } \\
\text { execute daily office tasks and serve } \\
\text { as the first point of contact for new } \\
\text { students, families, faculty, and staff }\end{array}$ & $\begin{array}{l}\text { - Time management } \\
\text { - Multi-tasking } \\
\text { - Self-knowledge, } \\
\text { - managing emotions, } \\
\text { - } \text { conflict resolution } \\
\text { - Ability to be a team player } \\
\text { - Professionalism }\end{array}$ \\
\hline $\begin{array}{l}\text { Senior Office } \\
\text { Specialist }\end{array}$ & $\begin{array}{l}\text { The Senior Office Specialist assists } \\
\text { the office manager in the overall } \\
\text { management of the office staff and } \\
\text { maintenance of office functions, and } \\
\text { serves as a role model and resource } \\
\text { for the Office Specialists }\end{array}$ & $\begin{array}{ll}\text { - } & \text { Delegations } \\
\text { - } & \text { Professionalism } \\
\text { - } & \text { Leadership } \\
\text { - } & \text { Conceptual thinking skills } \\
\text { - } & \text { Project management } \\
\text { - } & \text { Conflict resolution } \\
\text { - } & \text { Problem solving }\end{array}$ \\
\hline $\begin{array}{l}\text { Orientation } \\
\text { Leader }\end{array}$ & $\begin{array}{l}\text { Orientation Leaders acquaint new } \\
\text { students with the campus } \\
\text { environment and facilitate small } \\
\text { group interaction on various topics } \\
\text { at Orientation with new students, }\end{array}$ & $\begin{array}{ll}\text { - } & \text { Group dynamics } \\
\text { - } & \text { Managing emotions } \\
\text { - } & \text { Conflict resolution } \\
\text { - } & \text { Problem solving } \\
\text { - } & \text { Time management } \\
\text { - } & \text { Program development/planning } \\
\text { - } & \text { Ethical practices } \\
\text { - } & \text { Utilizing resources } \\
\text { - } & \text { Written communication } \\
\text { - } & \text { Self-knowledge } \\
\text { - } & \text { Public Speaking }\end{array}$ \\
\hline $\begin{array}{l}\text { Orientation } \\
\text { Assistant } \\
\text { (Head of } \\
\text { Orientation } \\
\text { Leaders) }\end{array}$ & $\begin{array}{l}\text { The Orientation Assistant mentors, } \\
\text { with general supervision } \\
\text { responsibilities the Orientation } \\
\text { Leader Team and facilitates } \\
\text { effective communication between } \\
\text { the Orientation Leader Team and the } \\
\text { Orientation Coordinators. }\end{array}$ & $\begin{array}{l}\text { - Supervisory responsibilities } \\
\text { - } \text { Professional ethics } \\
\text { - Legacy (Demonstrates } \\
\text { accountability for Orientation } \\
\text { tem and nurtures growth and } \\
\text { development in others) } \\
\text { - Ability to motivate others } \\
\text { - Conceptual thinking skills }\end{array}$ \\
\hline
\end{tabular}


Table 37 Continued

Eastern University Orientation and Family Programs Office Student Employee Positions, Goals of Positions, and Competencies for Assessment

\begin{tabular}{llc}
\hline Job Title & Summary of Duties & Competency Areas to Assess \\
\hline $\begin{array}{l}\text { Orientation } \\
\text { Coordinators }\end{array}$ & $\begin{array}{l}\text { Orientation Coordinators supervise } \\
\text { the Orientation Leader Team. They } \\
\text { also Plan, coordinate, and evaluate } \\
\text { the Orientation Leader Training } \\
\text { course in the spring }\end{array}$ & Not available \\
$\begin{array}{l}\text { Family } \\
\text { Program }\end{array}$ & $\begin{array}{l}\text { The Family Program Coordinator } \\
\text { assist in the coordination, } \\
\text { implementation, and evaluation of }\end{array}$ & - Leadership \\
& $\begin{array}{l}\text { Family Weekend and coordinates } \\
\text { collaborative efforts for Little } \\
\text { Sibling Program. }\end{array}$ & \\
\hline
\end{tabular}

In order to assess whether or not the articulated competency levels were achieved, the Director of Orientation and Family Programs explained they used a survey that required all student employees, except for the Orientation Leaders, to "first rate themselves [on each competency for that position] on a one to five scale... one being no skill evident, two being some skill evident, [five being mastery of that scale]... and so on." According to the Director, the survey included detailed definitions of each competency area. It should be noted that researcher was unable to secure and authenticate the survey used by the unit after repeated attempts via telephone and email to the director following the site visit. However, the Director did explain in detail how the survey was designed and administered. For instance, one of the competency areas assessed for many of the student employees perceptions of their leadership competency. Thus, it is the understanding of the researcher that a student would be provided with the following statement as listed on the unit's website:

Leadership is the ability to 'influence-nothing more, nothing less. This moves beyond defining the leader, to looking at the ability of the leader to influence others; both those 
who would consider themselves followers, and those outside the circle.' Demonstrating this competency will allow you to become aware of your ability to impact the lives of those around you and understand the type of leader you are and how to shift into different roles of leadership.

According to the Director, after reading the statement, a student would self-rate $\mathrm{him} /$ herself on the one to five Likert scale as described in the previous paragraph prior to beginning employment duties. He or she would then sit down with a professional staff member and discuss each competency area and why he or she rated him/herself at a certain level. The Director explained, "This gives me a temperature check, what [students] think; what's going on with [students]." This exchange, according to the Director, "allows time for reflection." She continued to explain that the professional staff member and the student reach a rating agreement for each competency and outline a plan for the student to enhance their competency levels. She continued to explain that students are then continually assessed every two weeks by their supervisor using the same assessment instrument, allowing the supervisor to say "This is where I see you, this is what potential I think you have." However, she also explained that every competency area may not be assessed each time because the student may "have not had a connection with a particular competency area during that [two-week] period." At the end of the student's employment, he or she is again asked to self-report his or her competency levels, thus providing the unit with evidence of learning over a student's entire employment period.

According to the Director, the greatest benefit of that individualized method of assessment was that she and her staff could tailor their advising styles to each student and encourage them to grow as learners. Moreover, she described a specific example of using the formative data from the survey to enhance the student employee experience. She explained that an assessment of the Senior Office Specialist indicated that the students were not comfortable in delegating tasks at the beginning of his/her employment and were not learning that skill over 
time. After further examination, she realized that 'the student's supervisor's background was not in student development and she struggled to motivate students in this area." As a result, the Director provided training to her professional staff on how to motivate student to delegate tasks when appropriate. Moreover, the Director indicated that the Office Specialists had team meetings every three weeks. In order to help students enhance and demonstrate their delegation abilities, meetings were altered and students were expected to lead them, in part "so they would develop more confidence and be able to say, 'I'm delegating this meeting."'

According to the Director, another method used by the Orientation and Family Programs office to assess student learning occurred in the Orientation Leadership program. She explained that when Orientation Leaders are hired they

must complete a 51 item Likert scale assessment [arranged similarly to the one previously described] related to each competency area... then we generate the data so what we have a picture of what the team looks like, what they may stand in need of training, because each of the competency areas are part of our training. Again, the researcher was unable to secure and authenticate this survey. The Director explained that the Orientation Leaders did not complete that assessment again because the "summer orientation schedule is so intense, so we can't have one-on-one meetings with each." As a result, she explained, "We had to be creative... so we do reflective circles [focus groups]." She explained the Orientation Leaders were divided into two groups and met five times with a graduate intern from the Orientation Office who was trained to lead the reflective circles. Each reflective circle had a particular theme related to the articulated competencies and Orientation Leaders were required to write a journal entry on that competency area prior to each meeting. According to the Director, the reflective circles allowed the unit to make formative decisions 
throughout the summer program and help individual students grow in each of the competency areas. The respondent did not provide the researcher an explanation of how the data was analyzed or a specific example of using the data to enhance student learning.

\section{Eastern University Student Affairs Educators' Perceptions of High Quality Learning Outcomes}

It was evident to the researcher at the time of his site visit that the majority of units relied primarily upon the Participant Learning Evaluation as an assessment method and most units were not articulating learning outcomes. However, the researcher still asked each of the Eastern's respondents to reflect upon what they believed to be high quality learning outcomes, particularly because the division was embarking on a new decentralized assessment process. Responses varied; with nearly one-half (44.4\%) indicating that high quality learning outcomes must be measurable (see Table 38). The Coordinator of Assessment stated, "Well obviously is it something we are going to be able to measure, because if you can't, you have to go back to the drawing board." The former Coordinator agreed and stated that high quality learning outcomes must be articulated so that there "....is a means to figure out if we have achieved... measurable." Table 38

Eastern University Interview Responses: Characteristics of High Quality Learning Outcomes

\begin{tabular}{lcc}
\hline \multicolumn{1}{c}{$\begin{array}{c}\text { Interview response: } \\
\text { Characteristics of high quality learning } \\
\text { outcomes }\end{array}$} & $\begin{array}{c}\text { Number of } \\
\text { responses } \\
\mathrm{N}=9\end{array}$ & $\begin{array}{c}\text { \% based upon number of } \\
\text { respondents } \\
(\mathrm{N}=9)\end{array}$ \\
\hline Measurable & 4 & 44.4 \\
$\begin{array}{l}\text { Flow from division's mission and } \\
\text { institution's mission }\end{array}$ & 2 & 22.2 \\
Specific & 2 & 22.2 \\
Attainable & 1 & 11.1 \\
\hline
\end{tabular}


Two respondents believed that high quality learning outcomes must flow from the division's and institution's mission. The Vice President stated, "Everything should be coming back to the mission. I want their learning outcomes to be based on the mission so there is some relationship [and] it all fits together in some nice package." The Assistant Director of Learning Services echoed the Vice President's statement insisting that the "overall mission is to support the academic progress of students, and from the standpoint of counseling there are a number of things we believe students need to learn to be able to do in order to progress in their academic programs."

The Assistant Dean of a branch campus stated, "I think they should be specific... easy to understand... clearly articulated. A lot of them I have seen are very flowery in how they are written and don't get to the heart of what you want to know, so I think that they need to be precise and clearly articulated." The Director of Orientation and Family Programs also felt that high quality learning outcomes must be specific and "clearly defined." An Associate Dean explained that learning outcomes must be attainable. She continued, "[Units] should ask themselves, '...can we operationalize what you are saying? Is it achievable? And is there a means to figure out if we have achieved the outcome?"'

\section{Eastern University Student Affairs Assessment Collaboration}

Respondents at Eastern University were quick to describe programming collaborative efforts on their campuses; however, similarly to the other two case studies, their learning outcomes assessment planning and implementation appeared to be primarily a non-collaborative process. Unit level assessment plans that were reviewed by the researcher were solely planned by that unit and the researcher did not secure any written evidence of joint assessment planning. However, it should be noted that the administration of the Participant Learning Evaluation was at 
times a collaborative effort, due to the fact that it was mandatory for units to administer for each of their programs. Thus, programs that were designed with a collaborative intent, such as one Curriculum and Faculty Development Coordinator described. She explained that the Women's Center worked with faculty and other staff members to promote a campus lecture delivered by Matthew Shepherd's mother, Judy, who discussed the murder of her son as well as proposed hate crime legislation. She continued, "A lot of people got involved in that one... housing got involved and [some faculty members] required [student attendance] for their classes. We had over 635 attend." She explained that the Participant Learning Evaluation was administered and then results were shared not only with the Women's Center, but also with those who had assisted in the promotion of the lecture.

Another collaborative assessment effort was described by the Acting Director of the Office of Diversity Programs and Services. She explained that annually, her office arranged four focus groups, which were conducted by the Provost and were referred to as "Provost's Teas." According to the Acting Director, the Provost would sit down with four distinct populations her office served including: “African Americans, Asians, Hispanic/Latino, and LGBTQ [Lesbian, Gay, Bisexual, Questioning, and Transgender] students." She indicated that Provost was responsible for preparing the interview protocol and was unable to provide the researcher with that protocol. However, she continued, "The Provost really focused on the question, 'How can we better reach out to you so that you have a better experience?" She explained, "Each 'Tea' lasted about an hour to an hour-and-a-half. Attendance varied from eight students to one with 31 students... the biggest one was with our African American students." When the Acting Director was asked what type of decisions were made to enhance the student learning experience based upon the "Provost's Teas," she explained that "One thing that happened... students were given 
the opportunity to host a food fare during their respective heritage months. They created the menu and shared their experiences with others on campus." She also explained that she believed part of the reason for the creation of "African American Studies on campus and recruitment of minority faculty" was in-part because "the Provost met with students and listened to their concerns.”

In addition to program collaboration, the Vice President described a "new" and "exciting" collaborative effort with one of the academic divisions on campus. She described it as "a co-curricular model that is really quite innovative." The academic division that Student Affairs was partnering with provided a "small-college experience with access to all the academic resources of a research university close to [adjacent metropolitan city]. It offers two unique programs: the First-Year Experience, open to all incoming first-year students, and degree programs in Integrative Studies" (Eastern University website, 2006). The Vice President explained,

We are going to be working with [that] academic department to develop an [electronic] portfolio system that will be part of the grading process and it will combine [students'] curricular and co-curricular learning into a written, web-based presentation of that learning... allow them to demonstrate what they have achieved.

She continued to explain that the collaboration was part of a project being conducted by the National Association of Student Personnel Administrators (NASPA). She admitted that Eastern University was in the "very early stages" of the project and that she could not elaborate on specific details. She also explained that NASPA was working with a "...team of institutions that are implementing e-portfolios in the student affairs departments... [those teams] will come together, I think, twice a year to share with each other... it is a two year process." 


\section{Eastern University Student Affairs Assessment Successes and Challenges}

Each respondent interviewed at Eastern University was provided the opportunity to describe to the researcher what they believed to be the successes and challenges of their division's assessment activities (see Table 39). One-third of the respondents suggested that a success had been overall assessment progress within the division since beginning its efforts in 2000. The Coordinator of Assessment explained, "We've made great strides overall... some [units] more than others." The Vice President echoed the Coordinator's comments when she stated, "We are moving in the right direction... this takes time." An Assistant Director of Learning Services also believed that select units had been very successful in their assessment efforts. She stated, "I think the units who have really found the time, money, and skills... have put together some nice assessments.... and have been very successful." She continued, "I think those units... learned some new information... and were able to make some changes in their programming related to the feedback they got. Some units are better at doing this than others." Table 39

Eastern University Student Affairs Interview Respondents' Reported Assessment Successes

\begin{tabular}{lcc}
\hline \multicolumn{1}{c}{ Success of assessing student learning outcomes } & $\begin{array}{c}\text { Interview Responses: } \\
\text { Responses } \\
\mathrm{N}=10\end{array}$ & $\begin{array}{c}\text { \% based upon } \\
\text { number of } \\
\text { respondents } \\
(\mathrm{N}=9)\end{array}$ \\
\hline $\begin{array}{l}\text { Student affairs division has made assessment progress since } \\
2000\end{array}$ & 3 & 33.3 \\
$\begin{array}{l}\text { Student affairs educators are now making decisions based } \\
\text { upon data }\end{array}$ & 2 & 22.2 \\
$\begin{array}{l}\text { Select student affairs units have excelled } \\
\text { The overall image of student affairs has been enhanced }\end{array}$ & 2 & 22.2 \\
Assessment has motivated junior-professionals & 2 & 22.2 \\
\hline
\end{tabular}


In addition to overall progress, two respondents (22.2\%) indicated that the use of assessment data to inform decision making had been a success. The Director of the Student Union and Student Affairs Programs praised the Orientation and Family Programs' work to use their assessment results. She stated, "[The Director] has done an amazing job. [Her office] really changed their orientation program based upon their new learning outcomes and their assessment results." The researcher discovered that the majority of respondents consistently cited the Women's Center and Orientation, and at times Career Services, as successful units that have excelled in their assessment efforts.

Another success identified by the Coordinator of Assessment was the enhanced image of the division's work. She stated,

Those that have really shown the commitment, they are doing best practices, they are the people that other universities are looking to, and their reputations within the profession have really grown in terms of what they do. I think it has definitely raised the appreciation and visibility of [Eastern University Student Affairs].

Additionally, an Associate Dean felt that the junior professionals within the division were motivated by the assessment initiative. "This work acted in a way to invigorate newer professionals... these were some of the folks that really got excited about assessment... wanted to be involved."

Respondents also described their perceptions of major assessment challenges. The most reported challenge $(56.6 \%)$ was that assessment was not a priority to everyone within the division (see Table 40). An Associate Dean said that it was a challenge to "get full compliance... getting people to understand the importance of it and helping people figure out how to make assessment not just an addition to their busy schedules." Likewise, the Assistant Director for 
Learning Services states that "research and [assessment] are always the last thing on the priority list." A Curriculum and Faculty Development Coordinator explained that "not everyone is on board. You can't sell everybody on everything. That is just the reality of certain things..." Table 40

Eastern University Student Affairs Interview Respondents’ Reported Assessment Challenges

\begin{tabular}{lcc}
\multicolumn{1}{c}{$\begin{array}{c}\text { Interview Responses: } \\
\text { Challenges of assessing student learning outcomes }\end{array}$} & $\begin{array}{c}\text { Number of } \\
\text { Responses } \\
\mathrm{N}=9\end{array}$ & $\begin{array}{c}\text { \% based upon } \\
\text { number of } \\
\text { respondents } \\
(\mathrm{N}=9)\end{array}$ \\
\hline $\begin{array}{l}\text { Assessment is not a priority to everyone within the student } \\
\text { affairs division. }\end{array}$ & 5 & 11.1 \\
Limited assessment expertise within units & 1 & 11.1 \\
Limited financial resources & 1 & 11.1 \\
Participant Learning Evaluations have become cumbersome & 1 & 11.1 \\
$\begin{array}{l}\text { Difficult to embed assessment activities into units' daily } \\
\text { activities }\end{array}$ & 1 & 1 \\
\hline
\end{tabular}

Other challenges reported by $11.1 \%$ of the respondents included limited assessment expertise within units and limited financial resources. The Assistant Director of Learning Services explained that. "Many units just don't have the expertise within their units to the technical aspects of [assessment]." Additionally, she stated that sometimes, "[lack of] money is the challenge for some units to engage in assessment."

Another challenge included the belief that Participant Learning Evaluation had become cumbersome for staff to administer and students to complete. The Assistant Dean of branch campus stated that the biggest challenge for her was

planning and organizing an event and getting [students] to complete the Participant Learning Evaluations for every one of those events. ...students were bored with them 
and they knew what I was asking and they would get cranky because they would say they had filled it out thirty times already that semester. That was a huge challenge. It just became cumbersome.

Finally, one respondent explained that units were finding it difficult to embed assessment activities into their daily activities, thus it was often overlooked. She explained, ...everybody is so busy that quite frankly... assessment is often an afterthought. We know people like to talk a good game and a lot of people do it — that is... think about assessment prior and beforehand. ...but when it comes right down to actually embedding assessment into daily activities... that is not happening.

After being asked about the challenges of Eastern's Student Affairs assessment efforts, respondents were asked to reflect upon what they believed would enhance the assessment initiative. First of all, all respondents believed that Student Voice was going to help advance their efforts in the upcoming year. However, three respondents, including the former Coordinator of Assessment and the current Coordinator of Assessment felt that the division needed to hire a full- time Director of Assessment. The Assistant Director of Learning Services expressed the need to "hire a full time person who can do the technical aspects and work with units, particularly with analysis." The Coordinator of Assessment explained, "Having someone with a formal experience in assessment would be extremely beneficial" in advancing the division's efforts.

The Director of the Student Union and Student Affairs Programs expressed the need for better communication in regard to assessment expectations. She stated, "We really need to describe our successes to the staff and explain... this is why we are doing this... this is what we are going to use the information for." She continued to explain that "we also need to get faculty 
to collaborate with us." The Vice President stated that she "wish[ed] she had the answer to that question" but continued, "The goal is to make [our assessment initiative] a nationally recognized program that other institution's look to... want to come and visit and learn more about what we do."

Summary of Findings

Eastern University's Student Affairs division first began discussing assessment in 2000 under the direction of a Vice President who came from the University's Sociology faculty. Assessment was introduced to gain a better understanding of the services the division provided. Initially, the initiative was coordinated by an Associate Dean within division and an assessment committee of seven volunteers who helped provide a series of professional development workshops to acquaint the unit level professionals with the assessment process. The assessment committee also created assessment incentive programs to encourage engagement, including mini-grants awarded to units who participated in high quality assessment activities.

The use of a standardized Scantron survey created by the assessment committee, known as the Participant Learning Evaluation, was the primary method of assessment for Eastern Student Affairs from 2002 through 2005. Yet, the division did not have a division level assessment plan. Every unit was required to administer the standardized survey to students who attended any program offered by their respective unit. Results were aggregated at the end of each academic semester, and units were expected to define "Program Improvement Goals" based upon those results.

Few units within Eastern University’s Student Affairs Division had created unit-level learning outcomes assessment plans at the time of this study. The Women's Center and the Orientation and Family Programs office had engaged in unit level assessment planning as 
described in this chapter. Both went beyond the use of the Participant Learning Evaluation as the sole data collection method, and both created locally developed instruments to measure whether or not their articulated learning outcomes were being achieved. Additionally, both units made decisions based upon their assessment results, with the Orientation unit making decisions to enhance the student learning experience based upon their data.

The appointment of a new Vice President in 2004 and the appointment of a new Coordinator of Assessment in 2005, resulted in the division ending the requirement for units to administer the Participant Learning Evaluation. The division shifted its focus to a decentralized assessment model of assessment with the assistance of StudentVoice. The intent of that shift was to help units create more defined unit level assessment plans and data collection methods that better met their needs. Moreover, a new assessment committee was created to include representation from each of the more than twenty units within the student affairs division to help guide the new decentralized model.

Eastern University Student Affairs educators believed that unit level learning outcomes must be measurable, flow from appropriate mission statements, be specific, and be attainable. The most reported assessment successes since the inception of the assessment initiative included the progress and evolution of the division's assessment efforts over time. The most reported challenge reported was that assessment of student learning outcomes was not a priority to everyone in the divisions. Yet, more than one-half of the respondents believed that the shift from a primarily centralized method of assessment data collection to one where a newly appointed Coordinator of Assessment and StudentVoice would help units articulate desired learning outcomes and develop customized surveys to measure whether or not those outcomes were being 
achieved, would enhance the division's assessment efforts; thus, help more professionals appreciate the value of engaging in learning outcomes assessment practices. 


\section{Chapter Eight}

High Quality Student Affairs Learning Outcomes Assessment Practices:

Cross Site Analysis of Three American Research Institutions

\section{Introduction}

The purpose of this study was to explore high quality student affairs learning outcomes assessment practices at three American Research I institutions (Carnegie Foundation, 2005). In this chapter, the researcher examines common themes that emerged across Southern University, Western University, and Eastern University from document analysis and interviews with 25 study participants. This discussion explores how those identified themes support or contradict appropriate assessment literature, specifically focusing upon six research questions that guided this study. Those research questions included:

1. What are the student learning outcomes articulated in the student affairs assessment plans?

2. How are these learning outcomes assessed?

3. Who is involved in the assessment planning process, and what are the major responsibilities of these individuals?

4. Are student affairs educators collaborating with others, such as academic affairs, in the creation and administration of assessments? How?

5. How are student affairs assessment data used to enhance student learning experiences?

6. What successes and challenges do student affairs educators face as they implement their assessment plans?

\section{Assessment Processes}

A synthesis of the literature revealed that assessment scholars collectively agree that assessment is an ongoing process aimed at enhancing student learning (AAHE, 1992; Angelo, 1999; Palomba \& Banta, 1999; Bresciani, 2002; Huba \& Freed, 2000; Maki, 2002a; Marchese, 
1987, Anderson, 2001a; Suskie, 2004). Findings from this study indicate that $52 \%$ of the 25 interview respondents shared the assessment scholars' definition. For instance, the Director of Assessment at Western University stated, "We have always framed this in terms of learning for improvement, not to justify [a unit's existence], not to prove [a unit] is the best or the worst. [This is for] units to use for improvements and document how they are making decisions for improvements." Moreover, the majority of respondents indicated that the reason for engaging in student learning outcomes assessment was to show evidence that the units in their division were contributing to the institution's mission of student learning. The Vice President of Western University stated, "I am not interested in learning outcomes that only serve to reserve the unit or to justify that unit's existence. I want outcomes that reinforce our presence at the university and the value that we bring to the overall university mission."

Assessment scholars also widely agree on the cyclical assessment process-a process that includes, but is not limited to the articulation of learning outcomes, the selection and/or creation of assessment measures, the implementation of assessments, and the use of assessment results to enhance student learning (AAHE, 1992; Palomba \& Banta, 1999; Huba \& Freed 2000; Council for Higher Education Accreditation, 2003; Bresciani et al., 2004; \& Maki, 2004). Figure 1, found in Chapter Two, clearly outlines the assessment cyclical process. Student affairs educators across the participating institutions viewed assessment as an ongoing process that required various levels of professional commitment, thus supporting the literature.

Reasons for engaging in student affairs assessment activities varied across participating cases. Authors of The Student Learning Imperative: Implications for Student Affairs insist that enhancing student learning and development must be the primary purpose of student affairs educators' work thus requiring systematic inquiry and assessment. Those same authors state that 
“...legislators, parents, governing boards, and students want colleges and universities to reemphasize student learning and personal development as the primary goals of undergraduate education" (ACPA, 1996, p. 1). However, Maki (2004) asserts that accountability may be an impetus for learning outcomes assessment activities; yet, she cautions that “... it is important to shift from an externally driven process to an internally driven one" (p. 13).

Southern University's Student Affairs division began assessing learning outcomes in response to accreditation requirements. Additionally, findings indicated that there was a strong culture of assessment within Southern's academic affairs community, thus the student affairs division "wanted to participate in the broader campus [assessment] discussion," according to the Associate Director of Southern's Scholars Office. In contrast, Western University Student Affairs division began their assessment efforts before their institution's academic community because, according to one-half of the respondents, they wanted to do a better job at educating students. Multiple respondents at Western University also indicated that they were leading the academic affairs community in their efforts to create a learning outcomes assessment culture. Eastern University began assessing learning outcomes roughly around the same time as their academic community began assessing learning outcomes, because, according to almost one-half of their respondents, they wanted to improve the programs, services, and learning opportunities they provided to students.

Individuals Involved in Student Affairs Assessment and Their Responsibilities

Maki (2004) asserts that high quality and successful learning outcomes assessment practices require a shared commitment from a variety of educators including campus leaders, administrators, and staff. This study found that those student affairs divisions that participated in this study fostered a shared commitment to assessment. For all cases, it was apparent that there 
were four levels of professional commitment to each student affairs division's assessment initiative. Those four levels of professional commitment included: vice presidents, directors/coordinators of assessment, assessment committees, and unit level professional staff. This section of the chapter explores the roles of those professionals and their responsibilities. Leadership is essential when creating a high quality learning outcomes assessment culture assessment (Huba \& Freed, 2000; Maki, 2004; \& Suskie, 2004). The vice president of student affairs at each institution provided the overarching leadership and resource allocations for their assessment initiative. Additionally, Huba and Freed (2000) insist that campus leaders must "identify responsible parties to move the assessment process along" (p. 87). Both Southern and Western Universities' Vice Presidents of Student Affairs created Student Affairs Assessment Director positions and employed full-time directors to facilitate and evaluate assessment activities across their respective divisions. Eastern University's new Vice President recently asked an Associate Dean to coordinate the division's assessment efforts as part of her daily duties.

Results also indicated that student affairs vice presidents across cases provided financial support to sustain their assessment initiatives, particularly in the form of funding professional development opportunities, thus supporting the literature found in The Student Learning Imperative (ACPA, 1996) and Principle of Good Practice for Student Affairs (NASPA \& ACPA, 1997) For instance, the Director of Assessment at Southern University explained that "when student affairs first started doing assessment of learning outcomes... they paid [Academic Affairs] a fair amount of money to work part-time with student affairs to help them with that process." She continued to explain that the money was used to pay an individual from the Academic Affairs assessment office work half-time with student affairs. This individual 
provided on-campus professional development learning outcomes assessment workshops for student affairs educators to help units begin articulating learning outcomes.

Two examples of a vice president providing financial support for professional development were revealed at Western University. Western's Dean of Student Life explained that her Vice President provided funding for "more than ten" members of that division's assessment committee to attend an assessment conference in North Carolina. Moreover, Western's Vice President provided financial support to host a two-day, on-campus assessment symposium for the entire university. That symposium, organized by Western's Student Affairs assessment committee and Director of Assessment, included nationally known assessment experts, Drs. Peggy Maki and Marilee Bresciani.

A final example of financial support for assessment from a vice president was revealed at Eastern University. That institution's Student Affairs Vice President had recently allocated nearly $\$ 20,000$ in order for her division to utilize an external consulting firm, to enhance unit level assessment efforts. Moreover, that division had a history of providing on-campus professional development workshops and mini-grants to units who engaged in high quality levels of assessment.

In addition to vice presidents providing leadership for their division's assessment activities, it was clear across cases that the Directors of Assessment at Southern and Western Universities and the Associate Dean/Coordinator of Assessment at Eastern University also provided leadership. The Directors of Assessment at Southern and Western Universities were full-time employees whose primary responsibility was to enhance the learning outcomes assessment efforts across their respective divisions by serving as assessment consultants for units within their respective divisions. The Coordinator of Assessment at Eastern University was also 
responsible for enhancing the learning outcomes assessment efforts of her division and served as the liaison between the assessment external consultants used to aid units in their assessment planning. However, she described that role as only $50 \%$ of her job, with the remaining $50 \%$ being devoted to administrative work as an Associate Dean within the division. The directors and coordinator at all case institutions facilitated the activities of their division-level assessment committees.

Maki’s (2004) asserts that these division-level assessment committees are essential when creating and sustaining a learning outcomes assessment culture. These types of committees existed at all three institutions that participated in this study, and committees consisted of volunteers from across the division. There was evidence of at least one academic affairs representative that served Southern and Western Universities' assessment committees. The assessment committees at each of the participating institutions convened at least once a month, and meetings were facilitated by the directors of coordinator of assessment for the division. Each of the participating student affairs divisions for this study heavily relied upon their division level assessment committee to create assessment reporting timetables, coordinate professional development opportunities, and to initiate learning outcomes assessment dialogue in order to sustain their efforts, thus supporting the literature. In addition, the assessment committees at Southern and Western Universities reviewed unit level assessment plans and provided feedback to each unit on how they could enhance those plans.

A final level of assessment involvement identified from this study was at the student affairs unit level. The assessment process at Southern and Western was a decentralized process, meaning that each unit was primarily responsible for their own assessment efforts. On an annual basis, units at those institutions were expected to articulate learning outcomes, identify 
assessment measures, implement their assessments, analyze their assessment data, report assessment results, and identify changes to programs and services based upon their assessment results in order to enhance student learning.

Eastern University approached assessment in a different way. Eastern did not have a division-level assessment plan. However, the division primarily relied upon a division-wide, standardized assessment method in the form of a survey that was administered during every single student affairs program in order to collect assessment data. Units at Eastern University were expected to submit Program Improvement Goals to the Vice President at the end of each academic semester based upon results from that standardized survey.

Few units with Eastern's Student Affairs Division created and implemented unit level assessment plans. Although, it is important to note that at the time of this study, Eastern University Student Affairs' units were in the process of moving to a decentralized model of assessment, much like Southern and Western Universities, with the assistance of external consultants. Respondents from Eastern explained that the shift to a decentralized model arose after the realization that the standardized survey was not always the appropriate method to measure student learning and each unit was very different from the other.

\section{Articulated Student Affairs Learning Outcomes}

Huba and Freed (2000) explain that student learning outcomes indicate what educators want students to know or do rather than what educational experience will be offered, maintaining that clearly stated learning outcomes offer guidance for all activities, services, and programs and inform undergraduates about student affairs educators' intentions. Additionally, Bresciani et al., (2004), explain that student learning outcomes are “...cognitive abilities, as well as affective dimensions that [student affairs] desire [their] program[s] to instill or enhance" (p. 11). More 
than one-half of the respondents for this study indicated that the purpose of assessment was to contribute to their institution's mission of learning; however, the majority of respondents across cases did not indicate that high quality learning outcomes should flow from the institution's mission.

As previously stated, the articulation of learning outcomes at Southern and Western Universities was a unit level responsibility; although the researcher discovered that those divisions had not articulated broad learning goals or objectives to guide their respective units as they began to articulate their learning outcomes. This was unusual because the literature indicates that student affairs educators must reach a consensual comprehension of the institution's mission, values, and goals prior to the articulation of student learning outcomes and both of these institution's had engaged in learning outcomes assessment practices for at least two years (AAHE, 1992; Palomba \& Banta, 1999; Huba \& Freed 2000; Bresciani et al., 2004; \& Maki, 2004). It should be noted that in 2005 both Southern and Western Universities' Student Affairs assessment committees created broad learning goals/objectives for their respective divisions, based upon their institution's missions, goals and values, as well as their division's mission statements.

A thorough analysis of Southern and Western Universities' Student Affairs unit-level assessment plans found that the majority $(65 \%)$ of their articulated learning outcomes were cognitive and only 35\% were affective (see Table 41 ). 
Table 41

Types of Learning Outcomes in Student Affairs Assessment Plans

\begin{tabular}{lcccc}
\hline Taxonomy & $\begin{array}{c}\text { Southern } \\
\text { University }\end{array}$ & $\begin{array}{c}\text { Western } \\
\text { University }\end{array}$ & $\begin{array}{c}\text { Eastern } \\
\text { University }\end{array}$ & $\begin{array}{c}\text { \% of outcomes } \\
\mathrm{N}=71\end{array}$ \\
\hline Cognitive & 22 & 24 & $\mathrm{~N} / \mathrm{A}$ & 64.8 \\
Affective & 10 & 15 & $\mathrm{~N} / \mathrm{A}$ & 35.2 \\
Total & 32 & 39 & $\mathrm{~N} / \mathrm{A}$ & 100.0 \\
\hline
\end{tabular}

The literature reviewed did not suggest that student affairs educators focus their assessment efforts on one dimension of learning over the other. On the contrary, the literature insisted that effective assessments require educators to recognize that learning is multidimensional (AAHE, 1992), thus student affairs educators should provide and assess learning experiences where students have opportunities to demonstrate gains in all levels of cognitive thinking. However, participating institutions did not assess learning experiences at all level of cognitive thinking. Southern and Western Universities articulated cognitive learning outcomes classified within the three lowest levels of Anderson's et al., (2001) levels of thinking: remembering, understanding, and applying (see Table 42). 
Table 42

Student Affairs Student Learning Outcomes Categorized Within Cognitive Taxonomy

\begin{tabular}{lcccc}
\hline $\begin{array}{l}\text { Cognitive } \\
\text { Taxonomy }\end{array}$ & $\begin{array}{c}\text { Southern } \\
\text { University }\end{array}$ & $\begin{array}{c}\text { Western } \\
\text { University }\end{array}$ & $\begin{array}{c}\text { Eastern } \\
\text { University }\end{array}$ & $\begin{array}{c}\text { \% of Cognitive } \\
\text { Outcomes } \\
\text { N=46 }\end{array}$ \\
\hline Remember & 5 & 7 & N/A & 26.1 \\
Understand & 6 & 8 & N/A & 30.4 \\
Apply & 9 & 9 & N/A & 39.1 \\
Analyze & 2 & 0 & N/A & 4.4 \\
Evaluate & 0 & 0 & N/A & 0.0 \\
Create & 0 & 0 & N/A & 0.0 \\
Total & 22 & 24 & N/A & 100.0 \\
\hline
\end{tabular}

In addition to measuring cognitive dimensions of learning, AAHE (1992) asserts that student affairs educators provide learning experiences which enable students to develop their emotions, feelings, and attitudes at all levels within the affective domain. An analysis of unit level articulated learning outcomes found that $80 \%$ of participating institution's affective outcomes were categorized within the receiving and responding levels of the affective taxonomy (Krathwohl et al., 1964) and 20\% within the value domain (see Table 43). Much like the cognitive domain, this suggests that that student affairs units who are in the early stages of student learning outcomes assessment will most likely focus primarily on the lowest levels within the affective domain. 
Table 43

Student Affairs Student Learning Outcomes Categorized Within Affective Taxonomy

\begin{tabular}{lcccc}
\hline $\begin{array}{l}\text { Affective } \\
\text { Taxonomy }\end{array}$ & $\begin{array}{c}\text { Southern } \\
\text { University }\end{array}$ & $\begin{array}{c}\text { Western } \\
\text { University }\end{array}$ & $\begin{array}{c}\text { Eastern } \\
\text { University }\end{array}$ & $\begin{array}{c}\% \text { of Affective } \\
\text { Outcomes } \\
\mathrm{N}=25\end{array}$ \\
\hline Receive & 3 & 7 & $\mathrm{~N} / \mathrm{A}$ & 40.0 \\
Respond & 5 & 5 & $\mathrm{~N} / \mathrm{A}$ & 40.0 \\
Value & 2 & 3 & $\mathrm{~N} / \mathrm{A}$ & 20.0 \\
Organize & 0 & 0 & $\mathrm{~N} / \mathrm{A}$ & 0.0 \\
$\begin{array}{l}\text { Internalize } \\
\text { values }\end{array}$ & 0 & 0 & $\mathrm{~N} / \mathrm{A}$ & 0.0 \\
Total & 10 & 15 & & $\mathrm{~N} / \mathrm{A}$ \\
\hline
\end{tabular}

Methods Used When Assessing Student Affairs Learning Outcomes

Assessment scholars (Palomba \& Banta, 1999; Bresciani, et al., 2004; \& Maki, 2004)

stress the importance of addressing both direct and indirect methods of assessment. The researcher found that a variety of assessment methods were used to measure student learning across cases.

Document analysis of Southern and Western Universities' unit-level assessment plans revealed that locally-developed surveys were the most commonly used methods of assessment across cases. Additionally, respondents from those institutions explained that the selection and implementation of assessment methods was a unit level decision and that most units were relying primarily on locally-developed surveys to assess student learning. The Director of Assessment at Western University stated, "We are over-surveying, and we know that." Additionally, an Assistant Vice President at Southern University commented, "It has been a challenge for folks to 
understand there are other ways [than surveys] to measure outcomes that are often more appropriate."

The researcher found that $58 \%$ of the 71 articulated learning outcomes at Southern and Western University were measured, at least in part, by a survey (see Table 44). The researcher was able to secure few of the actual survey instruments used by Southern and Western; however, it was clear that those secured surveys were designed to measure student learning. For example Southern's Physical Education department surveyed a random sample of alumni to measure their fitness habits. Results from the Likert scale survey indicated that the Physical Education department may need to focus their efforts on enrolled students" "time management and exercise adherence [because] perhaps students learn how to develop but need more assistance in maintaining and sustaining an active lifestyle."

Western's Student Orientation and Retention used a survey to measure both student satisfaction and student learning. In regard to student learning, that office sought to measure a variety of learning outcomes, such as whether or not students "know how to get to and log into Student Online Services." Students who attended summer orientation were emailed the survey and asked to rate their level of agreement in response to a series of statements - those statements that addressed student learning were categorized in a section entitled "Things I've Learned." 
Table 44

Most Common Methods Used to Assess Southern University and Western University Student Affairs' Learning Outcomes

\begin{tabular}{lcc}
\hline $\begin{array}{l}\text { Methods used to assess learning } \\
\text { outcomes }\end{array}$ & $\begin{array}{c}\text { Number of reported } \\
\text { methods } \\
\mathrm{N}\end{array}$ & $\begin{array}{c}\text { \% based upon total number of } \\
\text { articulated learning outcomes } \\
(\mathrm{N}=71)\end{array}$ \\
\hline $\begin{array}{l}\text { Survey } \\
\text { Interview }\end{array}$ & 41 & 57.8 \\
Observation & 11 & 18.3 \\
Document analysis & 7 & 15.5 \\
Pre- and post-test & 7 & 9.9 \\
\hline
\end{tabular}

As previously stated, Eastern University Student Affairs primarily relied upon a prescribed standardized survey to collect assessment data. At every single student affairs sponsored programs, Eastern students were asked to complete a Scantron produced survey that required students to rank their perceptions on a one to five scale (1=strongly disagree and $5=$ strongly agree) to a variety of statements. Those statements directly related to student learning included:

- I learned something new.

- I can apply what I have learned.

- I learned new skills.

- I expect to do things differently.

- My attitude changed.

In addition to the literature stressing the importance of direct and indirect methods of assessment, assessment scholars also stress the importance of using multiple methods to assess student learning outcomes (Palomba \& Banta, 1999; Huba \& Freed, 2000; Maki, 2004; \& 
Suskie, 2004). Maki (2004) states that "relying on one method to assess the learning described in the outcome statements restricts interpretations of student achievement within the parameters of that method" (p. 86). It was obvious that Eastern University relied primarily on one method of assessment.

A thorough review of Southern and Western's assessment plans indicated that only $28 \%$ of the articulated learning outcomes were measured by more than one assessment method. Research findings indicated that more than one-half of the articulated learning outcomes at those institutions were measured by the use of quantitative methods and approximately $44 \%$ of the articulated learning outcomes were measured by the use of qualitative methods - including interviews, observations, and document analyses (Patton, 2002). This discovery supports Whitt and Miller's (1999) synthesis of literature that indicated most research and assessments on student learning have been performed using quantitative methods in the forms of surveys and questionnaires.

\section{Student Affairs Assessment Collaboration}

In order to sustain learning outcomes assessment, scholars agree that student affairs educators must collaborate with other educators during the entire assessment process. (Pascarella, 1991; AAHE, 1992; Schroeder, 1999; AAHE et al., 1998; Banta \& Kuh, 1998; Pascarella \& Upcraft, 1999; Kuh \& Banta, 2000; Green, Kirkland, \& Kulick, 2002; Maki, 2002b; Kezar, 2003; NASPA \& ACPA, 2004). This study found that collaboration with other student affairs units and academic departments was uncommon when planning, implementing, analyzing, and reporting assessment results across the three institutions.

The majority of participants were able to describe areas of program collaboration between units at their respective institutions. Very few were able to provide explicit examples of 
learning outcomes assessment collaboration, although a Director of Multicultural Services at Southern University highlighted an assessment collaboration with her office and the office of Greek Life on that campus. She explained that that collaborative effort allowed those units to collect "data that helps us educate our students" regarding the myths of hazing. Additionally, the Acting Director of the Office of Diversity Programs and Services at Eastern University described a collaborative assessment effort between her office and the Provosts Office focusing upon distinct student populations including, African Americans, Asians, Hispanic/Latino, and LGBTQ [Lesbian, Gay, Bisexual, Questioning, and Transgender]. She indicated that "The Provost really focused on the question, 'How can we better reach out to you so that you have a better experience?"”

Some interview respondents at Southern and Western Universities described their collaborative assessment committee efforts, particularly noting the creation of broad learning goals/objectives. The Director of Assessment at Southern University felt that units within her student affairs division will be more apt to collaboratively plan their assessments as each becomes more engaged in the assessment process, and she explained that “...the division level objectives are going to help.... people are going to be able to see what their peers are doing." Enhancing Student Learning Based Upon Student Affairs Assessment Results

Palomba and Banta (1999) explain, "Assessment should foster conditions in which meaningful questions are raised and addressed and in which assessment evidence is valued and used" (p. 14). That evidence from assessment results should be used to "....promote change" which enhances the student learning experience (AAHE, 1992, p. 3).

The researcher found Southern University and Western University used assessment evidence to make a combined total of 29 decisions. That number appears low due to the fact that 
some assessment results were not available at Western University, because many units had not submitted their assessment results at the time of the researchers site visit. However, based upon the available data, the researcher was able to conclude that less than half (45\%) of the decisions made based upon assessment results were to modify the educational program or service where students were assessed (see Table 45). For instance, Western University's Student Health Services administered the National College Health Assessment (NCHA) to 1,129 students. They discovered that students did not view their peers as credible conveyors of health information. In response to that discovery, Western's Student Health Services modified its peer-education program. Traditionally that program emphasized trained students going into classrooms across campus educating their peers on health related issues. However, at the time of the study, professional health educators enhanced their roles as conveyors of health related information as a direct result of assessment results.

The researcher found that more than one-quarter of the decisions made based upon assessment results were to modify the method used to assess student learning. For instance, one respondent from Western University's Career Service unit explained in their assessment plans that their assessment results were invalid because "it became clear that we had not done an appropriate amount of training for our raters" who were using a defined rubric to measure effective student resume writing techniques. In addition, another one-quarter of the decisions made were to continue the same practices, thus indicating to the researcher the validation of student learning for the particular program or service that was assessed. 
Table 45

Types of Decisions Made by Southern and Western University Student Affairs' Educators Based Upon Assessment Results

\begin{tabular}{lcc}
\hline Type of decision made based on assessment results & $\mathrm{N}=29$ & \% of decisions made \\
\hline Modify educational program or service & 13 & 44.8 \\
Modify assessment instrument & 8 & 27.6 \\
Continue same practices & 7 & 24.1 \\
Enhance assessment administration training & 1 & 3.5 \\
\hline
\end{tabular}

In addition to decisions made based upon unit level assessment results, the researcher found that Eastern University Student Affairs had made recommendations to enhance their assessment initiative based upon their standardized assessment data collection results. In a 2004 report detailing results from the standardized survey, the researcher discovered five recommendations. Of those five recommendations, two had clearly been addressed by the time the researcher conducted his site visit. For example one recommendation read that the division must ensure that "...the assessment process moves from sporadic to on-going [and] having a half or full-time assessment person who has the skills to coordinate the efforts would be helpful." The Associate Dean that had recently assumed the role as coordinator of the division's assessment efforts and described that role as $50 \%$ of her job. Another recommendation from Eastern's comprehensive assessment report was to “... highlight and support the exemplary work being done at the unit level." In response to that recommendation, Eastern University employed external consultants to help units design customized surveys and reorganization of the division's assessment committee to include one representative from each student affairs unit demonstrates Eastern's commitment to supporting "work being done at the unit level." 


\section{Student Affairs Assessment Successes and Challenges}

Because there has been very little research on student affairs learning outcomes assessment practices, the researcher wanted to uncover assessment related successes and challenges identified by each of the study participants. When participants were asked to describe their assessment successes, it was common for them to report that student affairs educators across institutions were using assessment data to make informed decisions, thus supporting Palomba and Banta's (1999) call for assessment results to be "valued and used" (p.14). Eastern's Director of the Student Union and Student Affairs Programs commended the work of her institution's Orientation and Family Programs Office's use of assessment results. She stated that the office "... really changed their orientation program based upon their new learning outcomes and their assessment results." Likewise, The Director of Residence Life at Southern explained that here unit was "really proud of getting a handle on customer service levels of student desk workers... allowing the unit to reframe its training to enhance the knowledge of student desk workers." Western's Director of Services for Students with Disabilities felt that the assessments conducted by her office provided data that were used to “.... have more intentional [assessment] questions and see if we are hitting what we actually need to be hitting."

More than three-quarters of the respondents at Southern University felt that a success for their division was that professionals were embracing assessment and seeing the value in assessing student learning. For example, the Assistant Vice President stated, "People recognize the value of assessment. It is exciting as people are building new programs, building workshops and services and new activities and they are starting to think about [assessment] automatically." Similarly, one-half of the respondents at Western University felt that student affairs educators at their institution demonstrated a high level of commitment to the assessment initiative and they 
enjoyed assessment related professional development opportunities. The Assistant Director of Student Health Services stated, “...the energy level still continues to be high around this issue, and people aren't frightened anymore.” Moreover Western's Vice President stated “...we have been able to crate a function culture around assessment."

Another success identified by one-half of the Western's respondents was the enjoyment of assessment related professional development opportunities. A Career Services Program Coordinator stated that "a success has been, I have learned a ton. I think the success has been more a personal success for [me] within my unit, because I come away with a skill.” Western's Director of Assessment echoed those comments, stating "A lot of people work on campuses because they like learning, and sometime we can just get our jobs done and it doesn't hold the intellectual challenge for us." She continued to explain that she felt that individuals who served on the division's assessment committee enjoyed the intellectual challenge of serving on the committee.

Additionally, one-third of the respondents at Eastern University felt that a success was that they had made assessment progress over the past five years. The Coordinator of Assessment explained, "We've made great strides overall." The Vice President agreed with the Coordinator's comments and stated, "We are moving in the right direction." An Assistant Director of Learning Services also believed that select units had been very successful in their assessment efforts. She stated, "I think the units who have really found the time, money, and skills... have put together some nice assessments.... and have been very successful."

In addition to identifying successes, student affairs educators also identified several assessment challenges. It was apparent that respondents at Southern and Western Universities felt that finding the time to plan and administer their assessments and embed that work into their 
daily duties was a challenge. For example, Southern's Assistant Vice President insisted that high quality assessment requires "a fair amount of time... and if you have a one or two person [unit], that can be very very difficult... very very hard." Similarly, a Career Services Program Coordinator of Western stated, “.....as a student service unit... we have an open door policy where there are people in and out of my office all the time... so time is a challenge." This was not a surprise because Huba and Freed (2000) assert that "using learner-centered assessment may be more time consuming than previous [assessment] approaches" (p.25).

Another challenge identified at both Eastern and Southern Universities was that learning outcomes assessment was not a priority to everyone within the student affairs division. Likewise respondents at Western University felt that additional education was needed to help student affairs educators understand the value of assessment. One Eastern University respondent stated, "We really need to describe our success to the staff and explain... this is why we are doing this... this is what we are going to use the information for."

It was also common for participants across cases to note the need for additional resources to be allocated to their assessment initiatives, specifically in the form of professional assessment staff salaries. For instance, multiple respondents at Western and Southern Universities indicated the need for additional professional staff for their division's assessment directors - a statistician for Southern University and an assistant director of assessment at Western University. Likewise, multiple respondents at Eastern University indicated the need for a full-time coordinator or director of assessment.

\section{Summary}

This study found that participating student affairs divisions promoted a joint commitment to assessment. It was common across cases for four levels of professionals to contribute to the 
success of their respective division's assessment initiative. Those four levels consisted of vice presidents, directors/coordinators of assessment, assessment committees, and unit level professional staff. However, little to no evidence of actual assessment collaboration was discovered as a result of this study.

The findings from this research conclude that successful assessment of student affairs learning outcomes hinges upon the understanding that units are experts in their particular field. This means that a decentralized model of assessment, facilitated by a coordinator or director, is most appropriate in student affairs. Results from this study indicate that surveys were the most popular method of assessment used across cases. Moreover, examples were provided across cases of how units used assessment results to make programmatic changes and enhance the student learning experience.

Finally, results from this study indicate that reported successes and challenges varied across case institutions. It was common for respondents to identify the use of assessment results to enhance student learning as a success. It was also common for participants across cases to note the need for more money to be assigned to their assessment initiatives, specifically in the form of professional assessment staff salaries. 


\section{Chapter Nine}

Recommendations for Practice and Future Research

\section{Introduction}

Student affairs educators, who adhere to the multiple calls for reform in higher education and engage in the learning outcomes assessment process, may expect success when firmly adhering to the cyclical, ongoing assessment process as described by assessment scholars and as illustrated in Figure 1, found in Chapter Two (AAHE, 1992; Huba \& Freed 2000; Palomba \& Banta, 1999; Council for Higher Education Accreditation, 2003; Bresciani et al., 2004; \& Maki, 2004). This chapter is designed to offer major conclusions based upon the researcher's findings, to offer recommendations for practice, and to provide suggestions for future student affairs learning outcomes assessment research.

\section{Research Conclusions}

The assessment of student affairs learning outcomes hinges upon a variety of factors. First and foremost, this research found that a successful assessment model depends upon a commitment from multiple student affairs educators, including student affairs vice presidents, directors/coordinators of assessment for the division, division-level assessment committees, unit directors, and unit level employees. Student affairs vice presidents provide the overall leadership for the assessment of student learning outcomes, insisting that it is a high priority and part of their overall agenda and expectations for the division. Moreover, vice presidents are responsible for the organizational structure of their divisions, and this research revealed that participating case vice presidents identified one individual within their division to coordinate their assessment agendas. At two case institutions, the vice president had created a full-time director of student affairs assessment and at one case institution, the vice president embedded the oversight of her 
assessment efforts into the duties of an associate dean, who described that work as $50 \%$ of her job. Additionally, vice presidents provided financial support for those within their divisions to participate in assessment related professional development opportunities, both on-campus and off-campus.

Directors or coordinators of student affairs assessment served as facilitators and change agents for the division. They were not responsible for creating a division-level assessment plan. On the contrary, the researcher found that they were responsible for assisting units in articulating learning outcomes, selecting or designing assessment methods, analyzing assessment results, identifying opportunities for enhancing student learning based upon assessment results, and accurately reporting assessment results. Additionally, directors/coordinators of assessment served as the liaison between the vice president and the unit directors and in the case of one institution as a liaison between an external consulting firm and her student affairs division. These same assessment directors/coordinators worked with their respective university's Institutional Review Boards to secure approval for assessment research studies, and they worked with their respective Institutional Research Offices to secure existing data when appropriate. Moreover, directors/coordinators of assessment worked with directors of technology to provide units the opportunity to post on-line surveys. It should also be noted that Southern University's Assessment Director served as the student affairs representative on the university-level assessment committee, and Eastern University's Coordinator of Assessment served as the liaison between an external consulting group and units within that division. Lastly, it was common across cases for the director/coordinator of assessment to provide leadership for the assessment committee within their respective divisions. 
Assessment committees were also vital in advancing the assessment efforts across case institutions. These committees, most often comprised of volunteers across the division, met at least monthly. Assessment committees were primarily responsible for coordinating professional development opportunities, reviewing unit level assessment plans, providing feedback to units on how they could enhance their assessment plans, and initiating learning outcomes assessment dialogue in order to sustain their efforts.

Two of the case institutions relied upon a decentralized model of student learning outcomes assessment, meaning that the student affairs units were primarily responsible for their assessment activities. One case relied primarily on a centralized method of assessment; however there was evidence of sporadic unit level assessment activities. That same case had recently abandoned their centralized method of assessment, acknowledging that in order to sustain their student affairs learning outcomes assessment initiative, they needed to move to a decentralized assessment model. Thus, this research clearly indicates that successful assessment of student affairs learning outcomes requires the understanding that units are experts in their particular field; therefore, a decentralized model of assessment, facilitated by a coordinator or director, is most appropriate in student affairs.

This research concludes that assessment planning was primarily a single unit task, with very little evidence of collaboration during that process. Southern and Western University student affairs educators at the unit level were responsible for articulating cognitive and affective learning outcomes, supporting the notion that learning is multidimensional (AAHE, 1992). However, the research found that the majority of those articulated learning outcomes at Southern and Western Universities were classified within the cognitive taxonomy. 
Of those articulated cognitive outcomes identified by Southern and Western Universities, more than one-quarter were categorized within the remember level of the taxonomy, and more than $30 \%$ were categorized within the understand level. The majority (39\%) of the articulated cognitive learning outcomes were categorized within the application level and the least (4\%) of the articulated learning outcomes were categorized within the analysis level. None of the outcomes were classified within the two highest levels within the cognitive domain evaluation and creation.

The affective outcomes articulated by the two cases that relied upon a decentralized model of assessment were categorized within the three lowest levels of the affective domain. This study found that $40 \%$ of the affective outcomes were classified within the receiving level, and the same amount was classified within the responding level. Few (20\%) affective outcomes were classified within the valuing level, and no outcomes were categorized within the organization and internalization of values levels.

In addition to articulating learning outcomes, unit directors and their staff were responsible for selecting and/or creating their assessment methods, with few solid examples of collaboration. Indirect methods, particularly surveys, were identified as the overwhelming assessment method of choice at the two cases where a decentralized model of assessment was ongoing were surveys. Moreover, the third case institution required all programs and services to be assessed with an identical survey that included basic questions in regard to student learning. However, respondents indicated and the researcher discovered through document analysis that the use of other assessment methods including direct measures such as, but not limited to, observation, interviews, document analysis as well as indirect measures such as pre-and-post tests. 
This study also found that the majority of articulated learning outcomes were measured by the use of only one method of assessment; although a few examples of the use of multiple methods of assessment was revealed as well. For instance, Southern University's Student Union Activities Board indicated in its assessment plan the use of interviews and document analysis to measure students abilities to "articulate three personal goals that they will focus on developing over the course of the academic year by an action plan to accomplish these goals."

The study found that assessment results were being used to enhance student learning across case institutions. The majority of the decisions based upon assessment results at Southern University and Western University focused upon enhancing student learning opportunities. However, $28 \%$ of their decisions were based upon what they described as flawed results, citing the need to modify their assessment measures in order to collect useable assessment data. In addition, Eastern University revamped their entire assessment model based upon their assessment results, because they discovered that the use of a standardized assessment method of data collection did not always accurately measure student learning due to the fact that the intended learning outcomes across programs and services differed greatly. In response to that finding, as well as sporadic success within individual units who had created customized assessment plans and measures, Eastern University was in the process of moving to a decentralized model of assessment.

All of the case study participants identified what they believed to be their assessment successes and challenges. Most commonly, respondents mentioned the shift in a negative attitude to a positive attitude in regard to the assessment of learning outcomes within their divisions. The researcher would conclude that this shift in attitude was due in part to the completion of at least one full cycle of learning outcomes assessment at each institution, which allowed units to use 
their assessment results to either validate their current practices or provide evidence on how they could change a program or service to enhance student learning. However, a common challenge identified by respondents at Southern and Western Universities was finding the time to plan and administer their assessments and embed that work into their daily duties. Moreover, it was common across cases for respondents to indicate that additional assessment funding, specifically in the form of professional assessment staff salaries, would enhance their assessment efforts.

\section{Recommendations for Practice}

There are multiple recommendations for practice that resulted from the major findings of this study. The first recommendation is that student affairs divisions that engage in the assessment process must have an adequate level of support from their division's leaders as confirmed by the literature (Huba \& Freed, 2000; Maki, 2004; \& Suskie, 2004). This research found that a division can be successful, as illustrated by Western University’s Student Affairs division, without an institutional culture of assessment. Yet, that success depends greatly upon the creation of decentralized model of assessment, where units are responsible for their assessment activities. Moreover the vice president must identify and provide resources to hire a director/coordinator of assessment that provides units with the assessment related educational opportunities and support. The director/coordinator of assessment must also facilitate the activities of a division-level assessment committee, which should consist of volunteers from across the division.

The second recommendation is that student affairs divisions should identify broad learning goals or objectives based upon the overall mission of the institution in order to provide guidance for unit leaders when they are developing their learning outcomes. This recommendation is consistent with the literature which insists that student affairs educators must 
reach a consensual comprehension of the institution's mission, values, and goals prior to the articulation of student learning outcomes (AAHE, 1992; Palomba \& Banta, 1999; Huba \& Freed 2000; Bresciani et al., 2004; \& Maki, 2004). This study found that both Southern and Western Universities had recently created such broad division-level goals and Eastern University's former Coordinator of Assessment indicated that such guidance may have helped more individual units conduct unit level assessment activities. The creation of such broad learning goals/objectives may also enhance collaborative assessment efforts, allowing units to see how their articulated learning outcomes align with other units' learning outcomes in the division and the overall mission of the institution, thus sustaining student affairs learning outcomes assessment efforts and supporting the literature (Pascarella, 1991; AAHE, 1992; Schroeder, 1999; AAHE et al., 1998; Banta \& Kuh, 1998; Pascarella \& Upcraft, 1999; Kuh \& Banta, 2000; Green, Kirkland, \& Kulick, 2002; Maki, 2002b; Kezar, 2003; NASPA \& ACPA, 2004).

A third recommendation is for student affairs educators to carefully consider what they hope students will learn as a result of their programs and services. While the literature does not indicate that student affairs educators should focus their efforts more on the cognitive taxonomy versus the affective taxonomy, it does indicate that learning is multidimensional (AAHE, 1992). This study found that student affairs educators should focus their efforts on both taxonomies. Moreover, the researcher concludes that student affairs educators who are in the early stages of assessment may find success when articulating learning outcomes within the lowest levels found within those taxonomies. However, the researcher also recommends that as student affairs educators become more sophisticated in their assessment activities they consider articulating and measuring learning outcomes that coincide with the highest levels found in the cognitive and affective taxonomies. 
A fourth recommendation derived from a commonly revealed challenge in this study is that student affairs assessment directors/coordinators provide continuous professional development workshops and seminars to help unit leaders and their staff become assessment experts, and assist units in articulating meaningful and measurable learning outcomes, which is consistent with the literature (Palomba \& Banta, 1999). This will help units to achieve the second recommendation - articulate learning outcomes that coincide with the highest levels of thinking found within the cognitive and affective domains. Additionally, continuous professional development opportunities will help units to identify assessment methods that are appropriate for measuring those articulated learning outcomes and to determine what additional training is required to implement those measures, such as how to accurately rate a student's performance when relying on a rubric.

This study found that the majority of learning outcomes were measured by the use of surveys and few units relied upon multiple methods of assessment. Thus, the researcher recommends that student affairs professional organizations and student affairs higher education master's and doctoral level programs provide specific assessment related learning opportunities. For instance, because this study found that student affairs professionals were primarily relying upon surveys as their assessment methods, the researcher would encourage student affairs professional organizations and higher education programs to provide adequate learning opportunities on how to effectively and appropriately design and implement surveys, as well as how to analyze survey data. Learning opportunities such as survey design and qualitative research methods for student affairs professional staff members and masters and doctoral students will advance the profession's assessment role. Moreover, such learning opportunities will help student affairs educators consider the use of both indirect and direct methods of 
assessment as well as the use of multiple methods to measure articulated learning outcomes, which is consistent with the literature (Palomba \& Banta, 1999; Huba \& Freed, 2000; Maki, 2004; \& Suskie, 2004).

\section{Recommendations for Future Research}

This research explored how three research institutions' student affairs divisions were engaging in high quality learning outcomes assessment practices. This study focused on the broad picture of three student affairs divisions. Because student affairs divisions differ across institutions and considering the discovery that student learning outcomes are best implemented as a decentralized model, where units are responsible for their assessment activities, the researcher concludes it is beneficial for a future study to be duplicated at the unit level. This would require a researcher, for instance, to conduct case studies across career service units, multicultural units, or disability services.

The assessment of student learning outcomes is a relatively new activity for student affairs divisions. It would beneficial for this study to be duplicated in order to measure how student affairs divisions are enhancing or decreasing their assessment efforts over a period of time. A limitation of this study was that it focused only on research institutions; therefore, this study could be duplicated at institutions that are not classified as research institutions by the Carnegie Foundation, providing the student affairs profession with evidence of successful learning outcomes assessment efforts within a variety of contexts.

Another research study to benefit the literature would be a comparison between student affairs divisions' assessment efforts that are located within the various accrediting bodies across the nation. It would be useful to examine the co-curricular assessment standards for each of the accrediting bodies and how student affairs divisions are responding to those standards. In 
addition, a researcher may examine assessment recommendations provided from unit level professional organizations, such as the National Orientation Directors Association or the National Association of Colleges and Employers, and how units are responding to those recommendations.

This study found that assessment collaboration was limited across case institutions. The research indicates that collaboration is essential in order to sustain assessment efforts. It would be very useful to the profession for a study to be conducted that explores how student affairs units are collaborating within their division, across campus, and in some instances with the community.

In conclusion, this study produced rich and detailed evidence of high quality student affairs learning outcomes assessment practices. However, as the assessment of learning outcomes within the profession evolves, it is vital for scholars to continue to research how student affairs divisions are assessing co-curricular learning; how they are using those assessment results; and how they are collaborating to enhance their efforts. 


\section{References}

Aloi, S. L. (2004). The uses of assessment data in academic strategic planning. (Doctoral dissertation. West Virginia University, 1996). West Virginia University Electronic Thesis \& Dissertation Website. Retrieved November 15, 2004, from http://etd.wvu.edu American Association for Higher Education. (1992). Principles for good practice for assessing student learning. Washington, DC: AAHE.

American Association for Higher Education, American College Personnel Association, and National Association of Student Personnel. (1998). Powerful partnerships: A shared responsibility for learning. Retrieved May 25, 2004, from http://www.aahe.org American College Personnel Association. (1996). The student learning imperative: Implications for student affairs. Retrieved May 25, 2004, from http://www.myacpa.org (Original work published in 1994).

American College Personnel Association Main Page. (2005). Retrieved February 2, 2005, from http://www.myacpa.org

American Council on Education. (1983). The student personnel point of view: A report of a conference on the philosophy and development of student personnel work in colleges and universities. In G. L. Saddlemire \& A. L. Rentz (Eds.), Student affairsA profession's heritage: Significant articles, authors, issues and documents (American College Personnel Association Media Publication No. 25, pp. 122-140). Carbondale: Southern Illinois University Press. (Original work published in 1949).

Anderson, J. (Aug. 2001a). Why assessment is important to student affairs. NetResults. Retrieved February 6, 2005, from http://www.naspa.org 
Anderson, J. (Mar. 2001b). Tailoring assessment to student learning styles: A model for diverse populations. AAHE Bulletin. Retrieved February 2, 2005, from http://aahebulletin.com

Anderson, L. W., Krathwohl, D. R., Airasian, P. W., Cruikshank, K. A., Mayer, R. E., Pintrich, P. R., Raths, J., \& Wittrock, M. C. (2001). A taxonomy for learning, teaching, and assessing: A revision of Bloom's taxonomy of educational objectives. Needham Heights, MA: Allyn \& Bacon.

Andreas, R. E. \& Schuh, J. H. (1999). The student affairs landscape: Focus on learning. In E. J. Whitt (Ed.). Student learning as student affairs work: Responding to our imperative (pp. 1-9). Washington, DC: NASPA.

Angelo, T. A. (Nov., 1995). Reassessing (and defining) assessment. AAHE Bulletin. Retrieved February 6, 2005, from http://www.aahebulletin.com Angelo, T. A. (May, 1999). Doing assessment as if learning matters most. AAHE Bulletin. Retrieved February 5, 2005, from http://www.aahebulletin.com

Banta, T. W., \& Kuh, G. D. (Mar. - Apr. 1998). A missing link in assessment: A collaboration between academic and student affairs professionals. Change, (30)2, 4048.

Barr, R. B. \& Tagg, J. (1995). From teaching to learning: A new paradigm for undergraduate education. Change, 27(6), 13-25.

Blimling, G. S. (1999). Accountability for student affairs: Trends for the $21^{\text {st }}$ century. In C. S. Johnson \& H. E. Cheatham (Eds.), Higher education trends for the next century: A research agenda for student success. Retrieved February 1, 2005, from http://www.acpa.nche.edu/seniorscholars/trends/trends.htm 
Blimling, G. S., Whitt, E. J., (Eds.). (1999). Good practices in student affairs:

Principles to foster student learning. San Francisco: Jossey Bass.

Bloom, B. S. (1956). Taxonomy of education objectives: The classification of educational goals. New York: Longman Press.

Bresciani, M. J. (2001). Writing measurable and meaningful outcomes. NetResults Retrieved on October 15, 2004, from http://www.naspa.org

Bresciani, M. J. (2002). Outcomes assessment in student affairs. Moving beyond satisfaction to student learning and development. NetResults. Retrieved May 15, 2004, from http://www.naspa.org

Bresciani, M. J. (Apr., 2003a). Assessing student development and learning in the co-curricular: Moving our institutions closer to providing evidence of educating the whole student. AAHE Bulletin. Retrieved May 17, 2004, from http://aahebulletin.com

Bresciani, M. J. (2003b). An updated criteria checklist for an assessment program. NetResults. Retrieved February 4, 2005, from http://www.naspa.org

Bresciani, M. J., Zelna, C. L., \& Anderson, J. A. (2004). Assessing student learning and development: A handbook for practitioners. Washington, DC: NASPA.

Buros Institute of Mental Measurements Main Page. (2005). Buros Institute. Retrieved February 2, 2005, from http://www.unl.edu/buros

Carnegie Classification of Institutions of Higher Education Main Page. (2005). The Carnegie Foundation for the Advancement of Teaching Main Page. Retrieved February 17, 2005, http://www.carnegiefoundation.org/Classification/ 
Council for Higher Education Accreditation. (Sept., 2003). Statement of mutual responsibilities for student learning outcomes: Accreditation, institutions, and programs. Retrieved March 3, 2005, from http://www.chea.org

Council of Regional Accrediting Commissions. (May, 2003). Regional accrediting and student learning. Principles for good practices. Retrieved May 16, 2004, from http://www.msache.org/msache/content/pdf_files/Regnlsl.pdf

Edwards, K. (Sept. 2003). The academic side of student affairs. NetResults. Retrieved February 4, 2005, from http://www.naspa.org

Gardner, J. N. \& Van der Veer, G. (1998). The senior year experience: Facilitating integration, reflection, closure, and transition. San Francisco: Jossey-Bass.

Gay, L. R. \& Airasian, P. (2003). Educational research: Competencies for analysis and application (7th ed.). Uppersaddle River, NJ: Merrill Prentice Hall.

Green, R., Kirkland, C., \& Kulick, C. (2002). Why collaborate with academics? NetResults. Retrieved February 4, 2005, from http://www.naspa.org

Harry, B., Sturges, K. M., \& Klingner, J. K. (Mar. 2005). Mapping the process: An exemplar of process and challenge in grounded theory analysis. Educational Researcher, 34(2), 2-13.

Hoy, W. K., \& Miskel, C. G. (2001). Educational administration: Theory, research, \& practice $\left(6^{\text {th }}\right.$ ed.). Boston: McGraw Hill.

Huba, M. J. \& Freed, J. E. (2000). Learner centered assessment on college campuses: Shifting the focus from teaching to learning. Needham Heights, MA: Allyn \& Bloom.

Jones, J. B., \& Jones, D. P. (Oct., 2004). Student residence environment survey: Assessing residential learning communities. NetResults. Retrieved March 7, 2005, from http://www.naspa.org 
Kellogg Commission on the Future of State and Land-Grant Universities. (1997). Returning to our roots: The student experience. Washington DC: National Association of State Universities and Land-Grant Colleges.

Kezar, A. (2003). Achieving student success: Strategies for creating partnerships between academic and student affairs. NASPA Journal 41(1),1-22.

Krathwohl, D. R., Bloom, B.S., and Masia, B.B. (1964). Taxonomy of educational objectives: Handbook II: Affective domain. New York: David McKay Co.

Kuh, G. D. (Mar. - Apr., 1995). The other curriculum: Out of class experiences associated with student learning and personal development. The Journal of Higher Education, 66(2), 123-155.

Kuh, G. D., \& Banta, T. W. (Jan. - Feb., 2000). Faculty-student affairs collaboration on assessment: Lessons from the field. About Campus, 4(6), 4-11.

Lopez, C. L. (2004). A decade of assessing student learning: What we have learned, and what is next. In P. Hernon \& R.E. Dugan (Eds.). Outcomes assessment in higher education: Views and perspectives (pp. 29-71). Westport, CT: Libraries Unlimited.

Maki, P. L. (2002a). Developing an assessment plan to learn about student learning. Journal of academic librarianship, 28(1/2), 9-13.

Maki, P. L. (2002b). Using multiple assessment methods to explore student learning and development inside and outside of the classroom. NetResults. Retrieved March 2, 2005, from http://www.naspa.org

Maki, P. L. (2004). Assessing for learning: Building a sustainable commitment across the institution. Sterling, VA: Stylus Publishing.

Marchese, T. J. (1987). Third down, ten years to go. AAHE Bulletin, 40, 3-8. 
Merriam, S. B. (1998). Qualitative research and case study applications in education.

San Francisco: Jossey-Bass.

National Association of Student Personnel Administrators. (1987). A perspective on student affairs. Washington, DC: NASPA.

National Association of Student Personnel Administrators \& American College Personnel Association. (1997). The principles of good practice for student affairs. Washington, DC: NASPA.

National Association of Student Personnel Administrators \& American College Personnel Association. (2004). Learning reconsidered: A campus-wide focus on the student experience. Retrieved May 30, 2004, from http://www.naspa.org

National Association of Student Personnel Administrators Main Page (2005). Retrieved February 2, 2005, from http://www.naspa.org

National Institute of Education. (1984). Involvement in learning: Realizing the potential of American higher education. Washington, DC: US Government Printing Office.

North Carolina State University Student Affairs Research and Assessment Main Page. (2005). North Carolina State University. Retrieved February 2, 2005, from http://www.ncsu.edu/student_affairs/sara/index.html

Northern Arizona Student Affairs Assessment Main Page. (2005). Northern Arizona University. Retrieved February 2, 2005, from http://www.nau.edu/student_affairs/assessment Oregon State Student Affairs Research \& Evaluation Main Page. (2005). Oregon State University. Retrieved February 2, 2005, from http://oregonstate.edu/admin/student_ affairs/r\%20\%20research/res_introduction.html 
Palomba, C. A. \& Banta, T. W. (1999). Assessment essentials. San Francisco: JosseyBass.

Pascarella, E. T., \& Upcraft, M. L. (1999). Assessment strategies for the student learning imperative. In E. J.Whitt (Ed.). Student learning as student affairs work: Responding to our imperative (pp. 63-80).Washington, DC: NASPA.

Patton, M. Q. (2002). Qualitative research and evaluation methods $\left(3^{\text {rd }}\right.$ ed.). Thousand Oaks, CA; Sage.

Penn State Student Affairs Research and Assessment Main Page. (2005). The Pennsylvania State University. Retrieved February 2, 2005, from http://www.sa.psu.edu/sara

Pet-Armacost, J. \& Armacost, R. L. (Apr., 2002). Creating an effective assessment organization and environment. NetResults. Retrieved February 4, 2005, from http://www.naspa.org

Posner, K. J. (Mar., 2003). Assessment: Why bother? NetResults. Retrieved February 4, 2005, from http://www.naspa.org

Sanderson, R. A. (Sept., 2003). Where do we start with student learning outcomes? NetResults. Retrieved February 4, 2005, from http://www.naspa.org Schroeder, C. C. (1999). Collaboration and partnerships. In C. S. Johnson \& H. E. Cheatham (Eds.). Higher education trends for the next century: A research agenda for student success. Retrieved February 1, 2005, from http://www.acpa.nche.edu/seniorscholars/ trends/trends.htm

Schuh, J. \& Upcraft, M. L. (Eds.). (2004). ACPA assessment seminar: Writing reports and conducting briefings. Washington, DC. 
Stark, J. S. \& Luttuca, L. R. (1997). Shaping the college curriculum: Academic plans in action. Needham Heights, MA: Allyn and Bacon.

Suskie, L. A. (1996). Questionnaire survey research: What works? Tallahassee, FL: Association for Institutional Research.

Suskie, L. (2004). Assessing student learning: A common sense guide. Bolton, MS: Anker Publishing.

Terenzini, P. T. (1989). Assessing with open eyes: Pitfalls in studying student outcomes. The Journal of Higher Education, 60(6), 644-664.

Terenzini, P. T. (1991). Assessing with open eyes. In M.W. Peterson, E. E. Chaffee, \& T.H. White (Eds.). Organization and governance of higher education ( $4^{\text {th }} \mathrm{ed}$.). (pp. 326-339). Needham Heights, MA: Pearson Custom Publishing.

Terenzini, P., Pascarella, E. (1994). Living with myths. Change, 26(1), 28-32.

Texas A\&M Student Life Studies Main Page. (2005). Texas A\&M University. Retrieved February 2, 2005, from http://studentlifestudies.tamu.edu

Roberts, C. M. (2004). The dissertation journey: A practical and comprehensive guide to planning, writing, and defending your dissertation. Thousand Oaks, CA: Corwin Press.

Upcraft, M. L., \& Schu, J. (1996). Assessment in student affairs: A guide for practitioners. San Francisco: Jossey-Bass.

Upcraft, M. L., Gardner, J. N., \& Associates. (1989). The freshman year experience: Helping students survive and succeed in college. San Francisco: Jossey-Bass.

Whitt, E. J. \& Miller, T. E. (1999). Student learning outside the classroom: What does research tell us? In E. J. Whitt (Ed.). Student learning as student affairs work: Responding to our imperative (pp. 51-52). Washington, DC: NASPA. 
Wingspread Group. (1993). An American imperative: Higher expectations for higher education. Racine, WI: Wingspread Group on Higher Education, Johnson Foundation.

Woodard, D. B., Jr., Love, P., \& Komives, S. (Winter, 2000). The changing landscape of higher education. New directions for student services, (2000)92, 5-16.

Yin, R. K. (2003). Case study research design and methods. ( $3^{\text {rd }}$ ed.). Thousand Oaks, CA: Sage.

Zhao, C. \& Kuh, G. D. (2004). Adding value: Learning communities and student engagement. Research in Higher Education, 45, 115-13. 


\section{APPENDIX A}

Case Study Site Selection Criteria-Indicators of Excellence

(Adapted in part from Aloi's (2004) Review of Plans Criteria)

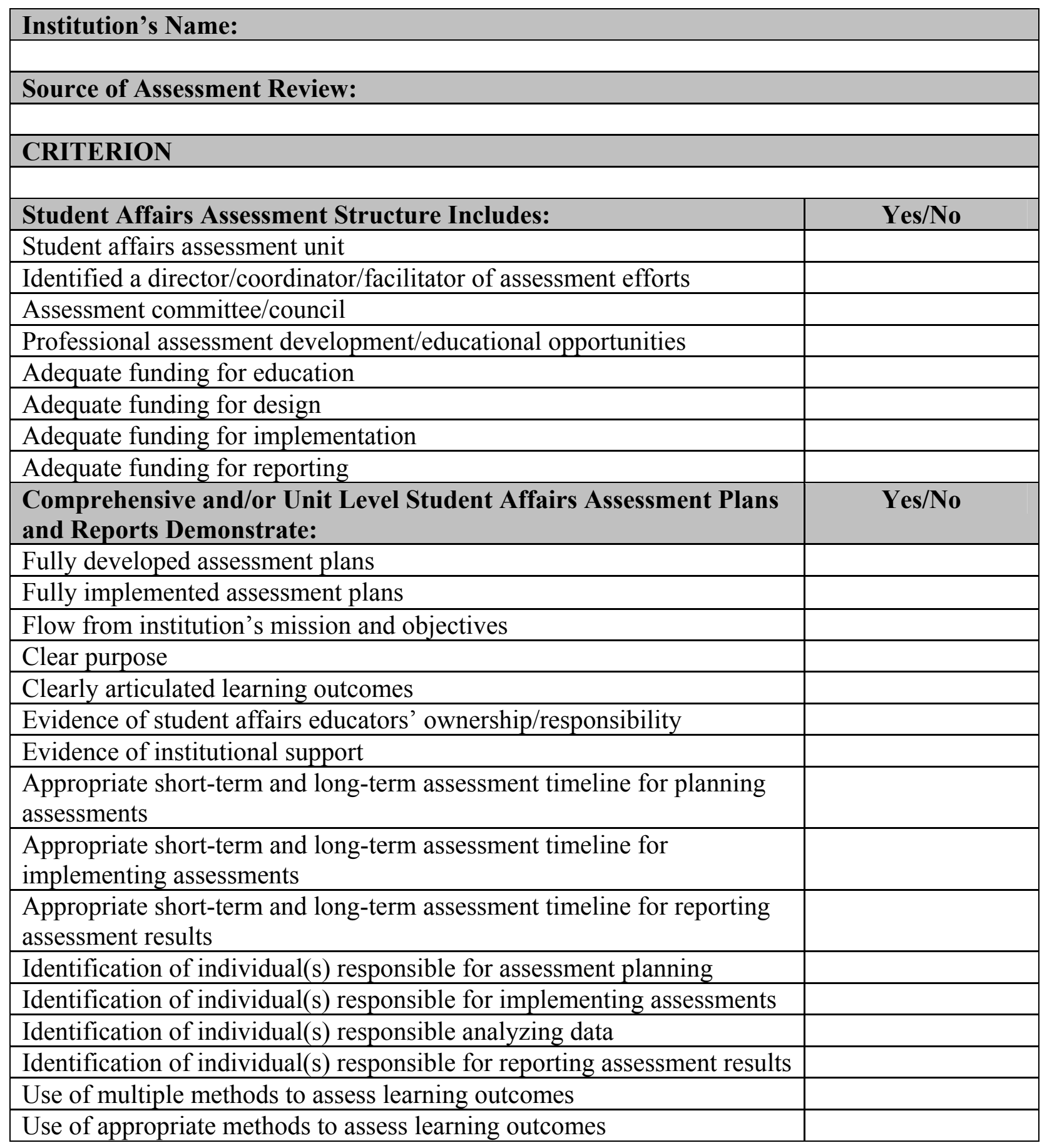


Case Study Site Selection Criteria-Indicators of High Quality (continued).

\begin{tabular}{|l|c|}
\hline $\begin{array}{l}\text { Comprehensive and/or Unit Level Student Affairs Assessment Plans } \\
\text { and Reports Demonstrate : }\end{array}$ & Yes/No \\
\hline Evidence of reliability & \\
\hline Evidence of validity & \\
\hline Identification of assessment participants & \\
\hline Identification of when those participants will be assessed & \\
\hline Assessment feedback to appropriate audiences & \\
\hline Collaboration within the division & \\
\hline Collaboration outside the division & \\
\hline $\begin{array}{l}\text { Recommendations/changes to be implemented to enhance student } \\
\text { learning experiences }\end{array}$ & \\
\hline Plan for evaluation of assessment process and plan(s) & Yes/No \\
\hline Institution Criteria Includes: & \\
\hline Carnegie Classification as Research I Extensive or Intensive & \\
\hline Willing to participate in study & \\
\hline Feasible location for researcher's travel and timeline & \\
\hline
\end{tabular}




\section{APPENDIX B}

Pilot Study Interview Protocol

Script:

Hello, my name is Adam Green, and I am a doctoral student at West Virginia University, majoring in higher educational leadership. First, I want to thank you for agreeing to participate in my dissertation project which is exploring high quality student affairs learning outcomes assessment practices. Through interviews of student affairs educators like you, I hope to identify how and why student affairs divisions are planning their assessment efforts, conducting their assessments, and using assessment findings to enhance student learning experiences. My goal is to illustrate best student affairs learning outcomes assessment practices.

I have received from West Virginia University's Institutional Review Board for the Protection of Human Participants, approval to conduct this dissertation study; hence, I want to point out a few things before we begin. First of all, your participation is entirely voluntary, and you do not have to respond to every question. I also want to assure you that your will responses will remain entirely anonymous, and confidentiality will be maintained throughout the collection and reporting process. Additionally, I want to assure you that your employment status will not be affected by refusing to participate. I would like to tape record this interview and record ongoing notes throughout the process to ensure the accuracy of your responses. May I tape record and record notes? YES/ NO

\section{$\underline{\text { Demographic questions }}$}

\section{IDENTIFIER}

1. Institution:

2. Location of interview:

3. Date and time of interview:

4. Name of subject:

5. Job title:

6. Specific unit within student affairs:

7. Number of years in position:

8. Number of years at this institution:

9. Number of years in higher education:

10. Educational background and related experiences:

11. Gender:

12. Race:
RESPONSE 
13. Student Affairs Assessment Role:

14. Number of years assessing learning outcomes (ongoing or episodic):

15. What is the purpose of assessing learning outcomes?

\section{Interview Protocol Questions}

1. What do you believe are the characteristics of good learning outcomes?

2. What are some of the student learning outcomes articulated in the [insert institution's name] student affairs assessment plans?

PROBES: Cognitive Taxonomy (ex: Critical Thinking): Remembering, Understanding, Applying, Analyzing, Evaluating, \& Creating.

Affective Taxonomy (ex: Attitudes/Values): Receiving, Responding, Valuing, Organizing, \& Internalizing Values.

3. What are some of the learning outcomes articulated within [insert interview participant's unit name] assessment plan?

a. (See question 2 PROBES)

4. How are those student affairs learning outcomes assessed?

a. What methods are used?

PROBES: Indirect methods (e.g. surveys, interviews) vs. direct methods

(e.g. Pre- \& post-test, portfolio review, essays)

b. How do you choose student participants to assess?

c. How do you motivate student participation?

5. Who is involved in the assessment planning process, and what are the major responsibilities of these individuals?

a. Who provides leadership for this process? How?

b. How committed are these individuals to the assessment process?

6. Who is involved in the assessment implementation?

a. Who provides leadership for this process? How? 
b. How committed are these individuals to the assessment process?

7. What, if any, incentives and rewards are provided for those student affairs educators who participate in the assessment process?

8. Are student affairs educators collaborating with others, such as academic affairs, in the creation and administration of assessments?

a. Would you give me a description of these collaborative efforts?

b. Would you please give me a few examples?

9. How are student affairs assessment data and results used to change/modify programs, activities, and services and ultimately student learning?

a. Would you please give me a few examples?

10. How is your assessment program evaluated?

a. How do you know if your recommendations for change are working?

b. Would you please give me am example?

11. What are the successes of your student affairs assessment process?

12. What are the challenges of your student affairs assessment process?

13. How would you improve your institution's student affairs assessment process?

14. Is there anything else that you would like to share with me today regarding your assessment efforts? 


\section{APPENDIX C}

Follow-up Questions for Pilot Study

1. Was my cover letter clear? Did the cover letter motivate you to participate in the study? What suggestions for improving my cover letter?

2. What suggestions do you have to make the purpose of this interview clearer?

3. What questions during this interview were unclear to you?

4. What suggestions do you have on how I can improve the clarity of the questions I asked?

5. How would you describe the flow of this interview? What suggestions do you have on how I could improve the organizational flow of this interview?

6. What additional questions may I want to include in the interview?

7. What other suggestions do you have for improving this interview process?

8. When is a good time (month) to conduct the study and obtain higher rates of participation of student affairs staff? 


\section{APPENDIX D}

Document Content Analysis Form for Pilot Study and Formal Site Visits

Institution:

Date of analysis:

Author of document:

Author's professional title:

Date of document:

Source of publication:

Document's source:

Intended audience:

Delivery format/style:

Document's Purpose:

Content description:

(including sources of

information, completeness,

and possible biases)

When appropriate, how does the document address the following:

1. What are the articulated learning outcomes?

2. What is the rational for articulating these specific learning outcomes? How were they developed?

3. How are these learning outcomes assessed? What methods are used to determine if learning outcomes are being achieved?

4. What are the major purposes of assessing these student learning outcomes?

5. How are validity and reliability of assessment methods assured? 
6. Who is involved in the assessment process, and what are the major responsibilities of these individuals?

7. How are student participants chosen?

8. Are student affairs educators collaborating with others, such as academic affairs, in the creation and administration of assessments? How?

9. How is student affairs assessment data used to enhance student learning experiences? Specific examples?

10. How is the assessment program evaluated?

11. What are the successes and challenges of the assessment process?

12. What recommendations are made to improve learning, services, activities, programs, and future assessment efforts?

13. What information presented in this document is unaccounted for in the aforementioned questions? 


\section{APPENDIX E}

Letter to request institutional site approval for pilot study

(on WVU letterhead)

Date:

Address:

\section{Dear Pilot Study Student Affairs VP:}

Thank you for your assistance in obtaining permission to visit your institution as part of my dissertation study, Exploring High Quality Student Affairs Learning Outcomes Assessment Practices at Three American Research Universities. The purpose of this letter is to inform you of the required steps involved in gaining written permission to conduct my pilot research study on your campus.

The purpose of my research study is to examine, by means of cases studies, the current practices of three of research institutions' student affairs learning outcomes assessment practices. In order to assure reliability and validity of my site selection criteria, interview protocol, and document content analysis protocol, I have chosen to pilot my study at your institution.

Valuable learning outcomes assessment information will be collected through interviews of a student affairs senior officer, a student affairs assessment coordinator, a student affairs assessment committee member, and a selected student affairs staff member. Additionally, evidence will be gathered through document analysis of assessment plans, annual reports, divisional newsletters and web-pages, and assessment committee meeting minutes. After a thorough analysis, synthesis, and evaluation of the collected data, the best student affairs assessment practices and perhaps, limitations, will be shared. The objective of my study is to advance the understanding, value, and usefulness of learning outcomes assessment within the student affairs profession.

Specifically, I am writing to secure permission to separately interview four student affairs professionals on your campus that are actively involved in your student learning outcomes assessment efforts. Additionally, I would like to review documents relevant to the student affairs division's assessment efforts, including each unit's assessment plan(s) and report(s) as well as assessment committee meeting agendas and minutes, related correspondence, and any other documentation relevant to understanding your assessment efforts. Dr. (insert liaison's name) has agreed to serve as a liaison on your campus and to assist me with interview arrangements and document collection. Upon your approval, I will schedule to visit your campus during the Summer 2005. 
In order for me to conduct my visit, I am required to gain approval from West Virginia University's Institutional Review Board (IRB) for the Protection of Human Participants. In order to gain such approval, I am required to submit a letter from you granting permission for me to conduct my pilot study research at your institution. I am attaching a template letter of approval, which you may alter as you see fit, and then copy to your institution's letterhead. Upon your request, I can email the template to you as well.

If you decide to allow your institution to participate, I ask that you forward me a letter of approval by (insert date). For your convenience, I have enclosed a postage-paid envelope. Upon securing Institutional Review Board approval from WVU, I will schedule my (insert institution's name) site visit and interviews with assistance of Dr. (insert liaison's name).

In closing, I want to reassure you that the results of this study will be used specifically for my dissertation and I will follow all IRB policies. I realize that interview participation is entirely voluntary, and participants do not have to respond to every question. Additionally, I assure you that participant responses will remain entirely anonymous, and confidentiality will be maintained throughout the collection and reporting process.

Should you require additional information or have any questions, please feel free to contact me via telephone at (304) 290-0357 or via email at adam.green@mail.wvu.edu.

I look forward to visiting your campus this summer.

Sincerely,

Adam S. Green

Doctoral Student

West Virginia University 


\section{APPENDIX F}

Letter from pilot study institution granting permission for site visit.

(On letterhead from case study institution)

Date:

Mr. Adam Green

284 Randolph Road

Morgantown, WV 26505

Dear Adam:

I am writing to offer my support for you dissertation pilot study research, Exploring High Quality Student Affairs Learning Outcomes Assessment Practices at Three American Research Universities, at (insert name of institution). I am aware that you will need to interview, during the summer, four student affairs professional staff members that are actively involved in our learning outcomes assessment efforts. Each interview will last for approximately one hour. Furthermore, I understand that you will be provided with various documents related to our assessment initiative.

Since you will receive approval from West Virginia University's Institutional Review Board for the Protection of Human Participants, I realize you have agreed to emphasize that interview participation is entirely voluntary, and participants do not have to respond to every question. Additionally, please remind participants that their responses will remain entirely anonymous, and confidentiality will be maintained throughout the collection and reporting process and their employment status will not be affected by refusing to participate.

Thank you for seeking my approval for this dissertation pilot project.

Sincerely,

Whomever has authority to grant institutional approval Individual's Title 


\section{APPENDIX G}

Cover letter for liaison at participating pilot institution

(on WVU letterhead)

Date:

Address:

\section{Dear (insert name):}

Thank you very much for agreeing to serve as a liaison for my dissertation pilot project, Exploring High Quality Student Affairs Learning Outcomes Assessment Practices at Three American Research Universities. I really appreciate your willingness to assist me in the coordination of interviews. I am writing to provide you with an outline of my research and to clarify the intent of this pilot study site visit.

I am planning to visit your campus on (insert date) and would like to interview four student affairs professionals who are active participants in your assessment efforts. Participants recruited for interviews should meet the following criteria:

- One Senior Student Affairs Officer (if not available then an Assistant Senior Student Affairs Officer)

- $\underline{\text { One }}$ Director/Coordinator of Student Affairs Assessment

- One Student Affairs Assessment Committee/Council Member

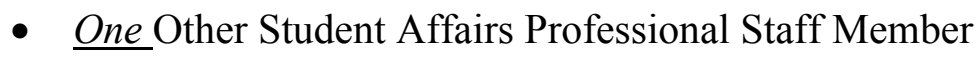

Each interview will last approximately one hour and will focus upon the following six assessment features:

1. Articulation of learning outcomes;

2. How those outcomes are assessed;

3. The purpose of your assessment efforts;

4. Who is involved in the assessment process;

5. Collaboration efforts; and

6. How results are used to enhance student learning experiences.

In addition to interviews, I would like to review documents relevant to your division's assessment efforts, including each unit's assessment plan(s) and report(s) as well as assessment committee meeting agendas and minutes, related correspondence, and any other documentation you believe appropriate for me to understand (insert institution's name) Student Affairs 
assessment efforts. You may either forward me these documents prior to my visit or help me locate such during my site visit.

I want to also let you know that I have approval from West Virginia University's Institutional Review Board (IRB) for the Protection of Human Participants to conduct this study. Therefore, it is important for me to emphasize that interview participants will not be identified and results and all responses will remain confidential.

Included with this letter, you will find four interview participant invitation letters. Please share with those individuals you have identified as possible interview participants.

I can not stress to you how much I appreciate your institution's willingness to support my research and your eagerness to assist me with my site visit. I look forward to seeing you on your campus in (insert month).

If you have any questions, please feel free to contact me via telephone at (304) 290-0357 or via email at adam.green@mail.wvu.edu.

Sincerely,

Adam S. Green

Doctoral Student

West Virginia University 


\section{Appendix H}

Pilot Institution Participant Invitation Letter (On WVU letterhead)

Date:

Dear Participant:

My name is Adam Green, and I am a West Virginia University doctoral student who is exploring high quality student affairs learning outcomes assessment practices. My intent is to pilot my dissertation study at your institution, and I would like for you to participate in this study. This research is being conducted to fulfill the requirements for a doctoral dissertation in Educational Leadership Studies in the Department of Advanced Educational Studies at West Virginia University, under the supervision of Dr. Elizabeth Jones.

During the summer, I will interview four purposefully selected student affairs professionals regarding (insert institution's name) student affairs assessment efforts. Interviews will last for approximately one hour and focus upon the following six assessment features:

1. Articulation of learning outcomes;

2. How those outcomes are assessed;

3. The purpose of our assessment efforts;

4. Who is involved in the assessment process;

5. How you collaborate with others; and

6. How results are used to enhance student learning experiences.

In order to enhance the validity and reliability of my interview protocol, I will also be asking you questions about the interview structure. Furthermore, I will be collecting a variety of assessment documents, including unit assessment plans and reports.

It is important to emphasize that this is not a performance evaluation. Your name or any other information that may identify you will not be released in the reported results and all responses will remain confidential. In any publications that result from this research, neither your name nor any information from which you might be identified will be published without your consent. Moreover, your participation is entirely voluntary, and you do not have to respond to every question I ask, and your employment status will not be affected by refusing to participate. Audiotapes will be kept locked up and will be destroyed as soon as possible after the research is finished.

Additionally, please note that there is no known or expected risks from participating in this study, except for the mild frustration associated with answering the questions. You may not receive any direct benefit from this study and the knowledge gained from this study may eventually benefit others in their future assessment efforts. Furthermore, no payments will be made for participating in the study. 
If you agree to participate in this study, please contact (insert liaison's name) as soon as possible to make arrangements for an interview time.

Should you have any questions or concerns, please contact me via telephone at 304.290 .0357 or via email at adam.green@mail.wvu.edu.

Sincerely,

Adam S. Green 


\section{APPENDIX I}

Letter to request institutional site approval

(on WVU letterhead)

Date:

Address:

\section{Dear Case Study Student Affairs VP:}

Thank you for your assistance in obtaining permission to visit your institution as part of my dissertation study, Exploring High Quality Student Affairs Learning Outcomes Assessment Practices at Three American Research Universities. The purpose of this letter is to inform you of the required steps involved in gaining written permission to conduct my research on your campus.

The purpose of my research study is to examine, by means of cases studies, the current practices of three of research institutions' student affairs learning outcomes assessment practices. Valuable information for the entire student affairs profession will be collected through interviews of student affairs senior officers, student affairs assessment coordinators, student affairs assessment committee members, and selected staff within the student affairs division. Additionally, evidence will be gathered through document analysis of assessment plans, annual reports, divisional newsletters and web-pages, and assessment committee meeting minutes. After a thorough analysis, synthesis, and evaluation of the collected data, the best student affairs assessment practices and perhaps, limitations, will be shared. The objective of this study is to advance the understanding, value, and usefulness of learning outcomes assessment within the student affairs profession.

Specifically, I am writing to secure permission to separately interview eight student affairs professionals on your campus that are actively involved in your student learning outcomes assessment efforts. Additionally, I would like to review documents relevant to the student affairs division's assessment efforts, including each unit's assessment plan(s) and report(s) as well as assessment committee meeting agendas and minutes, related correspondence, and any other documentation relevant to understanding your assessment efforts. Dr. (insert liaison's name) has agreed to serve as a liaison on your campus and to assist me with interview arrangements and document collection. Upon your approval, I will schedule to visit your campus during the Fall 2005 academic term.

In order for me to conduct my site visits, I am required to gain approval from West Virginia University's Institutional Review Board (IRB) for the Protection of Human Participants. In order to gain such approval, I am required to submit a letter from you granting permission for me 
to conduct research at your institution. I am attaching a template letter of approval letter, which you may alter as you see fit, and then copy to your institution's letterhead. Upon your request, I can email the template to you as well.

If you decide to allow your institution to participate, I ask that you forward me a letter of approval by (insert date). For your convenience, I have enclosed a postage-paid envelope. Upon securing Institutional Review Board approval from WVU, I will schedule my (insert institution's name) site visit and interviews with assistance of Dr. (insert liaison's name).

In closing, I want to reassure you that the results of this study will be used specifically for my dissertation and I will follow all IRB policies. I realize that interview participation is entirely voluntary, and participants do not have to respond to every question. Additionally, I assure you that participant responses will remain entirely anonymous, and confidentiality will be maintained throughout the collection and reporting process.

Should you require additional information or have any questions, please feel free to contact me via telephone at (304) 290-0357 or via email at adam.green@mail.wvu.edu.

I look forward to visiting your campus this fall.

Sincerely,

Adam S. Green

Doctoral Student

West Virginia University 


\section{APPENDIX J}

Letter from case study institutions granting permission for site visit. (On letterhead from case study institution)

Date:

Mr. Adam Green

284 Randolph Road

Morgantown, WV 26505

Dear Adam:

I am writing to offer my support for you dissertation research, Exploring High Quality Student Affairs Learning Outcomes Assessment Practices at Three American Research Universities, at (insert name of institution). I am aware that you will need to interview, during the Fall 2005 academic term, eight student affairs professional staff members that are actively involved in our learning outcomes assessment efforts. Each interview will last for approximately one hour. Furthermore, I understand that you will be provided with various documents related to our assessment initiative.

Since you will receive approval from West Virginia University's Institutional Review Board (IRB) for the Protection of Human Participants, I realize you have agreed to emphasize that interview participation is entirely voluntary, and participants do not have to respond to every question. Additionally, please remind participants that their responses will remain entirely anonymous, and confidentiality will be maintained throughout the collection and reporting process, and their employment status will not be affected by refusing to participate.

Thank you for seeking my approval for this dissertation project.

Sincerely,

Whomever has authority to grant institutional approval Individual's Title 


\section{APPENDIX K}

Cover letter for liaison at participating case study institution (on WVU letterhead)

Date:

Address:

\section{Dear (insert name):}

Thank you very much for agreeing to serve as a liaison for my dissertation pilot study project, Exploring High Quality Student Affairs Learning Outcomes Assessment Practices at Three American Research Universities. I really appreciate your willingness to assist me in the coordination of interviews. I am writing to provide you with an outline of my research and to clarify the intent of my site visit.

I am planning to visit your campus on (insert date) and would like to interview eight student affairs professionals who are active participants in your assessment efforts. Participants recruited for interviews should meet the following criteria:

- One Senior Student Affairs Officer (if not available then an Assistant Senior Student Affairs Officer)

- $\underline{\text { One }}$ Director/Coordinator of Student Affairs Assessment

- $\quad$ Three Student Affairs Assessment Committee/Council Members

- $\quad$ Three Other Student Affairs Professional Staff Members (with at least one serving in the capacity of unit director and one non-unit director)

Interviews will last approximately one hour and will focus upon the following six assessment features:

1. Articulation of learning outcomes;

2. How those outcomes are assessed;

3. The purpose of your assessment efforts;

4. Who is involved in the assessment process;

5. Collaboration efforts; and

6. How results are used to enhance student learning experiences.

In addition to interviews, I would like to review documents relevant to your division's assessment efforts, including each unit's assessment plan(s) and report(s) as well as assessment committee meeting agendas and minutes, related correspondence, and any other documentation you believe appropriate for me to understand (insert institution's name) Student Affairs 
assessment efforts. You may either forward me these documents prior to my visit or help me locate such during my site visit.

I want to also let you know that I have received approval from West Virginia University's Institutional Review Board (IRB) for the Protection of Human Participants to conduct this study. Therefore, it is important for me to emphasize that interview participants will not be identified and results and all responses will remain confidential.

Included with this letter, you will find eight interview participant invitation letters. Please share with those individuals you have identified as possible interview participants.

I can not stress to you how much I appreciate your institution's willingness to support my research and your eagerness to assist me with my site visit. I look forward to seeing you on your campus in (insert month).

If you have any questions, please feel free to contact me via telephone at (304) 290-0357 or via email at adam.green@mail.wvu.edu.

Sincerely,

Adam S. Green

Doctoral Student

West Virginia University 


\section{APPENDIX L}

Case Study Participant Invitation Letter (On WVU letterhead)

Date:

Dear Participant:

My name is Adam Green, and I am a West Virginia University doctoral student who is exploring high quality student affairs learning outcomes assessment practices. My intent is to conduct a study that best illustrates assessment practices within our profession, and I would like for you to participate in my study. This research is being conducted to fulfill the requirements for a doctoral dissertation in Educational Leadership Studies in the Department of Advanced Educational Studies at West Virginia University, under the supervision of Dr. Elizabeth Jones.

During the Fall 2005, I will interview four purposefully selected student affairs professionals regarding (insert institution's name) student affairs assessment efforts. Interviews will last for approximately one hour and focus upon the following six assessment features:

1. Articulation of learning outcomes;

2. How those outcomes are assessed;

3. The purpose of our assessment efforts;

4. Who is involved in the assessment process;

5. How you collaborate with others; and

6. How results are used to enhance student learning experiences.

It is important to emphasize that this is not a performance evaluation. Your name or any other information that may identify you will not be released in the reported results and all responses will remain confidential. In any publications that result from this research, neither your name nor any information from which you might be identified will be published without your consent. Moreover, your participation is entirely voluntary, and you do not have to respond to every question I ask, and your employment status will not be affected by refusing to participate. Audiotapes will be kept locked up and will be destroyed as soon as possible after the research is finished.

Additionally, please note that there is no known or expected risks from participating in this study, except for the mild frustration associated with answering the questions. You may not receive any direct benefit from this study and the knowledge gained from this study may eventually benefit others in their future assessment efforts. Furthermore, no payments will be made for participating in the study. 
If you agree to participate in this study, please contact (insert liaison's name) as soon as possible to make arrangements for an interview time.

Should you have any questions or concerns, please contact me via telephone at 304.290 .0357 or via email at adam.green@mail.wvu.edu.

Sincerely,

Adam S. Green

Doctoral Student

West Virginia University 


\section{APPENDIX M}

Formal Study Interview Protocol

Script:

Hello, my name is Adam Green, and I am a doctoral student at West Virginia University, majoring in higher educational leadership. First, I want to thank you for agreeing to participate in my dissertation project which is exploring high quality student affairs learning outcomes assessment practices. Through interviews of student affairs educators like you, I hope to identify how and why student affairs divisions are planning their assessment efforts, conducting their assessments, and using assessment findings to enhance student learning experiences. My goal is to illustrate best student affairs learning outcomes assessment practices.

I have received from West Virginia University's Institutional Review Board for the Protection of Human Participants, approval to conduct this dissertation study; hence, I want to point out a few things before we begin. First of all, your participation is entirely voluntary, and you do not have to respond to every question. I also want to assure you that your will responses will remain entirely anonymous, and confidentiality will be maintained throughout the collection and reporting process. Additionally, I want to assure you that your employment status will not be affected by refusing to participate. I would like to tape record this interview and record ongoing notes throughout the process to ensure the accuracy of your responses. May I tape record and record notes? YES/ NO

\section{$\underline{\text { Part A-Demographic Questions }}$}

\section{IDENTIFIER}

RESPONSE

1. Institution:

2. Location of interview:

3. Date and time of interview:

4. Name of subject:

5. Job title:

6. Specific unit within student affairs:

7. Number of years in position:

8. Number of years at this institution:

9. Number of years in higher education:

10. Educational background and related experiences:

11. Gender:

12. Race: 
13. Student Affairs Assessment Role:

14. Number of years assessing learning outcomes (ongoing or episodic):

15. How and why did [insert institution's name] student affairs division begin assessing learning outcomes? (PROBES: Institution driven? Student Affairs driven? Accrediting Board driven?)

16. What is the purpose of assessing learning outcomes: (PROBES: Formative and/or summative decision making to enhance student learning, maintain accreditation and/or grants, etc.)

\section{$\underline{\text { Part B-Interview Protocol Questions }}$}

Script:

Again, I want to reinforce that I am interested in [insert institution's name] student affairs learning outcomes assessment practices. Just to let you know, for the purpose of my study, I have defined learning outcomes as the knowledge, skills, attitudes, and habits of mind that students take with them from a learning experience. (Suskie, 2004, p. 75). Basically, assessment scholars explain that student learning outcomes indicate what educators want students to know or do rather than what educational experience will be offered (Huba and Freed, 2000). So, I'm going to ask you a series of questions to learn more about the learning outcomes assessment work within your division. I'd like to begin with:

1. What are some of the student learning outcomes articulated in the [insert institution's name] student affairs assessment plans?

PROBES: Cognitive Taxonomy (ex: Critical Thinking): Remembering, Understanding, Applying, Analyzing, Evaluating, \& Creating. 
Affective Taxonomy (ex: Attitudes/Values): Receiving, Responding, Valuing, Organizing, \& Internalizing Values.

2. What are some of the learning outcomes articulated within [insert interview participant's unit name] assessment plan?

a. PROBES: (See question 1)

3. Since you have explained to me the learning outcomes within the division and the learning outcomes within your unit, what do you believe are the characteristics of good learning outcomes?

a. PROBES: Flow from mission, be measurable, be meaningful, be realistic, and be ongoing.

4. How are the student affairs learning outcomes assessed?

a. What methods are used?

PROBES: Indirect methods (e.g. surveys, interviews) vs. direct methods

(e.g. Pre- \& post-test, portfolio review, essays)

b. How do you choose student participants to assess?

c. How do you motivate student participation?

5. Who is involved in the assessment planning process, and what are the major responsibilities of these individuals?

a. Who provides leadership for this process? How?

b. How committed are these individuals to the assessment process?

6. Who is involved in the assessment implementation?

a. Who provides leadership for this process? How?

b. How committed are these individuals to the assessment process?

7. What, if any, incentives and rewards are provided for those student affairs educators who participate in the assessment process?

8. Are student affairs educators collaborating with others, such as academic affairs, in the creation and administration of assessments?

a. Would you give me a description of these collaborative efforts?

b. Would you please give me a few examples?

9. How are student affairs assessment data and results used to change/modify programs, activities, and services and ultimately student learning?

a. Would you please give me a few examples?

10. How is your assessment program evaluated?

a. How do you know if your recommendations for change are working?

b. Would you please give me an example?

11. What are the successes of your student affairs assessment process? 
12. What are the challenges of your student affairs assessment process?

13. How would you improve your institution's student affairs assessment process?

14. Is there anything else that you would like to share with me today regarding your assessment efforts?

15. Should I need clarification of any of your responses or additional information, may I contact you in the future? Could you provide me with your contact information? 